\title{
Wind, Sea Ice, Inertial Oscillations and Upper Ocean Mixing in Marguerite Bay, Western Antarctic Peninsula: Observations and Modeling
}

\author{
By \\ Jason Hyatt \\ B.S.E, University of Pennsylvania, 1995 \\ M.S. University of California, Berkeley, 1997 \\ Submitted in partial fulfillment of the requirements of the degree of \\ Doctor of Philosophy \\ at the \\ MASSACHUSETTS INSTITUTE OF TECHNOLOGY \\ and the \\ WOODS HOLE OCEANOGRAPHIC INSTITUTION
}

September 2006

(C) 2006 Jason Hyatt

All rights reserved.

The author hereby grants to MIT and WHOI permission to reproduce paper and electronic copies of this thesis in whole or in part and to distribute them publicly.

Signature of Author

Joint Program in Oceanography/Applied Ocean Science and Engineering Massachusetts Institute of Technology

and Woods Hole Oceanographic Institution

June 2006

Certified by

Dr. Robert C. Beardsley, Dr. W. Brechner Owens

Thesis Supervisors

Accepted by

Dr. Joseph Pedlosky

Chair, Joint Committee for Physical Oceanography

Woods Hole Oceanographic Institution 
for Claudia, Luca and Elena

"The principle obstructions to creativity are self-imposed"

-Unknown author 


\title{
Wind, Sea Ice, Inertial Oscillations and Upper Ocean Mixing in Marguerite Bay, Western Antarctic Peninsula: Observations and Modeling
}

\author{
By \\ Jason Hyatt \\ Submitted in partial fulfillment of the requirements for the degree of \\ Doctor of Philosophy at the Massachusetts Institute of Technology \\ and the Woods Hole Oceanographic Institution \\ May 2006
}

\begin{abstract}
Two years of moored oceanographic and automatic weather station data which span the winter ice seasons of 2001-2003 within Marguerite Bay on the western Antarctic Peninsula (wAP) shelf were collected as part of the Southern Ocean Global Ocean Ecosystems Dynamics program. In order to characterize the ice environment in the region, a novel methodology is developed for determining ice coverage, draft and velocity from moored upward-looking acoustic Doppler current profiler data. A linear momentum balance shows the importance of internal ice stresses in the observed motion of the ice pack. Strong inertial, not tidal, motions were observed in both the sea ice and upper ocean.
\end{abstract}

Estimates of upward diapycnal fluxes of heat and salt from the Upper Circumpolar Deep Water to the surface mixed layer indicate almost no contribution from double diffusive convection. A one-dimensional vertical mixed layer model adapted for investigation of mixing beneath an ice-covered ocean indicates that the initial wind event, rather than subsequent inertial shear, causes the majority of the mixing. This work points towards episodic wind-forced shear at the base of the mixed layer coupled with static instability from brine rejection due to ice production as a major factor in mixing on the wAP shelf.

Thesis Supervisors: Robert C. Beardsley and W. Brechner Owens Senior Scientists, Department of Physical Oceanography

Woods Hole Oceanographic Institution 


\section{Acknowledgements}

The work described in this thesis was funded by the National Science Foundation Office of Polar Programs grant \# 99-100092. Additional funding came from the MIT Houghton Fund, the WHOI Ocean Venture Fund and the WHOI Education Office.

First a very special thanks to the faculty and staff at MIT and WHOI, particularly my advisors, Bob Beardsley and Breck Owens, my thesis committee and thesis defense chair. I also wish to express gratitude to all of my instructors in the Joint Program. Finally, thanks to Dick Limeburner for his critical role in collecting the data and providing fresh bay scallops.

My research would have been impossible without the cooperation and hard work of the Captain and Crew of RVIB N.B. Palmer and L.M. Gould. The same goes for the WHOI buoy group.

I appreciate my co-authors Laurie Padman and Susan Howard holding my hand through my first real experience writing a paper, Martin Visbeck letting me do it on my own. Miles McPhee provided valuable insight, as well.

I certainly would not have made it this far without my classmates M. Ohiwa, S. Kida and J.T. Farrar. K. Silverthorne provided the initial version of the original PWP model and C. Moffat spent lots of time getting the mooring data squared away. Thanks to all JP students for making the program what it is both academically and socially.

The WHOI Education office including Julia Westwater, Marsha Gomes, Judy McDowell and John Farrington kept the show running and answered my questions and made sure I filled out all the forms.

The biggest "thank you" goes to my entire family. My parents, Anneke and Gerry brought me up right and gave me a head start. My beautiful wife Claudia continued to encourage and push me to finish this thesis. I love her for that. Luca brings joy to me everyday with a fresh perspective, and thanks to Elena for putting the final pressure on to finish. 


\section{Contents}

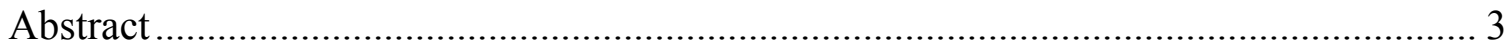

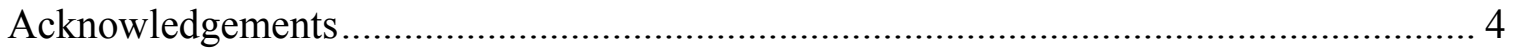

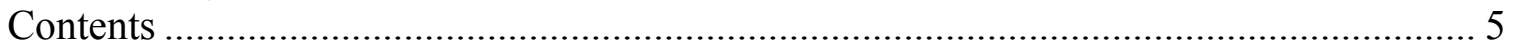

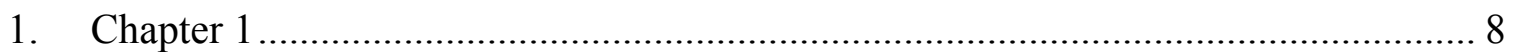

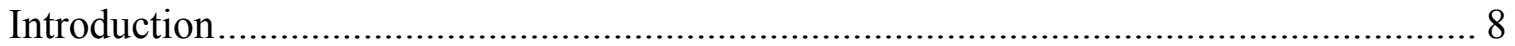

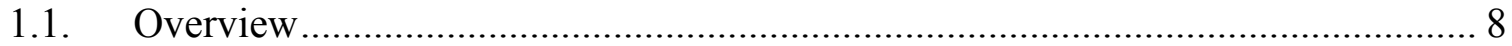

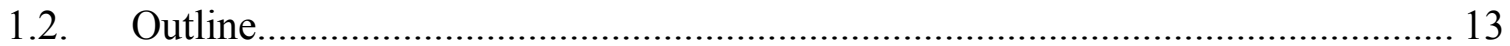

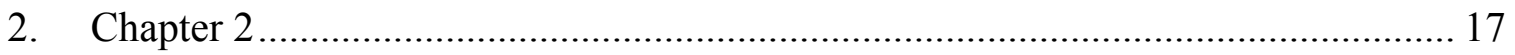

Mixing in the pycnocline over the western Antarctic Peninsula shelf during Southern

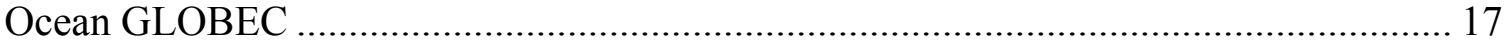

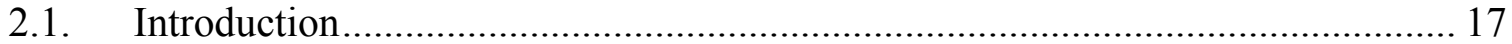

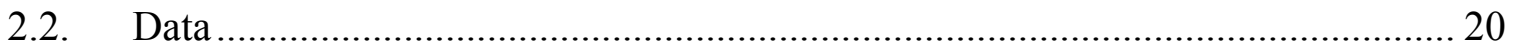

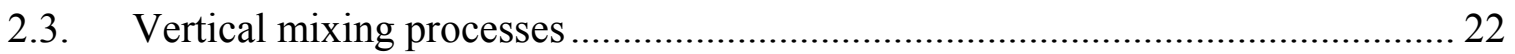

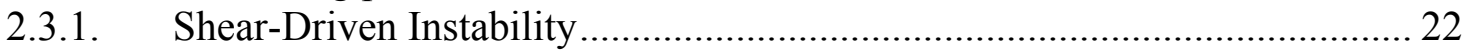

2.3.1.1. Near-inertial waves ..................................................................... 23

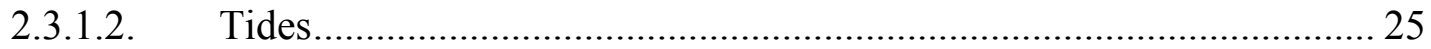

2.3.1.3. Mixing Rates Associated with Shear................................................. 26

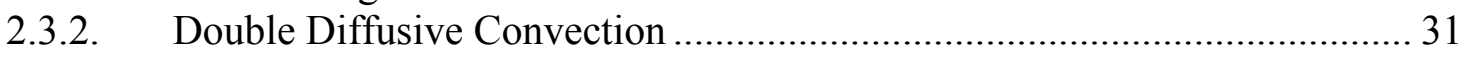

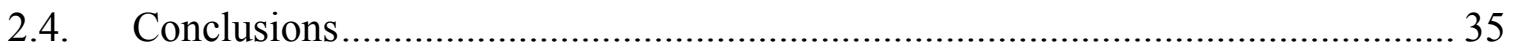

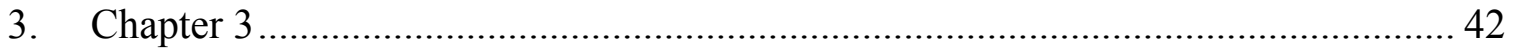

Measurements of sea ice properties using a moored upward-looking acoustic Doppler

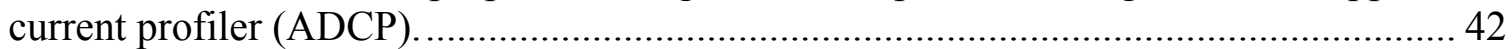

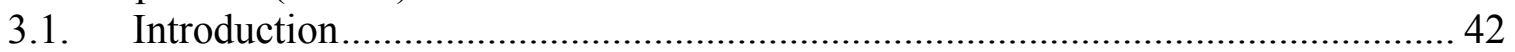

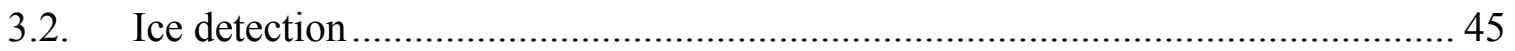

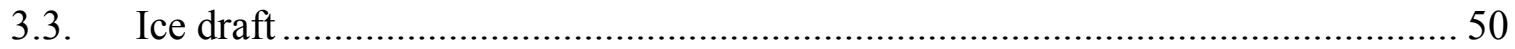

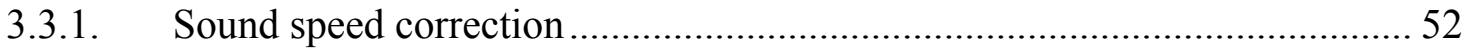

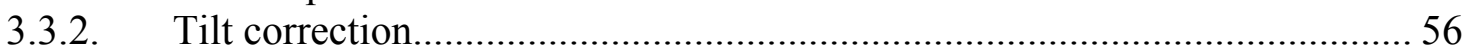

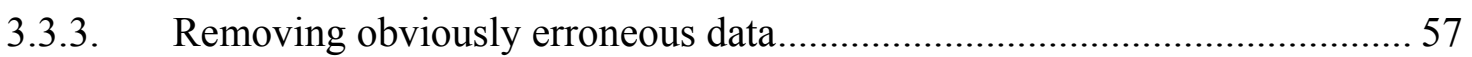

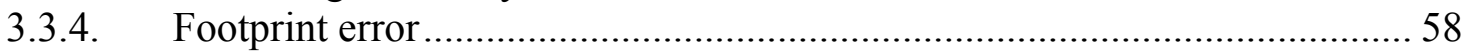

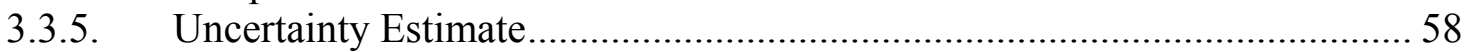

3.3.5.1. Uncertainty due to the empirical fitting function..................................58

3.3.5.2. Uncertainty in the Sound Speed Correction.............................................. 60

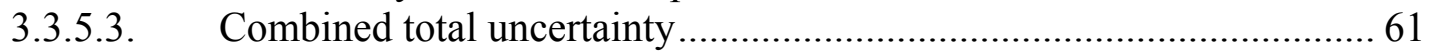

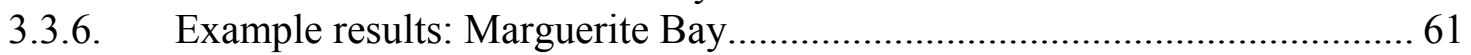

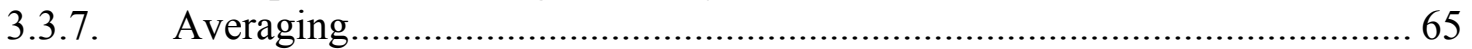

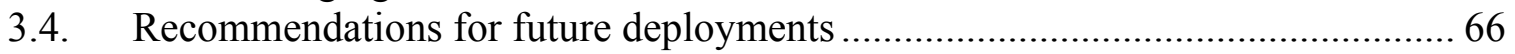

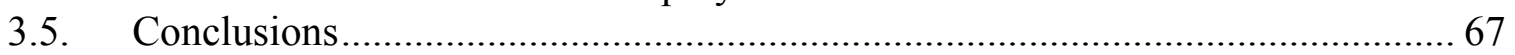

3.A APPENDIX: Data from Marguerite Bay, western Antarctic Peninsula shelf............ 68

4. Chapter 4 ............................................................................................... 72

Characterization of sea ice cover, motion and dynamics in Marguerite Bay, Antarctic

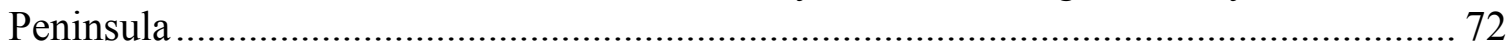

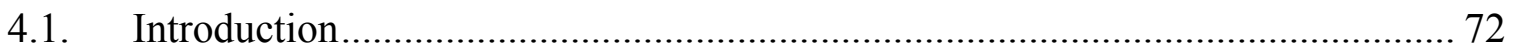




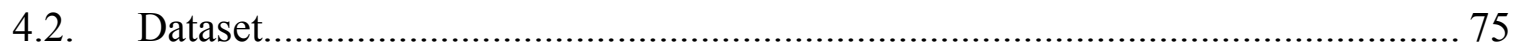

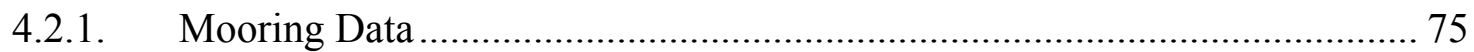

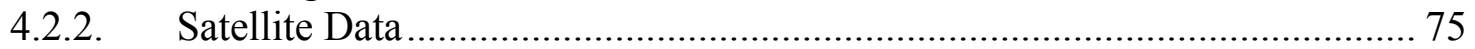

4.2.3. Automatic Weather Station Data ............................................................. 76

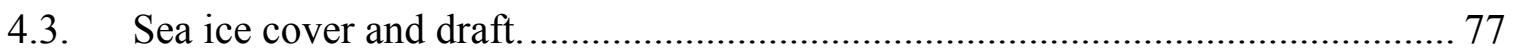

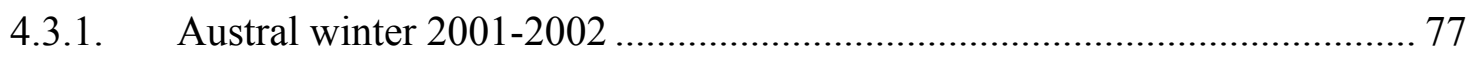

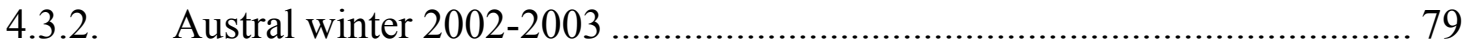

4.3.3. Interannual comparison of sea ice cover and draft .................................... 82

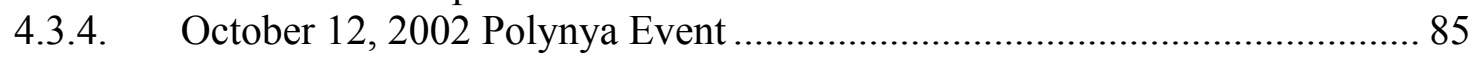

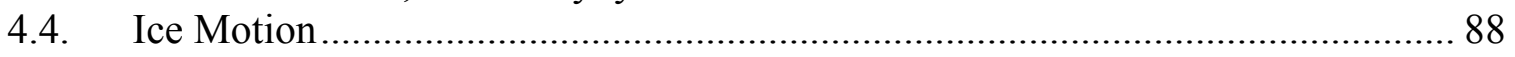

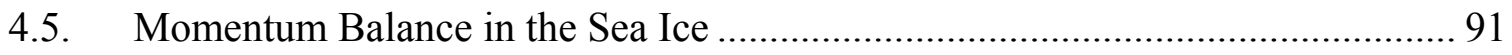

4.6. Near- Inertial Oscillations in Sea Ice and the Upper Ocean ................................ 97

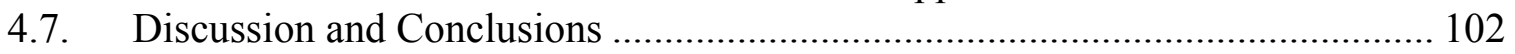

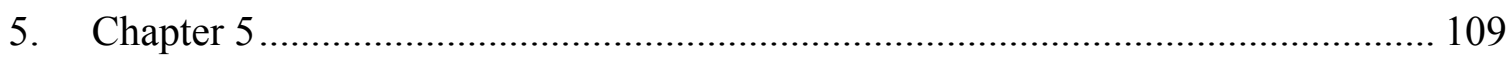

One-dimensional modeling of vertical mixing in a seasonally ice-covered, stratified,

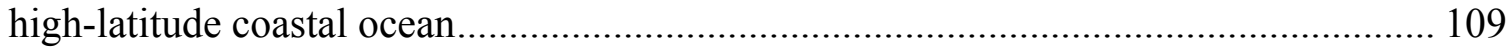

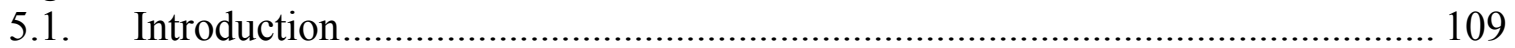

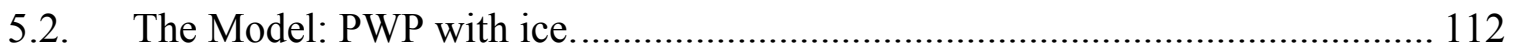

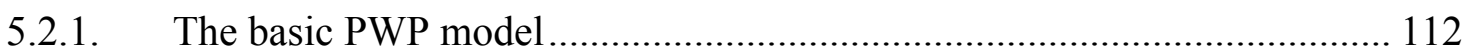

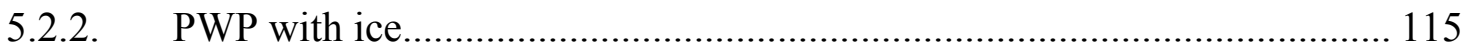

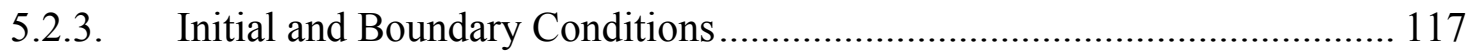

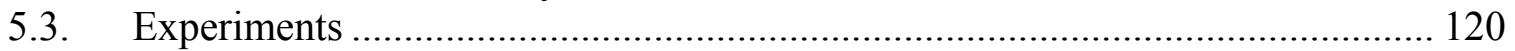

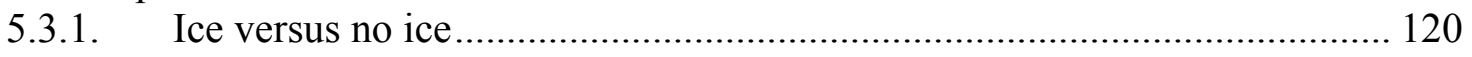

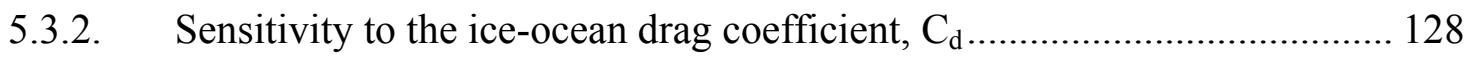

5.3.3. Lead opening and closing and air-sea heat fluxes ..................................... 131

5.3.4. Feedbacks from vertical heat flux.......................................................... 140

5.3.5. Slowing of mixed layer due to entrainment............................................... 141

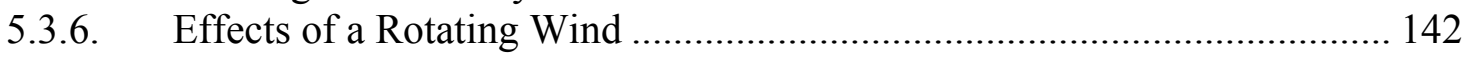

5.4. Application of idealized study to wAP region................................................. 144

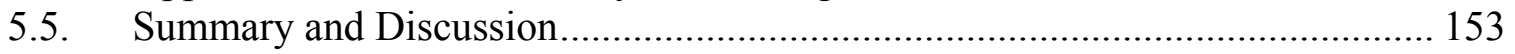

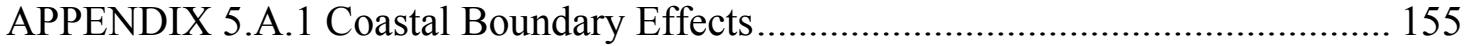

APPENDIX 5.A.2 Mixed Layer Heat Balance........................................................... 157

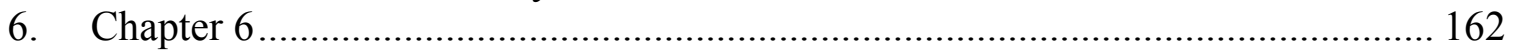

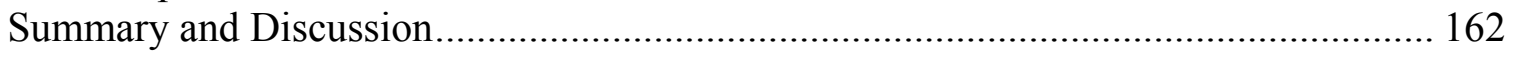

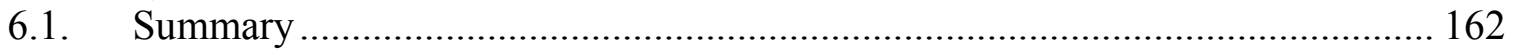

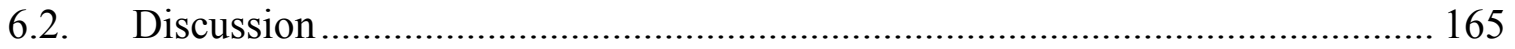

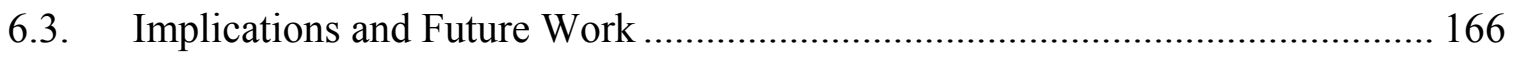




\section{Chapter 1}

\section{Introduction}

\subsection{Overview}

Ice in the world oceans plays an important role in regulating the Earth's climate. Sea ice acts to insulate the relatively warm ocean from the cold polar atmosphere. Furthermore, movement of ice from the formation to the melt region acts as a transport of latent heat and freshwater. This movement depends on a complicated balance between the winds, the surface ocean currents and the dynamics of the sea ice itself. Sea ice is also believed to play an important role in biological processes. The importance of the polar oceans in climate studies combined with a rapid increase in available technology to access and measure ice-covered seas have prompted a renewed interest in understanding sea ice and the ocean below it.

This interest in high latitude physical-biological processes led to the Southern Ocean Global Ocean Ecosystems Dynamics (SO GLOBEC) program, which chose the continental shelf of the western Antarctic Peninsula (wAP) for study due to its unusually high concentration of Antarctic Krill (Euphasia superba) and krill predators such as penguins, seals and whales (Figure 1.1.1). SO GLOBEC aims to determine what conditions favor the reproduction, recruitment, and retention of krill populations, including ice cover (high ice versus low ice years), on-shelf intrusion of warmer nutrient rich waters and subsequent vertical mixing. 


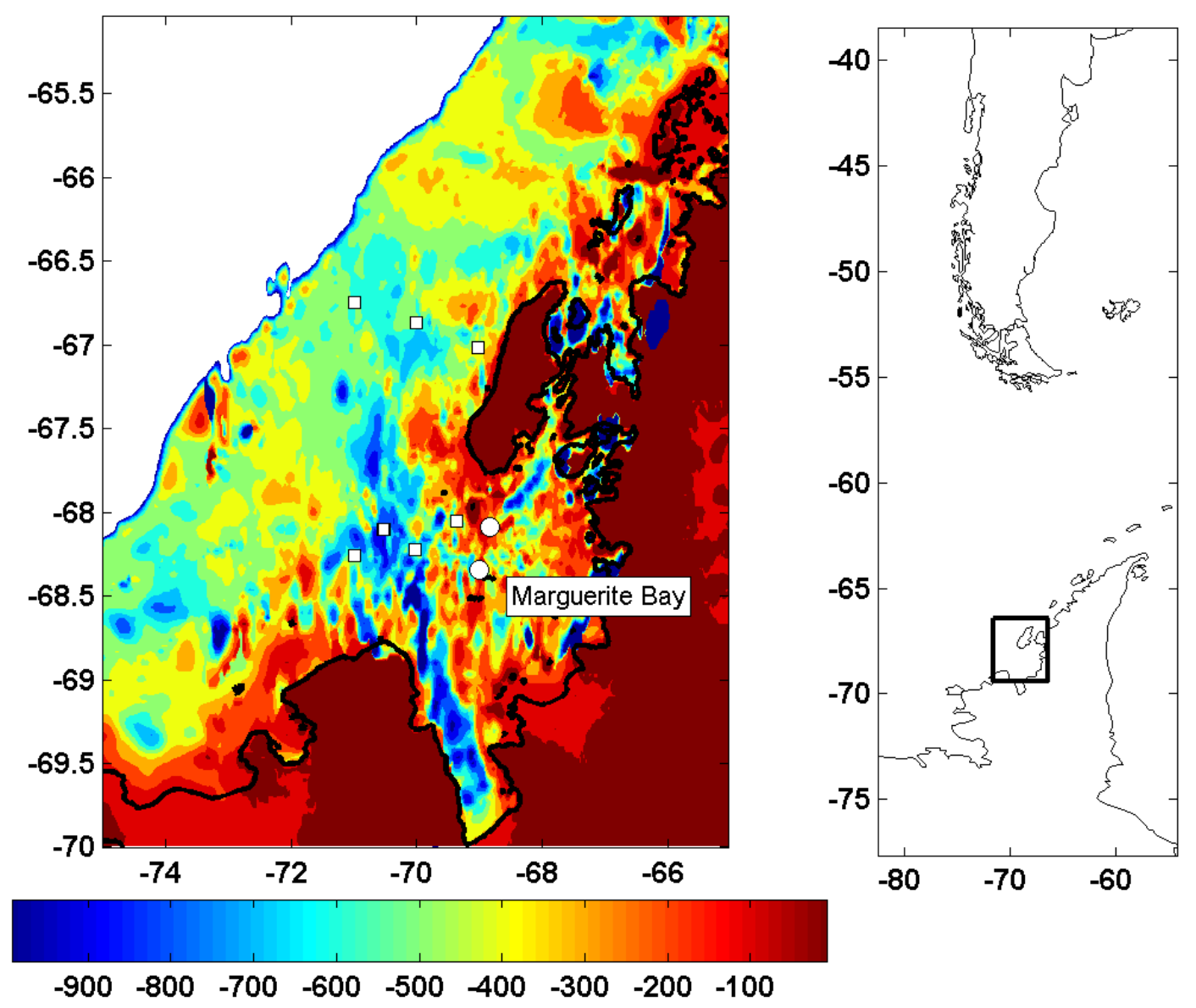

Figure 1.1.1 Left panel shows the Marguerite Bay region of the western Antarctic Peninsula shelf, depth is in meters. White squares and circles show the locations of the moorings and weather stations, respectively. The thick black line represents the coast and approximate position of the permanent ice shelf. The depth contours end at the $1000-\mathrm{m}$ isobath, the approximate location of the shelf break. The right panel shows the location of the study region in the larger context, with South America to the north.

The physical oceanographic environment of the wAP shelf has a number of features which differentiate it from a typical mid-latitude shelf, e.g., the North American Middle Atlantic Bight. The wAP shelf is nearly fully ice-covered in winter, and almost totally ice-free in summer. Most of the shelf is quite deep ( $\sim 500 \mathrm{~m})$ with a $\sim 800 \mathrm{~m}$ deep trough running from Marguerite Bay nearly to the shelf break. The Antarctic Circumpolar Current (ACC) flows northeastwards along the shelf break carrying relatively warm and salty Circumpolar Deep Water (CDW).

The surface waters above about $100 \mathrm{~m}$, known as Antarctic Surface Water (AASW), show a strong seasonal signal, becoming warmer in summer as a result of the positive surface heat flux (Figure 1.1.2). In addition, the wAP shelf surface waters 
freshen slightly as a result of glacier melt, coastal runoff and to a lesser extent ice melt (Dierssen et al., 2002; Meredith et al., 2006). In fall, negative surface heat flux causes rapid cooling of the surface waters that become saltier as they mix down into the remnant Winter Water (WW) and brine is rejected during the formation of sea ice (Smith et al, 1999). On interannual timescales, ice production and subsequent brine rejection has been found to be the main control on upper ocean stratification (WW production and maintenance) in northern Marguerite Bay off the British Antarctic Survey station Rothera (Meredith et al., 2004). Relatively warm and salty Circumpolar Deep Water (CDW) flows onto the shelf below the AASW and WW, and is divided by its properties into an Upper and Lower Circumpolar Deep Water (UCDW and LCDW). Despite strong atmospheric forcing, waters from the wAP shelf do not become dense enough to form Antarctic Bottom Water (Klinck, 1998; Hofmann and Klinck, 1998). 
(a)

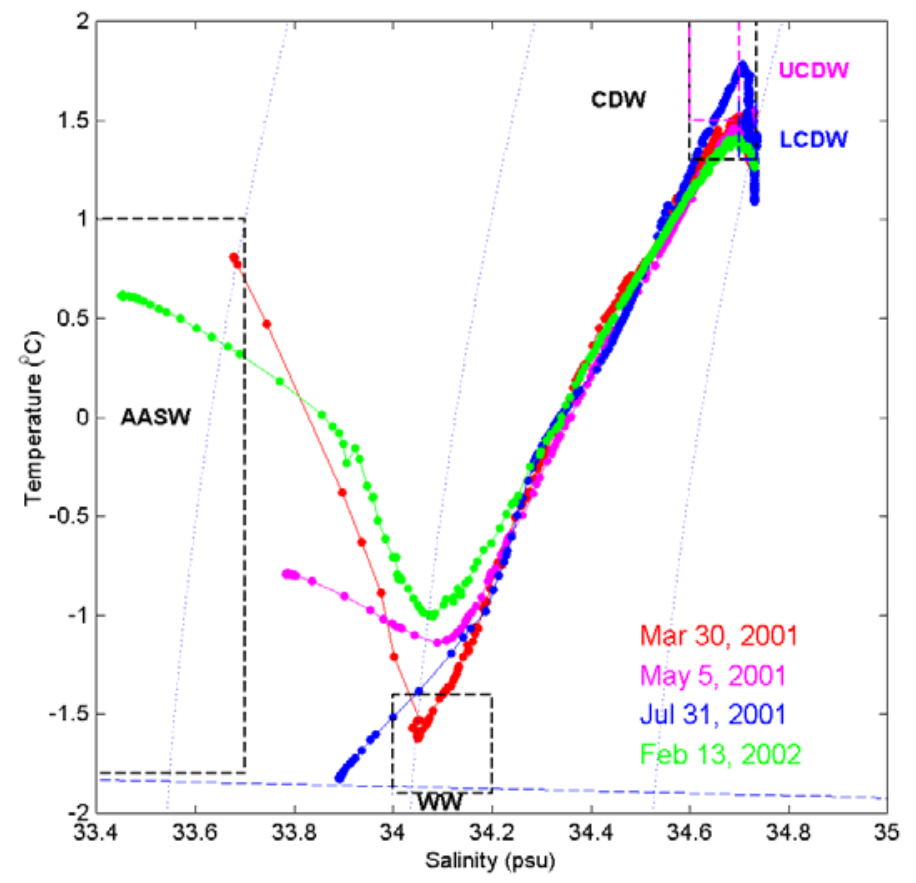

(b)
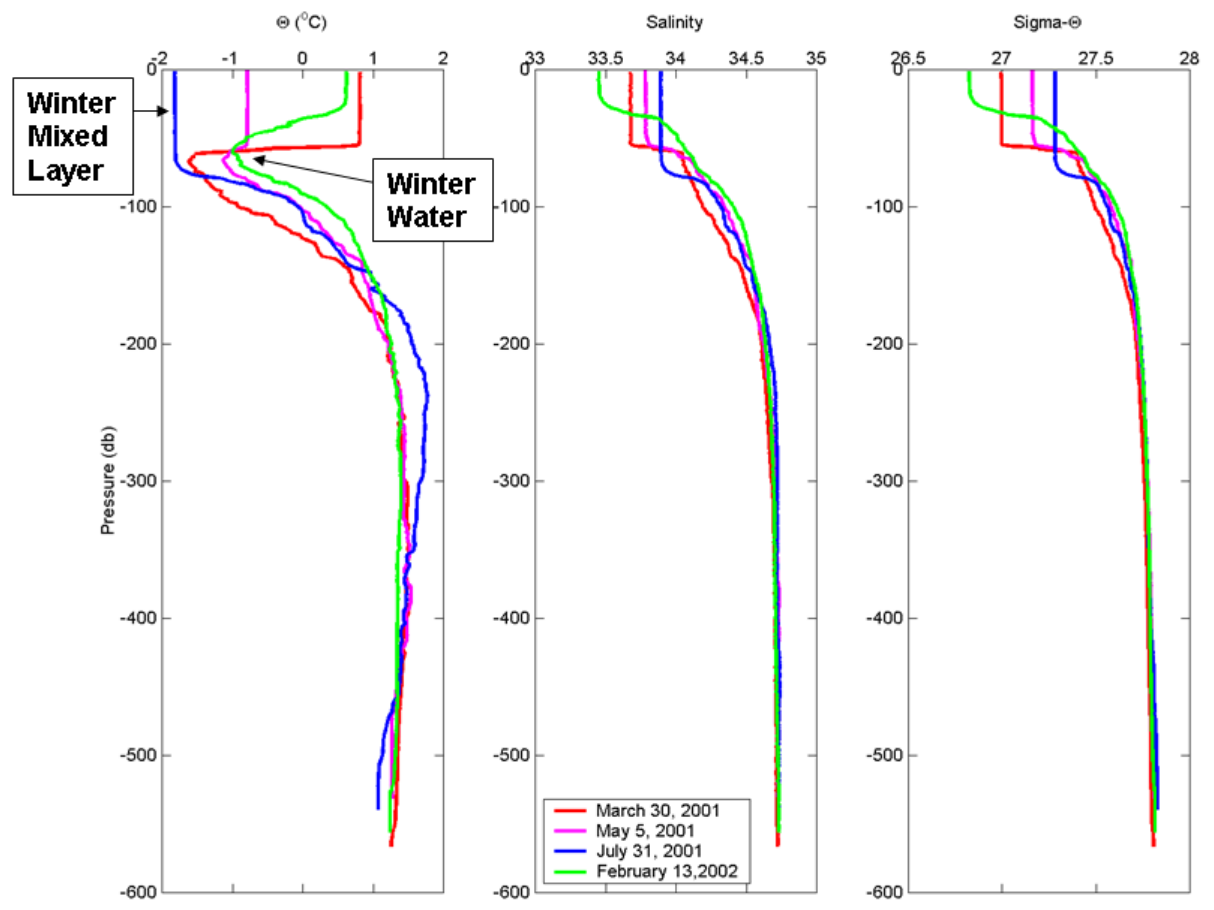

Figure 1.1.2 Four CTD casts on the wAP shelf showing water masses and the seasonal progression of the temperature and salinity in (a) a Temperature-Salinity plot and (b) vertical profiles of potential temperature, salinity and potential density. 
Air-sea heat flux is one to two orders of magnitude larger over open water than over thick $(\sim 1 \mathrm{~m})$ sea ice. Wind stress on sea ice is frequently balanced in large part by internal ice stresses rather than imparting momentum to the sea ice and upper ocean (e.g. Chapter 4 on wAP shelf; Uotila et al., 2000 in the Weddell Sea; Steele et al., 1997 in the Arctic). The strong influence sea ice has on the vertical transport of heat and momentum between the atmosphere and the ocean plays a major role in the hydrography of the wAP shelf and is a central theme of this thesis.

The data used in this thesis represent the most comprehensive set of physical oceanographic measurements made in Marguerite Bay to date. It consists primarily of two years of moored oceanographic and Automatic Weather Station (AWS) data which cover the winter ice seasons of 2001-2003. During the ice-free austral summer, subsurface moorings were deployed and remained beneath the ice for the duration of the ice-covered austral winter, including the onset and breakup of sea ice. They had an upward-looking acoustic Doppler current profiler (ADCP) and measured temperature, salinity, pressure and velocity at various depths (Figure 1.1.3). The locations of the moorings, as well as the two AWSs are shown in Figure 1.1.1. Details of the mooring and weather station data can be found in Moffat et al. (2005). Satellite data and Conductivity-Temperature-Depth (CTD) profile data collected on mooring and hydrographic cruises were used as well. 


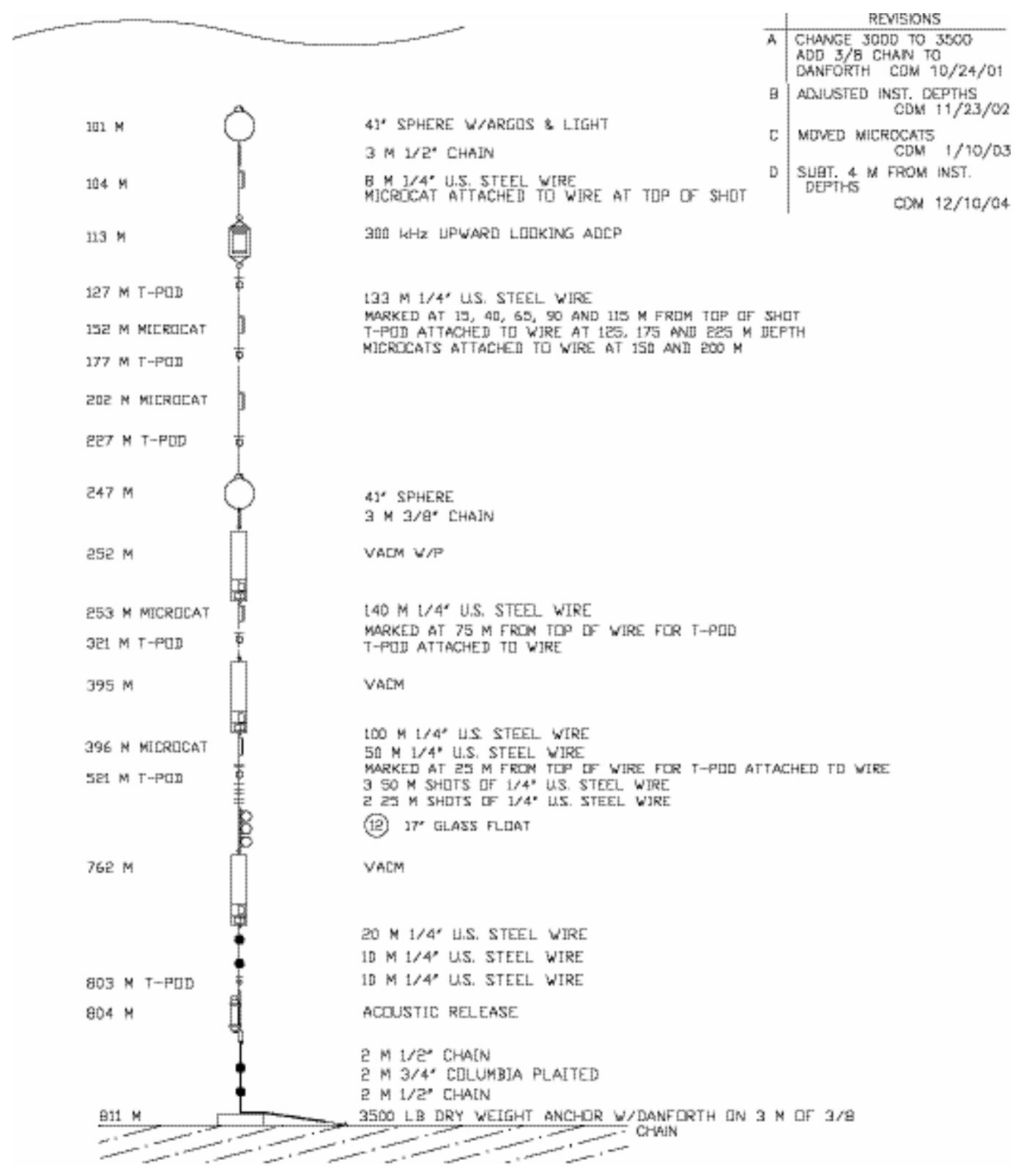

Figure 1.1.3 Schematic of the C3 mooring deployed during SO GLOBEC in Marguerite Trough in the mouth of Marguerite Bay $\left(6^{\circ} 6 .^{\prime}\right.$ ', $7^{\circ} 31.8^{\prime}$ W) (Moffat et al., 2005).

\subsection{Outline}

It is noted that Chapter 2 has been published (Howard et al., 2004) and Chapters 3 and 4 have been submitted for publication (Hyatt et al., 2006a and 2006b).

In Chapter 2, the small-scale processes that contribute to upward diapycnal fluxes of heat, salt and nutrients from the UCDW to the surface mixed layer are discussed and initial flux estimates based on published parameterizations are made. Near-inertial shear across the sharp pycnocline at the base of the mixed layer is observed and considered in 
the context of vertical mixing. A previous suggestion that double-diffusive convection (DDC) provides significant upward heat fluxes (of order $10 \mathrm{~W} \mathrm{~m}^{-2}$ ) in a nearby region (Smith and Klinck, 2002) is not supported by the analyses in Chapter 2, which indicate almost no contribution $\left(0.2-0.4 \mathrm{~W} \mathrm{~m}^{-2}\right)$ to diapycnal fluxes from DDC.

In Chapter 3, a technique for the analysis of data from a moored upward-looking ADCP to determine ice coverage, draft and velocity is presented and applied to data collected on the wAP shelf. This method provides sea ice information when no dedicated upward-looking sonar (ULS) data are available.

In Chapter 4, the onset, draft, motion and dynamics of sea ice within Marguerite Bay are characterized for the two ice seasons spanning 2001-2003 with data derived in part using the methods described in Chapter 3. Both years have roughly seven months of nearly complete ice cover, but the timing is quite different between the two years. The ice draft is considerable, over $3 \mathrm{~m}$ lasting for weeks during both winters. Internal ice stresses are shown to be important in explaining the observed motion of the ice pack. Tidal and near-inertial band motions are discussed as well.

Vertical fluxes of heat, salt and nutrients in a seasonally ice-covered, high-latitude coastal ocean have become a central question to the SO GLOBEC program. To address this, in Chapter 5 a one-dimensional model of vertical mixing is used to investigate two potentially important mixing processes, namely shear caused by a wind event and subsequent inertial oscillations; and convection due to brine rejection associated with freezing as leads open and close with divergent and convergent inertial motions. The model results indicate that the wind event is responsible for the majority of heat flux across the base of the mixed layer, not the subsequent inertial oscillations. When forced by observed atmospheric and ice conditions on the wAP shelf, large (one-day average of $\sim 300 \mathrm{~W} \mathrm{~m}^{-2}$ ) fluxes across the base of the mixed layer are produced during a strong forcing event. However, averaging on an annual timescale predicts a smaller flux, on the order of $10 \mathrm{~W} \mathrm{~m}^{-2}$.

Finally, Chapter 6 provides a summary of the thesis and discusses its implications and possible future work.

\section{References:}


Dierssen, H. M., Smith, R. C., and Vernet, M., 2002: Glacial meltwater dynamics in coastal waters west of the Antarctic Peninsula. Proceedings of the National Academy of Sciences, 99 (4), 1790-1795.

Hofmann, E.E. and Klinck, J.M., 1998: Thermohaline variability of the waters overlying the west Antarctic Peninsula continental shelf, in: S. Jacobs and R. Weiss, eds., Ocean Ice and Atmosphere: Interactions at the Antarctic Continental Margin (American Geophysical Union, Washington DC), 67-81.

Howard, S., Hyatt, J. and Padman, L., 2004: Mixing in the pycnocline over the western Antarctic Peninsula shelf during Southern Ocean GLOBEC. Deep-Sea Research II, 51, 1965-1979.

Hyatt, J., Visbeck, M., Beardsley, R.C. and Owens, W.B., 2006a: Measurements of sea ice properties using a moored upward-looking acoustic Doppler current profiler (ADCP). Submitted to Deep-Sea Research II.

Hyatt, J., Beardsley, R.C. and Owens, and W.B., 2006b: Characterization of sea ice cover, motion and dynamics in Marguerite Bay, Antarctic Peninsula. Submitted to Deep-Sea Research II.

Klinck, J. M., 1998: Heat and salt changes on the continental shelf west of the Antarctic Peninsula between January 1993 and January 1994. J. Geophys. Res., 103, 7617-7636.

Meredith, M.P., Renfrew, I.A., Clarke, A., King, J.C., and Brandon, M., 2004: Impact of the 1997/98 ENSO on upper ocean characteristics in Marguerite Bay, western Antarctic Peninsula. J. Geophys. Res., 109.9013-9032.

Meredith, M. P., Brandon, M. A., Wallace, M. I., Clarke, A., Leng, M. J., Renfrew, I. A., van Lipzig, N., and King, J. C., 2006: On the seasonal freshwater budget of northern Marguerite Bay, Antarctic Peninsula. Submitted to Deep-Sea Research II.

Moffat, C., Beardsley, R.C., Limeburner, R., Owens, B., Caruso, M., and Hyatt, J., 2005: Southern Ocean GLOBEC Moored Array and Automated Weather Station Data Report. Woods Hole Oceanographic Technical Report WHOI-2005-07. pp 1-128.

Smith, D.A., Hofmann E.E., Klinck, J.M., and Lascara C.M., 1999: Hydrography and circulation of the West Antarctic Peninsula Continental Shelf. Deep-Sea Research I (46) 925-949. 
Smith, D.A. and Klinck, J.M., 2002: Water properties on the west Antarctic Peninsula continental shelf: a model study of effects of surface fluxes and sea-ice. DeepSea Research II, 49, 4863-4886.

Steele, M., Zhang, J., Rothrock, D., and Stern, H., 1997: The force balance of sea ice in a numerical model of the Arctic Ocean. J. Geophys. Res., 102, 21,061-21,079.

Uotila, J., Vihma, T., and Launiainan, J., 2000: Response of the Weddell Sea pack ice to wind forcing. J. Geophys. Res., 105, 1,135-1,151. 


\section{Chapter 2}

\section{Mixing in the pycnocline over the western Antarctic Peninsula shelf during Southern Ocean GLOBEC}

\subsection{Introduction}

The western Antarctic Peninsula (WAP) shelf region (Figure 2.1.1) is an area of unusually high krill production and thus a favorable habitat for krill predators such as Adélie penguins and Crabeater seals. The Southern Ocean Global Ecosystem Dynamics (SO GLOBEC) program examined the unique physical and biological factors that contribute to enhanced krill growth, reproduction, recruitment and survivorship in this region throughout the year (Hofmann et al., 2004). 


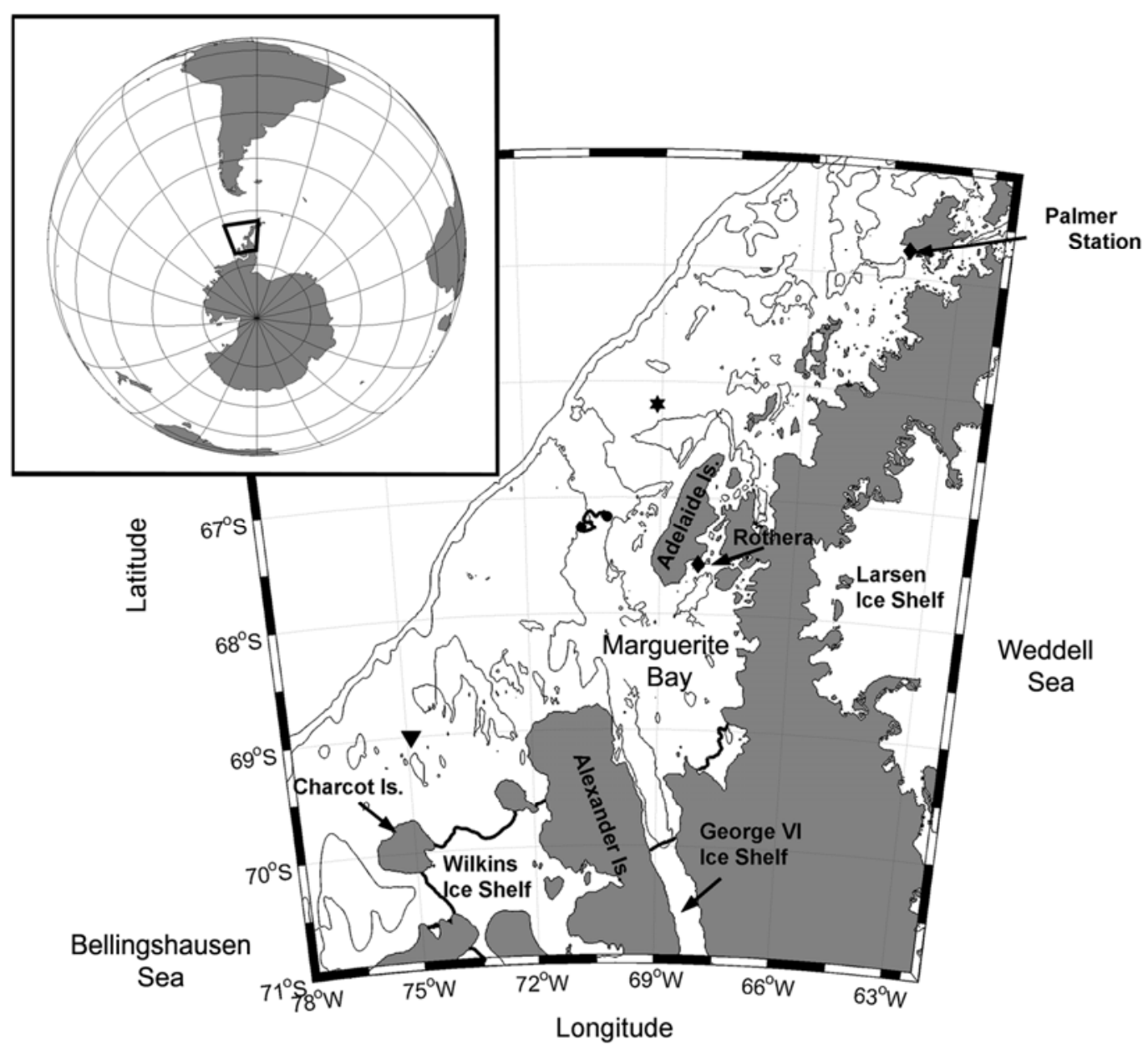

Figure 2.1.1. Map of the study area surrounding Marguerite Bay on the western side of the Antarctic Peninsula. Thin black lines are the 500 and $2000 \mathrm{~m}$ isobaths based on the Smith and Sandwell ETOPO2 dataset updated with GLOBEC bathymetry data. Bold black lines indicate fronts of major ice shelves. The location of Survey Station 3 near $66.2^{\circ} \mathrm{S}, 6^{69.1^{\circ} \mathrm{W}}$ (see Fig. 2.1.2) is indicated by a star, while CTD 76 near $69^{\circ} \mathrm{S}, 7^{\circ} \mathrm{W}$ from the fall 2001 survey cruise (see Fig. 2.3.3) is indicated by a filled triangle. The drift track for the section of the winter process cruise on $L . M$. Gould used in Fig. 2.3.1 is also indicated (centered near $67.2^{\circ} \mathrm{S}, 7_{0.5}^{\circ} \mathrm{W}$ ).

In this chapter we identify, and attempt to quantify the fluxes associated with, the small-scale physical oceanographic processes that facilitate the supply of heat, salt, and nutrients to the upper ocean over the WAP shelf. The principal pathway for these fluxes to the shelf is via large-scale lateral subsurface intrusions of warm, salty, nutrient-rich Upper Circumpolar Deep Water (UCDW). The UCDW is derived from the Antarctic Circumpolar Current (ACC) (Prézelin et al., 2000; Smith and Klinck, 2002) and flows shoreward along bathymetric features such as the Marguerite Trough (Klinck et al., 2004). Over the shelf, the UCDW typically lies below about $200 \mathrm{~m}$, well below the less 
dense surface waters that are formed from ocean/atmosphere buoyancy exchange and sea-ice processes. In a plot (not shown) of potential temperature $(\theta)$ against salinity $(S)$, the transition region between the UCDW and the surface waters (roughly the depth range 80-200 $\mathrm{m}$ in Figure 2.1.2) is fairly linear, suggesting that the $\theta-\mathrm{S}$ relationship in this depth range is set by diapycnal mixing between the end-member water types. Our goal is to determine the processes that drive this mixing.
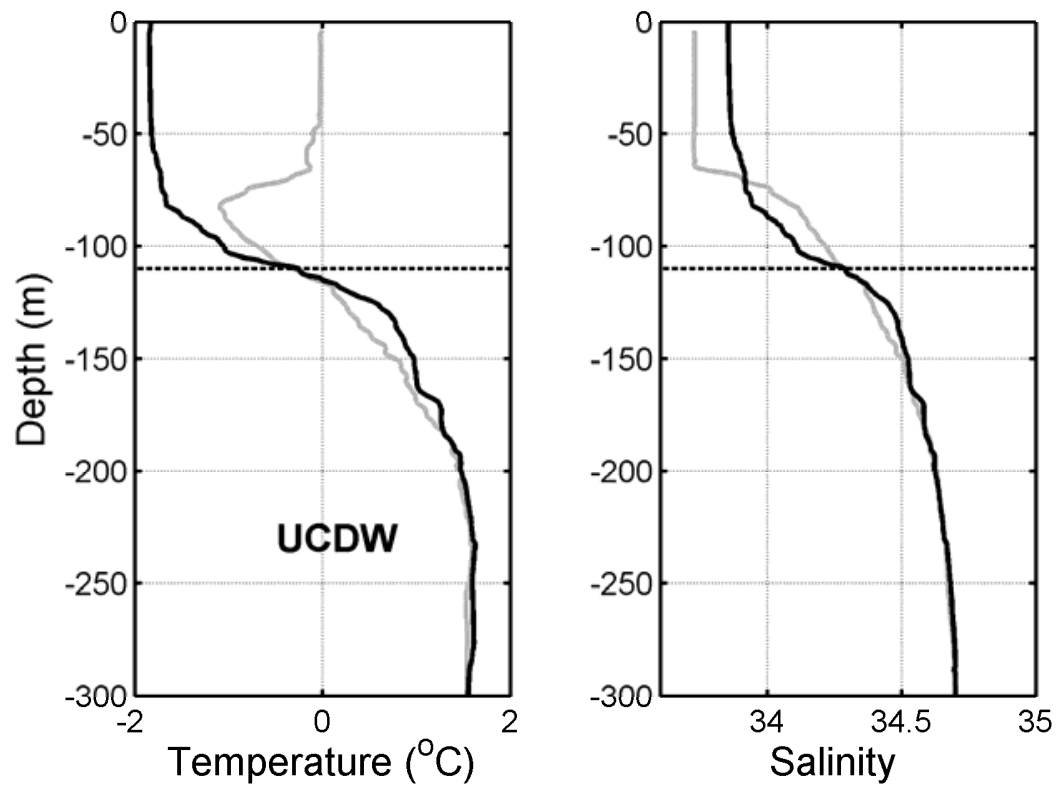

Figure 2.1.2. Profiles of temperature (left) and salinity (right) at survey station 3 from the fall (gray line) and winter (black line) survey cruises (see Fig. 2.1.1 for location). The profiles were separated by $\sim 89$ days. Upper Circumpolar Deep Water (UCDW) that has intruded onto the shelf occupies the water column below about $200 \mathrm{~m}$. On the assumption that lateral advection is negligible (Smith and Klinck, 2002), the heat and salt flux divergences associated with the change in heat and salt content of the profiles above $110 \mathrm{~m}$ (indicated by the horizontal dashed line) are $-72 \mathrm{~W} \mathrm{~m}^{-2}$ and $0.7 \mathrm{mg} \mathrm{m}^{-2} \mathrm{~s}^{-1}$, respectively.

The most likely candidates for pycnocline mixing processes in this environment are shear-driven instability (SDI) and double-diffusive convection (DDC). In turn, the most likely sources of energy for SDI are from wind stress and tides (see, e.g., Munk and Wunsch, 1998). The mixing rates associated with these processes can be estimated in three ways: a box-model of heat and salt budget calculations for the surface mixed layer 
(e.g., Smith and Klinck, 2002); measurements of scalars or velocity shear that fully resolve the turbulent microscales of order 1-10 cm (see Gregg, 1987); or by invoking parameterizations that relate mixing rates to measured "large-scale" quantities.

The difficulty of a box-model approach for the WAP region is illustrated in Figure 2.1.2. For a representative site (survey station 3; see Figure 2.1.1 for location) over the central WAP shelf, the change in upper-ocean heat and salt content between the austral fall and winter 2001 survey cruises is consistent with net vertical flux divergences of heat and salt across the mixed layer of $-72 \mathrm{~W} \mathrm{~m}^{-2}$ and $0.7 \mathrm{mg} \mathrm{m}^{-2} \mathrm{~s}^{-1}$, respectively. In contrast, the mean upward fluxes from below the mixed layer are likely of order $1-10 \mathrm{~W} \mathrm{~m}^{-2}$ and $0.01 \mathrm{mg} \mathrm{m}^{-2} \mathrm{~s}^{-1}$ (Smith and Klinck, 2002), implying that the upper ocean heat and salt budgets are dominated by the seasonal cycles of heat and fresh water exchange at the ocean surface. Attempts to estimate the diffusivities in the pycnocline from box-model studies of surface mixed layer heat and fresh water budgets are therefore subject to the significant errors associated with parameterizations of the large surface fluxes.

No microstructure data are available from SO GLOBEC year 1 cruises, hence the direct measurement of diffusivity in the pycnocline is not possible. Instead, for the present chapter we concentrate on the third approach; using fine-scale hydrographic and velocity data to identify mixing processes in the pycnocline. The data we analyze consist of hydrographic profiles from conductivity-temperature-depth (CTD) recorders and acoustic Doppler current profilers (ADCPs). The CTD resolution is $\sim 1 \mathrm{~m}$ when sea-state is not severe, and the ADCP collects velocity profiles at a vertical resolution of $\sim 10 \mathrm{~m}$.

We first describe the relevant data sets (Section 2.2), then review the processes of SDI and DDC and estimate their contribution to pycnocline mixing through parameterizations that are commonly employed in numerical models (Section 2.3). Section 2.4 provides a summary and discussion of our results.

\subsection{Data}

The SO GLOBEC program collected data in the WAP area during the austral fall and winter seasons of 2001 and 2002 using 4 survey cruises and 4 process cruises. Three additional cruises to deploy, service and recover moorings took place in the austral late 
summers of 2001, 2002, and 2003. For this study we concentrate on data from CTD profiles and the vessel-mounted ADCP during the fall and winter 2001 survey cruises on the RVIB N. B. Palmer (U.S. SO GLOBEC, 2001b,c) and the winter 2001 process cruise on the V L. M. Gould (U.S. SO GLOBEC, 2001c) (Table 1). Vertical profiles of temperature $(T)$ and conductivity $(C)$ as functions of pressure $(P)$ were obtained on a grid pattern (Figure 2.2.1) on the survey cruises using a SeaBird SBE $911^{+}$CTD system. Additional CTD profiles were obtained from the L. M. Gould process cruise using a similar CTD system. Salinity $(S)$ and potential density $\left(\sigma_{\theta}\right)$ were derived from $C, T$, and $P$. Accuracies of $T$ and $S$ are $\sim 10^{-4}{ }^{\circ} \mathrm{C}$ and $\sim 10^{-3}$ practical salinity units (psu), respectively, after post-calibration. The data that we use here were averaged initially over 1-m vertical bins: additional averaging used in our analysis is described where necessary. The cruise reports (U.S. SO GLOBEC 2001a,b,c) and Klinck et al. (2004) provide more details about the CTD data set and the general hydrographic structure and circulation that it reveals.
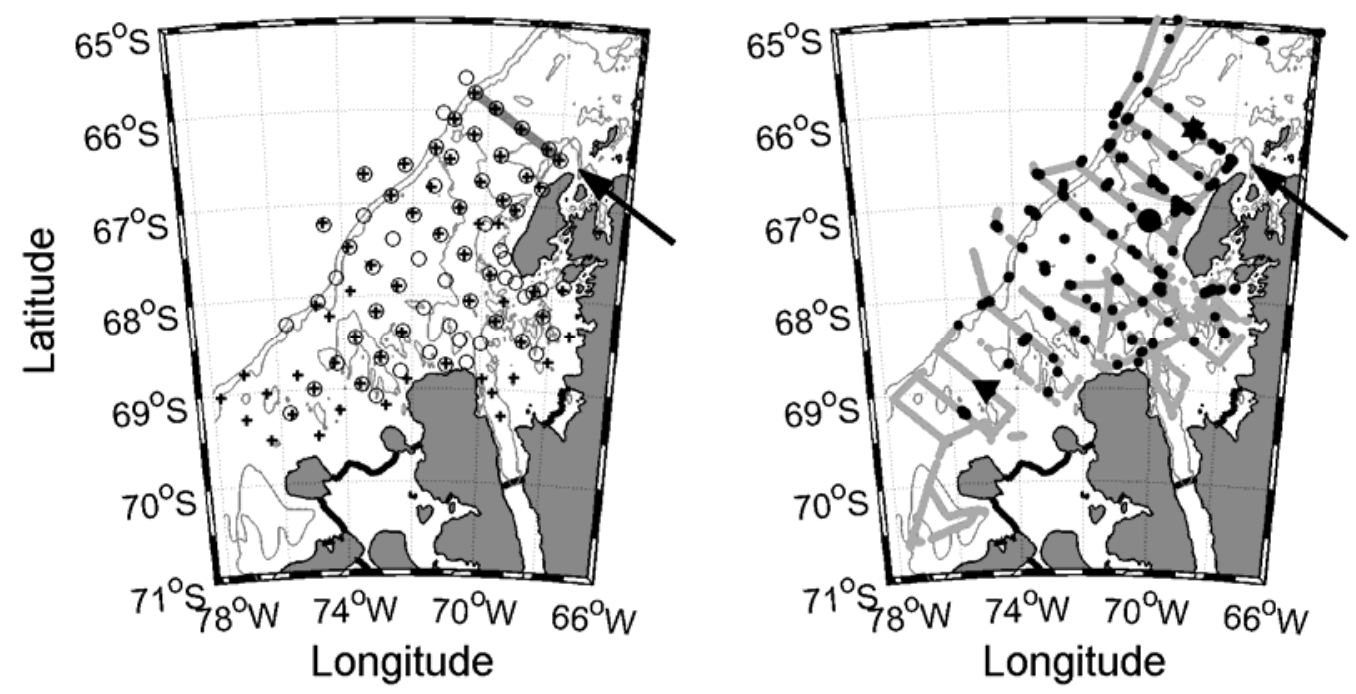

Figure 2.2.1. Left: Locations of CTD stations during the 2001 SO GLOBEC survey cruises. Fall stations are shown as plus symbols $(+)$. Winter stations are shown as circles (o). Right: Location of useable vessel-mounted ADCP data collected by the RVIB N.B. Palmer for the same cruises. Fall survey data are shown as gray dots. Winter survey data are shown as black dots. Large symbols indicate the locations of the same sites shown in Fig. 2.1.1. The cross-shelf transect 1 (Fig. 2.3.2), is indicated by an arrow.

Vertical profiles of upper-ocean horizontal current $(\mathbf{U}(z)=\mathrm{u}(z) \mathbf{i}+\mathrm{v}(z) \mathbf{j})$ were obtained from each vessel with RDI $150 \mathrm{kHz}$ vessel-mounted ADCPs. The ADCP 
systems were set for 8-m vertical bins, 8-m pulse length, and an ensemble averaging period of 5.0 minutes for all SO GLOBEC cruises except the 2001 mooring deployment and 2001 fall process cruises on the L. M. Gould. These two cruises used a 16-m pulse length. The resultant nominal accuracy of each estimate of $\mathbf{U}(z)$ is $\sim 1 \mathrm{~cm} \mathrm{~s}^{-1}$, per the manufacturer's design error estimate. The ADCP on the N. B. Palmer measures currents from $31 \mathrm{~m}$ to $\sim 300-350 \mathrm{~m}$ depths. Quoted depths refer to the center of the 8-m vertical bins. The ADCP on the L. M. Gould measures currents from $26 \mathrm{~m}$ to $\sim 300-350 \mathrm{~m}$ depths. Navigation data were obtained with an Ashtech 3D GPS system and were used in the processing of the ADCP data. Bottom tracking was used when the ship was in water less than $500 \mathrm{~m}$ deep. Figure 2.2.1 (right panel) shows the location of usable ADCP data from the 2001 N. B. Palmer survey cruises. Sea state and ice cover both interfered with collection of ADCP data. Sea-state effects can be seen as gaps in the grid for the fall survey cruise. Sea ice interferes with ADCP data collection while the ship is underway. During the winter cruise, therefore, data were acquired only as time series at fixed sites while the vessel was stopped during CTD and other station operations. These measurements lasted for as long as the on-station work, which typically took a few hours depending on water depth and sampling activities.

\begin{tabular}{|c|c|c|}
\hline Year 1 Cruises & Type & Date \\
\hline NBP01-03 & Fall survey & Apr. 23- June 6 \\
\hline NBP01-04 & Winter survey & July 22 - Aug. 31 \\
\hline LMG01-06 & Winter process & July 21 - Aug. 31 \\
\hline
\end{tabular}

Table 2.1. Summary of 2001 SO GLOBEC cruises discussed in this chapter. Dates and types of cruises are included. LMG - ARSV L. M. Gould, NBP - RVIB N. B. Palmer

\subsection{Vertical mixing processes}

\subsubsection{Shear-Driven Instability}

Shear-driven instability (SDI) is the primary source of mixing in the World Ocean pycnocline. The source of energy for SDI is a combination of atmospheric forcing (primarily wind stress, but also surface buoyancy fluxes) and tides: Munk and Wunsch (1998) and Wunsch (2000) suggest that about 50\% of the globally integrated mixing is associated with each source. This ratio is, however, strongly dependent on local conditions. Tides can be the dominant source of mixing via production of baroclinic 
tides and higher frequency internal waves in regions where strong barotropic tidal currents flow across steep topography; see, e.g., Padman and Dillon (1991) and Wijesekera et al. (1993) for high-latitude examples. The spatial distribution of shear is complicated by the propagation of super-inertial waves away from the energy source (see, e.g., Dushaw et al., 1995; Muench et al., 2002; Lozovatsky et al., 2003). Thus for any particular location, determining the likely strength of mixing through SDI requires knowledge not only of the local strength of forcing of baroclinic waves but also the potential for wave energy to propagate from elsewhere to the observation site.

For reasons explained below, we believe that the dominant source of shear in the WAP pycnocline is associated with wind-forced near-inertial waves. Baroclinic tides may provide additional shear in certain localized regions. We discuss each of these shear sources separately.

\subsubsection{Near-inertial waves}

At process site 3 from the winter process cruise while the L. M. Gould drifted in pack ice, we observed persistent shear in the ADCP data, with the shear being concentrated across the sharp pycnocline at the base of the mixed layer (Figure 2.3.1). The dominant signal in this record is a semidiurnal oscillation, where the current vectors in the layers above and below the sharp pycnocline rotate anticlockwise but are roughly $180^{\circ}$ out of phase with each other. Current speeds are up to $24 \mathrm{~cm} \mathrm{~s}^{-1}$ in the upper mixed layer, and weaker but still significant in the lower layer. Although the ADCP record does not reach full depth ( $\sim 500-650 \mathrm{~m})$ in this region, the impression is that the net depthintegrated flow is small, with the volume flux in the faster and thinner surface layer being compensated for by the opposing flux in the thicker but slower-moving lower layer. 

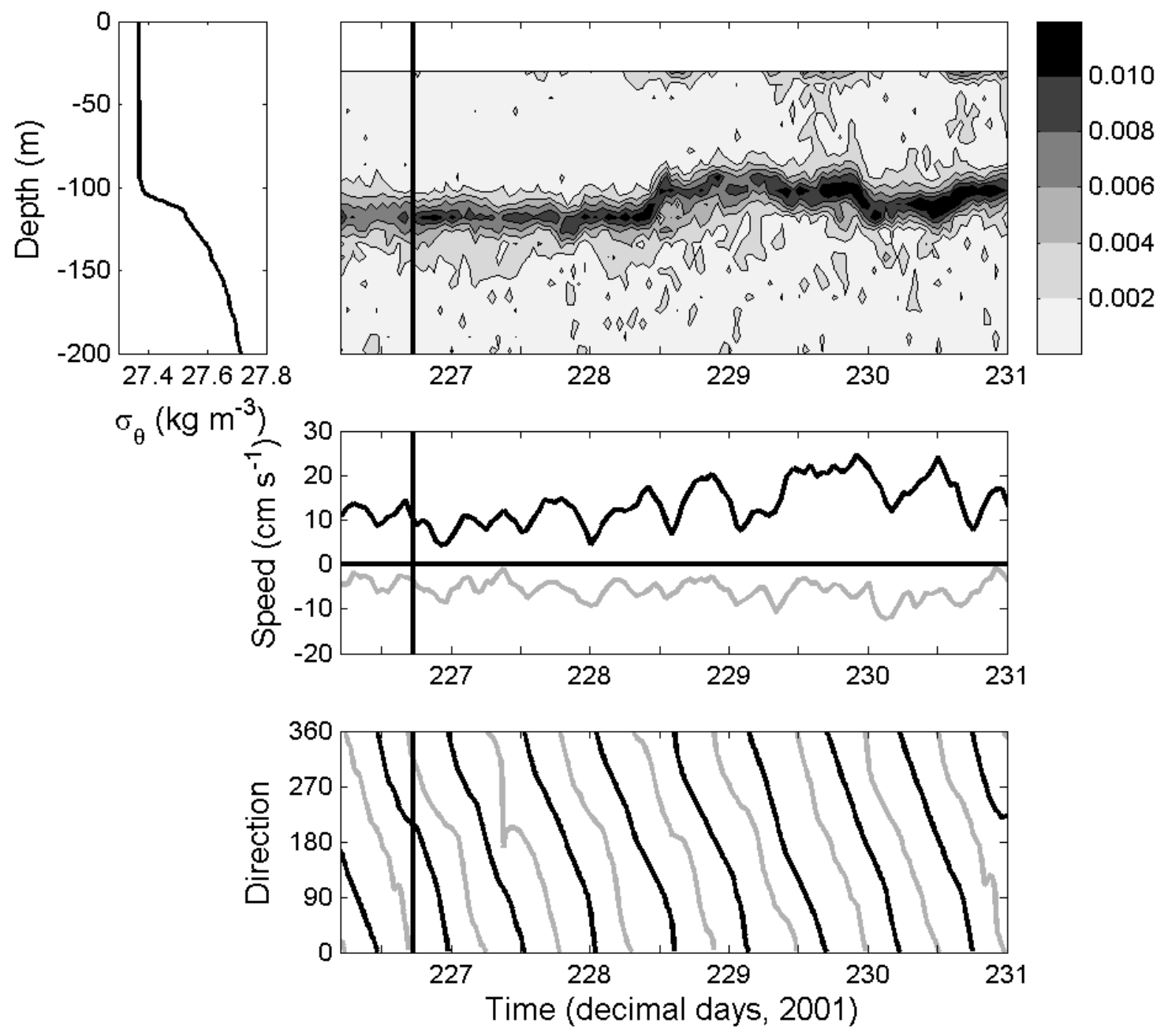

Figure 2.3.1. Density and velocity fields for process site 3 from the winter process cruise on $L$. $M$. Gould (see Fig. 2.1.1 for location). Vertical profile of potential density for CTD 227 (upper left), time series of shear magnitude $\left\langle\left|U_{z}\right|\right\rangle\left(s^{-1}\right)$ calculated from ADCP data (upper right), time series of current speed $\left(\mathrm{cm} \mathrm{s}^{-1}\right.$ ) at $50 \mathrm{~m}$ depth (black line) and the negative of the speed at $154 \mathrm{~m}$ depth (gray line) from the vessel-mounted ADCP (central right), and time series of current direction for $50 \mathrm{~m}$ depth (black line) and $154 \mathrm{~m}$ depth (gray line) (lower right). The solid vertical lines on the right-hand panels show the time of CTD 227. The fundamental periodicity of the phase lines is $\sim 12.9 \mathrm{~h}(\sim f)$, and the surface layer is roughly 180 degrees out of phase with the deeper layer for the entire time period.

The duration of this record at a fairly constant location allows us to identify the semidiurnal signal, on the basis of its dominant periodicity, ellipticity and rotation direction (counter-clockwise), as being near-inertial (period $\sim 2 \pi / f \approx 13.0 \mathrm{~h}$ at $67^{\circ} \mathrm{S}$ ) rather than tidal: the principal semidiurnal tidal constituents, $\mathrm{M}_{2}$ and $\mathrm{S}_{2}$, have periods of $\sim 12.42 \mathrm{~h}$ and $12.00 \mathrm{~h}$, respectively. Analyses of satellite-tracked drifter paths (Beardsley et al., 2004) indicate that near-inertial surface currents are frequently energetic over the WAP shelf and into the mouth of Marguerite Bay. Near-inertial oscillations are 
commonly associated with rapid changes in wind stress, i.e., the passage of storm fronts, and such events are frequent in this region (U.S. SO GLOBEC, 2001a,b,c). The shear across the sharp pycnocline associated with the near-inertial currents is strong (Figure 2.3.1), suggesting that these waves may provide sufficient energy for SDI mixing to be significant.

\subsubsection{Tides}

A second plausible source of shear and turbulence for the pycnocline in the study area is from tides, specifically baroclinic tides generated as the barotropic tide flows across sloping topography; see, e.g., Levine et al. (1997) and Muench et al. (2002) for two Antarctic examples. The two principal tidal species, semidiurnal and diurnal, behave very differently in the Antarctic (Foldvik et al., 1990): in the WAP region, $\omega_{\text {tide }}>f$ for all semidiurnal tidal harmonics, whereas $\omega<f$ for the diurnal tides. Super-inertial baroclinic semidiurnal tides can be easily generated and propagate freely away from the generation sites, whereas the sub-inertial diurnal tides are much more restricted in their ability to support shear and will be constrained to topographic wave guides such as the shelf break.

There are few existing current meter data sets for the WAP region, hence we base our knowledge of tides on a numerical model, the Circum-Antarctic Tidal Simulation, version 02.01 (CATS02.01) (Padman et al., 2002). This model predicts that the barotropic semidiurnal tidal kinetic energy on the WAP shelf is very small. Indeed, Beardsley et al. (2004) show that, over the mid-shelf, predicted tidal current speeds are only $\sim 1 / 10$ of the surface near-inertial currents. Thus, it is unlikely that significant shear can be generated by semidiurnal tides, and this hypothesis is confirmed by a primitiveequation numerical model that we have run of the three-dimensional structure of $\mathrm{M}_{2}$ tides for the region offshore of Marguerite Bay. In contrast, CATS02.01 predicts that the timeaveraged diurnal tidal current speed exceeds $10 \mathrm{~cm} \mathrm{~s}^{-1}$ at a few locations along the WAP shelf break. Maximum tidal current speeds ("spring” tides) usually exceed mean speeds by a factor of $\sim 2$. The strong currents are associated with diurnal-band topographically trapped vorticity waves (DTVWs), which are known to have a significant cross-slope component over the upper slope and shelf break in many locations around Antarctica (Middleton et al., 1987; Padman and Kottmeier, 2000; Padman et al., 2003). For a variety of reasons the energy of DTVWs are difficult to accurately model (Foldvik et al., 
1990; Padman and Kottmeier, 2000; Cummins et al., 2000) and so we only use CATS02.01 to indicate the approximate magnitude of currents. Some support for the model is provided, however, by observations of the diurnal-band variability of velocity evaluated from surface drifters (Beardsley et al., 2004). The diurnal-band velocity of one of these drifters that spent significant time over the outer continental shelf was up to $\sim 15 \mathrm{~cm} \mathrm{~s}^{-1}$, broadly consistent with model predictions. These data, and studies of DTVWs in the Arctic Ocean (Padman and Dillon, 1991; Padman et al., 1991; Padman et al., 1992), support our hypothesis that barotropic tidal energy in the form of DTVWs may result in mixing near the shelf break. Further work is required to determine whether a significant fraction of the energy in the primarily barotropic DTVWs can be transferred to higher frequency baroclinic motions capable of inciting the growth of shear instabilities in the pycnocline. While the previously cited studies support this energy pathway to mixing for the Arctic Ocean, the weaker stratification of the WAP region may preclude significant baroclinic wave generation associated with DTVWs.

\subsubsection{Mixing Rates Associated with Shear}

In the absence of microstructure measurements, estimates of pycnocline mixing rates due to SDI can only be made through parameterizations based on larger-scale features of the hydrographic and velocity structure. Such parameterizations fall into two broad categories; schemes based on Richardson number Ri (e.g., Pacanowski and Philander, 1981; hereinafter called PP-81), and those based on energy flux to smaller scales via wave-wave interactions in an internal wave field frequency-wavenumber spectrum (e.g., Gregg, 1989; Wijesekera et al., 1993; Levine et al., 1997).

Parameterizations of vertical diffusion in numerical models tend to be based on $R i$, e.g., Large et al. (1994). However, the relationship between $R i$ and the turbulent diffusivity $K_{\mathrm{v}}$ in the ocean is not well constrained (Peters et al., 1988), and any Ri-based estimate of $K_{\mathrm{V}}$ will have large errors associated with it. Nevertheless, it is instructive to see what value of $K_{\mathrm{v}}$ would be predicted by physical or coupled physical-ecological models that attempt to reproduce the SO GLOBEC data sets.

The Richardson number is defined as $N^{2} /|\partial \mathbf{U} / \partial z|^{2}$, where $N$ is the buoyancy frequency and $\mathbf{U}(z)=u(z) \mathbf{i}+v(z) \mathbf{j}$ is the vertical profile of horizontal velocity. We define a “mean" gradient Richardson number $\overline{R i}$, as 


$$
\overline{R i}=\frac{\left\langle N^{2}\right\rangle}{\left\langle U_{z}^{2}\right\rangle},
$$

where angle brackets $\langle\ldots\rangle$ indicate averaging in space and/or time and $\left\langle U_{z}^{2}\right\rangle=(\partial u / \partial z)^{2}+(\partial v / \partial z)^{2}$. The overbar on $\overline{R i}$ reminds the reader that this parameter is based on averaged $\left\langle N^{2}\right\rangle$ and $\left\langle U_{z}^{2}\right\rangle$. Values of $R i$ based on fully resolved density and velocity fields can be used to identify when the necessary condition for dynamic instability of the shear flow is met. Values of $R i<0.25$ are generally taken to indicate that shear instabilities are likely to occur according to linear theory for two-dimensional stratified shear flow, while $R i<1$ indicates that the potential exists for advective instabilities (Orlanski and Bryan, 1969). The interpretation of $\overline{R i}$ is, however, intimately related to the vertical and temporal averaging scales for density and velocity gradients (Padman and Jones, 1985). In this view, $\overline{R i}$ is some measure of the probability of shear instabilities occurring at time and/or space scales smaller than the averaging scales, not a threshold criterion separating fully turbulent from laminar flow.

Velocity shear $\left(\mathbf{U}_{z}=\partial \mathbf{U} / \partial z\right)$ is approximated in the ADCP ensemble data as

$$
\left\langle\mathbf{U}_{z}\right\rangle=\left(\frac{\Delta\langle u\rangle}{\Delta z}, \frac{\Delta\langle v\rangle}{\Delta z}\right),
$$

where $\Delta\langle u\rangle$ and $\Delta\langle v\rangle$ are the differences in east and north velocity components between adjacent ADCP depth bins separated by $\Delta z \mathrm{~m}$. As before, angle brackets $\langle\ldots\rangle$ denote averaging over space and/or time scales. Here, $u$ and $v$ are averaged over an ADCP depth bin that is $\Delta z(8 \mathrm{~m})$ thick and over times as described herein, typically of order $1 \mathrm{~h}$.

Large values of shear magnitude, $\left|\left\langle\mathbf{U}_{\mathrm{z}}\right\rangle\right|$, were frequently found in the upper water column on the WAP shelf. Figure 2.3.2 shows a cross-shelf plot of $\left|\left\langle\mathbf{U}_{\mathrm{z}}\right\rangle\right|$ for transect line 1 from the fall survey cruise on N. B. Palmer (see Figure 2.2.1 for location). The "onstation" data were removed from the total transect record prior to making this figure. There is a strong shear layer $\left(\left|\mathbf{U}_{\mathrm{z}}\right|>0.01 \mathrm{~s}^{-1}\right)$ in the $70-80 \mathrm{~m}$ depth range, coincident with the strong stratification at the base of the surface mixed layer. Throughout the study region, the strongest shears tended to occur in this portion of the water column, although there are also several occurrences of relatively strong shear in the deeper pycnocline. 
The transect shown in Fig. 2.3.2 took $\sim 26 \mathrm{~h}$ to complete ( $\sim 2$ inertial, and $\sim 1$ or $\sim 2$ tidal periods) and so the plotted variability is a combination of both spatial and temporal changes in currents.

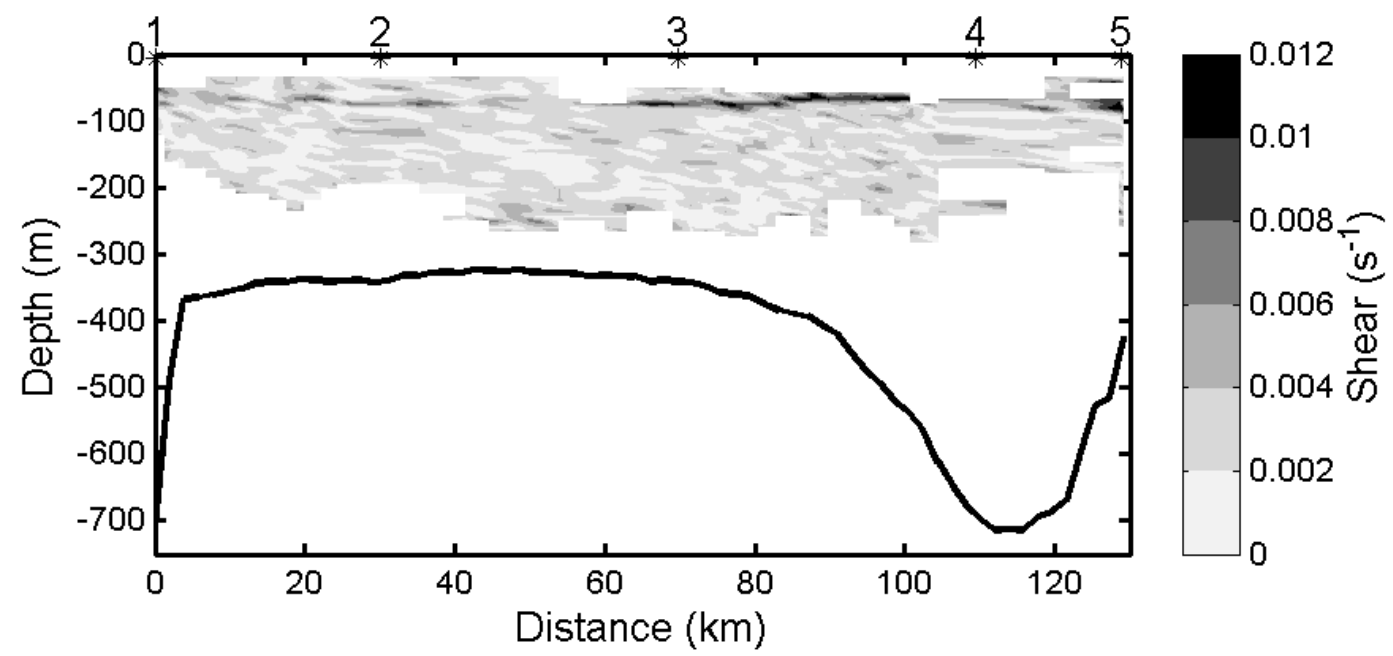

Figure 2.3.2. Transect of shear magnitude $\left\langle\left|\mathrm{U}_{\mathrm{z}}\right|\right\rangle\left(\mathrm{s}^{-1}\right)$ calculated from ADCP data collected on the fall survey cruise Transect 1 (see Fig. 2.2.1 for location). Station locations are shown at the top of the plots. Station 1 is at the shelf break and Station 5 is nearest to the coast. The transect took $\sim 26 \mathrm{~h}$ to complete.

We can only calculate $\overline{R i}$ from (1) with on-station data, where measurements of $\left\langle N^{2}\right\rangle$ and $\left\langle U_{z}^{2}\right\rangle$ are simultaneously available. The value of $\left\langle N^{2}\right\rangle$ in (1) is based on potential density $\sigma_{\theta}(z)$ from a single CTD profile. For consistency with the estimation of $\left\langle U_{z}^{2}\right\rangle$, we first average $\sigma_{\theta}$ in the same 8-m depth bins used for ADCP-based velocity, then calculate $\left\langle N^{2}\right\rangle$ from

$$
\left\langle N^{2}\right\rangle=\frac{g}{\rho_{o}} \frac{\Delta\left\langle\sigma_{\theta}\right\rangle}{\Delta z},
$$

where $\Delta\left\langle\sigma_{\theta}\right\rangle$ is the potential density difference between adjacent 8-m ADCP-based depth bins and $\rho_{\mathrm{o}}$ is a characteristic density. The averaging time for $\left\langle U_{z}^{2}\right\rangle$ is taken as the duration of the CTD cast, up to a maximum of $2.7 \mathrm{~h}$ centered on the mean time of the cast. With $\Delta z=8 \mathrm{~m}$ and $\Delta t=0.5-2.7 \mathrm{~h}$, we cannot fully resolve the expected shear and density gradient joint frequency-wavenumber spectrum (see, e.g., Wijesekera et al., 1993). These averaging scales are, however, of the same order of magnitude as the time 
step and vertical resolution in regional numerical models, and thus our interpretation of mixing based on $\overline{R i}$ emulates mixing parameterizations in those models.

In Figure 2.3.3 we show an example of the steps in calculating $\overline{R i}$ for one station; station 76 during the fall 2001 survey cruise on N. B. Palmer. Well-defined shear layers were present at the base of the mixed layer and between $\sim 150 \mathrm{~m}$ and $\sim 210 \mathrm{~m}$ within the main pycnocline (Figure 2.3.3c). Values of $\overline{R i}$ within the latter shear layer are near unity (Figure 2.3.3f). We have applied these methods to create profiles of $\overline{R i}$ for all on-station data obtained during the 2001 fall and winter N. B. Palmer survey cruises. Very few profiles show $\overline{R i}<0.25$ and the fraction of the total data set with $\overline{R i}<1$ is also low, indicating that parameterized occurrences of energetic mixing by SDI is rare.
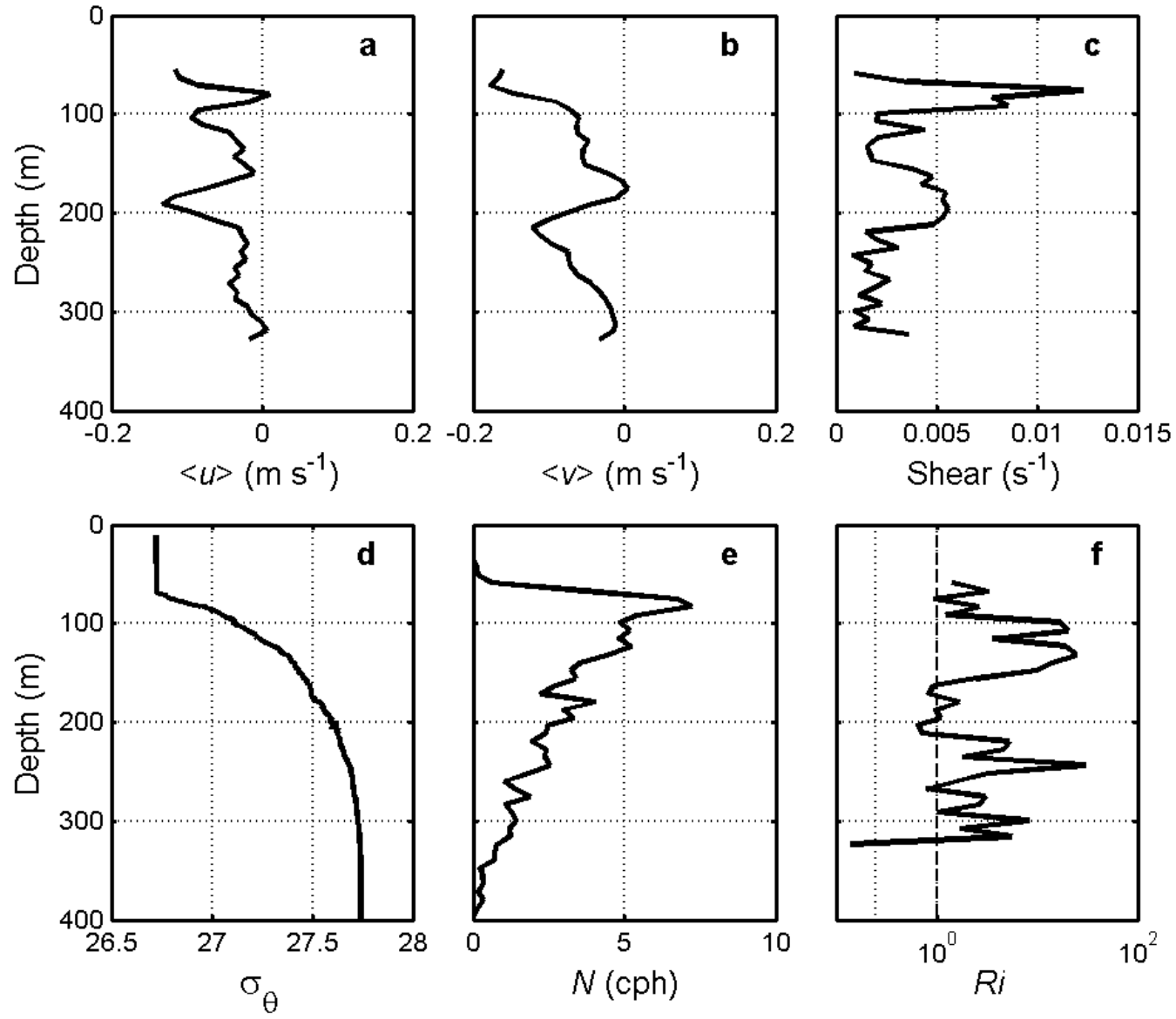

Figure 2.3.3. Example showing results of mixing parameter calculations from the CTD and ADCP for Station 76 from the fall survey cruise (see Fig. 2.2.1 for location): (a) east component of timeaveraged velocity $\langle u\rangle$; (b) north component of time-averaged velocity $\langle v\rangle$; (c) time-averaged shear magnitude $\left\langle\left|U_{z}\right|>\right.$; (d) potential density $\sigma_{\theta}$; (e) Buoyancy frequency, $\langle N\rangle$; (f) Richardson number (vertical dashed lines indicate $\overline{R i}=\mathbf{1} / 4$ and $\overline{R i}=1$ ). 
The mean diffusivity $\overline{K_{v}}$ that would be predicted by the turbulence parameterizations in general circulation models can be estimated by applying the same algorithms to our profiles of $\overline{R i}$. We report this calculation for just one such scheme (PP-81). The PP-81 scheme is based on matching numerical model predictions with observations of the Pacific Ocean Equatorial Undercurrent, and so may have little relevance to a high-latitude coastal-ocean pycnocline. Nevertheless, Muench et al. (2002) used this model to obtain predictions of mixing rates that were consistent with the expected dissipation of internal tides generated along the South Scotia Ridge. That paper describes in detail how CTD and ADCP data can be used with PP-81 to make predictions of $\overline{K_{v}}$, although note that eq. (2) $\left(K_{\mathrm{v}}=\mathrm{f}(R i)\right)$ in Muench et al. (2002) is incorrectly printed.

Most estimates of $\overline{R i}$, in both the sharp pycnocline and the more weakly stratified "deep" part of the pycnocline, are sufficiently large that PP- 81 predicts values of $K_{\mathrm{V}}$ which are close to the asymptotic lower limit of $1 \times 10^{-5} \mathrm{~m}^{2} \mathrm{~s}^{-1}$. That is, there is no significant difference between PP-81 and using a constant diffusivity of $1 \times 10^{-5} \mathrm{~m}^{2} \mathrm{~s}^{-1}$, this constant being consistent with values found in the mid-latitude main thermocline (Ledwell et al., 1993; Ruddick et al., 1997). The heat fluxes $F_{\mathrm{H}}$ associated with this value of $K_{\mathrm{v}}$ in the sharp pycnocline and the deep pycnocline are about 1-2 $\mathrm{W} \mathrm{m}^{-2}$ and $<0.5 \mathrm{~W} \mathrm{~m}^{-2}$, respectively. A more recent, "modified" form of PP-81 (R. Houghton, personal communication, 2003) has a lower asymptotic limit for $K_{\mathrm{v}}$ at high $\overline{R i}$, thus the mean value of $F_{\mathrm{H}}$ may be $<1 \mathrm{~W} \mathrm{~m}^{-2}$.

There are, however, a few areas where $\overline{R i}$ was low enough to indicate mixing (e.g., the 2 depth ranges of relatively low $\overline{R i}$ in Figure 2.3.3f). Shear associated with the near-inertial currents at process site 3 (Figure 2.3.1) of the winter process cruise leads to low $\overline{R i}$ at the time of the CTD cast shown on the figure. When the heat flux is averaged vertically over the entire sharp pycnocline (the region in which $N$ exceeds $3 \mathrm{cph}$ ), the estimated average pycnocline flux at this time is $\sim 5 \mathrm{~W} \mathrm{~m}^{-2}$. The shear is clearly stronger later in the time series, but no CTD data are available for further calculations of $K_{\mathrm{v}}$ and $F_{\mathrm{H}}$. Intermittent but relatively energetic events such as this may be the dominant contributors to mean turbulent diapycnal fluxes. 
Our focus in this chapter is on mixing in the main pycnocline as a mechanism for transporting the scalar properties of UCDW into the surface layer through the intervening pycnocline. Nevertheless, as we have previously noted (see Figure 2.3.1), the variability of mixed layer properties is dominated by the seasonal cycle associated with surface buoyancy fluxes. Surface stress also contributes to the seasonal cycling of the upper ocean. M. McPhee (personal communication, 2004) has run a one-dimensional local turbulence closure (LTC) model (McPhee, 1999) for the winter process site 3 data set reported herein (see Figure 2.3.1). His model successfully reproduces the ice drift velocity, which provides some support for other predictions of the LTC model. Strong upward heat flux ( $\sim 10 \mathrm{~W} \mathrm{~m}^{-2}$ averaged over the 4 days) is predicted in the center of the surface layer near $55 \mathrm{~m}$ depth from $t \approx 227.5$ to $t \approx 231.5$ days. This average is, however, dominated by a short period of intense mixing from $t \approx 230.4$ to $t \approx 230.8$ days in which the modeled $F_{\mathrm{H}}$ exceeds $50 \mathrm{~W} \mathrm{~m}^{-2}$. The modeled 4-day average flux of $\sim 10 \mathrm{~W} \mathrm{~m}^{-2}$ for the center of the surface mixing layer is close to our estimate of the flux through the sharp pycnocline based on ADCP and CTD data at the time of the single CTD profile for this site. Wind stress clearly contributes to the transfer of heat from the upper pycnocline to the ocean surface. Importantly, the model results also confirm our data-based view that rare but energetic events may dominate the mean mixing rates and associated fluxes in the upper ocean. That is, it is quite possible that our mean flux values based on field data are lower than the true mean values because of inadequate sampling of these important events.

\subsubsection{Double Diffusive Convection}

Double-diffusive convection (DDC) is a process that is driven by the different molecular diffusivities of $T$ and $S$ in a stratified fluid where both properties increase with depth (Turner, 1973). Such stratification is frequently found in high-latitude oceans where a cold, fresh surface layer formed by local air/sea/ice interactions overlies warmer and saltier water that has been advected into these regions from lower latitudes (Padman and Dillon, 1987; Robertson et al., 1995). Where DDC is active, the process forms a "thermohaline staircase", a vertical sequence of quasi-homogeneous layers separated by sharp interfaces in which vertical gradients of $T$ and $S$ are large. This feature allows us to 
identify, from high-resolution CTD or scalar microstructure profiles, where DDC is likely to be a significant contributor to total vertical scalar fluxes.

Smith and Klinck (2002) estimated that, for a region of the west Antarctic Peninsula continental shelf just north of the SO GLOBEC study region, $\sim 5-10 \mathrm{~W} \mathrm{~m}^{-2}$ of upward vertical heat flux across the pycnocline was required to balance the total heat budget of the upper ocean in their one-dimensional vertical numerical model of this region. They also concluded that they needed a higher effective pycnocline diffusivity for $T$ than for $S$, which is consistent with DDC being the dominant source of mixing. These authors noted the presence of steppiness in many of the CTD profiles from their study region: the vertical scale of this finestructure was consistent with DDC layer heights that would be required to reconcile laboratory-based DDC flux formulas with the heat and salt fluxes determined by their model-based analyses.

Our inspection of the "raw" $(24 \mathrm{~Hz})$ SO GLOBEC CTD profiles from the winter 2001 survey cruise identified a few profiles containing finestructure that was reminiscent of thermohaline steps, suggesting that DDC may occasionally be contribute to vertical fluxes in the study area and that further study of DDC is warranted. However, in general the observed "interfaces" are much thicker than we would expect for DDC $(\sim 1-10 \mathrm{~cm}$ : Padman and Dillon (1987)). We therefore believe that the steppy hydrographic structure is generally associated with non-DDC processes such as intrusive activity near the coast and ice fronts, and the finestructure remnants of shear-driven mixing.

In keeping, however, with our goal of investigating fluxes that would arise from the application of 1-D turbulence parameterizations such as Large et al. (1994), we apply models of DDC fluxes to the CTD data collected in 2001 during the winter survey cruise on N. B. Palmer. The fundamental parameter describing DDC activity is the density ratio $R_{\rho}$ (Turner, 1973), given by:

$$
R_{\rho}=\frac{\beta \partial S / \partial z}{\alpha \partial \theta / \partial z},
$$

where $\beta\left(\mathrm{psu}^{-1}\right)$ is the haline contraction coefficient and $\alpha\left({ }^{\circ} \mathrm{C}^{-1}\right)$ is the thermal expansion coefficient. To create profiles of $R_{\rho}, T(z)$ and $S(z)$ were first filtered over a 30-m vertical scale, which was chosen to be much larger than likely DDC layer heights of $\sim 1-10 \mathrm{~m}$. The mean gradients of the filtered $T$ and $S$ were then calculated over the high- 
gradient core of the pycnocline separating the surface mixed layer from the depth of the UCDW temperature maximum. The DDC instability cannot occur below the depth of maximum temperature due to the change in sign of $\partial \theta / \partial z$. Values of $R_{\rho}$ slightly above 1 indicate strong double diffusion. As $R_{\rho}$ increases above 2, DDC fluxes become quite small. Estimates of DDC heat fluxes in polar oceans range from $<0.1 \mathrm{~W} \mathrm{~m}^{-2}$ in the Canada Basin in the Arctic $\left(\mathrm{R}_{\rho}>4\right.$; Padman and Dillon, 1987) to $\sim 20 \mathrm{~W} \mathrm{~m}^{-2}$ in the central Weddell Sea $\left(\mathrm{R}_{\rho} \approx 1\right.$; Muench et al., 1990).

We calculated $R_{\rho}$ over the winter survey cruise to estimate the possible strength of DDC processes on the WAP shelf. We concentrated on this survey because the seasonal upper-ocean stratification that is present throughout much of the fall survey cruise complicates automated detection of the core of the pycnocline below the Winter Water, the subsurface temperature minimum layer representing the remnant of the previous winter's near-freezing surface mixed layer. Furthermore, CTD profiles taken while the vessel is becalmed in ice are of higher quality than the wave-influenced "open ocean" profiles obtained during the fall survey cruise. Some steppiness is seen in profiles from the winter survey cruise when $R_{\rho}$ is low, $\sim 2$. This relatively low value of $R_{\rho}$ indicates the potential for DDC to occur; however, inspection of the raw (24 Hz) CTD profiles of $T$ and $C$ confirm that sharp steps are rare. Most of the profiles in the WAP region have higher $R_{\rho}$ values (typically $\sim 3.6$ ) in the pycnocline, indicating only weak DDC.

Several models have been developed to estimate DDC heat fluxes. Robertson et al. (1995) provide an overview and comparison (their Fig. 7) of these models. In the present study, we use the Kelley (1990) heat flux parameterization, defined as

$$
F_{H-K}=0.0032 \rho_{o} c_{p} \alpha^{-1} \exp \left[4.8 R_{\rho}^{-0.72}\right]\left(g \kappa_{t}^{2} v^{-1}\right)^{1 / 3}(\alpha \Delta \theta)^{4 / 3}
$$

where $\rho_{\mathrm{o}}$ is the mean density, $c_{\mathrm{p}}$ is the specific heat capacity of seawater at constant pressure $\left(\sim 4.0 \times 10^{3} \mathrm{~J} \mathrm{~kg}^{-1} \mathrm{~K}^{-1}\right), \kappa_{\mathrm{t}}$ is the molecular diffusivity for heat, $\mathrm{v}$ is the kinematic viscosity of seawater, and $\Delta \theta$ is the thermal step between adjacent well-mixed layers. The thermal step is estimated by first obtaining the DDC layer height, $H$, using a relationship based on large-scale stratification parameters proposed by Kelley (1984);

$$
H=\left[0.25 \times 10^{9} R_{\rho}^{1.1} v \kappa_{t}^{-1}\left(R_{\rho}-1\right)\right]^{0.25}\left(\kappa_{t}\left\langle N^{-1}\right\rangle\right)^{0.5} .
$$


The thermal step is then obtained using

$$
\Delta \theta=\langle\partial \theta / \partial z\rangle H,
$$

where the temperature gradient $\langle\partial \theta / \partial z\rangle$ is the average gradient over the depth range in which evidence of DDC is sought.

Heat fluxes were estimated by applying (5)-(7) to all stations from the winter 2001 survey cruise. The area-averaged heat flux due to DDC was $\sim 0.2-0.4 \mathrm{~W} \mathrm{~m}^{-2}$ over the central and inner continental shelf, and $\sim 0.4-0.9 \mathrm{~W} \mathrm{~m}^{-2}$ over the continental slope where the average value of $R_{\rho}$ was smaller than for the central shelf. The error bars associated with these values are uncertain. Another DDC heat flux model developed by Marmorino and Caldwell (1976) predicts values up to a factor of 2 greater than $F_{\mathrm{H}-\mathrm{K}}$ for $R_{\rho}$ values between 1.4 and 1.5 (Robertson et al., 1995). However, as $R_{\rho}$ increases, the differences between the estimates from the various analytical models decrease (see also, Fig. 4b in Large et al., 1994). Note, however, that all models of DDC assume that the hydrography has organized into a thermohaline staircase, in which a continuous upward flux of heat is maintained by molecular diffusion through extremely sharp interfaces ("sheets") $\sim 1-10 \mathrm{~cm}$ thick and buoyancy-driven convection in the adjacent layers 1-10 m thick (see Padman and Dillon, 1987). When these sheets and layers are not present, as in the present data set, expected heat fluxes will be less than the models predict.

Assuming, however, that these fluxes do at least represent some potential level of DDC activity, we can estimate the thermal diffusivities associated with these heat fluxes from

$$
K_{v}^{T}=\frac{F_{H-K}}{\rho_{o} c_{p}\langle\partial \theta / \partial z\rangle}\left(\mathrm{m}^{2} \mathrm{~s}^{-1}\right),
$$

where $\langle\partial \theta / \partial z\rangle$ is again averaged over the pycnocline. Using this method, the average DDC thermal diffusivity in the main pycnocline on the continental slope is $\sim 0.5 \times 10^{-5} \mathrm{~m}^{2} \mathrm{~s}^{-1}$, and $\sim 0.3 \times 10^{-5} \mathrm{~m}^{2} \mathrm{~s}^{-1}$ over the central and inner continental shelf.

The diffusivity for salt, $K_{v}^{S}$, is lower than $K_{v}^{T}$ for DDC (see Fig. 2 in Kelley, 1984). The ratio of the two diffusivities is given by

$$
K_{v}^{S} / K_{v}^{T}=R_{F} R_{\rho}^{-1}
$$


(Kelley, 1984), where the buoyancy flux ratio $R_{F}$ is given by

$$
R_{F}=\frac{R_{\rho}+1.4\left(R_{\rho}-1\right)^{3 / 2}}{1+14\left(R_{\rho}-1\right)^{3 / 2}},
$$

(Kelley, 1990). Based on (9) and (10), $K_{v}^{S}$ is $\sim 0.5 \times 10^{-6} \mathrm{~m}^{2} \mathrm{~s}^{-1}$ over the continental slope and $\sim 0.1 \times 10^{-6} \mathrm{~m}^{2} \mathrm{~s}^{-1}$ over the central and inner continental shelf. The salt fluxes associated with these diffusivities are $\sim 0.002 \mathrm{mg} \mathrm{m}^{-2} \mathrm{~s}^{-1}$ over the continental slope and $\sim 0.001 \mathrm{mg} \mathrm{m}^{-2} \mathrm{~s}^{-1}$ over the shelf.

It remains an open question whether DDC fluxes in the ocean can be correctly parameterized by formulas developed in laboratory studies. For example, Padman (1994) suggested that the addition of mean shear to thermohaline steps can increase the vertical momentum and scalar fluxes relative to unsheared steps. A fundamental assumption in the Padman (1994) model was that the applied shear was "relatively" weak (incapable of causing mixing in the absence of the finestructure established by DDC), and the sharp DDC interfaces were, therefore, not significantly disrupted by the applied shear. We reiterate that very few cases of sharp interfaces separating truly homogeneous layers were found in the SO GLOBEC data, which implies that DDC was not active at the time the observations were made. There are several plausible explanations for the observed steppy fine-structure in some CTD profiles, however it is possible that some of this finestructure points to prior double-diffusive activity that has since been partially erased by more recent shear-driven turbulence.

\subsection{Conclusions}

We use CTD and ADCP data from the first year (2001) of Southern Ocean GLOBEC field work to study diapycnal mixing processes in the pycnocline separating UCDW from the surface layer over the western Antarctic Peninsula (WAP) continental shelf near Marguerite Bay. Based on a recent box-model study of a region of the WAP shelf just north of the SO GLOBEC study area (Smith and Klinck, 2002), our a priori expectation was that double-diffusive convection (DDC) would be the dominant process driving the upward flux of heat, salt and nutrients from the UCDW, with an additional contribution from shear-driven instability (SDI). 
Detailed examination of high-resolution CTD profiles from the winter 2001 survey cruise on N. B. Palmer, combined with the application of common parameterizations of DDC fluxes to the observed hydrographic profiles, suggest that DDC is either not active or is very weak during this cruise. The maximum likely DDC heat flux is $<1 \mathrm{~W} \mathrm{~m}^{-2}$, compared with Smith and Klinck's estimate of order $10 \mathrm{~W} \mathrm{~m}^{-2}$.

We attribute most of the velocity shear observed in the pycnocline with hullmounted ADCP to wind forcing. With the exception of small regions near the shelf break, the tidal currents predicted from an Antarctic tide model (CATS02.01) are an order of magnitude weaker than typical wind-forced, near-inertial oscillations of the upper ocean. A simple parameterization of vertical mixing due to SDI, following Pacanowski and Philander (1981), suggests that the mean vertical diffusivity $\left(K_{\mathrm{v}}\right)$ in the pycnocline in winter 2001 is $\sim 1 \times 10^{-5} \mathrm{~m}^{2} \mathrm{~s}^{-1}$ with a corresponding upward heat flux from the UCDW of $\sim 1 \mathrm{~W} \mathrm{~m}^{-2}$. We caution, however, that this parameterization was developed for oceanic conditions (the mean-sheared Equatorial Undercurrent) that are quite different from the WAP region.

The pycnocline fluxes that we estimate are two orders of magnitude less than those required to explain the loss of heat from the surface mixed layer between the fall and winter survey cruises: as expected, surface buoyancy fluxes are the primary causes of the strong seasonal cycle in the upper ocean. The destabilizing buoyancy flux in fall and winter, as a source of entrainment of the pycnocline at the base of the mixed layer, is augmented by the turbulent stress penetrating the ice pack.

We conclude that the downward flux of momentum originating in the wind stress field is the dominant process driving diapycnal fluxes in the pycnocline through downward propagation of near-inertial internal waves, and is also a critical component of upper-ocean seasonal variability. There are several practical consequences to this observation. First, since the actual stress transmitted to the upper ocean through the sea ice (when present) depends on the roughness, thickness and mobility of the sea ice, mixing in the pycnocline cannot be evaluated in isolation from either accurately prescribed or modeled sea ice conditions. Second, since the wind stress in this region is extremely variable (U.S. SO GLOBEC, 2001a,b,c), we risk undersampling the rare but energetic events that might dominate mean mixing rates, and so may significantly 
underestimate mean pycnocline diffusivity. Third, generating realistic near-inertial behavior in a model of the upper ocean requires atmospheric model forcing fields with high resolution in both time and space. The output from global atmospheric models is typically every 6-12 $\mathrm{h}$ and on a coarse spatial grid, thus a new high-resolution regional atmospheric model will be required before WAP shelf circulation models can hope to capture the physics of mixing.

We hypothesize that, given the importance of wind forcing, coastal upwelling could be a significant factor contributing to the upward flux of UCDW properties. Upwelling may raise UCDW into the depth range affected directly by surface stress. Given the short Rossby radius $(\sim 5 \mathrm{~km})$ in high-latitude coastal seas, sampling very close to the coast under upwelling-favorable wind conditions would be required to test this hypothesis.

Finally, we note that the study period covers only the fall and winter of one year, 2001, whereas we expect that both SDI and DDC could be sensitive to interannual variability of stratification. The Amundsen-Bellingshausen Sea sector of Antarctica experiences significant El Niño-Southern Oscillation (ENSO) atmospheric and sea-ice variability (Kwok and Comiso, 2002), while the Antarctic Circumpolar Wave (ACW) provides an additional multi-year signal (White and Peterson, 1996). It is possible that quite different annual-mean fluxes in the pycnocline occur during appropriate phases of the ENSO and ACW cycles.

\section{Acknowledgements}

This work was supported by NSF Grant OPP-9910102 to ESR, and OPP-9910092 to WHOI. We thank the crews of N. B. Palmer and L. M. Gould and the Raytheon Polar Services seagoing personnel for their considerable logistic support for this study. The efforts of E. Firing, J. Hummon, and T. Chereskin in managing the ADCP systems on the L. M. Gould and N. B. Palmer, including post-processing, were critical to creating a high quality ADCP data set for SO GLOBEC. We gratefully acknowledge R. Limeburner's

provision of drifter position data for our analyses of diurnal tidal current variability. R. Beardsley, J. Klinck, M. McPhee, V. Strass, and editor E. Hoffmann provided valuable 
suggestions for improvements of the original manuscript. We particularly wish to thank M. McPhee for providing the results of his 1-D local turbulence closure model for analyzing upper-ocean and sea ice behavior due to wind stress.

\section{References:}

Beardsley, R.C., Limeburner, R., Owens, W.B., 2004. Drifter measurements of surface currents near Marguerite Bay on the west Antarctic Peninsula shelf during austral summer and fall. Deep-Sea Research II, 51, 1947-1964

Cummins, P.F., Masson, D., Foreman, M.G.G., 2000. Stratification and mean flow effects on diurnal tidal currents off Vancouver Island. Journal of Physical Oceanography $30,15-30$.

Dushaw, B.D., Cornuelle, B.D., Worcester, P.F., Howe, B.W., Luther, D.S., 1995. Barotropic and baroclinic tides in the central North Pacific Ocean determined from long-range reciprocal acoustic transmissions. Journal of Physical Oceanography 25 , $631-647$

Foldvik, A., Middleton, J.H., Foster, T.D., 1990. The tides of the southern Weddell Sea. Deep-Sea Research 37(8), 1345-1362.

Gregg, M.C., 1987. Diapycnal mixing in the thermocline: A review. Journal of Geophysical Research 92, 5249-5286.

Gregg, M.C., 1989. Scaling turbulent dissipation in the thermocline: A review. Journal of Geophysical Research 94, 9686-9698.

Hofmann, E.E., Wiebe, P.H., Costa, D.P., Torres, J.J., 2004. An overview of the Southern Ocean Global Ocean Ecosystems Dynamics Program. Deep-Sea Research II, 51, 1921-1924.

Kelley, D., 1984. Effective diffusivities within thermohaline staircases. Journal of Geophysical Research 89, 10,484-10,488.

Kelley, D., 1990. Fluxes through diffusive staircases: A new formulation. Journal of Geophysical Research 95, 3365-3371.

Klinck, J.M., Hofmann, E.E., Beardsley, R.C., Salihoglu, B., Howard, S., 2004. Water Mass Properties and Circulation on the west Antarctic Peninsula Continental Shelf in 
Austral Fall and Winter 2001. Deep-Sea Research II, 51, 1925-1946.

Kwok, R., Comiso, J.C., 2002. Southern Ocean climate and sea ice anomalies associated with the southern oscillation. Journal of Climate 15, 487-501.

Large, W.G., McWilliams, J.C., Doney, S.C., 1994. Oceanic vertical mixing: A review and a model with a nonlocal boundary layer parameterization. Reviews of Geophysics $32(4), 363-403$.

Ledwell, J.R., Watson, A.J., Law, C.S., 1993. Evidence for slow mixing across the pycnocline from an open-ocean tracer-release experiment. Nature 364, 701-703.

Levine, M.D., Padman, L., Morison, J.H., Muench, R.D., 1997. Internal waves and tides in the western Weddell Sea: observations from Ice Station Weddell, Journal of Geophysical Research 102, 1073-1089.

Lozovatsky, I.D., Morozov, E.G., Fernando, H.J.S., 2003. Spatial decay of energy density of tidal internal waves. Journal of Geophysical Research 108(C6), 3201, doi:10.1029/2001JC001169.

Marmorino, G.O., Caldwell, D.R., 1976. Heat and salt transport through a diffusive thermohaline interface. Deep-Sea Research 23, 59-67.

McPhee, M.G., 1999. Parameterization of mixing in the ocean boundary layer. Journal of Marine Systems, 21, 55-65.

Middleton, J.H., Foster, T.D., Foldvik, A., 1987. Diurnal shelf waves in the southern Weddell Sea. Journal of Physical Oceanography 17, 784-791.

Muench, R.D., Fernando H.J.S., Stegen, G.R., 1990. Temperature and salinity staircases in the northwestern Weddell Sea, Journal of Physical Oceanography 20, 295-306.

Muench, R.D., Padman, L., Howard, S.L., Fahrbach, E., 2002. Upper ocean diapycnal mixing in the northwestern Weddell Sea. Deep Sea Research II 49, 4843-4861.

Munk, W., Wunsch, C., 1998. Abyssal recipes II: Energetics of tidal and wind mixing. Deep-Sea Research 45, 1977-2010.

Orlanski, I. Bryan, K., 1969. Formation of the thermocline step structure by largeamplitude internal gravity waves. Journal of Geophysical Research 74, 6975-6983.

Pacanowski, R.C., Philander, S.G.H., 1981. Parameterization of vertical mixing in numerical models of tropical oceans. Journal of Physical Oceanography 11, 1443-1451. 
Padman, L., 1994. Momentum fluxes through sheared oceanic diffusive-convective steps. Journal of Geophysical Research 99, 22491-22499.

Padman, L., T.M. Dillon, 1987. Vertical heat fluxes through the Beaufort Sea thermohaline staircase, Journal of Geophysical Research 92, 10799-10806.

Padman, L., Dillon, T.M., 1991. Turbulent mixing near the Yermak Plateau during the Coordinated Eastern Arctic Experiment. Journal of Geophysical Research 96, 47694782.

Padman, L., Dillon, T.M., Wijesekera, H.W., Levine, M.D., Paulson, C.A., Pinkel, R., 1991. Internal wave dissipation in a non-Garrett-Munk ocean. Proceedings of the 'Aha Huliko'a Hawaiian Winter Workshop, University of Hawaii at Manoa, Honolulu, pp31-51.

Padman, L., Erofeeva, S., Joughin, I., 2003. Tides of the Ross Sea and Ross Ice Shelf cavity. Antarctic Science 15(01), 31-40.

Padman, L., Fricker, H.A., Coleman, R., Howard, S., Erofeeva, S., 2002. A new tidal model for the Antarctic ice shelves and seas. Annals of Glaciology 34, 247-254.

Padman, L., Jones, I.S.F., 1985. Richardson number statistics in the seasonal thermocline. Journal of Physical Oceanography 15, 844-854.

Padman, L., Kottmeier, C., 2000. High-frequency ice motion and divergence in the Weddell Sea. Journal of Geophysical Research 105, 3379-3400.

Padman, L., Plueddemann, A.J., Muench, R.D., Pinkel, R., 1992. Diurnal tides near the Yermak Plateau. Journal of Geophysical Research 97, 12,639-12,652.

Peters, H., Gregg, M.C., Toole, J.M., 1988. On the parameterization of equatorial turbulence. Journal of Geophysical Research 93, 1199-1218.

Prézelin, B.B., Hofmann, E.E., Klinck, J.M., Menglet, C., 2000. The linkage between Upper Circumpolar Deep Water (UCDW) and phytoplankton assemblages on the west Antarctic Peninsula continental shelf. Journal of Marine Research 58, 165-202.

Robertson, R., Padman, L., Levine, M.D., 1995. Finestructure, microstructure, and vertical mixing processes in the upper ocean in the western Weddell Sea. Journal of Geophysical Research 100, 18,517-18,536.

Ruddick, B.R., Walsh, D., Oakey, N., 1997. Variations in apparent mixing efficiency in the North Atlantic central waters. Journal of Physical Oceanography, 27, 2589-2605. 
Smith, D.A., Klinck, J.M., 2002. Water properties on the west Antarctic Peninsula continental shelf: A model study of effects of surface fluxes and sea-ice. Deep-Sea Research II 49, 4863-4886.

Turner, J.S., 1973. Buoyancy Effects in Fluids, Cambridge University Press, New York, $368 \mathrm{pp}$.

U.S. SO GLOBEC, 2001a. Reports of R/V Lawrence M. Gould Cruises LMG01-03 and LMG01-04 to the Western Antarctic Peninsula, 18 March to 13 April 2001 and 23 April to 6 June 2001. U.S. Southern Ocean GLOBEC Report Number 1, 94 pp.

U.S. SO GLOBEC, 2001b. Reports of RVIB Nathaniel B. Palmer Cruise NBP01-03 to the Western Antarctic Peninsula, 24 April to 5 June 2001. U.S. Southern Ocean GLOBEC Report Number 2, 189 pp.

U.S. SO GLOBEC, 2001c. Reports of RVIB Nathaniel B. Palmer Cruise NBP01-04 and R/V Lawrence M. Gould Cruise LMG01-06 to the Western Antarctic Peninsula, 24 July to 31 August 2001 and 21 July to 1 September 2001. U.S. Southern Ocean GLOBEC Report Number 3, 240 pp.

White W.B., Peterson, R., 1996. An Antarctic Circumpolar Wave in surface pressure, wind, temperature, and sea ice extent. Nature 380, 699-702.

Wijesekera, H., Padman, L., Dillon, T., Levine, M., Paulson, C., Pinkel, R., 1993. The application of internal-wave dissipation models to a region of strong mixing. Journal of Physical Oceanography 23, 269-286.

Wunsch, C., 2000. Moon, tides and climate. Nature 405, 743-744. 


\section{Chapter 3}

\section{Measurements of sea ice properties using a moored upward-looking acoustic Doppler current profiler (ADCP).}

\subsection{Introduction}

Upward-looking Acoustic Doppler Current Profilers (ADCPs) have been successfully deployed in the world oceans for many years on bottom-anchored subsurface moorings. The primary purpose for the ADCP has been to measure vertical profiles of ocean currents. When an upward-looking ADCP is deployed in a location that experiences seasonal sea ice cover, it can also be used to collect ice data (Belliveau et al., 1990; Strass, 1998). This has become more important as the effort to observe polar seas has increased due to their significant role in the climate system. The remoteness of the polar seas demands the use of every piece of information obtained.

The presence of sea ice has a strong influence on the exchange of heat and momentum between the atmosphere and the ocean. The lateral motion of sea ice moves both fresh water and heat. Furthermore, the presence of seasonal sea ice is believed to play a vital role in krill ecosystems throughout Antarctica. Combined in situ observations of sea ice coverage, velocity and draft provide data are of great benefit to many investigations, particularly when measured at the same time and location.

Ice draft has been successfully measured with a dedicated upward-looking sonar (ULS) (Hudson, 1990; Strass, 1998). An ULS typically samples at high frequency (e.g., $0.5 \mathrm{~Hz}$ ) using one narrow vertical beam. This single beam avoids errors due to lateral scattering between multiple slanted beams that can occur with the four-beam ADCP. Ice drift velocities can also be measured using ADCPs in bottom-track mode (Belliveau et al, 1990). These bottom-track pings require additional power which can be problematic in 
long-term moored deployments and may be unavailable in post-processing of archived ADCP data. Visbeck and Fischer (1995) estimated the presence of ice and drift velocity using a narrow-band ADCP in water-track mode, the mode normally used for water velocity profiling, but did not estimate ice draft. The combination of ULS and ADCP provides the best measurements of ice draft and motion and allows proper spatial averaging of ice properties to obtain statistical descriptions of ice (Melling et al, 1995). This configuration still has problems estimating ice draft due to errors in the estimation of range-averaged sound speed since one cannot make in-situ measurements between the ULS and the sea surface (the sensors would block the single vertical acoustic beam). The methodology presented here provides an improvement that could be used even in the ULS/ADCP configuration.

In sections 3.2 and 3.3, we describe a method for processing water-track mode ADCP data from a standard subsurface mooring (as in Figure 3.1.1) to estimate ice coverage and draft that can be applied to both broad- and narrow-band ADCP data. This method provides estimates of sea ice draft in the absence of ULS data by taking advantage of auxiliary data from other instruments on the mooring. We estimate the uncertainty in the ice draft estimate, and compare this with the uncertainty of an ULS estimate. The information provided by this method, while by no means a substitute for actual ULS data, can improve the interpretation of the ocean current data recorded by the ADCP. This method can also be used with archived ADCP data to provide historical estimates of ice draft. 


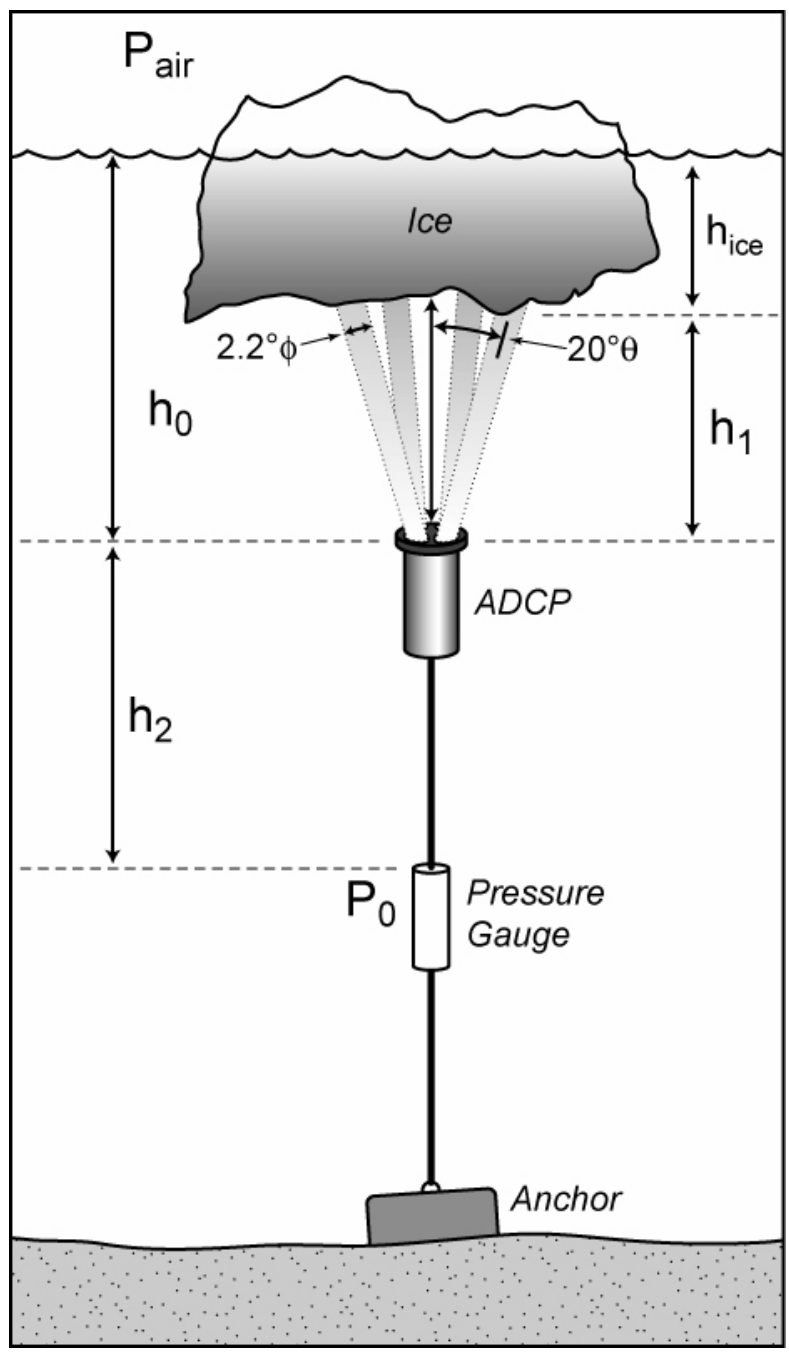

Figure 3.1.1 Schematic of mooring and names of variables used in ice draft calculations.

The following information is needed to estimate sea ice coverage, draft and velocity:

1. The data from an upward-looking ADCP on a subsurface mooring.

2. The data from a high-precision pressure gauge on the mooring, preferably close to the ADCP.

3. Atmospheric pressure and some estimate of the time-variable sound speed profile above the ADCP. In the case shown here, the atmospheric pressure was measured nearby and the sound speed profile is estimated based on moored temperature and salinity measurements made near the ADCP in conjunction with shipboard CTD profiles made in the area.

The ice drift velocity can simply be taken as the velocity in the bin just above the 
surface bin (maximum backscatter) during times of ice coverage (Visbeck and Fischer, 1995) using standard water-track pings.

Data from a mooring in Marguerite Bay on the western Antarctic Peninsula shelf are analyzed to demonstrate that the proposed method can provide useful estimates of ice draft. These data are described in greater detail in the appendix. The final two sections of this chapter make recommendations for future deployments of ADCPs in ice covered regions and present conclusions of our study.

\subsection{Ice detection}

The detection of ice has been performed using ADCP bottom-track pings (Belliveau et al. 1990), upward-looking sonars (ULS) (Strass, 1998), and narrow-band ADCP water-track pings (Visbeck and Fischer, 1995). The method described here essentially duplicates the method for a narrow-band ADCP in water-track mode, with some noted differences for a broad-band ADCP.

We employ a set of criteria which discriminate, from time averages of the ADCP data, in a binary way the presence of ice. First, the ADCP bin that samples the sea surface or bottom of the sea ice is identified as the bin above the one with maximum backscatter intensity. The bin above maximum backscatter is chosen to ensure ice-only data due to overlapping cell information as a result of the range gating in an ADCP (RDIPrimer, 1996). While it is possible to use a weighted average of bins, we chose the simplest option of using only one bin.

Possible ice detection criteria are vertical and error velocity windowed variances, surface backscatter intensity, the horizontal surface speed, and the signal correlation. The signal correlation is the only additional piece of information provided by the broad-band ADCP which is not provided by a narrow-band ADCP. These properties are all greatly influenced by the presence of sea ice (Visbeck and Fischer, 1995). A successful criterion for the presence of sea ice is one where the variable has a strongly bimodal distribution with the two maxima in the probability distribution function significantly separated and identifiable with times when the location is ice-covered or icefree. One then defines a "cut-off" value that delineates the boundary between the two regions. 
The top panel of Figure 3.2.1 shows a time series of the high-pass boxcar filtered error velocity with a filter period of $24 \mathrm{hrs}$ and clearly reveals approximate times of ice. This is used to make a first approximation of the presence of ice (marked in black) based on inspection of the time series and identification of periods of low variance by eye. (In this example, we based the first approximation of ice cover on the filtered error velocity, but one could choose any one of the criteria, such as vertical velocity, and get nearly identical results). Next, cumulative histograms are made of each of the criteria to find a suitable cutoff value (Figure 3.2.1). Criteria which show a clear separation between ice and no ice are, in our case, the windowed variance of the error velocity, the squared windowed variance of vertical velocity, and the surface speed. We squared the windowed variance of vertical velocity in order to expand the scale of the data. 
(a)

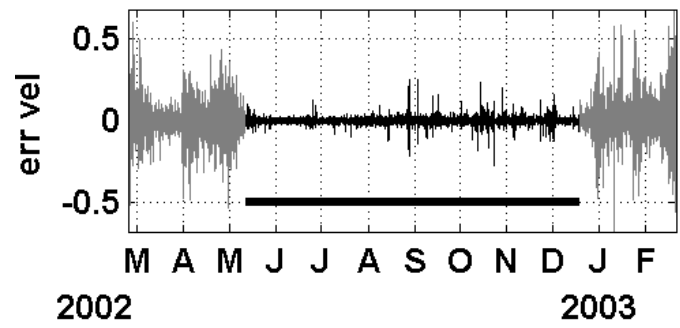

(c)

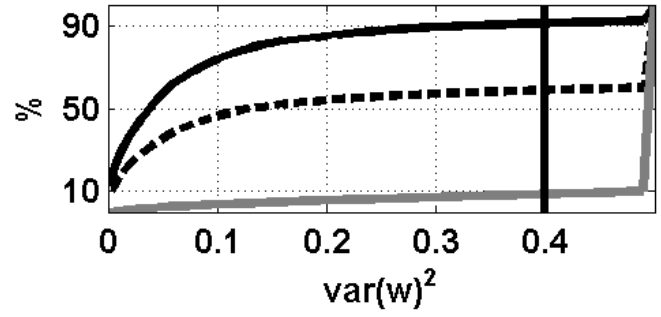

(e)

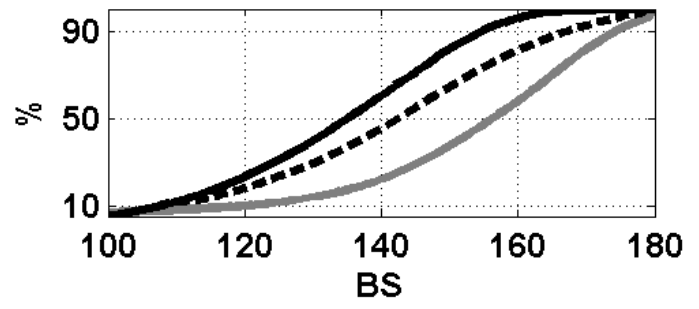

(b)

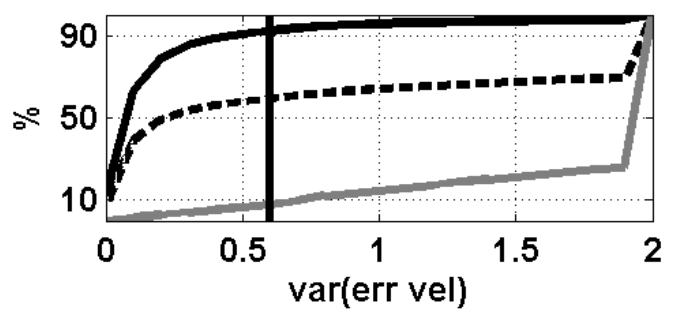

(d)

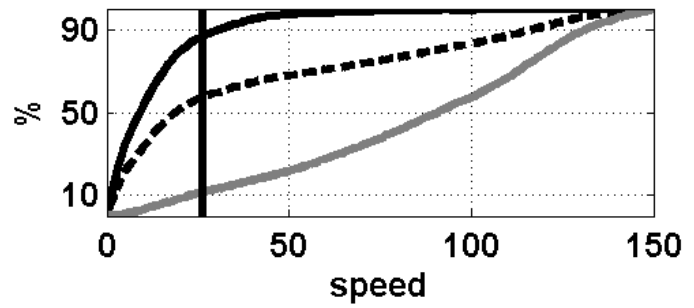

(f)

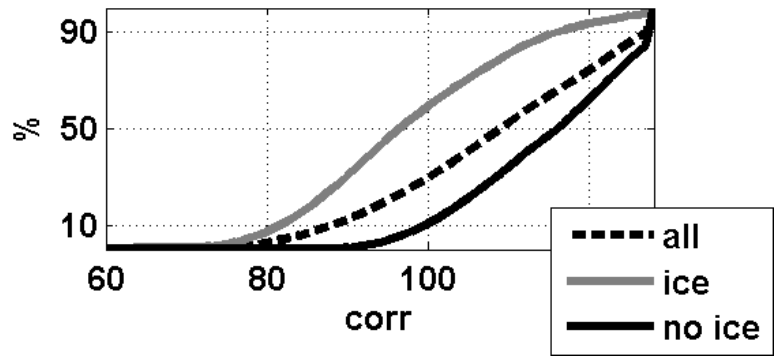

Figure 3.2.1 (a) Time series of surface error velocity $\left(10^{3} \mathrm{~cm} / \mathrm{s}\right)$, with black showing initial selection of ice periods. The other panels show cumulative histograms, with the percentage on the $y$ axis and the value of the data on the $x$ axis of (b) variance of surface error velocity $\left(\mathrm{cm}^{2} / \mathrm{s}^{2}\right)$, (c) squared variance of surface vertical velocity $\left(\mathrm{cm}^{4} / \mathrm{s}^{4}\right)$, (d) surface speed $(\mathrm{cm} / \mathrm{s})$, (e) surface backscatter intensity (RDI relative backscatter units, or BSU), and (f) surface signal correlation (no units). In the histograms, the black and gray lines contain data from the time periods shown in black and grey in panel (a) respectively, and the dashed lines contain data from the entire dataset. The vertical black lines in panels (b) - (d) show the threshold values as described in the text.

The cutoff values for the presence of ice were first determined by examining these histograms. As an ad hoc rule, we have taken the cutoff values to be when the cumulative histograms for the ice period reaches $90 \%$ and the open water period is less than $10 \%$. These values were chosen using a subjective trial and error process. They not only work best at identification of the best criteria for discerning ice in the record, but provide the best cutoff values for these criteria when compared with satellite-based estimates of ice coverage, as described below.

Then a time series of ice presence is made by tagging each half hourly data point as 'ice' or 'no ice'. One can choose to simply use one of the criteria, or combine them by 
taking the average or cross-correlation of two or more indicators. Next, a daily average ice concentration in the area of the mooring is calculated as the percentage of 'ice' measurements in one day (Visbeck and Fischer, 1995). This assumes that the ice is moving overhead in a statistically random way on daily time scales.

Finally, the time series of ice concentration can be compared with remotelysensed ice estimates and cutoff values for criteria for ice coverage can be fine tuned if necessary. One might need to identify and possibly omit times of calm winds which can produce low vertical velocity variance and thus false ice detection (Visbeck and Fischer, 1995). However, in the example shown here, surface wind data collected nearby had no periods of time where winds were light enough for a long enough period of time (less than $5 \mathrm{~m} \mathrm{~s}^{-1}$ for more than 2 days) to warrant this extra step.

The ice concentrations derived using the initial choice of cut-off values from Figure 3.2.1 are indicated by the black line in Figure 3.2.2. In this case, we applied the cutoff criteria of windowed variance of error velocity $\left(0.0006 \mathrm{~cm}^{2} \mathrm{~s}^{-2}\right)$, the squared windowed variance of vertical velocity $\left(0.4 \mathrm{~cm}^{4} \mathrm{~s}^{-4}\right)$, and the surface speed $\left(26.5 \mathrm{~cm} \mathrm{~s}^{-1}\right)$, and then averaged the ice concentration derived from these three. The two SSMI satellite estimates in Figure 2.2 employ different algorithms and show the range in estimates of remotely-sensed sea ice coverage by the shaded gray area. The ADCP estimate derived from the initial selection falls within the range of the satellite estimates for most of the time series without further correction. That is, the satellite data was not used to correct the cutoff criteria. 


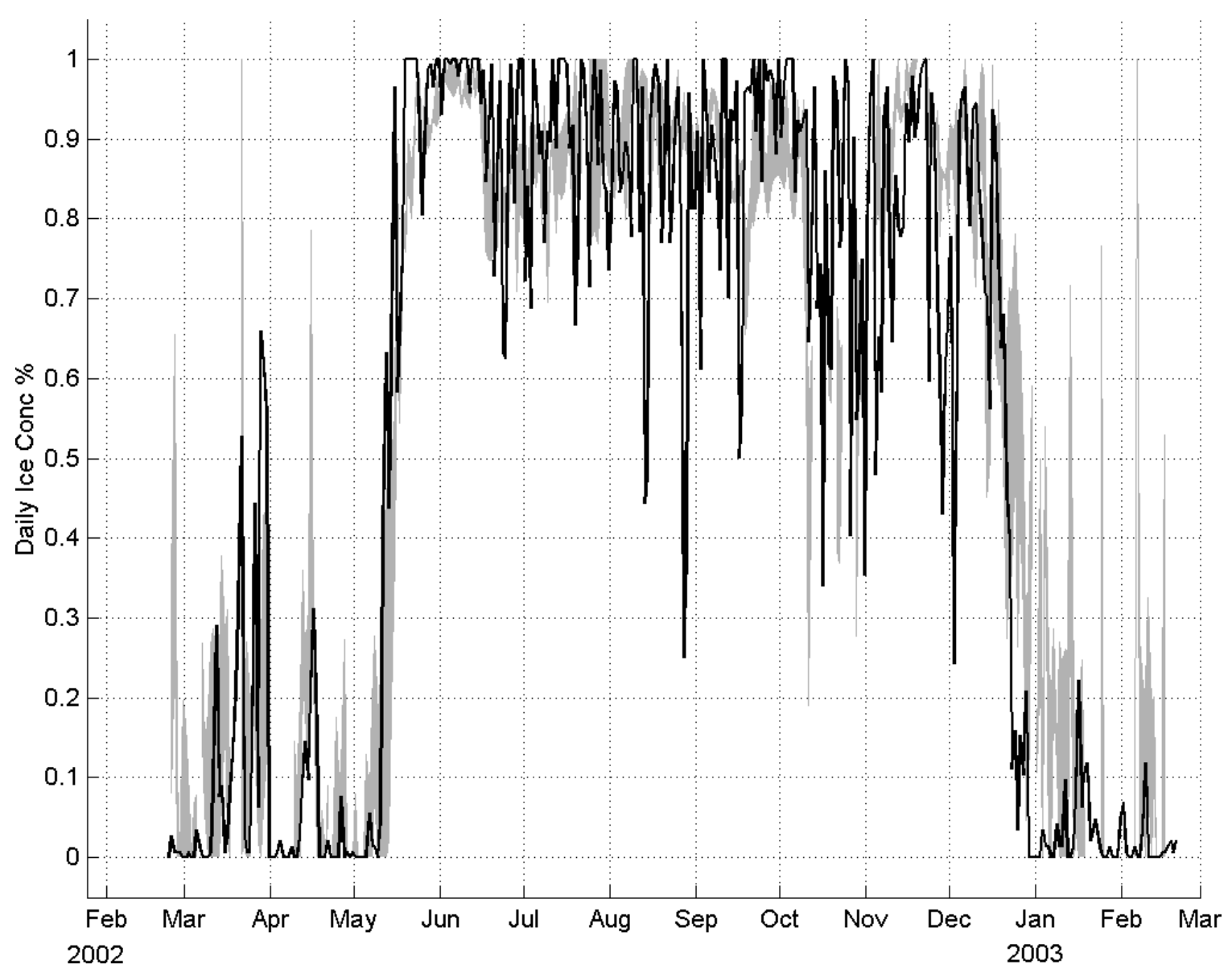

Figure 3.2.2 Estimated sea ice concentrations at the mooring site using the ADCP data and the methods described in the text (black line), and estimated by two different algorithms applied to SSMI satellite data whose range are shown by the gray shaded area.

The greater variability in the ADCP estimate can be attributed to the spatial average for the moored ADCP versus that of the SSMI satellite. The nominal pixel size of the satellite products is $12.5 \mathrm{~km}$ and $25 \mathrm{~km}$ (see appendix for details), making 156.25 $\mathrm{km}^{2}$ and $625 \mathrm{~km}^{2}$ footprints. The total area of the footprints of the four ADCP beams is $4 \pi[0.5 h[\sin (\theta+\varphi / 2)-\sin (\theta-\varphi / 2)]]^{2}$, where $\theta$ is the beam angle, $\varphi$ is the beam spread and $h_{o}$ is the nominal depth of the ADCP (Figure 3.1.1). In our example, the $300 \mathrm{kHz}$ broad-band $\mathrm{ADCP}$ had a beam angle of $20^{\circ}$, a beam spread of $2.2^{\circ}$ at $-3 \mathrm{~dB}$ (RDI-Primer, 1996), and a nominal depth of $108 \mathrm{~m}$, giving an instantaneous footprint of $48 \mathrm{~m}^{2}$. One must take into account ice motion when making averages of moored ice observations using the width of the beam times the distance the ice has traveled for the footprint. Here, the total width of the four beams, $4[h[\sin (\theta+\varphi / 2)-\sin (\theta-\varphi / 2)]]$, is $16 \mathrm{~m}$ and the 
average distance traveled by the ice in a day is $1.1 \mathrm{~km}$, with $95 \%$ of the values less than $28 \mathrm{~km}$. This gives an average footprint of $17,600 \mathrm{~m}^{2}$, or four orders of magnitude smaller than the satellite footprints. For a thorough treatment of the subject of spatial and temporal averaging of ice data from a moored platform, the reader is referred to Melling et al (1995).

\subsection{Ice draft}

Ice draft, $h_{\text {ice }}$ in Figure 3.1.1, is defined as the depth of ice below waterline. The estimate of ice draft is made using ocean pressure, atmospheric pressure, sound speed derived from temperature and salinity, and backscatter and tilt data from a moored upward-looking ADCP. The ice draft is calculated as the difference between the depth of the ADCP and the acoustically measured distance to the underside of the ice:

$$
h_{\text {ice }}=h_{o}-h_{1}
$$

Using hydrostatics, the ADCP depth, or distance from the waterline to the ADCP, can be calculated as:

$$
h_{o}=\frac{P_{o}-P_{a i r}}{\bar{\rho} g}-h_{2}
$$

with the variables defined in Figure 3.1.1. The pressure $P_{o}$ is measured anywhere near the ADCP and $h_{2}$ is determined by the mooring design. The time varying average

density between the ADCP and the sea surface, $\bar{\rho}$, is calculated from CTD casts taken at deployment and recovery and moored temperature and salinity time series data.

Substituting equation (3.2) into the ice draft expression, equation (3.1), we have an expression for the ice draft:

$$
h_{i c e}=\frac{P_{o}-P_{a i r}}{\bar{\rho} g}-h_{2}-h_{1}
$$

The cumulative uncertainty in the first two terms is less than $1 \mathrm{~cm}$. The acoustic range estimate from the ADCP to the underside of the ice, $h_{l}$ requires careful consideration and a series of specific corrections. 
The initial estimate of $h_{1}$ is obtained for each of the four beams using the backscatter profile. To obtain an estimate of $h_{1}$ at a resolution greater than the bin intervals, the centered first-difference of the observed backscatter profile $d B S$ at $z_{i}$, the midpoint between bins $i$ and $i+1$, is modeled using a slightly modified first-difference of a standard normal distribution:

$$
d \hat{B} S\left(z_{i}\right)=A\left[\frac{\left(-z_{i}+\mu\right)}{\sqrt{2 \pi} \sigma^{3}} \exp \left(\frac{\left(-z_{i}+\mu\right)^{2}}{2 \sigma^{2}}\right)\right]+C
$$

This functional form includes a constant multiplier $A$ and an added constant $C$ to improve the fit with the data and have the same units as $d B S . \sigma, \mu$ and $z_{i}$ have units of meters. The four parameters $A, C, \sigma$ and $\mu$ are obtained by a non-linear least-squares fit to the observed $d B S$ in 3 bins above and below the bin with the maximum backscatter, for 7 total bins, or 6 differences. This gives two degrees of freedom for this fit. The zero-crossing of $d \hat{B} S$, defined as $d \hat{B} S\left(\hat{z}_{o}\right)=0$, is the peak of the fitted backscatter profile, which is taken as the ice-water or air-water interface (Visbeck and Fischer, 1995). We believe that this function improves upon the second-order polynomial fit used by Visbeck and Fischer (1995) since it gives a range to the surface which achieves a better match to the hydrostatic-based range $h_{o}$ during times of open water. The initial attempt to estimate $h_{1}$ using the parabolic fit did not track variations of pressure at tidal frequencies, while equation (3.4) did accomplish this (section 3.6). Furthermore, there is no acoustic process which favors or suggests one empirical fitting function over another.

In the example here, a $20^{\circ}$-beam angle, a $4.4^{\circ}$-beam aperture and a nominal instrument depth of $108 \mathrm{~m}$ yields a minimal width of the surface energy peak of $2.9 \mathrm{~m}$ (equation 1 in Visbeck and Fisher, 1995), which is resolved by the 2-m bin averaging. This confirms that the surface energy peak affects more than one of the ADCP bins.

A set of corrections to this raw estimate must be made. These corrections take into account changes which would not greatly affect the velocity profile and are therefore not included in standard ADCP processing, but are of the order of the signal when ice draft is estimated. Since they are multiplicative, they become more important as the depth of the ADCP increases. These corrections for sound speed and instrument tilt are 
described in detail in separate sections below. As a final step, bad data are removed and a footprint error correction is made.

Finally, a best estimate for vertical range $\overline{\hat{z}}_{o}$ is made from the 4 beams by averaging the 2 most similar corrected estimates $\frac{1}{2}\left(\hat{z}_{o 1}+\hat{z}_{o 2}\right)$. Local atmospheric pressure is used to estimate the depth of the ADCP (equation 3.3). In our case, $P_{\text {air }}$ was measured at a nearby automatic weather station. If this data were not available, one could use meteorological reanalysis products to estimate $P_{\text {air }}$. However, in a location with little actual data these reanalysis products are much less reliable than actual measurements (e.g. Marshall, 2002).

\subsubsection{Sound speed correction}

A site-specific method for estimating the sound speed profile is required to accurately convert the round-trip travel time to range (Strass, 1998). Standard RDI ADCP processing uses a depth-independent sound speed profile computed from the ADCP temperature measurement and a constant salinity specified by the user, since sound speed variation is much more sensitive to changes in temperature than salinity (RDI-Primer, 1996). The multiplicative factor to correct for the sound speed profile is

$$
\varepsilon=\frac{C_{A D C P}}{C_{\text {real }}}
$$

where $C_{A D C P}$ is the sound speed used by the ADCP, and $C_{\text {real }}$ is the harmonic mean of the true sound speed profile.

In most cases, one does not have a full time series of sound speed profile. In fact, deep keeled icebergs often occur in regions of sea ice, jeopardizing any attempts at upper water column density measurements. Therefore, one must use other information and a model of the evolving mixed layer to estimate the sound speed profile (Strass, 1998). We use the UNESCO formulas for calculating seawater properties, such as sound speed (Fofonoff and Millard, 1983) in our example.

The first correction uses salinity measured at a sensor very close (in this case, 10 $\mathrm{m}$ above) to the ADCP to replace the constant salinity preprogrammed into the ADCP. Another simple correction takes into account the effect of pressure on the sound speed profile. This assumes, for lack of better information, a well-mixed water column from 
the surface down to the ADCP, which means a constant profile of potential temperature. Since sound speed depends on in situ temperature, the sound speed will be greater and actual range will decrease. Figure 3.3.1 shows the resulting corrections for a nominal range of $108 \mathrm{~m}$. Salt and pressure have a combined effect of about 5-10 cm for most of the time series.

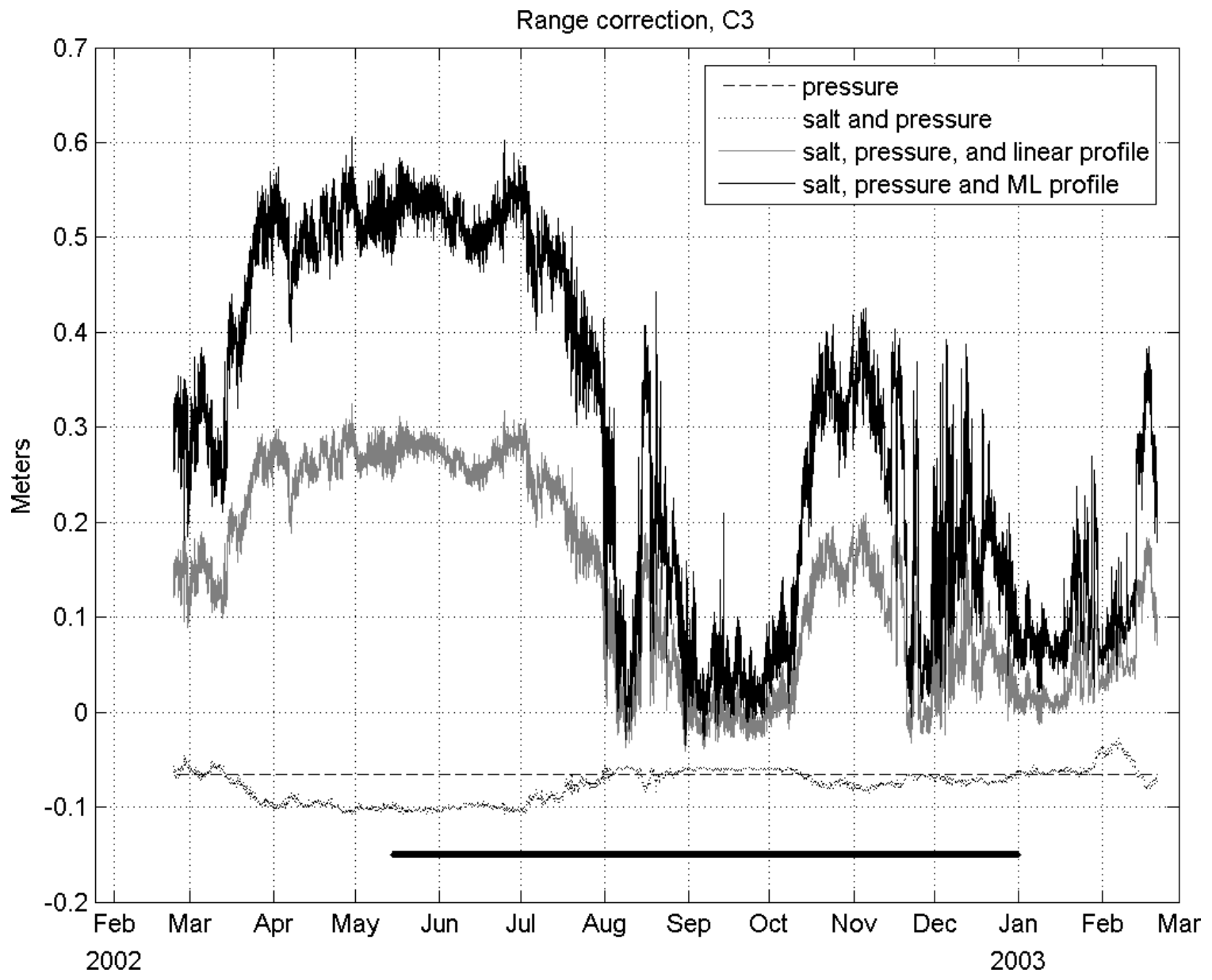

Figure 3.3.1 Time series of sound speed correction to nominal 108-m range estimate based on different methods described in the text, where ML profile refers to the mixed layer profile. The thick black line at the bottom shows the approximate period of nearly complete ice cover.

The next correction is site-specific and requires a simple model of the upper layer hydrographic structure. In the presence of sea ice, the surface temperature value can be assumed to be at the freezing point at the ambient surface salinity. Using all available CTD profiles, one constructs a functional form to estimate the mixed layer depth and the underlying temperature and salinity profile that can be empirically related to the temperature and salinity measurements on the mooring (Strass, 1998). The exact 
structure of the profile is not critical, but rather the harmonic mean of the resulting sound speed profile. This correction must also be applied to ULS sea ice draft estimates, so it is a general problem for ice draft estimates based on acoustic measurements.

In the case of Marguerite Bay, the general features of the wintertime density profile are an upper mixed layer of water at the surface freezing point overlying a pycnocline which warms towards the relatively warm Upper Circumpolar Deep Water (Smith et al., 1999). Therefore, under these circumstances we wish to find the timevarying depth of the mixed layer which is at freezing, and then linearly interpolate down to the uppermost temperature and salinity measurement.

The base of this mixed layer is usually associated with high rates of shear (Howard et al., 2004) so one could use the ADCP velocity data to find the mixed layer depth. We found the ADCP current data too noisy to derive a reliable mixed layer depth based on shear, and instead used the temperature and salinity measured at $99 \mathrm{~m}$, just above the ADCP. Mixed layer depths from 87 CTD stations during a previous winter hydrographic survey were examined. A linear regression was made between the temperature at $99 \mathrm{~m}$ and the mixed layer depth. The results of this regression can be seen in Figure 3.3.2, with the fit to the temperature data having an $\mathrm{R}^{2}$ value of 0.59 . This linear fit was then applied to the time series of temperature measured at $99 \mathrm{~m}$ on the ADCP mooring, providing a reasonable time series of estimated mixed layer depth. The salinity of the mixed layer was held at 33.95 PSU based on examinations of temperaturesalinity plots of the moored sensors, the hydrographic surveys, and historical data (Hofmann et al., 1996). It should be noted that this method is applied to the entire year, while it is strictly only valid for winter stratification. During times of open water there was often a surface layer of warm fresh meltwater that could not be represented with a simplistic empirical approach. Therefore, the zero ice draft estimates are more uncertain because the sound speed correction is most likely incorrect during times of extended open water. Application of the sound speed profile measured by CTD during the mooring recovery reveals an overestimation of the ice draft by $0.31 \mathrm{~m}$ on February 21, 2003, which brings the estimated ice draft from $0.61 \mathrm{~m}$ to $0.30 \pm 0.40 \mathrm{~m}$ and has zero-draft within the uncertainty. 


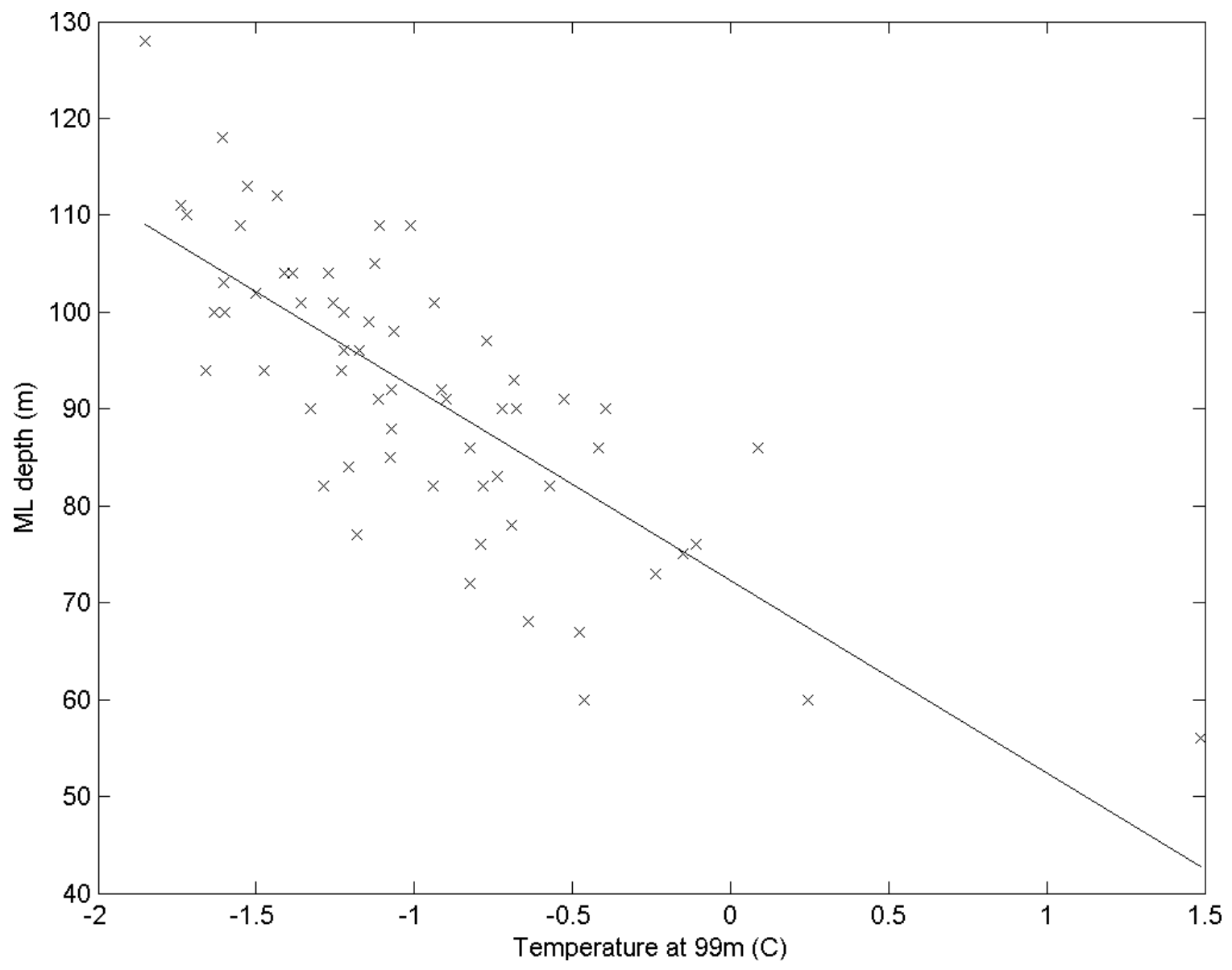

Figure 3.3.2 Linear regression of temperature measured at $99 \mathrm{~m}$ with a CTD and the mixed layer depth of the cast.

As seen in Figure 3.3.1, these mixed layer depth corrections have a larger effect than the salt and pressure corrections described above. The correction is as much as 50 $\mathrm{cm}$ for May and June, when sea ice is forming. During September and parts of August and December, the mixed layer extended all the way down to the ADCP, so the correction is unnecessary.

As a final check, we have compared the modeled sound speed profile with that observed during the only winter-time CTD cast taken 9.3 kilometers away on August 26, 2002. As shown in Figure 3.3.3, the salinity, temperature, density and sound speed profiles match well. The overall range correction is nearly identical, with the modeled correction adding $19.9 \mathrm{~cm}$ onto the range and the sound speed correction using the observed profile adding $20.6 \mathrm{~cm}$. 

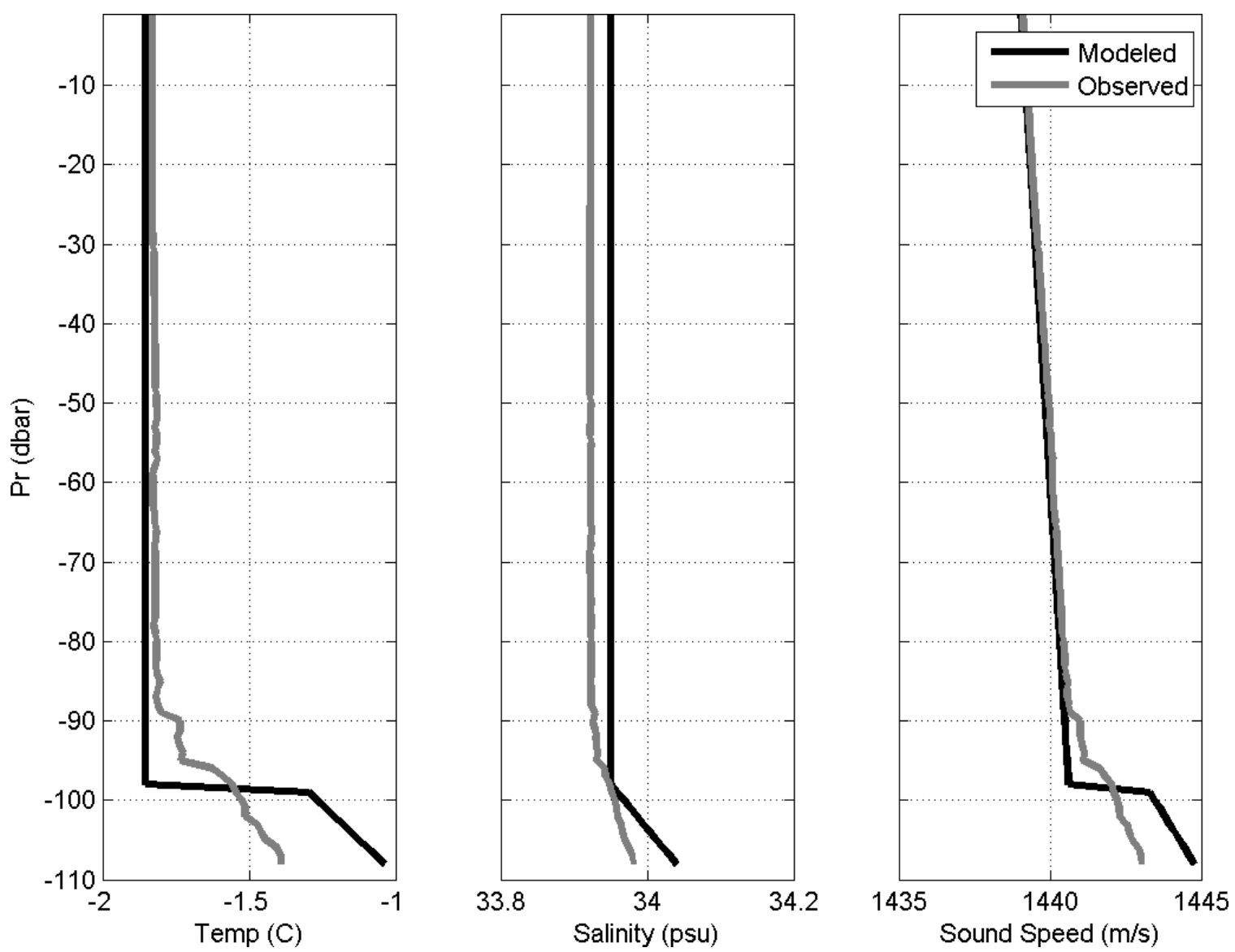

Figure 3.3.3 Comparison of observed and modeled sound speed correction on August 26, 2002. Panels are (left to right): temperature, salinity and sound speed. The black line is the modeled profile, and the grey line is the observed profile. Units: ${ }^{\circ} \mathrm{C}, \mathrm{psu}$, and $\mathrm{m} / \mathrm{s}$.

\subsubsection{Tilt correction}

The backscatter profile must be corrected for instrument pitch and roll, as standard ADCP processing uses the instrument tilt to binmap the velocities but not the backscatter (RDI-Primer, 1996). Due to the beam geometry, this correction affects each beam differently, and inherently collapses the separate estimates from each of the four beams towards one value. The multiplicative factor applied to the range estimate to correct for instrument tilt can be expressed as

$$
\frac{\cos \left(\theta_{o} \pm\left(\left(\theta_{p}(t)+\theta_{p}{ }^{\prime}\right),\left(\theta_{r}(t)+\theta_{r}{ }^{\prime}\right)\right)\right)}{\cos \left(\theta_{o}\right)}
$$

where $\theta_{\mathrm{o}}$ is the beam angle of the ADCP, $20^{\circ}$ in the case of the RDI Workhorse, and $\left(\theta_{\mathrm{r}}\right.$, $\left.\theta_{\mathrm{p}}\right)$ is the roll or pitch angle, with the \pm indicating that one should add or subtract 
depending on the sign convention dictated by the configuration of the sensors in the instrument. For an upward-looking RDI ADCP, one should add roll for beam 1, subtract roll for beam 2, add pitch for beam 3 and subtract pitch for beam 4 .

The standard tilt sensors on an RDI Workhorse ADCP have a resolution of $0.01^{\circ}$, yet have an accuracy and precision of only $\pm 0.5^{\circ}$. The latter represents about $32 \mathrm{~cm}$ of error for every $100 \mathrm{~m}$ of instrument depth. To improve the accuracy of these measurements, a constant offset $\left(\theta_{r}{ }^{\prime}, \theta_{p}{ }^{\prime}\right)$ is added to each of the time series of roll and pitch. These values are chosen to minimize, in a least squares sense, the difference between the range estimates from the two beams affected by that axis of the tilt sensor for the entire time series. The range of acceptable values for $\left(\theta_{r}{ }^{\prime}, \theta_{p}{ }^{\prime}\right)$ is constrained by the accuracy and precision of the sensor. In this case, $\theta_{r}{ }^{\prime}=-0.27^{\circ}$ and $\theta_{p}{ }^{\prime}=0.04^{\circ}$, corresponding to $19 \mathrm{~cm}$ and $3 \mathrm{~cm}$ corrections, respectively, on a total nominal range of $108 \mathrm{~m}$.

\subsubsection{Removing obviously erroneous data}

A series of criteria are applied to find erroneous data and remove them (Strass, 1998). Since many data sources contribute to the ice draft estimate, the first step involves acceptable range checking of any auxiliary data (temperature, salinity, air or water pressure). Next, data were eliminated for times when the ADCP ensemble averaging in space and time and the fitting function (equation 3.4) to the backscatter profile for a single ADCP beam failed to accurately determine the range to the surface. When the standard deviation of the residuals of the fitted function $\sigma_{\hat{z}_{o}}$ exceeded a chosen threshold, the range estimate was omitted. The threshold chosen here was 6.7 backscatter units (BSU), which eliminated about $10 \%$ of the values. There was no significant bias in the residuals.

Finally the difference between the estimates from the two most similar beams, $d_{d i f}$, as described in section 3.3, was examined. A maximum limit, $0.25 \mathrm{~m}$, for this difference excluded $8 \%$ of the remaining data. Overall, about $18 \%$ of the data was removed due to these combined tests. 


\subsubsection{Footprint error}

A footprint error is associated with the wide beam of the ADCP. This error is defined as the difference between the measured draft and the mean ice draft and does not scale with the ADCP depth (Vinje et al., 1998, appendix). The diameter of an individual beam, $h[\sin (\theta+\varphi / 2)-\sin (\theta-\varphi / 2)]$, is $3.9 \mathrm{~m}$ for this ADCP, which gives a footprint error of 0.4 meters which has been subtracted from the measured ice draft to get the expected mean draft. We have assumed the underwater roughness of ice in Marguerite Bay resembles Arctic winter ice for purposes of the footprint error. Readers are referred to Vinje et al, 1998, (appendix) to find an estimate of footprint error given the footprint diameter and winter or summer ice.

\subsubsection{Uncertainty Estimate}

The uncertainty in the range estimate for each ensemble can be divided into that due to the empirical fitting function (equation 3.4) and that due to the sound speed correction. First, we describe each separately here, since the former is specific to the ADCP and the latter is universal to all acoustic ice draft estimates. Then we discuss the combined uncertainty.

\subsubsection{Uncertainty due to the empirical fitting function}

Estimation of the error in the ice draft estimate is complicated because the range is obtained from a non-linear fitting procedure for $\hat{z}_{o}$. Therefore, we performed a Monte Carlo simulation of the range estimate $\hat{z}_{o M C}$ obtained from fits of equation (3.4), in order to estimate range uncertainties due to random errors in the backscatter intensity. The median values for the one-year time series of the coefficients in equation (3.4) ( $A=$ $1450 \mathrm{BSU}, C=-1 \mathrm{BSU}, \sigma=2.8 \mathrm{~m}$ and $\mu=107.5 \mathrm{~m}$ ) were used to calculate a median range and six-point synthetic profile. Normally distributed random noise was then added to each $d B S$ point in the synthetic profile to test the sensitivity of the range estimate to noise in the backscatter profile. The synthetic noise had zero mean, and a standard deviation $\sigma_{n}$ which we varied from zero to ten BSU. For each value of $\sigma_{n}$, the mean of $\hat{z}_{o M C}$ was indistinguishable from that of the median value profile. A KolmogorovSmirnov test confirmed that $\hat{z}_{o}$ in the Monte Carlo simulation had a normal distribution. 
The standard deviation of $\hat{z}_{o M C}, \sigma_{\hat{z}_{o M C}}$, was calculated as a function of $\sigma_{n}$ and shown in Figure 3.3.4. $\sigma_{\hat{z}_{o M C}}$ increases linearly with $\sigma_{n}\left(\sigma_{\bar{z}_{o M C}}=0.031 \sigma_{n}-0.0019, \mathrm{R}^{2}=\right.$ 0.99). We then applied this relationship to each of the two most similar beams $\sigma_{\hat{z}_{o 1}}, \sigma_{\hat{z}_{o_{2}}}$ and then estimated the total uncertainty $\sigma_{\overline{\bar{z}}_{o}}=\frac{1}{2} \sqrt{\sigma_{\hat{z}_{o 1}}{ }^{2}+\sigma_{\hat{z}_{o 2}}{ }^{2}}$ in the final range estimate $\overline{\hat{z}}_{o}$ due to the empirical fitting in our example data, a time series and histogram of which is shown in the light gray lines in Figure 3.3.5. The peak in the distribution at $0.065 \mathrm{~m}$ gives an estimate of the most likely uncertainty due to the empirical fitting in our example dataset. The upper bound on uncertainty lies at a $\sigma_{\overline{\bar{z}}_{o}}$ of $0.15 \mathrm{~m}$. This appears to be relatively constant during the one-year time series.

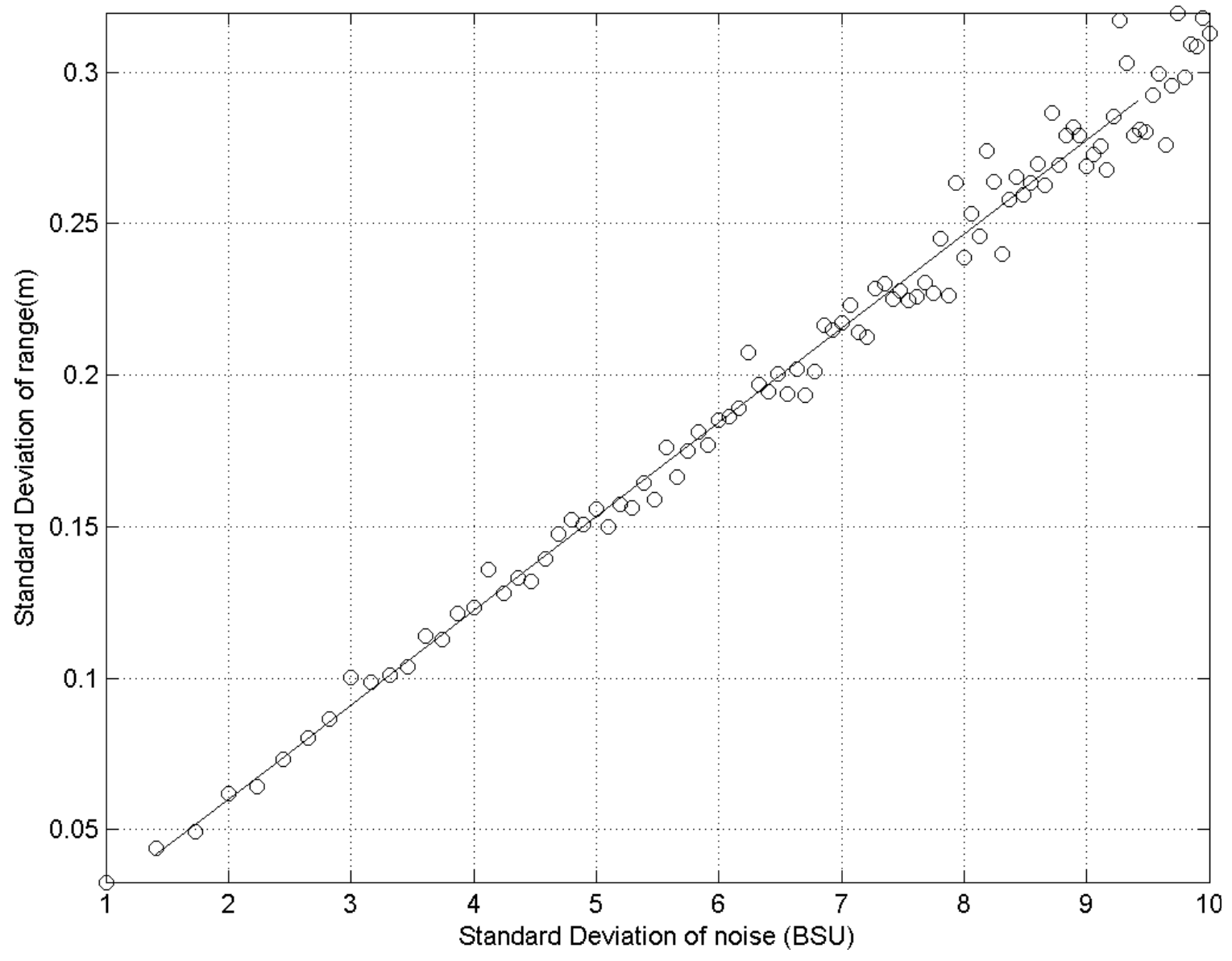

Figure 3.3.4 Standard deviation of zero-crossings $\sigma_{\hat{z}_{o M C}}$ s standard deviation of residuals ${ }^{n}$ of synthetic profiles created in the Monte Carlo simulation (circles) and linear fit (line). 


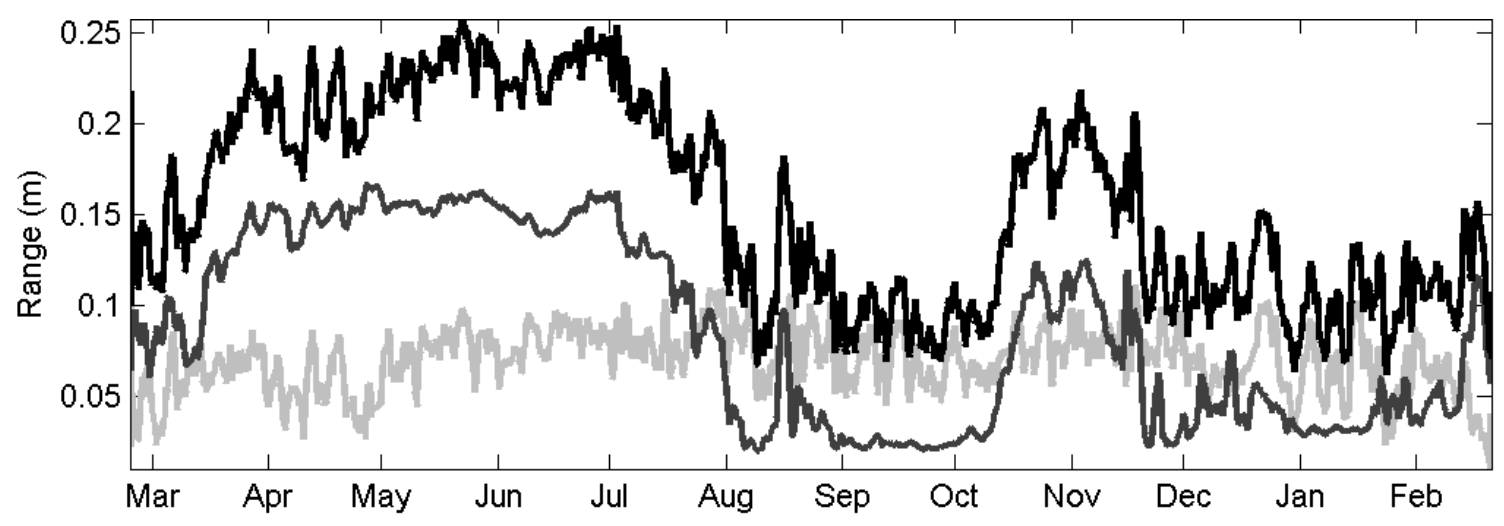

2002

2003

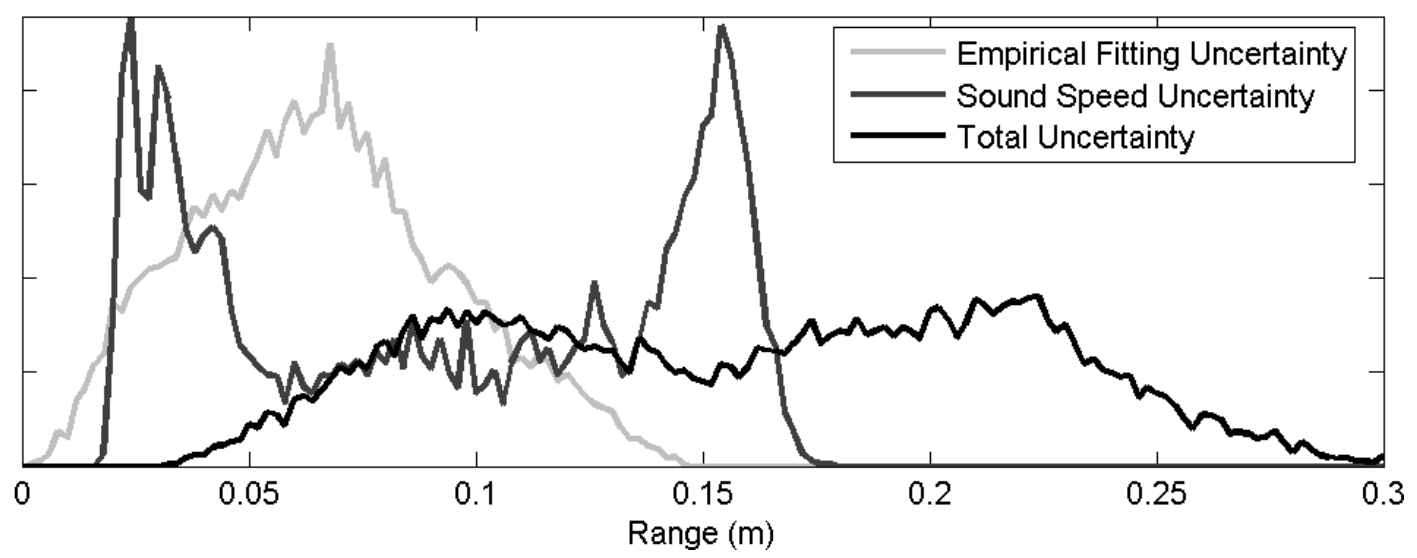

Figure 3.3.5 Uncertainty in ice draft estimate. Upper panel shows time series, lower panel shows histogram of time series. In both panels, light gray line is empirical fitting uncertainty, dark gray line is sound speed uncertainty, and black line is total uncertainty.

\subsubsection{Uncertainty in the Sound Speed Correction}

The range correction due to sound speed carries an uncertainty associated with the modeling of the sound speed profile. In our example, this depends on the uncertainty in the estimate of the mixed layer depth. To quantify this, we express equation (3.5) as:

$$
\varepsilon=\frac{C_{A D C P}}{C_{\text {real }}} \pm \frac{C_{A D C P}}{C_{\text {real }}} \frac{\sigma_{C_{\text {real }}}}{C_{\text {real }}}
$$

where the first term is the ratio in equation (3.5) and the second term quantifies the uncertainty. To calculate $\sigma_{C_{\text {real }}}$, we added and subtracted the standard deviation $\sigma_{M L}$ of the misfit in the linear regression shown in Figure 3.3.2 $(21.8 \mathrm{~m})$ to the estimated mixed layer depth for each ensemble. We used these upper and lower bounds and the method in section 3.1 to calculate bounds on $C_{\text {real }}$, the difference being $\sigma_{C_{\text {real }}}$. A time series and histogram of the resulting uncertainty in the range $108 \cdot C_{A D C P} \sigma_{C_{\text {real }}} / C_{\text {real }}^{2}$ is shown by the 
dark grey lines in Figure 3.3.5. The time series shows the uncertainty to be about $0.15 \mathrm{~m}$ from April to July when the mixed layer is well above the ADCP, and about $0.025 \mathrm{~m}$ from August to February (except November) when the mixed layer extends down to the ADCP and is thus well-resolved. These two periods correspond to the two peaks in the histogram. The upper bound on uncertainty due to the sound speed correction is $0.18 \mathrm{~m}$.

\subsubsection{Combined total uncertainty}

The combined total uncertainty due to the empirical fitting function and the sound speed correction can be expressed as:

$$
\overline{\hat{z}}_{o} \varepsilon=\overline{\hat{z}}_{o}\left(\frac{C_{A D C P}}{C_{\text {real }}}\right) \pm\left[\sigma_{\bar{z}_{o}}\left(\frac{C_{A D C P}}{C_{\text {real }}}\right)+\overline{\hat{z}} \frac{C_{A D C P}}{C_{\text {real }}} \frac{\sigma_{C_{\text {real }}}}{C_{\text {real }}}\right]
$$

where the first term on the right side is the best estimate of the range and the second term in brackets is the total uncertainty. The total uncertainty is comprised of two parts, the first is associated with the empirical fitting function and the second with the sound speed profile. The time series and histogram of the total uncertainty and its two parts are shown by the black line in Figure 3.3.5.

The time series and histogram show that during periods of low uncertainty in the sound speed correction (i.e., deep mixed layer), the uncertainty associated with the empirical fitting dominates and we calculate a total uncertainty of about $0.10 \mathrm{~m}( \pm 0.20$ m 95\% confidence interval). In April to July, the sound speed correction uncertainty was greater than that associated with the empirical fitting, making the total uncertainty around $0.22 \mathrm{~m}( \pm 0.43 \mathrm{~m} \mathrm{95 \%}$ confidence interval). This demonstrates that the uncertainty in the sound speed profile is of the same importance as that of the acoustic ranging for ice draft estimation.

\subsubsection{Example results: Marguerite Bay}

As a first test of the method, range estimates at high frequencies are examined. The surface height tidal amplitude for Marguerite Bay is 1-2 m which is the same order as the ice draft and smaller than the ADCP bin size. One would expect this signal to be seen in both the bottom pressure record and in the range estimates from the ADCP to the surface so that the effect of tides is removed when equation (3.3) is evaluated. The surface detection method was accurate enough to discern the tidal fluctuations in the 
acoustic estimate of range to surface even when the surface remains in one ADCP bin for nearly the entire year. Figure 3.3.6 shows the ADCP range estimate $h_{l}$ and the hydrostatic range $h_{o}$ for a period of 10 days of open water in April, 2002. The average difference of the two time series is $0.11 \mathrm{~m}$. The average of the absolute value of the difference is 0.14 $\mathrm{m}$, with $95 \%$ of those values less than $0.32 \mathrm{~m}$.

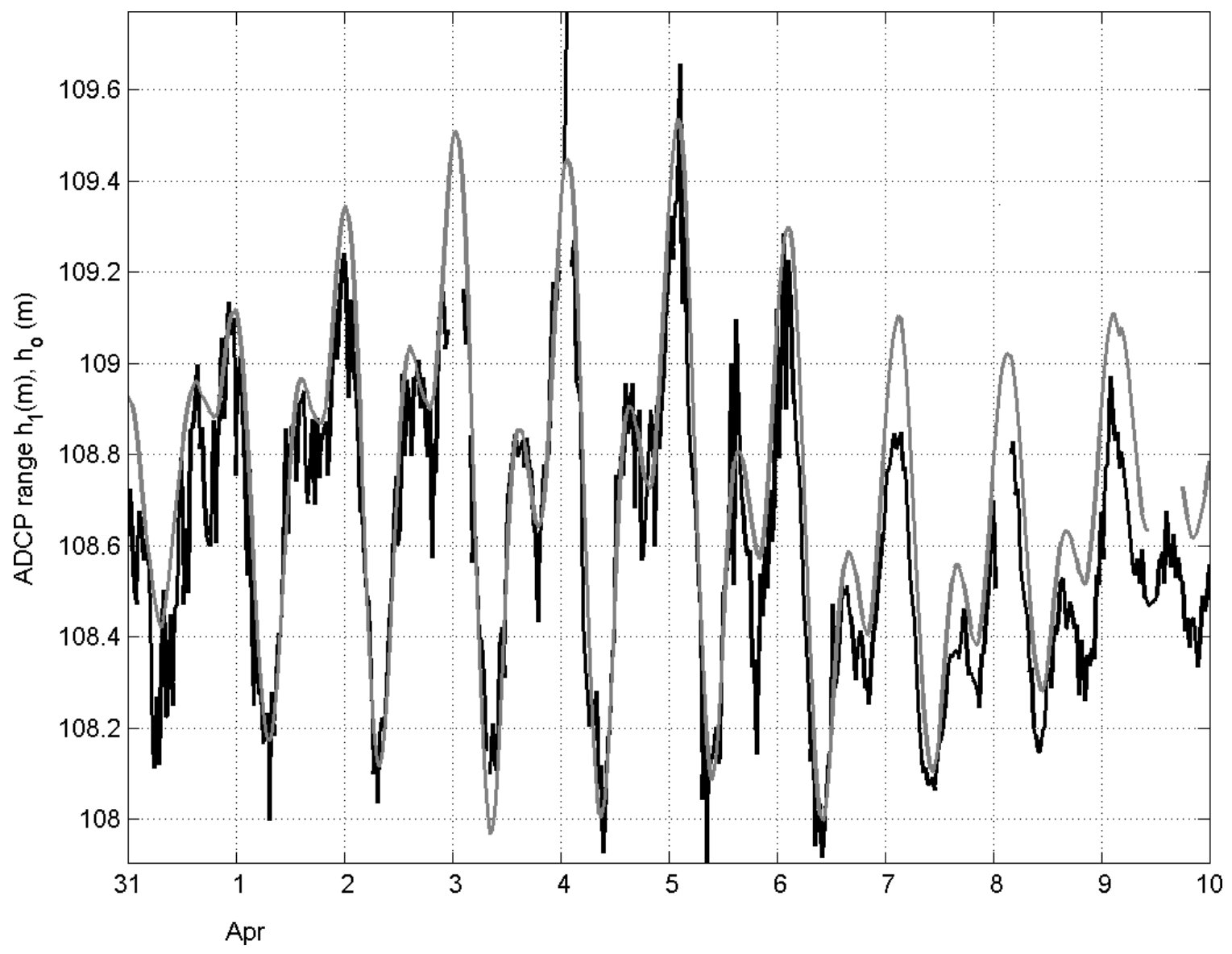

Figure 3.3.6 Detail of nearly ice free period in April, 2002 showing the strong presence of tides in the corrected ADCP range, $h_{1}$ (black) when compared with the tides derived from hydrostatics $h_{0}($ gray).

Two phenomena are responsible for the non-zero ice draft estimate during times of open water. First, the ambiguity of the sound speed profile prevents a truly accurate range estimate during the spring melt, around December and January in Marguerite Bay, when a fresh mixed layer with temperatures well above freezing forms which is unresolved by our sound speed correction. Second, it is unclear how the ensemble averaging of the ADCP resolves the surface waves during times of open water. The acoustic return from wave troughs versus peaks may not be identical and could introduce some bias. Furthermore, air bubbles entrained during wave breaking could have an effect 
on the acoustic return. Because these errors are based on sea state, they are difficult to correct. However, as shown in Figure 3.3.6 the method does work well in the fall when the spring melt layer is absent.

The final ice draft time series is shown in Figure 3.3.7. The maximum drafts were quite large, with extended periods of average daily values of 2 to $4 \mathrm{~m}$ in August and September, 2002. This period of thick ice ended abruptly, but ice was still present until January, as seen in Figure 3.2.2. This early arrival of multimeter-thick ice in Marguerite Bay in 2002 was observed by the RVIB Nathaniel B. Palmer as it was trapped in the ice for several days during this period. The indication of 50-100 cm thick ice in February 2003 is most likely due to a poor estimate of the sound speed profile as a result of an unresolved surface melt layer. It is worth noting that a warm surface layer increases sound speed, which causes the ADCP range to the surface to decrease and apparent ice draft to increase, making this explanation of the error physically consistent. Accurate ice draft estimates for springtime would be possible provided that the mixed layer temperatures were measured. Furthermore, one could potentially use short windows of open water to improve the uncertainty in the sound speed estimate during this period. 


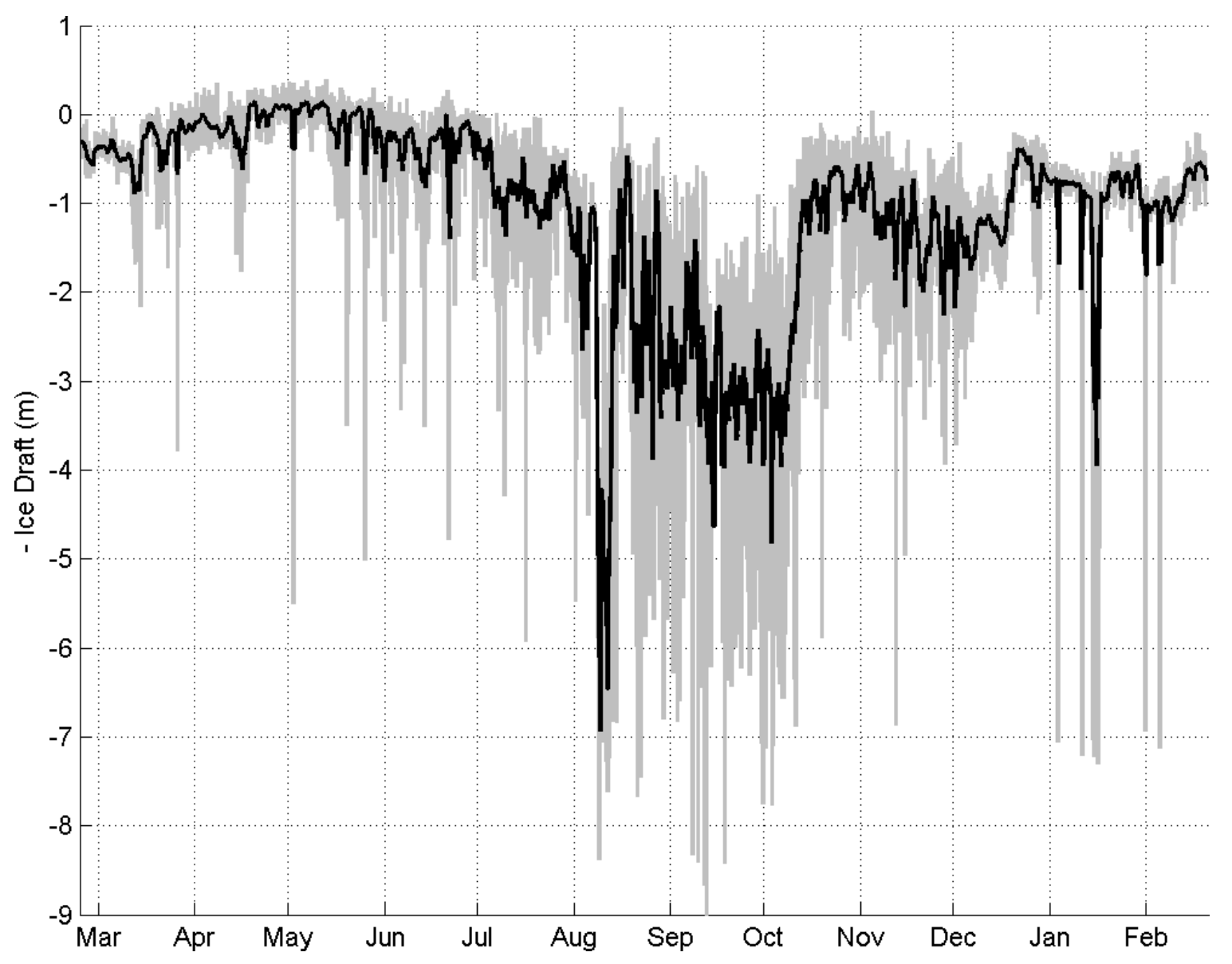

Figure 3.3.7 Ice draft observed in Marguerite Bay, 2002. The thick black line is a 24 hour running average and the shaded area indicates the daily maximum and minimum values within this average.

The time series of ice draft allows one to compute an ice draft distribution as seen in Figure 3.3.8. The distribution is binned in 1-m bins and shows the initial condition of nearly ice-free waters, which freeze up and by September 2002 have 18\% 2-3 m ice, and $12 \% 3-4 \mathrm{~m}$ ice. 


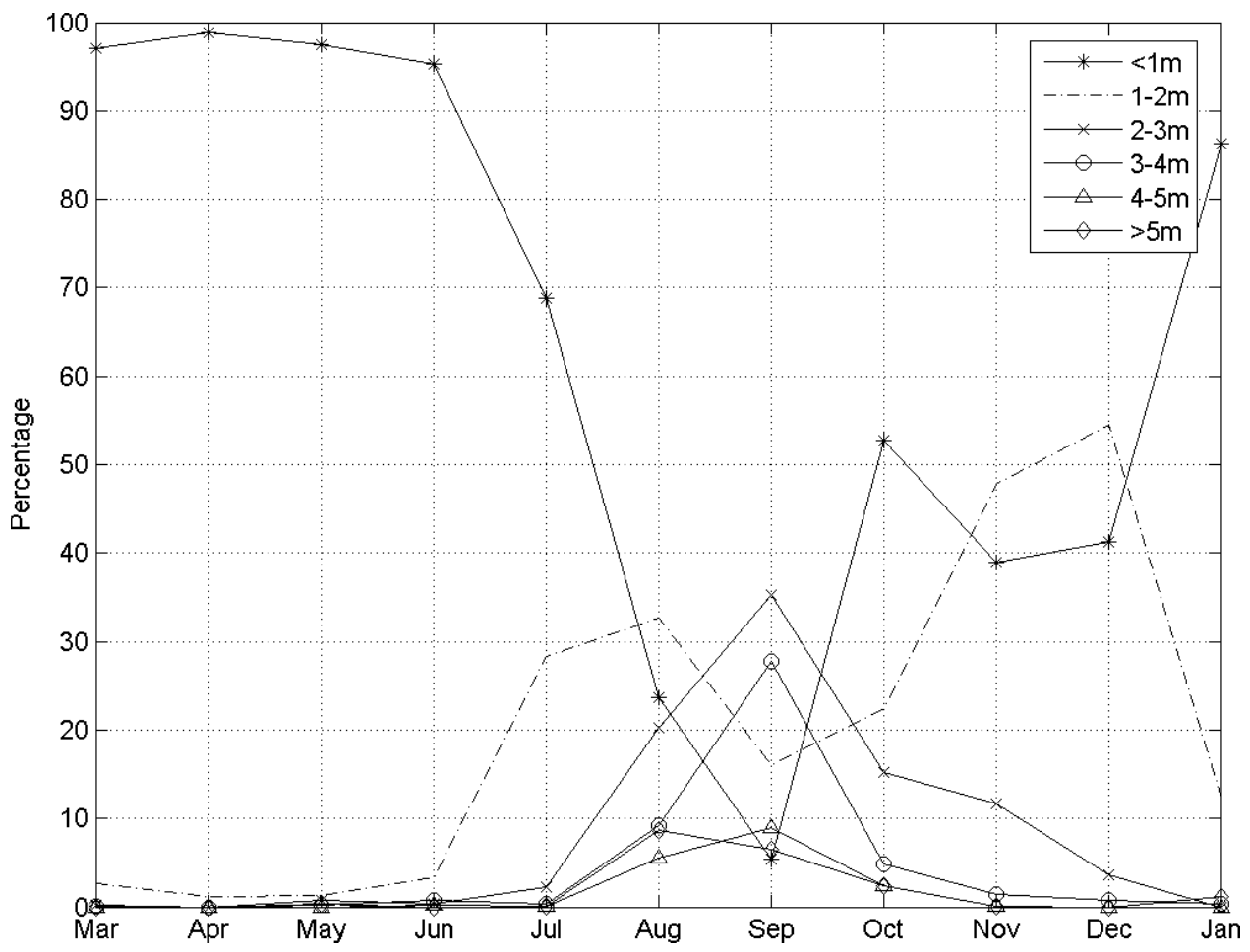

Figure 3.3.8 Monthly average draft distributions of sea ice observed in Marguerite Bay in 2002-2003 in 1-m bins.

\subsubsection{Averaging}

The temporal/spatial averaging of the ADCP also affects ice draft estimation.

Figure 3.3.9 shows a transect of ice draft and thickness measured by drilling through the ice every $2 \mathrm{~m}$ along a $100-\mathrm{m}$ linear transect at an ice camp $9 \mathrm{~km}$ from the mooring site during August 2001 (Perovich et al., 2004). This figure clearly illustrates the great variability in ice draft on very short horizontal scales. The ensemble averaging in time of the ADCP results in further spatial averaging as the ice moves beyond the area averaged by the combination of the data from the four beams into a single estimate of draft for each observation. Thus, since the ADCP-based estimates are an areal average, they can not resolve the short spatial variability found in Marguerite Bay. An ULS is needed to sample this small-scale variability. If the ULS were moored at $108 \mathrm{~m}$, its beam width at the sea surface would be $3.4 \mathrm{~m}\left(1.8^{\circ}\right.$ spread vertical beam). 


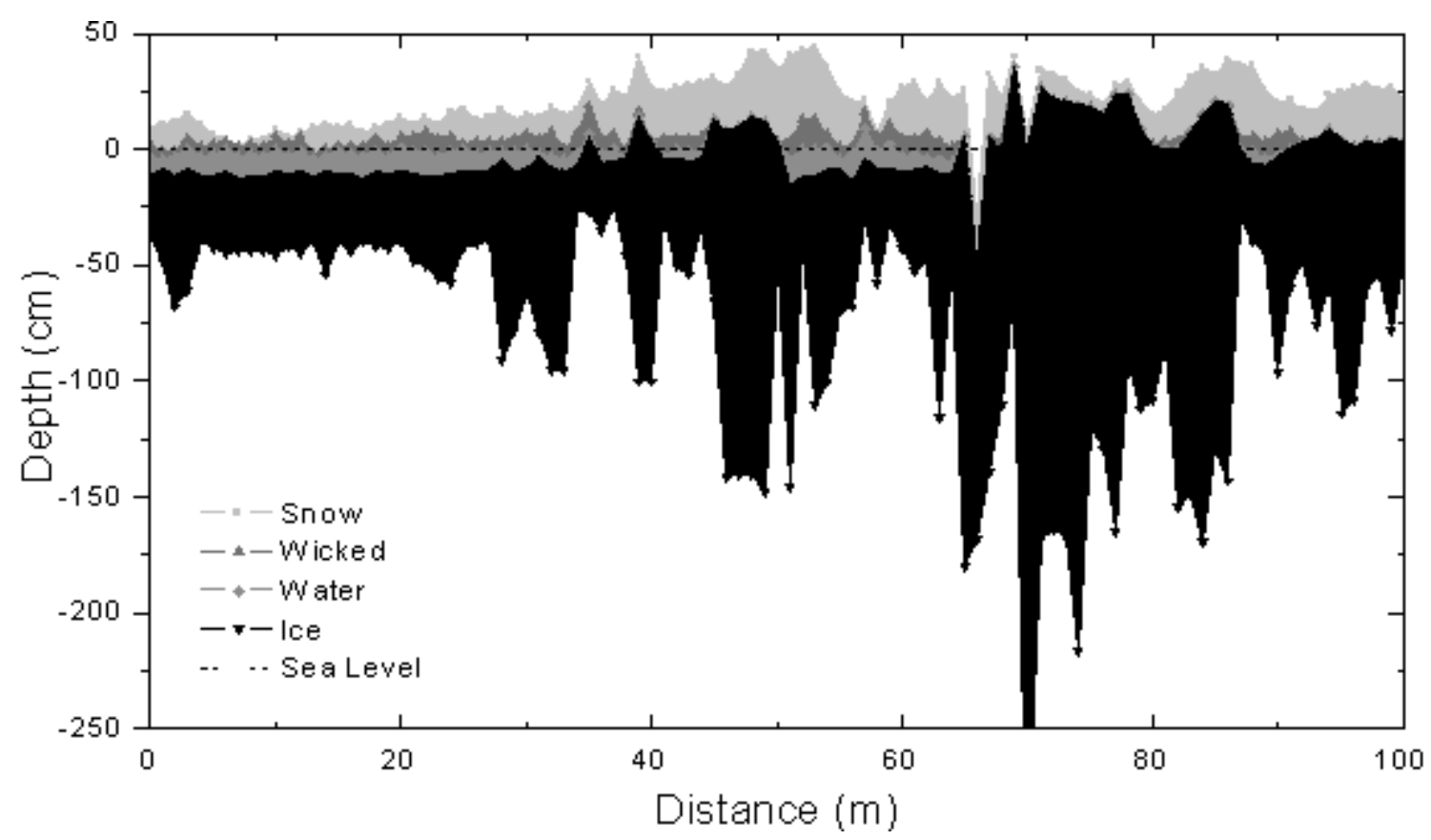

Figure 3.3.9 Ice thickness transect measured at ice station Robert in Marguerite Bay by the Perovich group on August 5 through 9, 2001. Ice thickness mean $=71.4 \mathrm{~cm}$; standard deviation $=\mathbf{5 0 . 3} \mathrm{cm}$; minimum $=19 \mathrm{~cm}$; and maximum $=235 \mathrm{~cm}$. (This figure kindly supplied by D. Perovich.)

\subsection{Recommendations for future deployments}

Use of an upward-looking ADCP to observe ice can be improved by carefully including additional measurements. A precise pressure gauge is required for the estimate of ice draft. First, measuring pressure $P_{o}$ close to the ADCP would reduce or eliminate any possible error due to mooring motion. Second, locally measured atmospheric pressure data, such as that used in this example, removes the uncertainty introduced by using distant observations or atmospheric reanalysis products. Third, some plan for estimating the sound speed profile would be of great benefit and would improve not only ADCP estimates but also ULS estimates of ice draft. Finally, the shallower the ADCP is deployed, the more accurate the ice draft estimate will be both for decreased geometric errors and smaller errors in the extrapolation of sound speed. However, ADCPs are usually deployed to provide velocity profiles over a significant depth range. Sound speed depends more on temperature than salinity so a simple thermistor chain or a winched system such as the HOMER (HOMing Environmental Recorder) could provide an improved sound speed correction. The latter would provide coverage throughout the 
upper water column and also avoid damage due to deep ice keels or ice bergs. An improved tilt sensor in the ADCP would also avoid the need for the constant tilt offsets $\left(\theta_{r}{ }^{\prime}, \theta_{p}{ }^{\prime}\right)$ as described in section 3.2. Finally, there is firmware available for RDI ADCPs (LADCP bottom-track mode) which examines the entire backscatter profile and locates the range of maximum backscatter near the surface and its peak intensity.

\subsection{Conclusions}

Upward-looking ADCPs have been shown to be viable tools for determination of ice coverage, ice draft and drift velocity as shown in the example case presented here from the western Antarctic Peninsula shelf. The techniques described provide additional information about the sea ice at a mooring location without, in most cases, any additional instrumentation.

Ice detection with the ADCP using windowed variances of vertical velocity and error velocity, and surface horizontal speed can be made independent of additional satellite information. In the example case, we found signal correlation and backscatter intensity to be poor indicators of the presence of ice at this site, but this may not hold elsewhere.

Estimation of the ice draft using the ADCP requires corrections to the range for instrument tilt and sound speed profile. The instrument tilt correction is greatly improved by a constant offset which minimizes the difference between beams. This offset introduces a $3 \mathrm{~cm}$ and $19 \mathrm{~cm}$ correction to pitch and roll, respectively. The sound speed correction introduced an offset of between about 0 and $55 \mathrm{~cm}$, with an average magnitude of about $30 \mathrm{~cm}$.

There are two separate ways to calculate the uncertainty in the ice draft estimate. First, the range estimate during times of open water, as described in section 3.6, resolves the surface tides to within $\pm 0.32 \mathrm{~m} 95 \%$ of the time. Second, a Monte Carlo simulation determines the sensitivity of the zero-crossing of the fitting function in equation 3.4 to backscatter noise. The most likely uncertainty associated with the empirical fitting function is $\pm 0.13 \mathrm{~m}$ (95\% confidence interval). The uncertainty associated with the sound speed correction had two regimes. One regime occurred during midwinter when the mixed layer extended down to the ADCP and the sound speed correction was nearly 
zero with a small uncertainty, most likely $0.025 \mathrm{~m}$. The other regime carries a larger uncertainty, most likely $0.15 \mathrm{~m}$, due to the ambiguity in the location of the mixed layer depth. We calculated a most likely total combined uncertainty of $\pm 0.20 \mathrm{~m}(95 \%$ confidence interval) during midwinter and $\pm 0.43 \mathrm{~m}$ (95\% confidence interval) when we had less confidence in our assessment of the mixed layer depth.

The two independent estimates of the uncertainty during times of open water ( \pm 0.32 and $\pm 0.43 \mathrm{~m}$ ) are consistent and suggest an uncertainty of $\pm 0.40 \mathrm{~m}$ on the estimate of the ice draft for this example, or about $0.4 \%$ of the nominal range of the ADCP. This is larger than that reported for an optimized ice draft estimate $(4 \mathrm{~cm})$ using a ULS deployed at a nominal depth of $150 \mathrm{~m}$ in the Weddell Sea (Strass 1998), or 0.026\% of the nominal depth. In other words, on a percentage basis, the ULS has one order of magnitude less uncertainty than the ADCP. The uncertainty in both cases depends highly upon the modeling of the sound speed profile.

Our study indicates that the ADCP is not a substitute for a dedicated ULS for ice detailed ice draft measurements, but it does give additional information about both ice and ocean velocities. An ADCP is more than adequate to observe the onset and breakup of sea ice and can provide estimates of ice draft and velocity, valuable information with little extra effort.

\section{A APPENDIX: Data from Marguerite Bay, western Antarctic Peninsula shelf}

The methods described in this chapter were applied to a data set from the U.S. Global Ocean Ecosystems Dynamics Southern Ocean (GLOBEC-SO) program, which collected data using a wide variety of instruments on the western Antarctic Peninsula (WAP) shelf, in and around Marguerite Bay. This work specifically utilized data collected by an Automatic Weather Station (AWS), CTD casts from hydrographic surveys, SSMI satellite data and one year of data from one subsurface mooring as an example.

The mooring (C3 in GLOBEC-SO array) was deployed during the ice-free season, recording data during the formation and subsequent breakup of the seasonal sea ice. The instrumentation was relatively successful in enduring the ice in Marguerite Bay. Upward-looking acoustic ice profilers were deployed on some other moorings. However, 
regionally concurrent ULS and ADCP ice draft measurements were not obtained. At the mooring used in this example, conductivity-temperature sensors at various depths gave some data of the evolution of the stratification, with the highest sensor at a depth of $99 \mathrm{~m}$. The reader is referred to the moored array technical report (Moffat et al., 2005) for more details about this and other moorings and the moored data collected in the GLOBEC-SO program.

The ADCP was a standard $300 \mathrm{kHz}$ broad-band RDI Workhorse deployed at a nominal depth of $108 \mathrm{~m}$, bin spacing of $2 \mathrm{~m}$ and 120 pings per ensemble over a 30-min period (15 sec between pings). The VACM pressure sensor (Paine 0-4400 psi) was part of a Vector Averaging Current Meter (VACM) deployed at a nominal depth of $250 \mathrm{~m}$.

Two separate Automatic Weather Stations (AWSs) were deployed in Marguerite Bay in close proximity to provide redundancy in case of failure, as well as the ability to check for failure by intercomparison. The stations were located on small rocky islets named Kirkwood Island and Dismal Island and had sensor heights of 12 and $25 \mathrm{~m}$ above mean sea level, respectively, and were separated by $29 \mathrm{~km}$. They transmitted their data via ARGOS satellite to the Antarctic Meteorological Research Center at the University of Wisconsin, where the data were processed into a time series of atmospheric pressure, temperature, relative humidity, and wind speed and direction with an averaging interval of 10 minutes. The data were then edited and averaged to construct time series with hourly resolution. The Kirkwood and Dismal atmospheric pressure data agreed to within $\pm 1 \mathrm{mb}$ after adjustment for the difference in sensor height. The Kirkwood station was slightly closer to the mooring $(68 \mathrm{~km})$ so it was used in this study.

Time series of ice concentration derived from the passive microwave sensor $\mathrm{SSM} / \mathrm{I}$ microwave imaging satellite data were provided by the Arctic and Antarctic Research Center at Scripps Institution of Oceanography in San Diego. Two separate time series of estimates of ice concentration are used because they feature different spatial averaging and distance from the center of the estimate to the mooring location. In addition, they use different bands and algorithms, and since neither is clearly superior, both are utilized. The first estimate is based on the $85 \mathrm{GHz}$ channel, with a pixel resolution of $12.5 \mathrm{~km}$. The second estimate uses the NASA team algorithm, which combines the $37 \mathrm{GHz}$ channel with a variety of other data and has a resolution of $25 \mathrm{~km}$ 
(Cavalieri, 1997). The ice concentration estimated at the pixel center closest to the mooring location was extracted about twice per day and then a daily average was made. The distance from the pixel center to the mooring location is only $170 \mathrm{~m}$ for the $85 \mathrm{GHz}$ channel, while the distance for the NASA algorithm varies, averaging about $10 \mathrm{~km}$, and never exceeding $17 \mathrm{~km}$.

\section{Acknowledgements}

The DMSP SSM/I data used in this project were provided by the Arctic and Antarctic Research Center at Scripps Institution of Oceanography in San Diego with the help of S. Hart. The AWS stations and data acquisition and initial processing were provided by the Antarctic Meteorological Research Center at the University of Wisconsin, with the support and help of M. Lazzara. Thanks to the captain and crew of the RV L.M. Gould and RVIB N.B. Palmer, R. Limeburner and the WHOI Subsurface Mooring Operations Group led by S. Worrilow, and the Raytheon Polar Services support crew responsible for collecting the moored array and AWS data. Thanks to D. Perovich for the ice camp data, discussions and Figure 12. This work benefited from conversations with A.Y. Shcherbina. This work was supported by the NSF Office of Polar Programs grant OPP 99-10092 and the WHOI Education Office.

\section{References:}

Belliveau, D., G. Bugden, B. Eid and C. Calnan, 1990: Sea ice velocity measurements by upward-looking Doppler current profilers. J. Atmos. Oceanic Technol., 7, 596-602.

Cavalieri, D., C. Parkinson, P. Gloerson, and H.J. Zwally. 1997, updated 2005. Sea ice concentrations from Nimbus-7 SMMR and DMSP SSM/I passive microwave data. Boulder, CO, USA: National Snow and Ice Data Center. Digital media.

Fofonoff, N., and R. J. Millard, 1983: Algorithms for computation of fundamental properties of seawater. UNESCO Technical Papers in Marine Science 44, 53 pp.

Hofmann, E. E., J. M. Klinck, C. M. Lascara and D. A. Smith, 1996: Water mass distribution and circulation west of the Antarctic Peninsula and including Bransfield 
Strait. Antarctic Research Series, Foundations for Ecological Research West of the Antarctic Peninsula, 70, 61-80.

Howard, S. L., J. Hyatt and L. Padman, 2004: Mixing in the pycnocline over the Western Antarctic Peninsula shelf during Southern Ocean GLOBEC. Deep-Sea Res. II, 51(1719), 1965-1980.

Hudson, R., 1990: Annual measurements of sea-ice thickness using an upward-looking sonar. Nature, 344, 135-137.

Marshall, G., 2002: Trends in Antarctic Geopotential Height and Temperature: A comparison between Radiosonde and NCEP-NCAR Reanalysis data. J. Climate, 15, 659-674.

Melling H., Johnston P.H., Riedel D.A., 1995: Measurements of the underside topography of sea-ice by moored subsea sonar. J. Atmos. Oceanic Technol., 12, 589602.

Moffat, C., R. Beardsley, R. Limeburner, B. Owens, M. Caruso, and J. Hyatt, 2005: Southern Ocean GLOBEC Moored Array and Automated Weather Station Data Report. WHOI Technical Report 05-XX, in review.

Perovich, D.K. B.C. Elder, K.J. Claffey, S. Stammerjohn, R. Smith, H.R. Krouse, A.J. Gow and S.F. Ackley, 2004: Winter sea ice properties in Marguerite Bay, Antarctica. Deep-Sea Res. II, 51(17-19), 2023-2040.

RDI-Primer, 1996: Acoustic Doppler current profiler principles of operation: A Practical Primer. Tech. rep., RD Instruments, San Diego, CA.

Smith, D. A., E. E. Hofmann, J. M. Klinck and C. M. Lascara, 1999: Hydrography and circulation of the West Antarctic Peninsula continental shelf. Deep-Sea Res. II, 46, 925-949.

Strass, V., 1998: Measuring sea ice draft and coverage with moored upward looking sonars, Deep-Sea Res., 45, 795.

Vinje, T., Nordlund, N. and A. Kvambekk, 1998: Monitoring ice thickness in the Fram Strait. J. Geophys. Res., 103(C5), 10,437-10,449.

Visbeck, M., and J. Fischer, 1995: Sea surface conditions remotely sensed by upwardlooking ADCPs. J. Atmos. Oceanic Technol., 12, 141-149. 


\section{Chapter 4}

\section{Characterization of sea ice cover, motion and dynamics in Marguerite Bay, Antarctic Peninsula}

\subsection{Introduction}

The Southern Ocean Global Ocean Ecosystems Dynamics Southern Ocean (SO GLOBEC) project has chosen the continental shelf of the western Antarctic Peninsula (wAP) for study due to its unusually high concentration of Antarctic Krill (Euphasia superba) and the predator populations supported such as penguins, seals, and whales. SO GLOBEC aims to determine what conditions favor the reproduction, recruitment, and retention of krill populations, including ice cover (high ice versus low ice years), on-shelf intrusion of warmer nutrient rich waters and subsequent vertical mixing, and a sluggish cyclonic circulation. A number of features differentiate the wAP shelf from a typical mid-latitude shelf, e.g., the North American Middle Atlantic Bight, in addition to those mentioned above. The wAP shelf is about twice as deep (500 m, see Figure 4.1.1), and has the zonally uninterrupted Antarctic Circumpolar Current (ACC) flowing along the shelf break. The surface waters above about $100 \mathrm{~m}$ show a strong seasonal signal. They become warmer and slightly fresher in summer as a result of the positive surface heat flux and resulting ice melt. In fall, they cool rapidly and become saltier as they mix down into the remnant Winter Water. Finally, the shelf is nearly fully covered with ice in winter, and almost totally ice free in summer. 


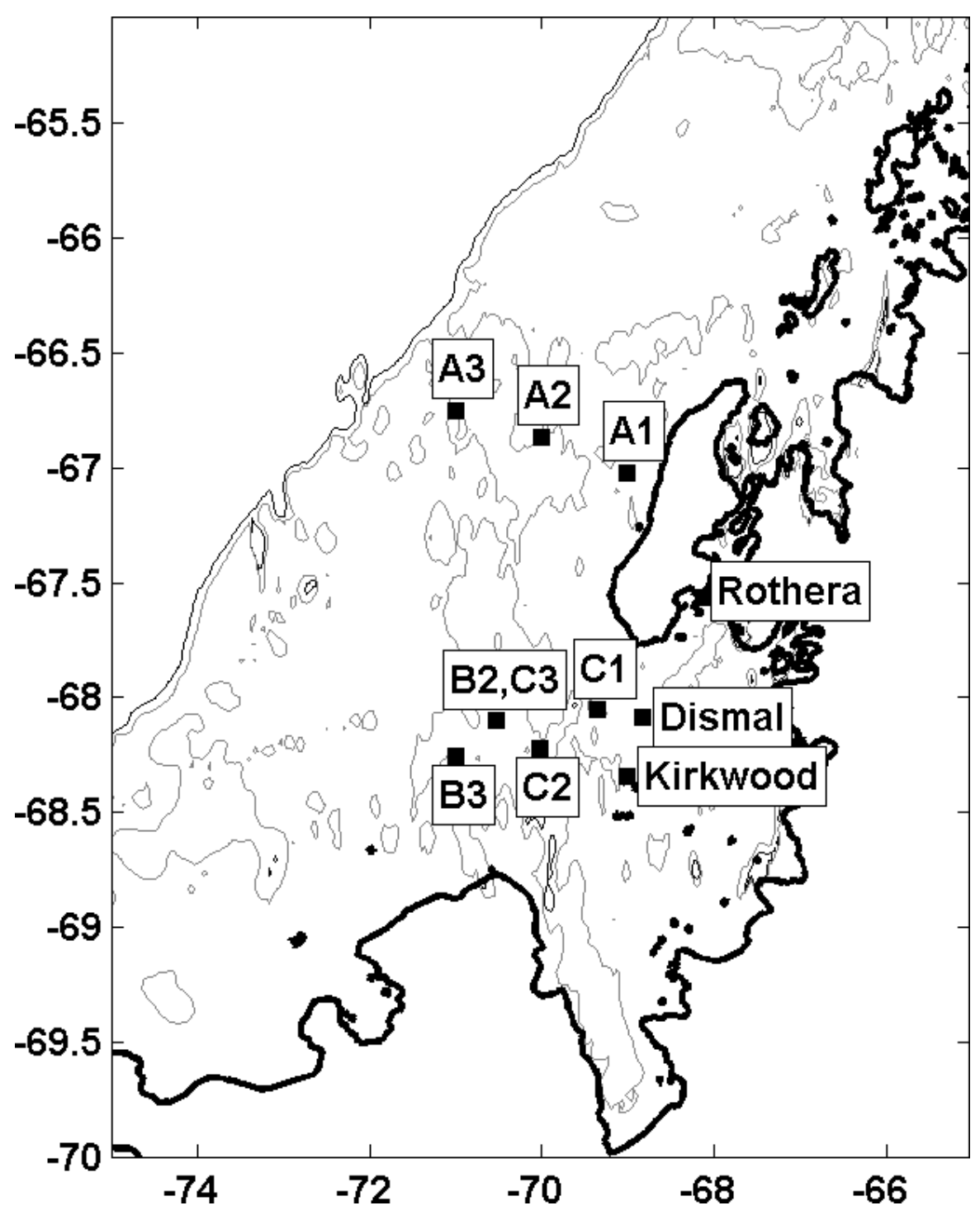

Figure 4.1.1 Marguerite Bay region of the western Antarctic Peninsula shelf. The moorings and weather stations are shown by their name (e.g., $\mathrm{C} 1$ and Dismal, respectively). The thick black line represents the coast and approximate position of the permanent ice shelf, and the 500-m and 1000-m isobaths are shown, with the latter being the location of the shelf break.

The presence of sea ice has a strong influence on the vertical transport of heat and momentum between the atmosphere and the ocean. One of the most biologically productive polynyas on the continent exists in Marguerite Bay (Arrigo and van Dijken, 2003). Furthermore, the presence of seasonal sea ice is believed to play a vital role in krill ecosystems throughout Antarctica (Quetin and Ross, 1991; Quetin et al., 1994; Siegel and Loeb, 1995). Finally, ice production has been found to be the main control on upper ocean stratification in Marguerite Bay (Meredith et al, 2004). Therefore, the 
characterization of the presence of sea ice, its thickness and motion in Marguerite Bay are important to the overall Southern Ocean GLOBEC goals.

The sea ice in the Marguerite Bay area has been shown to be strongly influenced by snow cover. Deep snow weighs down the ice and causes surface flooding as sea water percolates up through the ice. This leads to the formation of snow-ice which makes up a significant portion of the total ice (Perovich et al, 2004). This is typical of Antarctic ice, which tends to be deformed first-year ice with significant flooding and snow-ice formation. The existence of significant snow-ice without accurate precipitation data prevents the estimation of brine rejection since snow-ice introduces fresh water into the sea ice budget. Perovich et al (2004) also found evidence of significant ridging which suggests the importance of ice dynamics in the region. Outside of the Bay, on the outer shelf, Stammerjohn et al (2003) examined a winter period (1992) when sea-ice advance and retreat were both anomalously early. They found that the dynamics, as opposed to the thermodynamics, initiate, and thereby dominate, the production of ice-edge anomalies.

This chapter begins with a brief description of the unique data set available from the first moored time series of ice data on the wAP shelf, including ice concentration, draft and motion for two winter seasons in 2001-2003. We refer to the austral winter of 2001-2002 as the 'first season', and the austral winter of 2002-2003 as the 'second season'. Then some relevant aspects of the observed meteorology are presented. We show time series of ice coverage and draft for both seasons. We start with a comparison of the seasonal cycle between the outer shelf and Marguerite Bay during the first year. We then compare the ice during the two seasons at the same location in the Bay and examine both the onset and break-up of the seasonal ice cover. These comparisons along with historical data are used to characterize sea ice in Marguerite Bay. Next, we examine the motion of the ice and how it relates to the wind and ocean forcing. We accomplish this by examining progressive vector diagrams and calculating the full linear momentum balance. Finally, we consider the energetic near-inertial band of motion in both the seaice and upper ocean. 


\subsection{Dataset}

The Southern Ocean GLOBEC program collected data using a wide variety of instruments. This work focuses on data collected by moored instruments, satellites and Automatic Weather Stations.

\subsubsection{Mooring Data}

A total of nine subsurface moorings were deployed, six the first year 2001-2002 (A1, A2, A3, B1, B2, B3), and three the second year 2002-2003 (C1, C2, C3), with the locations and names shown in Figure 4.1.1. The moorings were deployed during the icefree season and recorded data during the formation and subsequent breakup of the seasonal sea ice. The instrumentation was relatively successful in enduring the ice on the wAP shelf. One upward-looking sonar (ULS) provides data on the evolution of the ice draft at A2. Upward-looking broadband acoustic Doppler current profilers (ADCPs) successfully measured currents and ice coverage, draft and velocity at the B2, C1 and C3 sites. The B2 and C3 moorings were collocated and give a two-year time series, while the $\mathrm{C} 1$ and $\mathrm{C} 3$ mooring were separated by $49 \mathrm{~km}$ and provide a look at the spatial variability within the Bay. The A2 ULS allows a comparison between its location at midshelf and the B2 site $139 \mathrm{~km}$ away in the Bay itself. The ice data were derived from the ADCP data using the method described by Hyatt et al (2005) (Chapter 3). The drafts have an uncertainty of $\pm 0.20 \mathrm{~m}$ during midwinter and $\pm 0.40 \mathrm{~m}$ when the base of the mixed layer is above the ADCP (spring and fall). Conductivity and temperature sensors at various depths provide data on the evolution of vertical stratification. Pressure sensors were used to observe tides and to remove atmospheric effects when estimating ice draft (time mean pressure of 813, 254 and $236 \mathrm{dbar}$ at B2, C3 and C1, respectively). The total water depths at the sites were 808 and 432 at B2/C3 and C1, respectively. The reader is referred to the moored array technical report (Moffat et al, 2005) for more details about the moored data collected in the SO GLOBEC program

\subsubsection{Satellite Data}

Sea ice concentration maps, concentrations at A2 and longer term data (19782002) were extracted from the Cavalieri et al. (1997) Nimbus-7 SMMR and DMSP 
$\mathrm{SSM} / \mathrm{I}$ passive microwave data provided on CD by the National Snow and Ice Data Center (NSIDC).

\subsubsection{Automatic Weather Station Data}

Two Automatic Weather Stations (AWSs) were deployed in Marguerite Bay in close proximity to each other to provide redundancy in case of failure, as well as the ability to check for failure by intercomparison. The stations were located on small rocky islets named Kirkwood Island and Dismal Island and had sensor heights of 12 and $25 \mathrm{~m}$ above mean sea level, respectively, and were separated by $29 \mathrm{~km}$ (Figure 4.1.1). They transmitted their data via ARGOS satellites to the Antarctic Meteorological Research Center at the University of Wisconsin, where the data were processed into a time series of atmospheric pressure, temperature, relative humidity, and wind speed and direction with an averaging interval of 10 minutes. The data were then edited and averaged to construct time series with hourly resolution. The Kirkwood and Dismal atmospheric pressure data agreed to within $1 \mathrm{mb}$ after adjustment for the difference in sensor height. The Dismal station was slightly closer to the moorings $(78 \mathrm{~km}, 12 \mathrm{~km}$ and $38 \mathrm{~km}$ from A2, C1 and $\mathrm{B} 2 / \mathrm{C} 3$, respectively) so it was used in this study. The COARE 2.6 algorithm (Fairall et al, 2003) was used to calculate wind stress. The reader is referred to Moffat et al, (2005) for a detailed description of the AWS instrumentation and data processing, and to Beardsley et al. (2006) for an in-depth analysis of the local meteorology.

The meteorological variables significant to the sea ice are the wind forcing and air temperature. The strong wintertime winds tended to blow towards the southwest, out of the Bay during both years, with light and variable winds in between. Taking all wind events with a wind stress magnitude greater than $0.2 \mathrm{~N} / \mathrm{m}^{2}$ and blowing towards the southwestern quadrant, we find 44 in the first ice season, and 23 in the second ice season. These winds also tended to be relatively warm, averaging $-2.5^{\circ} \mathrm{C}$ the first season and $3.3^{\circ} \mathrm{C}$ the second season, but still cold enough for strong air-sea interaction. The average wind stress during these events was $0.5 \mathrm{~N} / \mathrm{m}^{2}$ both years. Thus, the first observed ice season had more frequent strong forcing events. 


\subsection{Sea ice cover and draft.}

\subsubsection{Austral winter 2001-2002}

For the first season a comparison between the A2 and B2 sites was possible. The A2 mooring was placed on the wAP shelf $61 \mathrm{~km}$ from the coast and $139 \mathrm{~km}$ away from the B2 mooring, which was deployed at the mouth of Marguerite Bay, in the axis of the deep Marguerite Trough (Figure 4.1.1). Figure 4.3.1a shows ice drafts, which have been boxcar filtered with a 24-hour window. The drafts are the same (within experimental uncertainties) between July and early October. The drafts grow steadily to $1 \mathrm{~m}$ by the end of July, nearly $2 \mathrm{~m}$ by the end of August and over $2 \mathrm{~m}$ by the end of September. In October, the ice continues to thicken at B2 but starts to retreat at A2.

The 2-minute sampling of the A2 ULS shows the finer details of the ice cover (gray shaded area in Figure 4.3.1a), including 4 ice keels greater than $10 \mathrm{~m}$ (one just missing the ULS at $45 \mathrm{~m}$ ), which are presumably icebergs. Furthermore, frequent deep keels greater than $5 \mathrm{~m}$ suggest significant ice convergence and associated ridging at the mid-shelf site, as these drafts are unattainable with simple thermodynamic ice production. The B2 site also experienced deep ice drafts, with daily averaged ice drafts of up to $5 \mathrm{~m}$ observed during late October/early November. 

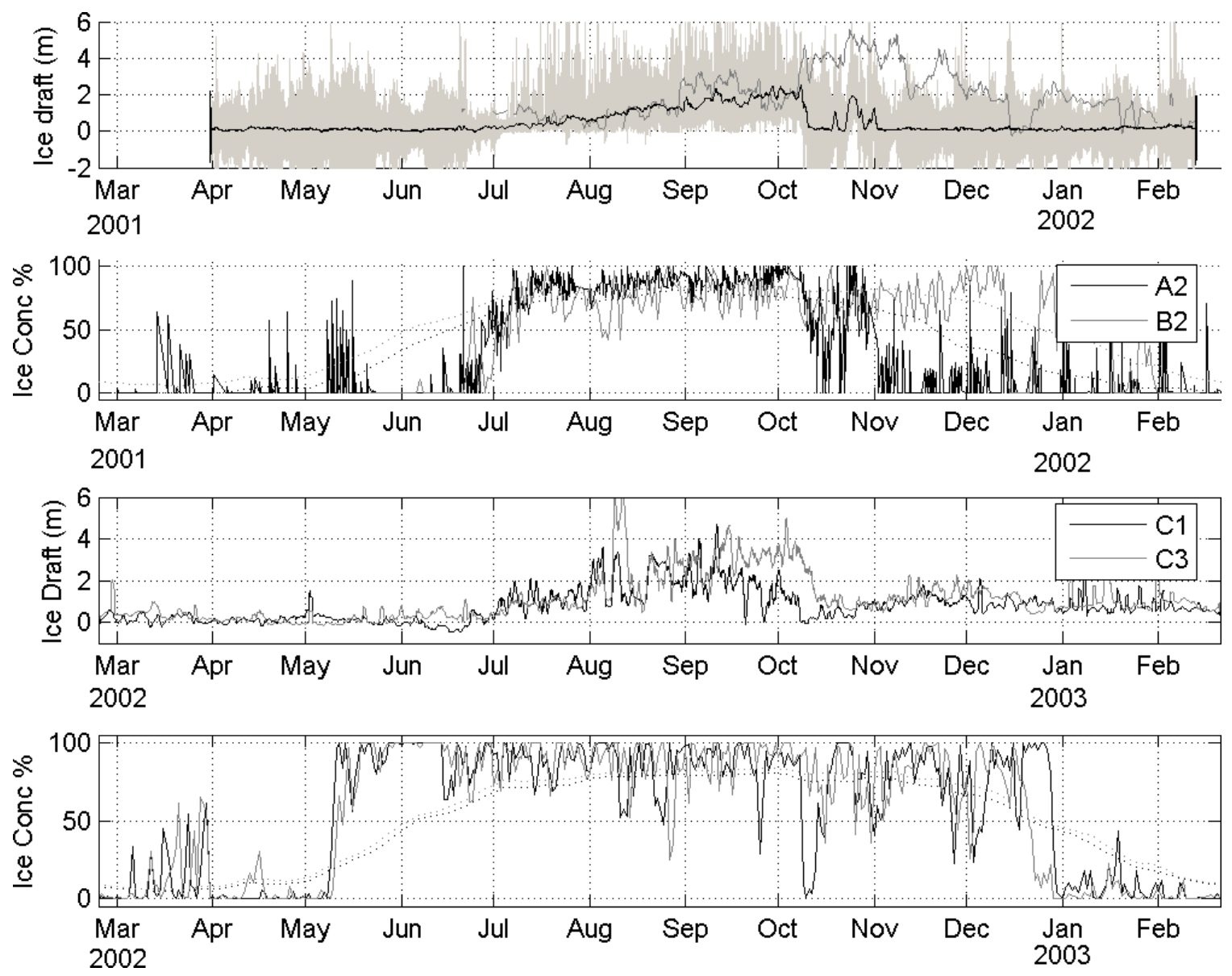

Figure 4.3.1 Daily averaged (a) ice draft and (b) concentration during the first season at the A2 (black) and B2 (grey) mooring sites; daily averaged (c) ice draft and (d) concentration during the second season at the $\mathrm{C} 1$ (black) and $\mathrm{C} 3$ (grey) mooring sites. In (a), the shaded grey area shows the range of the 2-minute measurements taken by the ULS at A2. The large variability in range shown before the onset of ice in July and after the ice retreat in October/November is due to surface waves. In (b), the ice concentrations at A2 site were measured by SSMI satellite. In (b) and (d), the dotted lines represent the weekly climatology of ice concentration. Note that (a)-(d) refer to top to bottom panels, respectively.

Figure 4.3.1b shows the daily averaged ice concentration at the A2 and B2 sites, with a weekly-binned climatology derived from the NSIDC data plotted as dotted lines. The ice concentrations at the A2 site were measured by SSMI satellite, as the ULS does not measure ice concentration in the same manner as the ADCP (Hyatt et al, 2005). The ice covered the mooring sites at about the same time, but the ice remained for about 2.5 months longer in the Bay near B2. The meteorological forcing measured by the AWSs within the Bay is not necessarily representative of that on the shelf. Therefore we cannot confidently explain the shorter ice coverage at A2. However, based on the long-term NSIDC ice concentration data, ice typically lasts approximately 1 to 2 months longer at 
B2 than A2 (dotted lines in Figure 4.3.1b). At B2, the ice covered the mooring site in early July and remained until mid-December. The ice cover in late December and January of the first season was isolated to southern Marguerite Bay, as revealed by the NSIDC satellite data (not shown), just barely reaching the mooring site. Although ice was not present at the mooring site for December/January of the previous year in the NSIDC data, the satellite record shows it frequently extended to the mooring site at that time of year.

Overall, the sites are similar until mid-October, when the ice retreats from the mid-shelf site (with a brief return a few weeks later), but thickens dramatically at B2. The ice retreats from B2 in mid-December, only to return again for a short period. This produces a climatologically short ice-free season in the Bay, as described later in this chapter.

\subsubsection{Austral winter 2002-2003}

In the second season, two moorings ( $\mathrm{C} 1$ and $\mathrm{C} 3)$ in the mouth of Marguerite Bay provide time series of ice cover and draft with a $49-\mathrm{km}$ separation. $\mathrm{C} 1$ was further into the Bay, almost due east of $\mathrm{C} 3$ (Figure 4.1.1). Figure 4.3.1c shows ice draft at the two sites, which have been boxcar filtered with a 24-hour window, and Figure 4.3.1d shows the daily averaged ice concentrations with the NSIDC-based weekly climatology shown by the dotted lines.

At $\mathrm{C} 1$, the ice covered the mooring site in mid-May and remained until late December, with daily averaged ice drafts of up to $4 \mathrm{~m}$ observed during late October/early November. At C3, ice also covered the mooring site in mid-May and remained until late December. There, daily averaged ice drafts of 2-3 $\mathrm{m}$ were observed from mid-August through mid-October. Around October 12 the ice broke up, and the ice draft dropped dramatically to $\sim 1 \mathrm{~m}$ at both sites. In addition, the ice concentration dropped somewhat at both sites, but still remained above $60 \%$ for most of the remaining ice season.

The drafts at $\mathrm{C} 1$ and $\mathrm{C} 3$ are the same (within observational uncertainties) except for a period in August with 5-6 m drafts at the $\mathrm{C} 3$ mooring and from mid-September through mid-October when the ice draft at $\mathrm{C} 3$ was 1-2 $\mathrm{m}$ larger than at $\mathrm{C} 1$. Ice first appears at the $\mathrm{C} 3$ mooring 3 days after the $\mathrm{C} 1$ mooring, and retreats from the $\mathrm{C} 3$ site 7 
days before $\mathrm{C} 1$. The ice cover at the two sites has a correlation coefficient of 0.85 , and the ice draft has a correlation coefficient of 0.67 .

A polynya appeared for a short period at the $\mathrm{C} 1$ site around October 12, 2002, but did not extend to C3. The polynya was also apparent in satellite imagery (Figure 4.3.2a) which showed a short-lived area of low ice cover. The moored observations clearly show that the polynya did not extend to the $\mathrm{C} 3$ mooring site, despite the ambiguity in the NSIDC satellite data. This event is described in greater detail in section 3.4. 
(a)
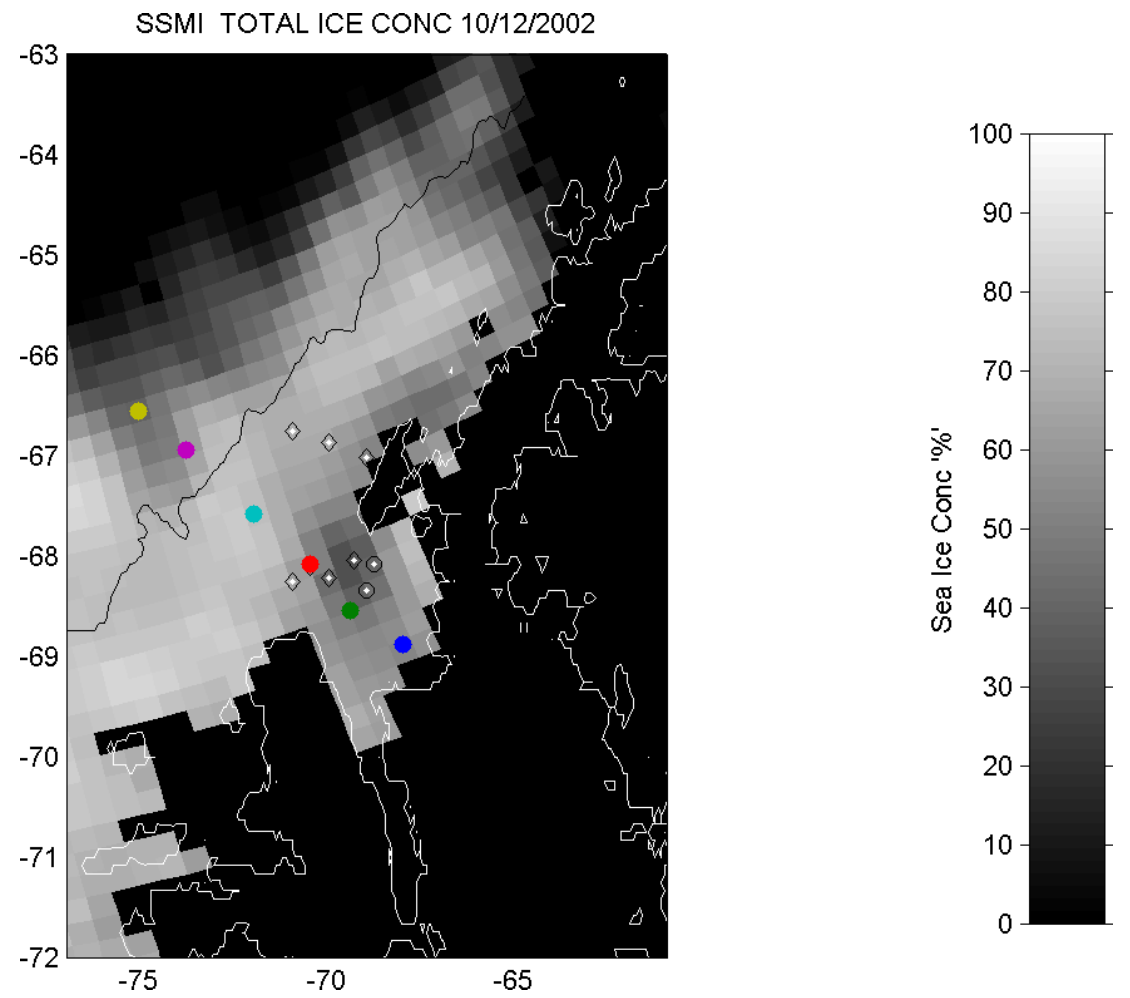

(b)

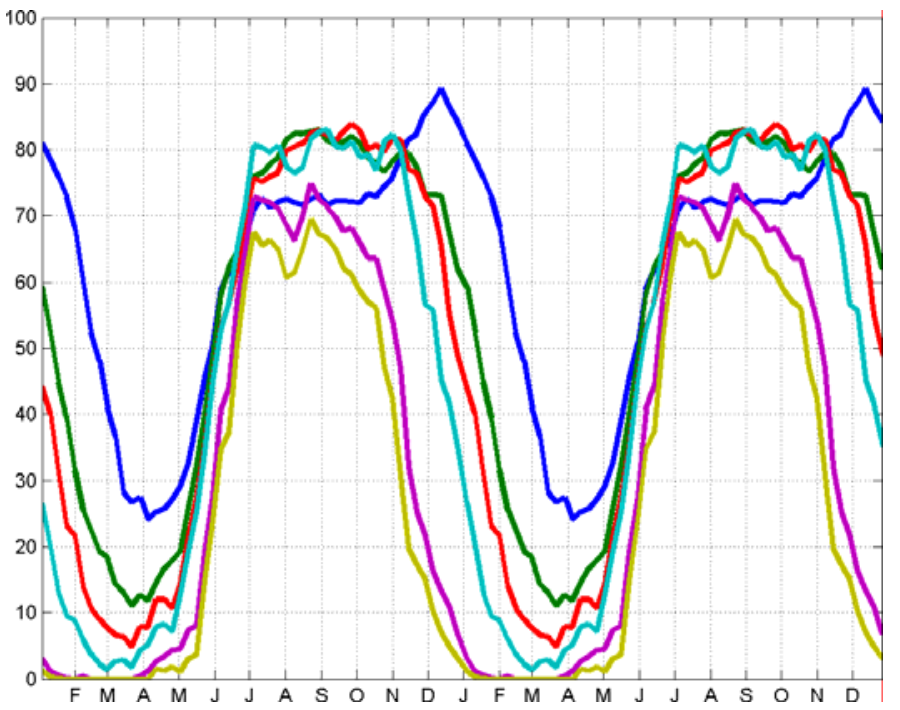

Figure 4.3.2 (a) NSIDC satellite-derived sea ice concentration data on October 12, 2002 show the area of low ice concentration around the $\mathrm{C} 1$ site, which did not extend to the $\mathrm{C} 3$ site. (b) Weekly climatological transect of ice coverage in at six points, with the colors corresponding to locations of the colored dots in (a). The climatology has been repeated for clarity and is based on the period of 1978-2002. 


\subsubsection{Interannual comparison of sea ice cover and draft}

The collocation of the $\mathrm{B} 2$ and $\mathrm{C} 3$ moorings provides an interannual comparison of the sea ice cover and draft independent of any spatial variability. Both years have roughly seven months of nearly complete ice cover, but the onset of ice formation is about two months earlier in 2002-2003 than in the previous year (Figure 4.3.1a and 4.3.1c). The early ice in $2002-2003$ can be explained by the large negative surface heat flux associated with cold air temperatures which came earlier than normal in early May. As shown in Figure 4.3.3, 2003 had the coldest May/June on record (since 1976). The climatology is based on temperature recorded at the British Antarctic Survey's Rothera station on the northern shore of Marguerite Bay, and is a good proxy for temperature in the center of the Bay (Beardsley et al., 2006). In both years, the ice cover gets above $60 \%$ only after the air temperature goes below $-9^{\circ} \mathrm{C}$. To further test the relationship between the first cold event in austral autumn and the onset of ice, we utilized the 19772003 air temperature data from Rothera station and the NSIDC ice concentration data. We compared the first date of $-9.2^{\circ} \mathrm{C}$ in a 3-day filtered temperature record and found it correlated to the first time that greater than 70\% 3-day filtered ice concentration occurred at the $\mathrm{B} 2 / \mathrm{C} 3$ site with a correlation coefficient of 0.81 . The standard deviation of the mismatch in the least-squares linear regression is 18 days. This suggests that local surface cooling is the dominant process in ice formation in the region. 


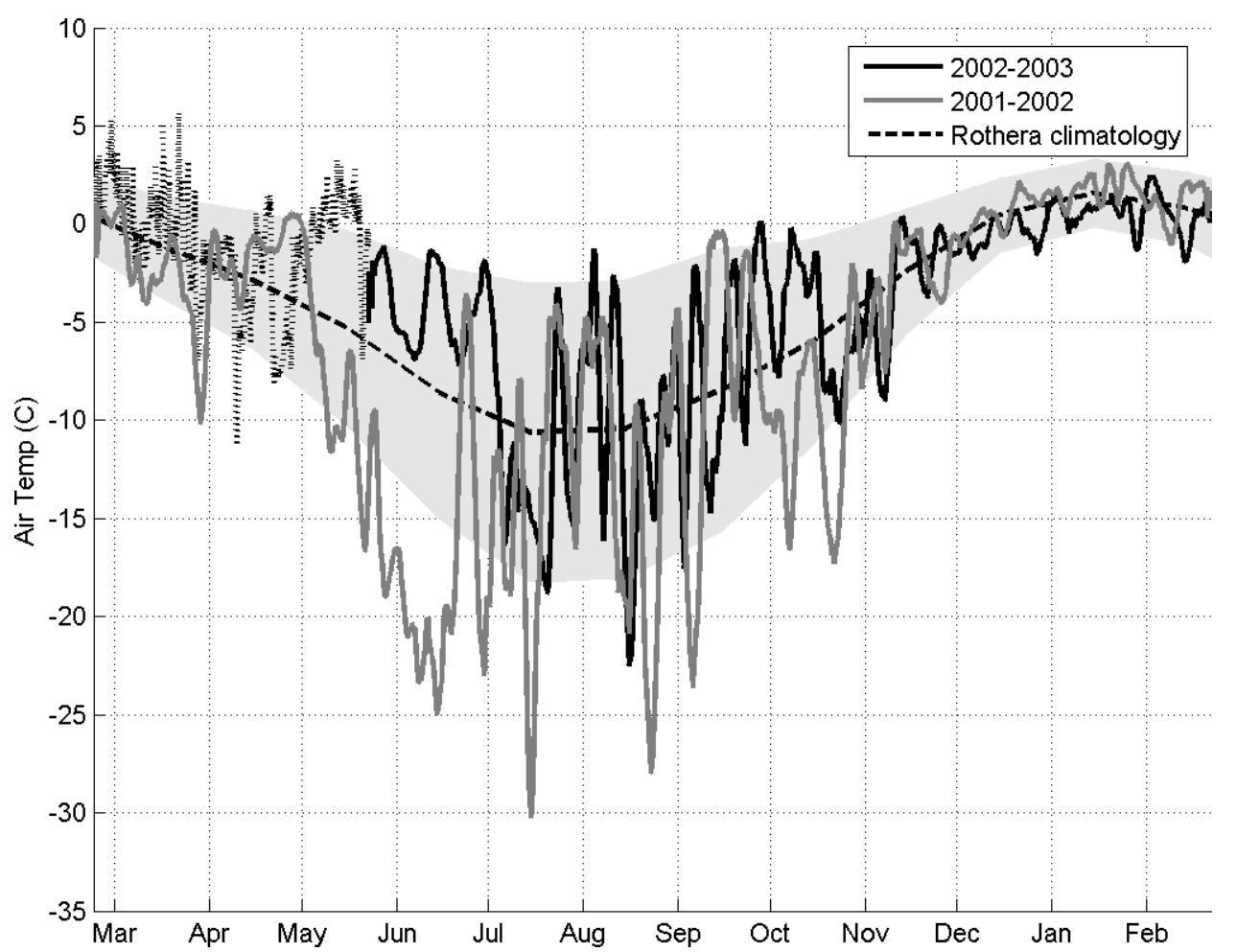

Figure 4.3.3 Air temperatures (24-hr box-filtered) measured at the AWS during the first season (gray) and second season (black). The dotted black line is the air temperature in 2001 recorded at the British Antarctic Survey Rothera station before the AWS was deployed. The monthly climatology based on measurements at Rothera for the period 1976-2003 is plotted as a dashed black line, with the light gray shaded area showing plus and minus one standard deviation.

A climatology of ice cover along a transect from within Marguerite Bay to beyond the shelf break provides further evidence of local ice formation (Figure 4.3.2b). The ice on the shelf forms at nearly the same time in June, with the off-shelf points following about two weeks later. The more gradual disappearance of ice, with the inshore points lagging the offshore ones, suggests that the ice does not melt locally, but rather breaks up and is advected away. A final piece of evidence which suggests local formation of ice in the Marguerite Bay region in the second season is found in the net surface heat flux (the sum of shortwave, longwave, sensible and latent fluxes) calculated from the shipboard meteorological data collected on the RVIB N.B. Palmer during a survey in the area (Figure 4.3.4). This shows that in the time preceding the onset of ice, the net surface heat flux averaged about $40 \mathrm{~W} / \mathrm{m}^{2}$ until May 3, 2002. Then there were six days of average heat loss in excess of $180 \mathrm{~W} / \mathrm{m}^{2}$ at which point the ice began to form, followed by six more days with an average heat loss of $260 \mathrm{~W} / \mathrm{m}^{2}$. If we assume that this heat loss went solely into ice production, the amount of ice formed during the May 3-9 
period would be $\sim 0.5 \mathrm{~m}$ thick and during the May 3-16 period would be $\sim 1.5 \mathrm{~m}$ thick. These large heat losses coinciding with the onset of sea ice imply local formation rather than advection into the region.

(a)

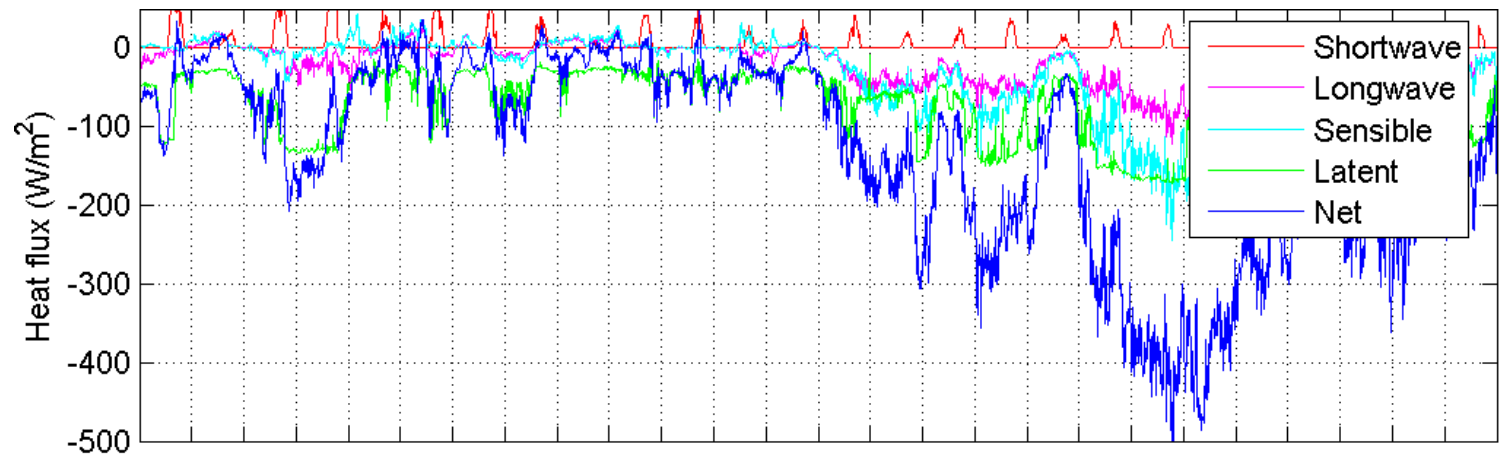

(b)

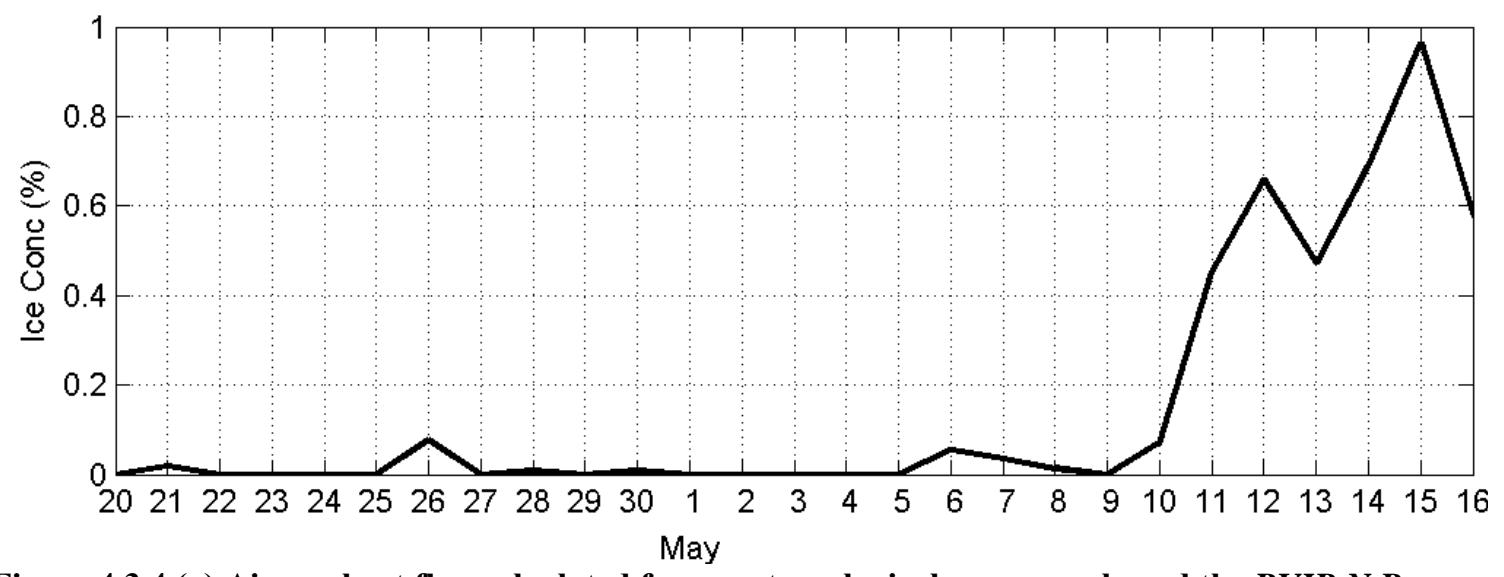

Figure 4.3.4 (a) Air-sea heat flux calculated from meteorological sensors onboard the RVIB N.B. Palmer, which was surveying the area and (b) sea ice concentration at $\mathrm{C} 3$ during the same period in 2002.

Both years have very thick ice, with extended periods (including one continuous month) with drafts over $3 \mathrm{~m}$. The thick ice occurs about one month earlier in 2002 than in 2001, which can be attributed to the early ice season. However, the month of highest ice draft had 1-2 m thicker draft in 2001.

The combination of late ice in December/January at the B2 site and early ice observed at the $\mathrm{C} 3$ site made for a relatively short ice-free period of only 3 months at the B2/C3 site. Historical NSIDC satellite data since 1978 show only four shorter ice-free seasons in 24 years. In 1980, ice remained at the B2/C3 site for the entire summer. 


\subsubsection{October 12, 2002 Polynya Event}

On October 12, 2002, a polynya opened up at $\mathrm{C} 1$ which did not extend to $\mathrm{C} 3$

(Figure 4.3.2a). A similar polynya was not observed in the NSIDC satellite data in 2001. The open area was about $50 \mathrm{~km}$ across and occurred during a strong westward wind event. This wind event, however, was not exceedingly strong for the region (Beardsley et al., 2006). The meteorological data and ice conditions surrounding the event are shown in Figure 4.3.5. The air-sea heat flux is the sum of the sensible and latent flux (Fairall et al, 2003) weighted by the open water fraction (assuming a sea surface temperature of $1.8^{\circ} \mathrm{C}$ ) and is meant to be a gross estimate to show that there is a large heat flux from the ocean to the atmosphere. Although not measured, the net radiative heat flux (long and shortwave) was presumably negative and possible quite large, based on the shipboard measurements shown in Figure 4.3.4(a), and would give an even larger negative surface heat flux. 

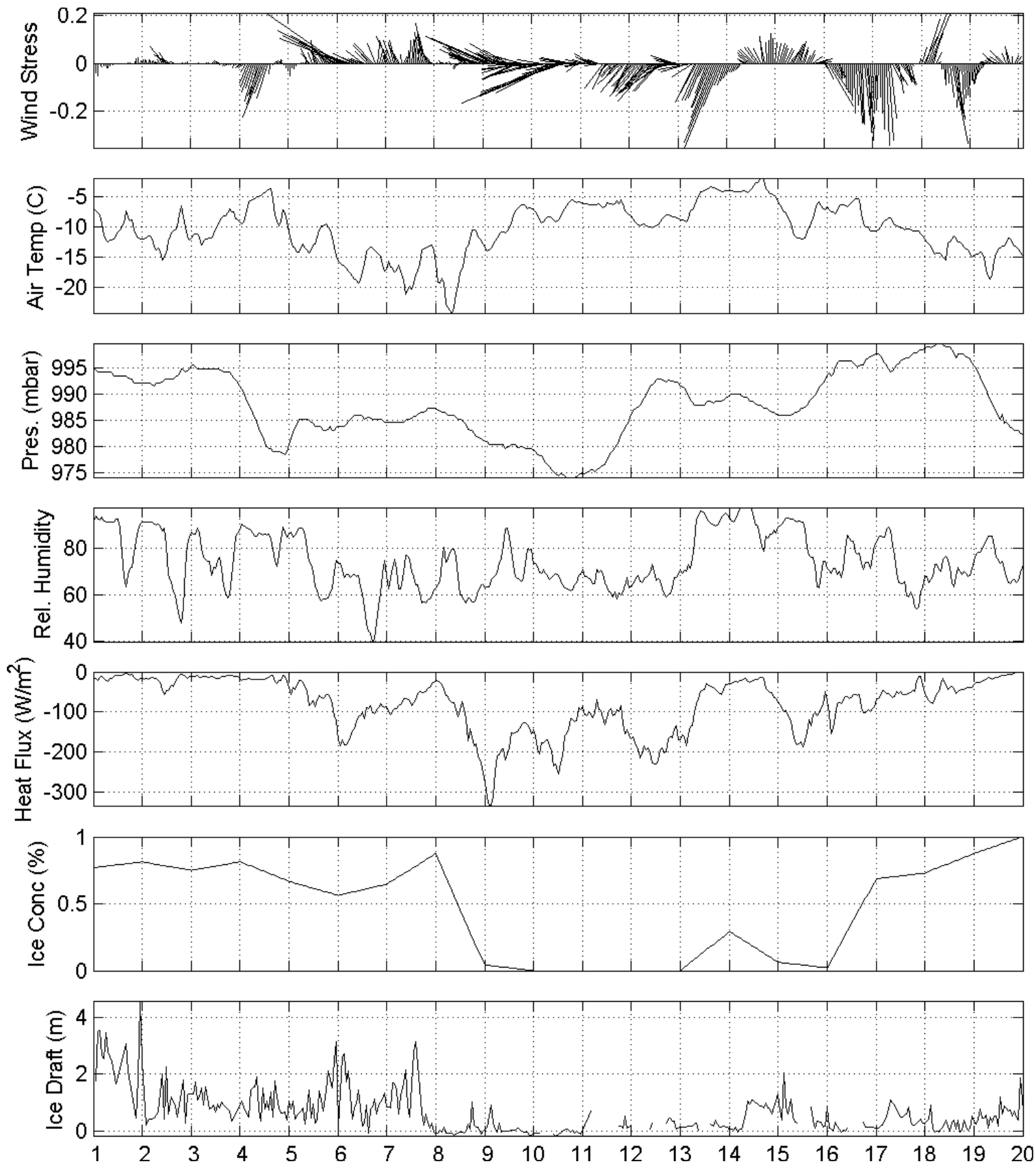

Figure 4.3.5 (a)-(d) AWS measurements surrounding the period of open water on October 12, 2002. Sensible and latent heat flux (e) into the ocean weighted by the open water fraction (see text for details), and ice concentration (f) and draft (g) derived from the ADCP at C1. Note that (a)-(g) refer to top to bottom panels, respectively.

The upper ocean at the $\mathrm{C} 1$ site responded strongly to the event. Direct exposure to the strong westward winds initiated a strong westward current of $15 \mathrm{~cm} / \mathrm{s}$ at $6 \mathrm{~m}$ below the bottom of the ice, which is quite energetic for the wintertime in the region. The upper $150 \mathrm{~m}$ cooled approximately $0.5^{\circ} \mathrm{C}$ in these two days, with effects observed down to 200 $\mathrm{m}$ (Figure 4.3.6). The strong cooling at the surface was presumably caused by the large 
net air-sea heat flux with the cold $\left(-10^{\circ}\right.$ to $\left.-5^{\circ} \mathrm{C}\right)$ atmosphere and strong winds. This was followed on October 14 by a sharp warming of about $1^{\circ} \mathrm{C}$. This warming could be associated with upwelling along the new ice edge due to a wind burst towards the north (e.g. Roed and Obrien, 1983).

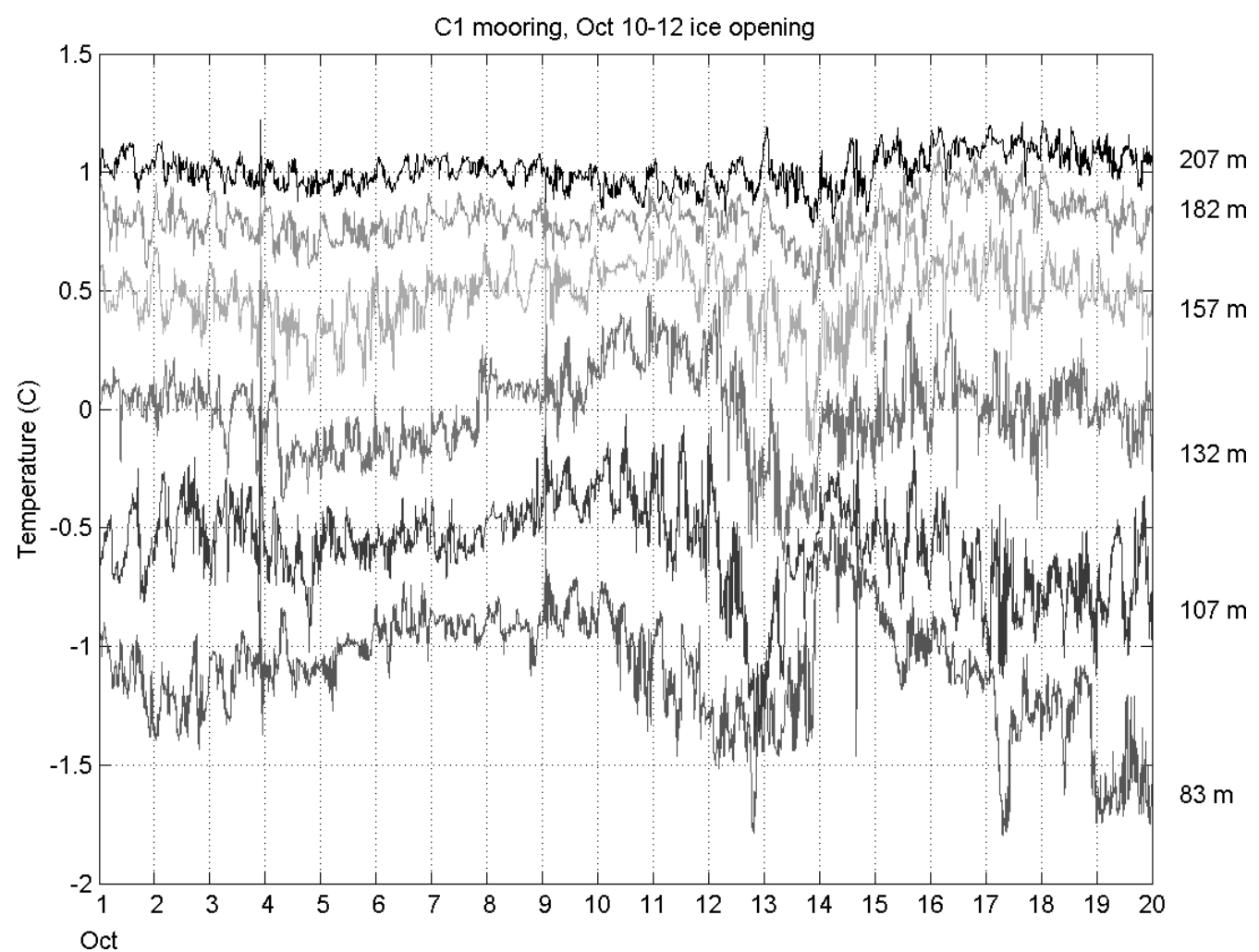

Figure 4.3.6 Upper ocean temperature response to the open water event at $\mathrm{C1}$ on 10-12 October, 2002. The depth of each temperature record is labeled on the right.

One possible explanation is that the ice broke along the edge of thicker ridged fast ice within the Bay. The ice draft at C3 declined significantly during the event, further evidence that the ice broke up. Evidence of this can be seen in two MODIS satellite images of the wAP shelf on (a) October 24, 2001 and (b) September 6, 2002 (Figure 4.3.7). The interior of the Bay contains ice which appears nearly solid. The mouth of the Bay and beyond, while having very high ice concentrations, contains large pieces of ice, with areas of broken ice in between, which could lower internal ice stresses and allow greater ice motion. 


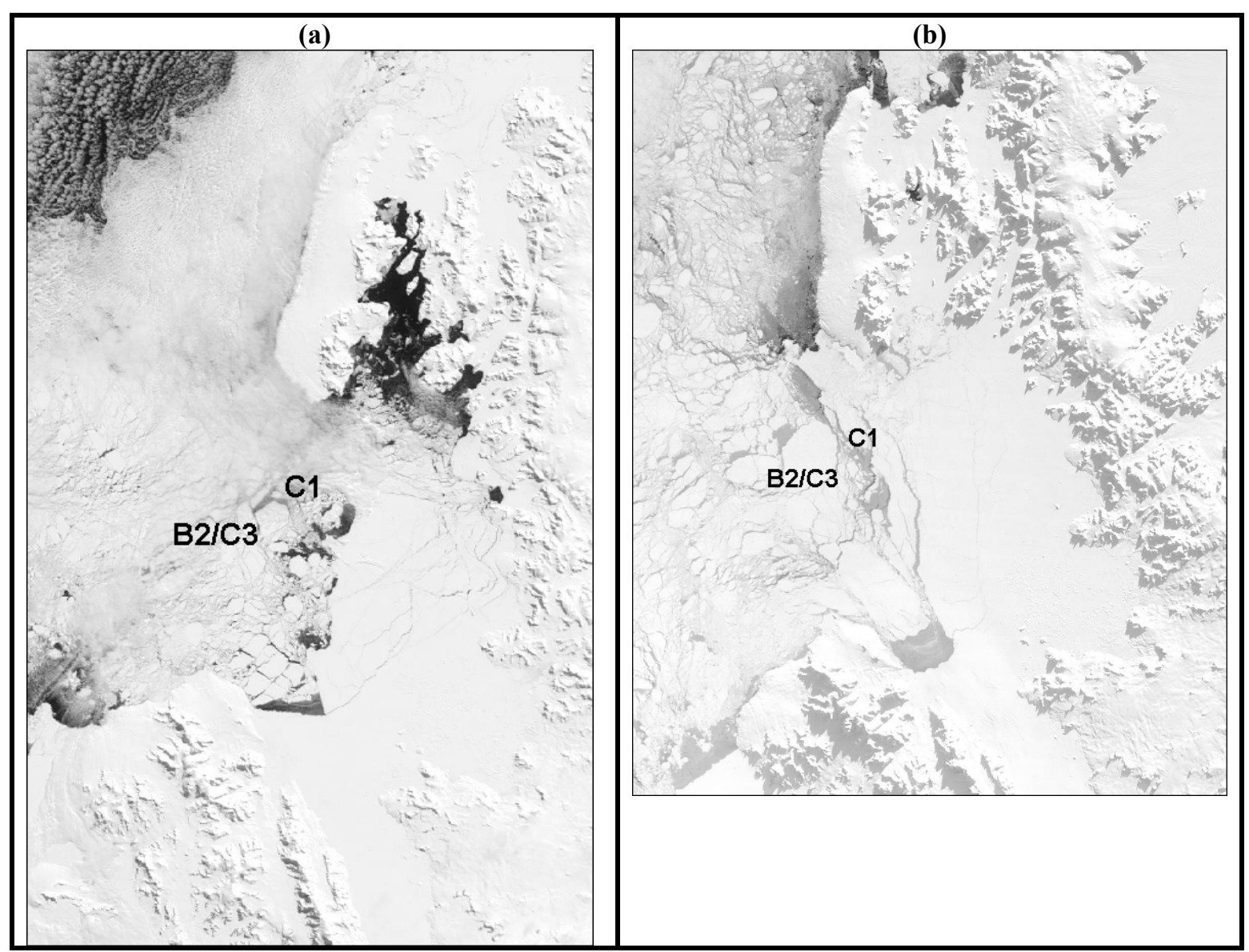

Figure 4.3.7 MODIS satellite images of the region on (a) October 24, 2001 and (b) September 6, 2002 and the approximate locations of the moorings.

\subsection{Ice Motion}

Ice motion was measured using an $\mathrm{ADCP}$ at the $\mathrm{B} 2, \mathrm{C} 1$ and $\mathrm{C} 3$ sites. Some statistics of this motion are given in Table 1. The statistics do not vary greatly from year to year and site to site. The average distance traveled in one day by the ice ranged from $9.6 \mathrm{~km}$ at the $\mathrm{C} 3$ site to $10.5 \mathrm{~km}$ at the $\mathrm{B} 2$ site, with an average ice speed ranging from $10.5 \mathrm{~cm} / \mathrm{s}$ at $\mathrm{C} 1$ to $12.9 \mathrm{~cm} / \mathrm{s}$ at B2. This motion was rarely unidirectional, so that the time-averaged net distance traveled per day was 6.6 and $7.6 \mathrm{~km}$ at the $\mathrm{C} 1$ and $\mathrm{C} 3$ sites, and $7.8 \mathrm{~km}$ at the $\mathrm{B} 2$ site. 


\begin{tabular}{|c|c|c|c|c|c|c|c|c|c|c|c|c|c|}
\hline Mooring & \multicolumn{2}{|c|}{$\begin{array}{c}\text { Distance traveled in a } \\
\text { day (km) }\end{array}$} & \multicolumn{10}{|c|}{$\begin{array}{c}\text { Average Daily } \\
\text { Displacement }(\mathrm{km})\end{array}$} & \multicolumn{2}{c|}{$\begin{array}{c}\text { Mean Daily-averaged } \\
\text { speed (cm/s) }\end{array}$} & $\begin{array}{c}\text { Days } \\
\text { of ice } \\
\text { cover } \\
>70 \%\end{array}$ \\
\hline & Mean & Std & Min & Max & Mean & Std & Min & Max & Mean & Std & Min & Max & \\
\hline B2 & 10.5 & 6.0 & 1.6 & 30.6 & 7.8 & 5.7 & 0.2 & 28.5 & 12.9 & 7.4 & 1.9 & 38.1 & 122 \\
\hline C1 & 8.8 & 8.2 & 1.5 & 44.3 & 6.6 & 7.5 & 0.2 & 39.2 & 10.5 & 9.8 & 1.7 & 53.0 & 189 \\
\hline C3 & 9.6 & 7.0 & 1.2 & 36.0 & 7.6 & 6.4 & 0.1 & 35.5 & 11.6 & 8.3 & 1.5 & 42.3 & 185 \\
\hline
\end{tabular}

Table 1: Ice velocity statistics.

Another way to present the motion of the ice and upper ocean is to use a progressive vector diagram (PVD). This integrates the Eulerian velocity in time assuming that it is spatially homogeneous, i.e. $\vec{x}=\int_{T_{1}}^{T_{2}} \vec{u} d t$, to give a synthetic particle trajectory. During the first season, the more frequent occurrence of strong southwestward winds caused a net southward ice motion at B2 (Figure 4.4.1a). At C3 during the second season, during the period of nearly solid ice pack (June 21, 2002 through December 20, 2002) the ice had almost no net motion, with the displacements remaining in a roughly $100 \mathrm{~km}$ by $100 \mathrm{~km}$ box (Figure 4.4.1b). The southward wind events push the ice southward, then the slow but steady northward ocean current returns the ice to near its position prior to the wind event. This suggests that the same ice remains in the $\mathrm{C} 3$ area for 6 months during the second season. 


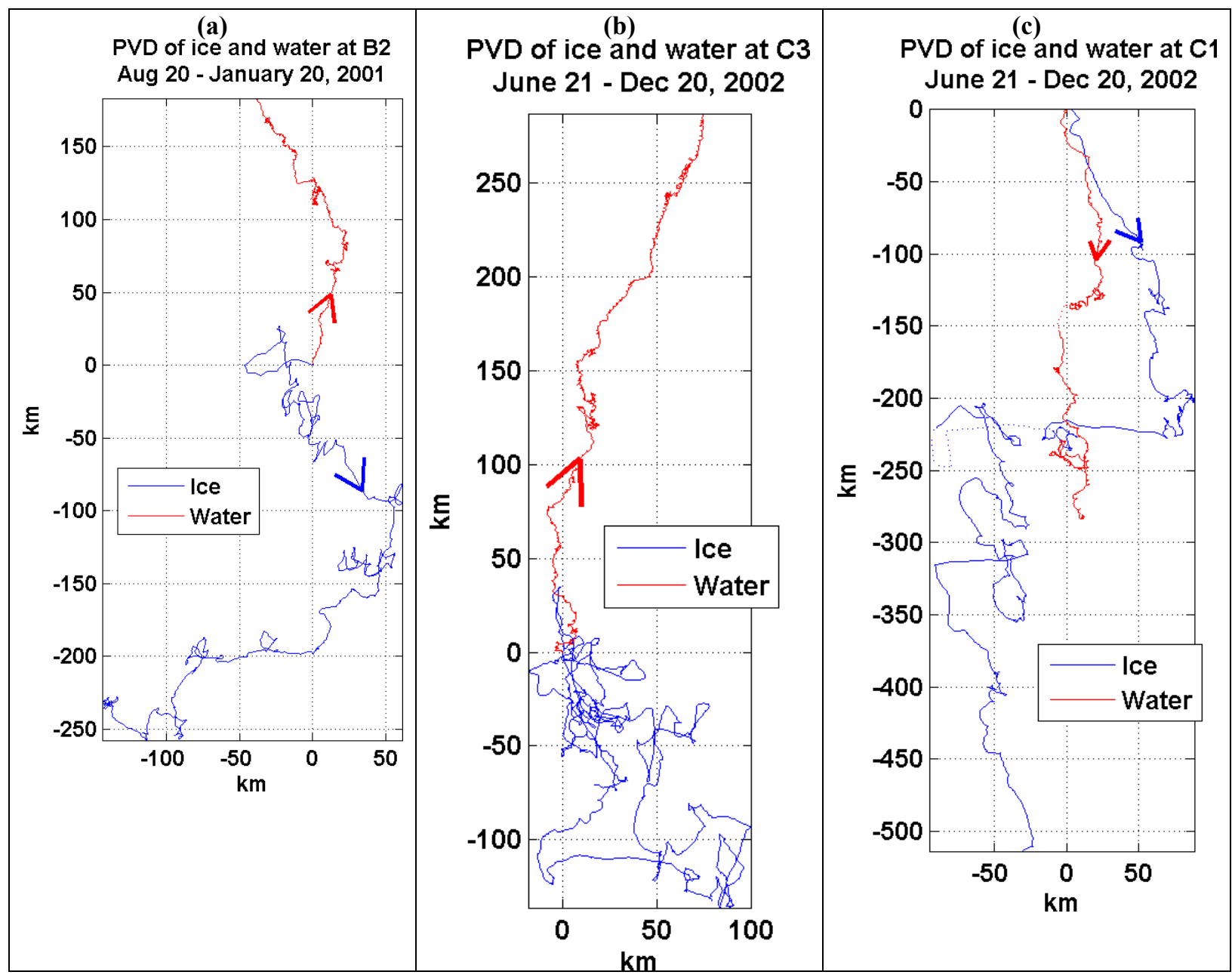

Figure 4.4.1 Progressive vector diagrams of (a) B2 (b) C3 and (c) C1 with ice shown in blue and the upper ocean shown in red. The time of isolated very low $(<10 \%)$ ice concentration at $\mathrm{C} 1$ is identified by the dashed line. The integrations begin at $(0,0)$.

The nearby $\mathrm{C} 1$ site exhibits entirely different behavior (Figure 4.4.1c). There, the ocean has a net southward drift, in the same direction as the strong winds. This suggests a strong southwestward ice drift over the winter, implying that the same ice does not remain at this site for the winter.

Inner rotary coherence spectra (Emery and Thomson, 2001) of the ice at $\mathrm{C} 1$ and C3 for the time series shown in Figure 4.4.1b and c show that the near-inertial motions are coherent in the ice. The left-turning rotary coherence squared in the frequency band from 12.21 to 13.75 hours, centered at 12.89 hours, (the inertial period at $69 \mathrm{~S}$ is 12.81 hours) is 0.59 with zero phase lag. The right-turning rotary coherence for the same band has low coherence, as do higher frequencies in both directions. 


\subsection{Momentum Balance in the Sea Ice}

A momentum balance vertically integrated from the bottom to the top of the ice can be estimated from the data available. Neglecting nonlinear advection, we represent this balance as

$$
\rho_{i} h_{i}\left[\frac{\partial \mathbf{u}_{i}}{\partial t}+\hat{k} \cdot\left(f \times \mathbf{u}_{i}\right)\right]=\rho_{i} h_{i} g \nabla \zeta+A\left(\overrightarrow{\tau_{a}}+\overrightarrow{\tau_{w}}\right)+\overrightarrow{F_{h}}
$$

where $\rho_{i}$ is the ice density, taken to be constant at $920 \mathrm{~kg} / \mathrm{m}^{3}$, assuming the ice is in hydrostatic balance, the ice thickness $h_{i}$ is the measured draft divided by the density ratio of ice to seawater, $\mathbf{u}_{i}$ is the ice velocity, $f$ is the Coriolis parameter, $\nabla \zeta$ is the sea surface slope, $A$ is the fractional area ice coverage, $\overrightarrow{\tau_{a}}$ and $\overrightarrow{\tau_{w}}$ are the air and water stresses on the ice, respectively, and $\overrightarrow{F_{h}}$ is the ice dynamics term (Hibler, 1979). Using geostrophy, the surface slope can be expressed in terms of the ocean geostrophic flow $\mathbf{u}_{\mathbf{g}}, \nabla \zeta=-\frac{1}{g}\left[\hat{k} \cdot\left(f \times \mathbf{u}_{\mathbf{g}}\right)\right]$. Assuming no geostrophic shear, we used the velocities at a deep current meter $(400 \mathrm{~m}, 232 \mathrm{~m}$ and $247 \mathrm{~m}$ at B2, C1 and C3, respectively) as a proxy for $\mathbf{u}_{\mathbf{g}}$, which is accurate to within $10 \%$ at $\mathrm{C} 3$, the only mooring where shear was measured. The water stress $\overrightarrow{\tau_{w}}$ is calculated using a quadratic drag law with a drag coefficient of 0.015 (based on Table 1 in Shirasawa and Ingram, 1991). No turning angles were used in the air or water stresses due to the close proximity of the measurements to the ice. Next, we assume complete ice cover and estimate the divergence of the internal ice stresses as the residual sum of the directly estimated terms, or $A \approx 1, \overrightarrow{F_{h}}=\nabla \cdot \vec{\sigma}$. Therefore, we only estimate the balance when the measured ice concentration exceeds $70 \%$. This leaves us with an expression for the momentum balance in the ice, where the residual of the measured terms is the divergence of the internal ice stresses.

$$
\rho_{i} h_{i}\left[\frac{\partial \mathbf{u}_{i}}{\partial t}+\hat{k} \cdot\left(f \times\left(\mathbf{u}_{i}-\mathbf{u}_{g}\right)\right)\right]=\overrightarrow{\tau_{a}}+\overrightarrow{\tau_{w}}+\nabla \cdot \vec{\sigma}
$$

Since the residual of the measured terms includes both the internal ice stresses as well as the sum of the errors in the estimated terms, this residual estimate should be used 
cautiously. We refer to the second term on the left hand side as the Coriolis/tilt term. The time series used to construct the momentum balance terms were low-pass filtered with a 33-hour window.

The momentum terms derived at B2 show a primary balance between wind stress and internal ice stresses, with ocean stresses taking a primary role at times, particularly early in the season (Figures 4.5.1 and 4.5.2). In July and early-August, strong ocean stresses on the ice are balanced primarily by internal ice stresses. Then, beginning in mid-August, there were many strong southward wind bursts (Beardsley et al., 2006), which are generally balanced by internal ice stresses. Overall, wind, ocean and ice stresses form the dominant balance, the Coriolis/tilt term plays a minor role at times and the acceleration term is not significant.

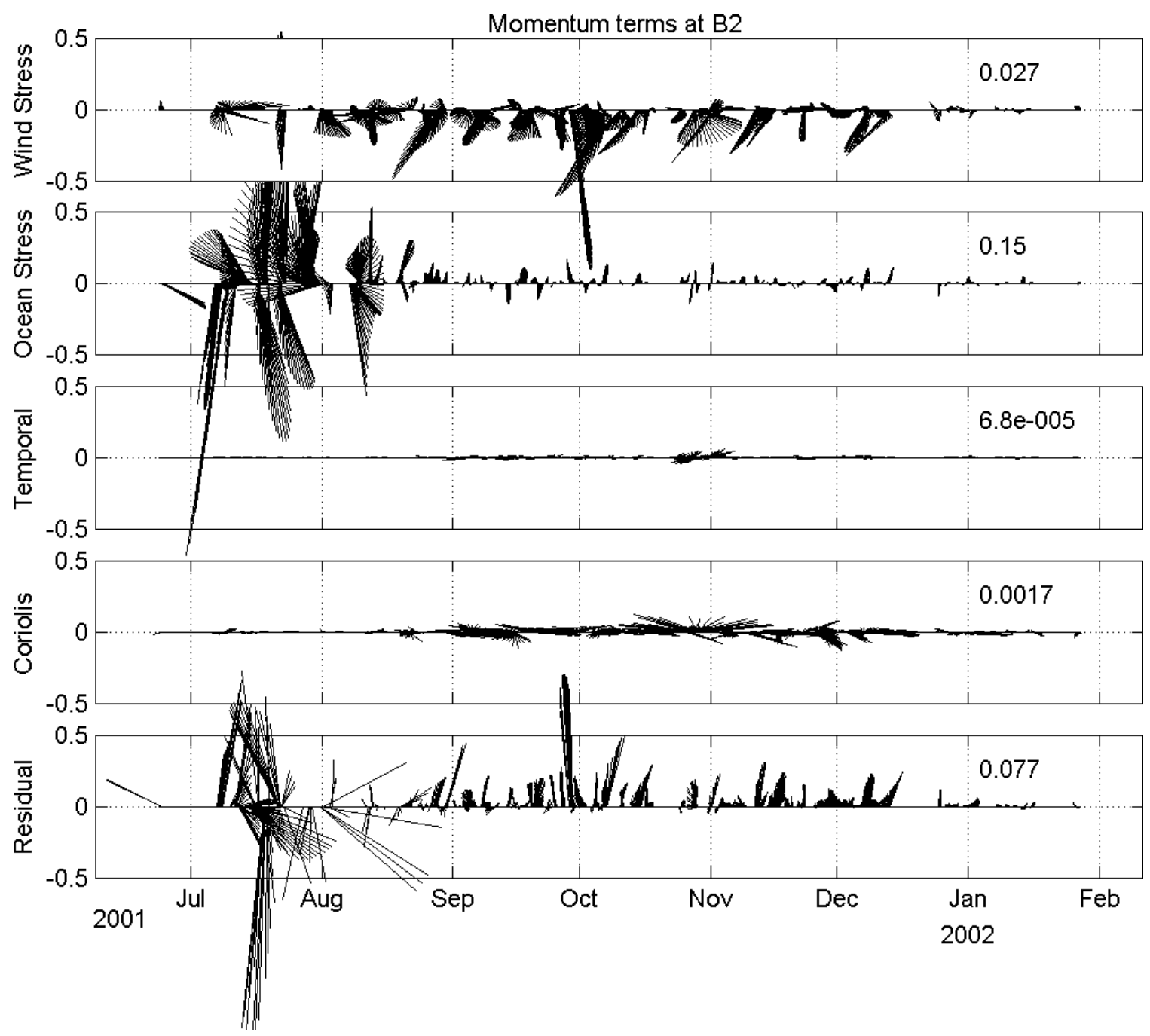

Figure 4.5.1 Momentum terms in ice at the $\mathrm{B} 2$ site. The variance of each term is shown in the upper right of each axis. 

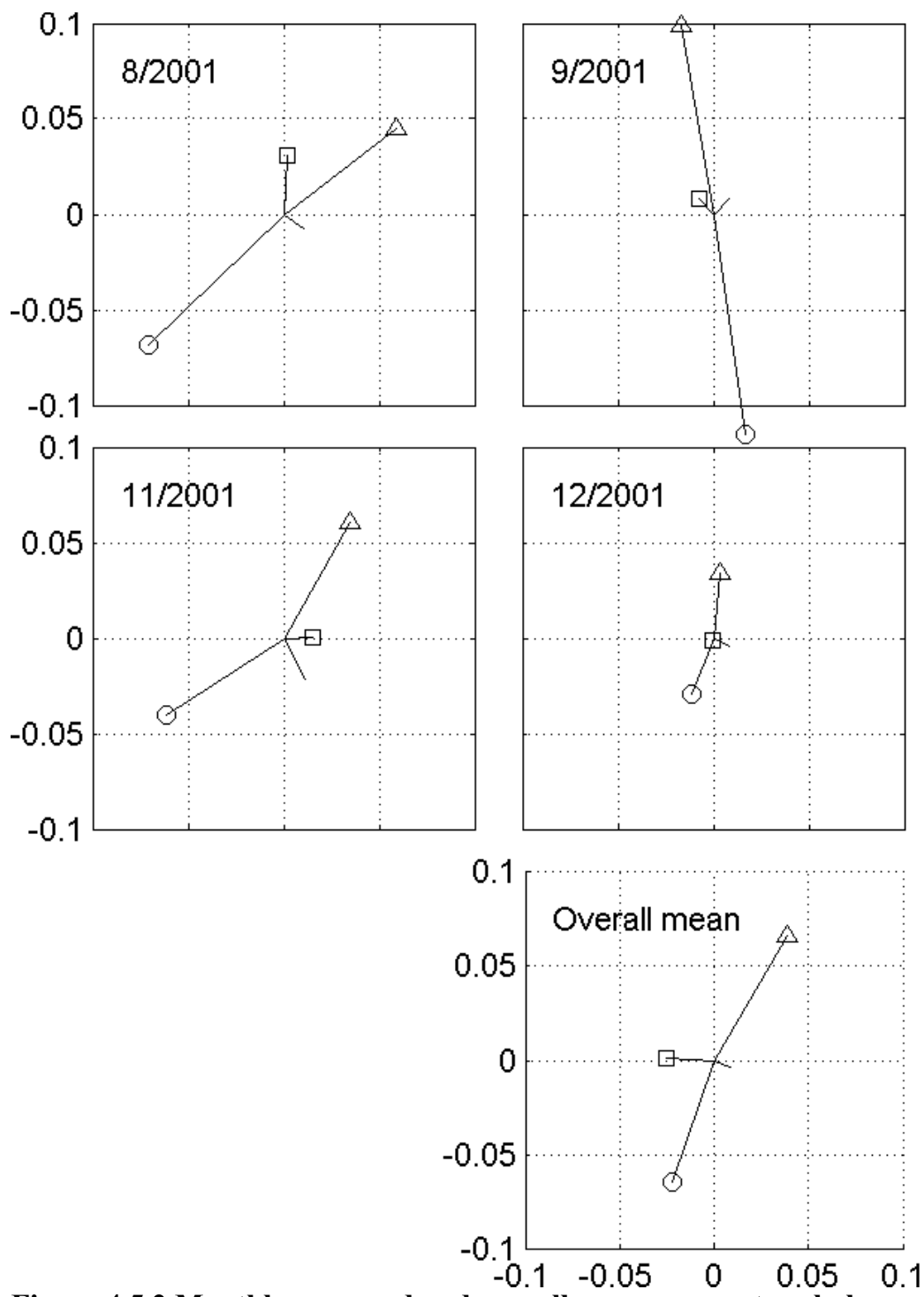

Figure 4.5.2 Monthly averaged and overall mean momentum balance at B2.

The following season at C3, the primary balance is between wind stress and internal ice stresses, with ocean stresses taking a primary role at times (Figures 4.5.3 and 4.5.4). In 2002 there were less frequent southward wind bursts, and all of the terms in the balance are generally smaller. Again, earlier in the season the ocean stress is more important. Overall, wind and ice stresses form the dominant balance. 

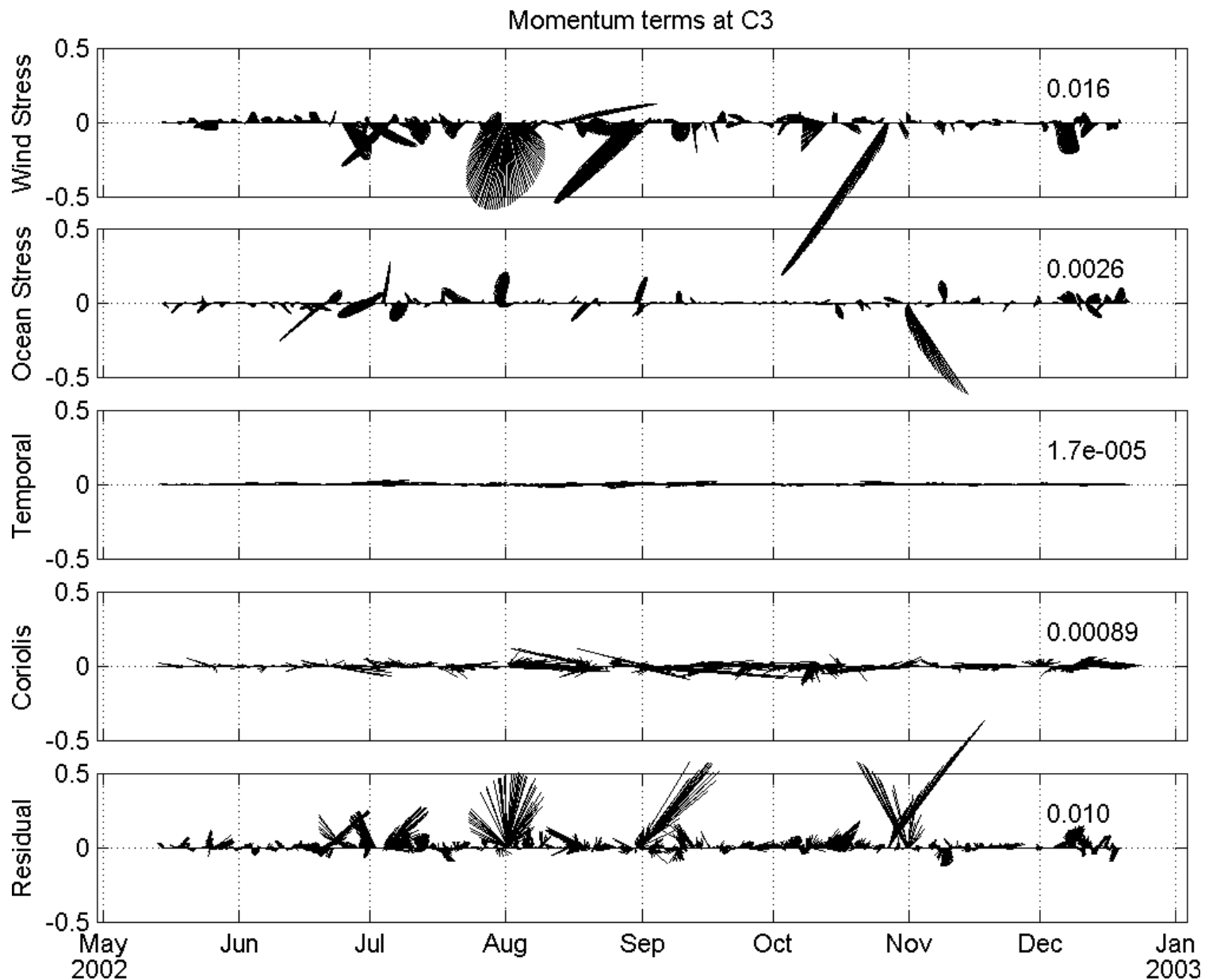

Figure 4.5.3 Momentum terms in ice at the $\mathrm{C} 3$ site. The variance of each term is shown in the upper right of each axis. 

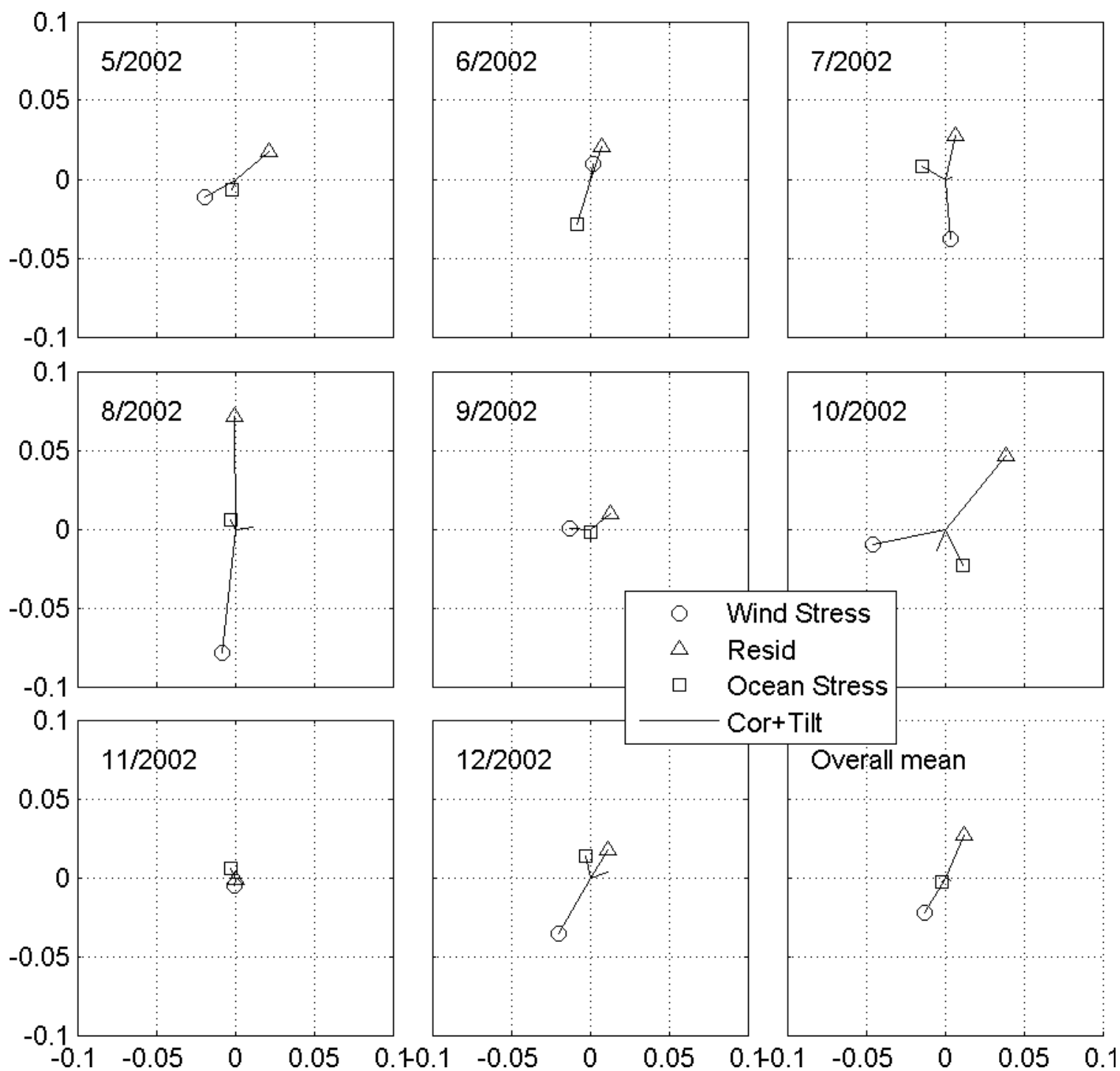

Figure 4.5.4 Monthly averaged and overall mean momentum balance at C3.

At the nearby $\mathrm{C} 1$ site, we once again see a primary balance between wind stress and internal ice stresses, with ocean stresses taking a primary role at times (Figures 4.5.5 and 4.5.6). In particular, we see this early in the season, and then again in October and November. As at the $\mathrm{C} 3$ site, wind, ocean and ice stresses form the dominant balance. The ocean stress was more important at $\mathrm{C} 1$ than $\mathrm{C} 3$. At both $\mathrm{C} 1$ and $\mathrm{C} 3$ the Coriolis/tilt term made a small contribution and the acceleration term was essentially negligible. The variance of each term, an indicator of its importance, is shown in the upper right corner of each axis for all terms at all sites. 

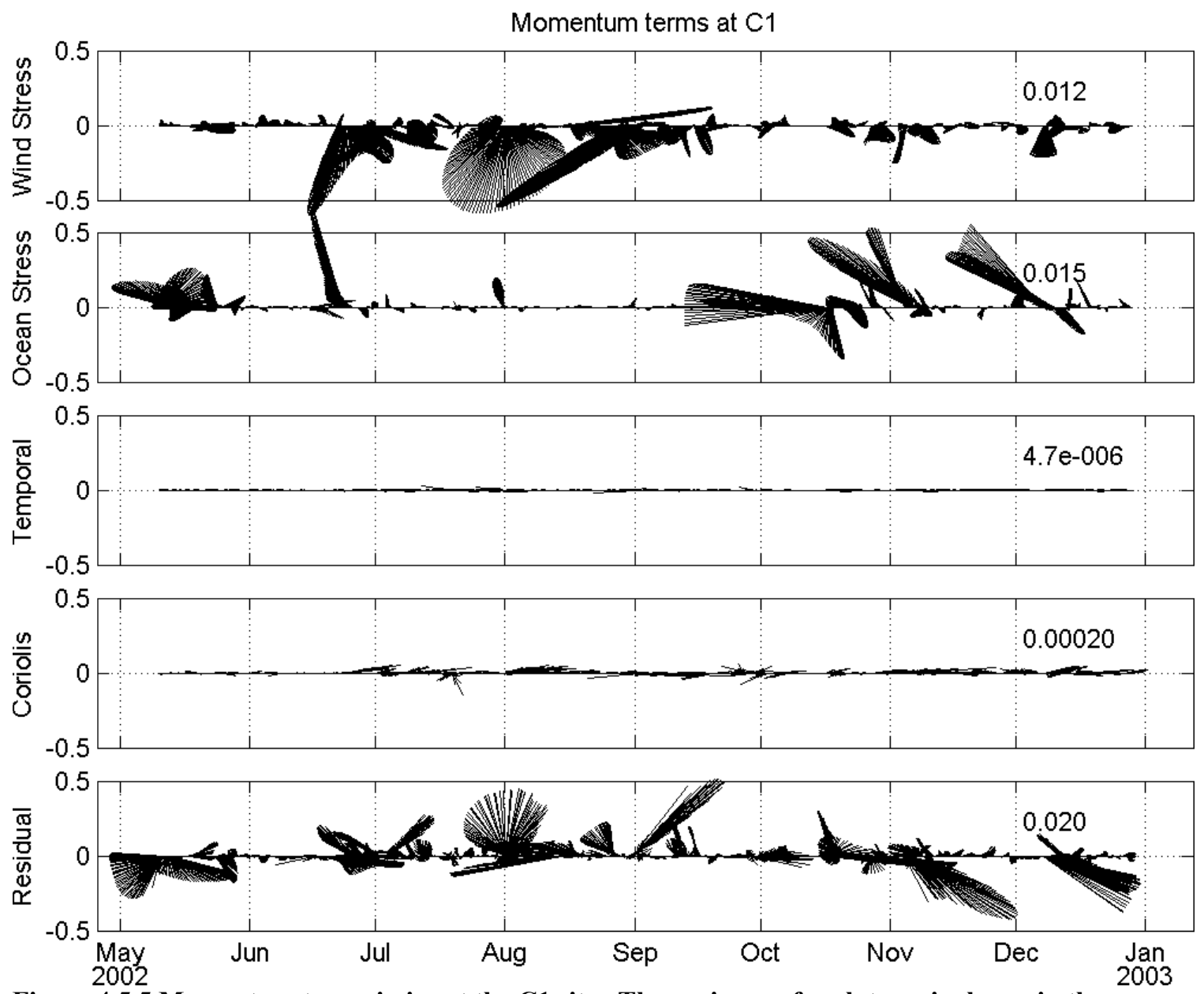

Figure 4.5.5 Momentum terms in ice at the $\mathrm{C} 1$ site. The variance of each term is shown in the upper right of each axis. 

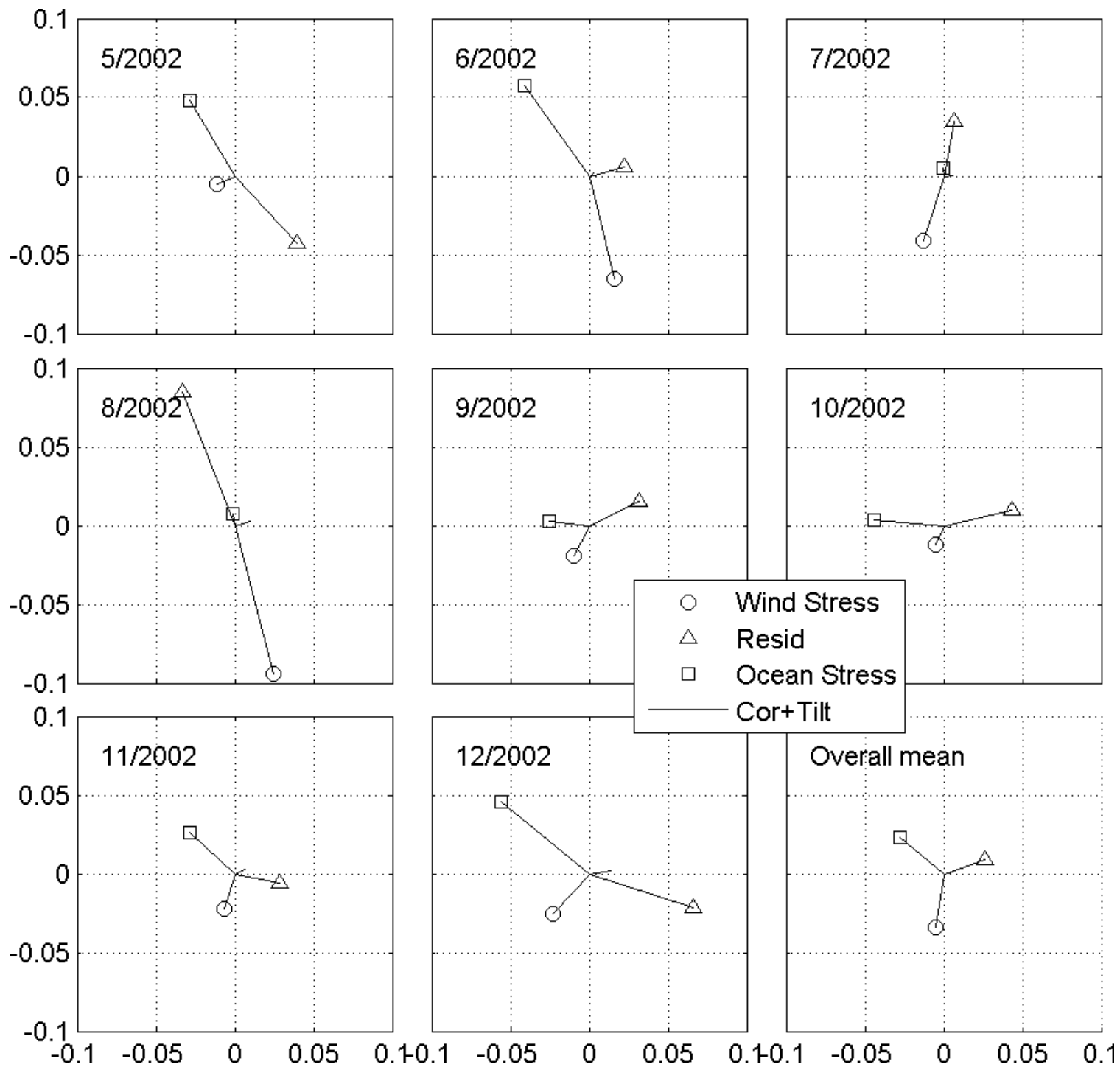

Figure 4.5.6 Monthly averaged and overall mean momentum balance at C3.

\subsection{Near- Inertial Oscillations in Sea Ice and the Upper Ocean}

Thick $(\sim 1 \mathrm{~m})$ sea ice acts an effective insulator, reducing air-sea heat flux by one to two orders of magnitude from open water values. Therefore, the overall air-sea heat flux budget can be controlled by small areas (as little as 1\%) of open water or thin ice in the icepack. High frequency motions, such as near-inertial or tidal oscillations, are often spatially inhomogeneous, with alternating convergence and divergence. This differential ice motion can open and close leads on time scales shorter than the thermodynamic time scale for freezing, thus providing insufficient ice strength to prevent relative ice motion: 
the new ice is crushed and deposited around floe edges. Heil et al., (2001) realized an increase in ice thickness of about $13 \%$ over a 5 -month model simulation by inclusion of moderate high frequency (subdaily) deformation dynamics in a dynamic/thermodynamic ice model. Heil and Hibler (2002) included "inertial embedding" (McPhee, 1978) into the dynamics of the oceanic boundary layer of a Arctic sea ice and found not only improved reproduction of observed ice motion, but an increase in winter ice mass of about $20 \%$. Furthermore, shear at the base of the mixed layer and convection during ice production associated with high frequency ice motion could enhance oceanic vertical mixing. This motivates the characterization of observed near-inertial motions in the sea ice and upper ocean.

Power density spectra of ice and ocean velocities at B2, C1 and C3 (Figure 4.6.1, dashed lines show total spectra) show peaks at a period of about 12-13 hours. There is more energy in this band in the ice than in the water. C3 had the largest peak, with C1 nearly as large. The peak at lower frequencies is the synoptic 3-4 day weather band. The first year (B2) had a less pronounced spectral peak near the inertial frequency, despite the more frequent occurrence of strong wind forcing events. could possibly be explained by the fact that near-inertial coupling requires anti-clockwise rotation in the wind stress vector, as well as strong forcing. 


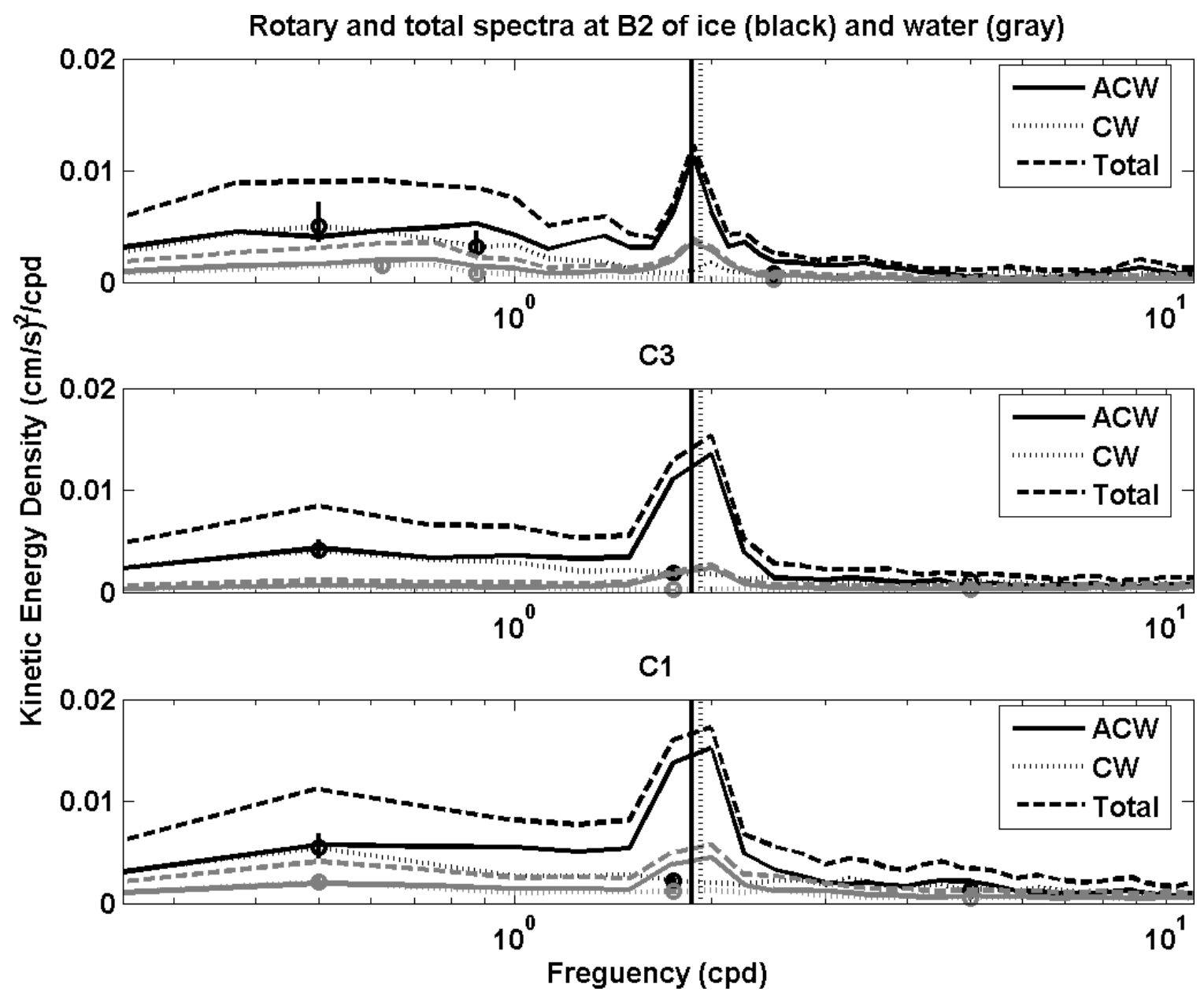

Figure 4.6.1 Rotary and total spectra at (upper panel) B2 (middle panel) C1 and (lower panel) C3 for the same time periods as shown in Figure 4.4.1. The ice is shown in black and upper ocean in gray, with solid lines showing the anticlockwise component and dashed lines the clockwise component. The short vertical lines with circles show the $95 \%$ confidence interval at three points for the ice (black) and ocean (gray). The solid black vertical line shows the inertial frequency and the dashed black vertical line shows the $\mathrm{M} 2$ tidal frequency.

At these latitudes, the near-inertial band and the M2 semidiurnal tide have very similar periods of 12.92 and 12.42 hours, respectively. Here we show that the energy is indeed near-inertial. The rotary spectra at C3 show that the spectral energy peak is almost entirely in the anti-clockwise direction in both the ice and water, consistent with nearinertial motion (Figure 4.6.1). Furthermore, near-inertial motion is wind-forced and therefore intermittent, while the tide should be present throughout the time series and have a constant phase. Figure 4.6.2b shows that during times of high measured kinetic energy, the kinetic energy accounted for by counter-clockwise complex demodulation at the inertial period is also high and not phase locked (Figure 4.6.2a). These energetic periods have rms amplitudes up to $\sim 30 \mathrm{~cm} / \mathrm{s}$. A tidal analysis (Pawlowicz et al, 2002) of 
the same period shows the dominant semidiurnal component M2 having current amplitudes of only $\sim 2 \mathrm{~cm} / \mathrm{s}$. Similar results also hold at B2 and C1 (not shown for brevity). Therefore we conclude that the motion is due to near-inertial oscillations.

(a)

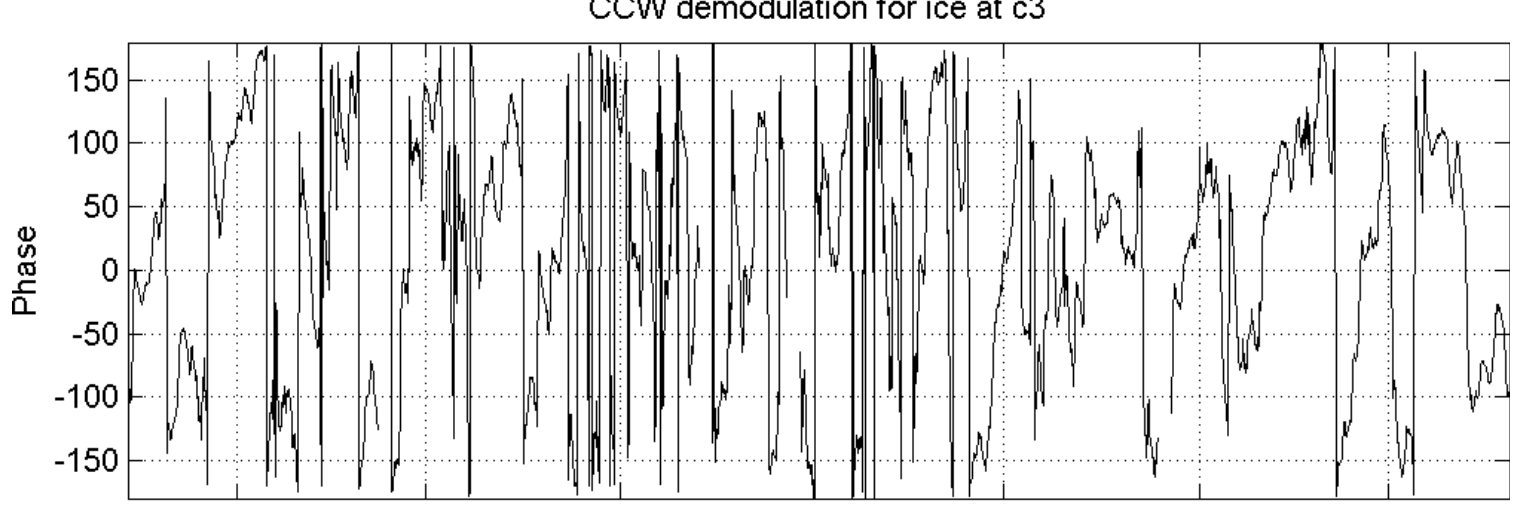

(b)

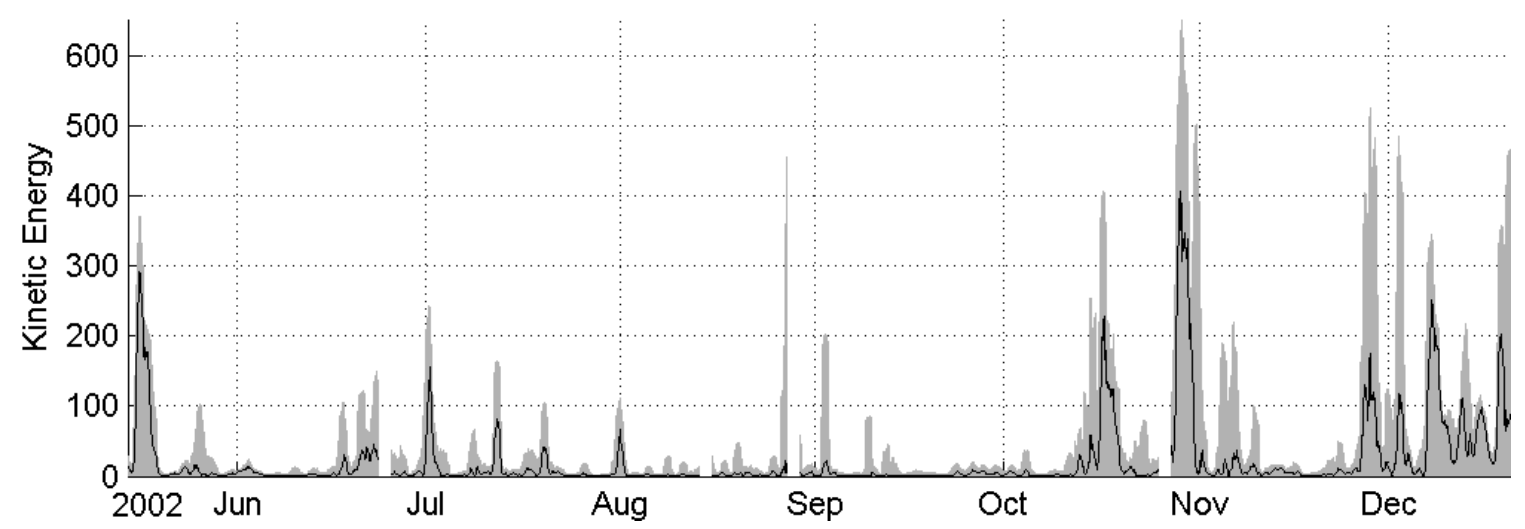

Figure 4.6.2 Counterclockwise complex demodulation of ice velocity at $\mathrm{C} 3$ at the near-inertial frequency showing (a) phase and (b) measured kinetic energy in gray shading and kinetic energy accounted for by the complex demodulation in black.

An example of strong near-inertial oscillations in the second year on October 2831, 2002 is shown in Figure 4.6.3. There is a strong wind event on October 26-28, 2002 with an anti-clockwise wind shift followed abruptly by calm conditions, causing oscillations in both the sea ice and upper ocean. The kinetic energy per unit volume in the near-inertial band is greater in the sea ice than in the upper ocean. The internal ice stresses are low during this period, with about $75 \%$ of the kinetic energy in the ice reproduced with near-inertial complex demodulation. Then on October 31, a strong internal ice stress (some non-local process) causes northward ice velocity and is partially balanced by ocean stress and the oscillations cease. The high-pass filtered momentum 
balance during this period using the method described in section 4.5 (not shown) does not show a simple inertial wave balance between the temporal change and coriolis terms. There are also significant contributions at high frequencies from the wind stress and internal ice stresses.
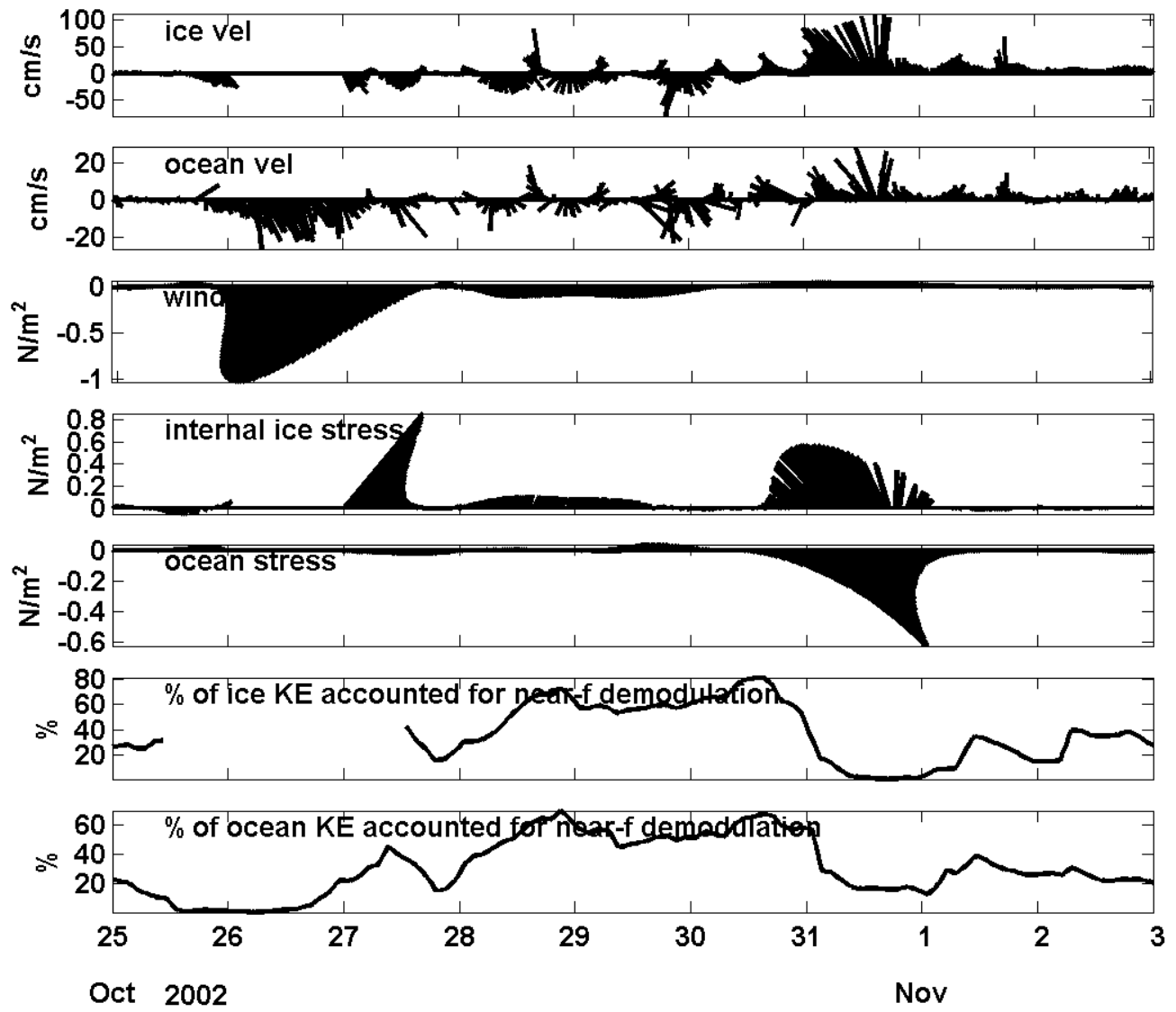

Figure 4.6.3 An example of a near-f event at the C3 mooring.

The effects of the initial wind burst which caused the near-inertial oscillations can be seen down to $200 \mathrm{~m}$ (Figure 4.6.4). The heat content $\rho c_{p} \int_{z}^{0} T d z$ for each mooring is calculated using linear interpolation of the temperature data and assuming that the surface temperature is at the freezing point (Figure 4.6.4b). A possible scenario is as follows: the $\mathrm{C} 1$ site had $60-90 \%$ ice cover during this period, so leads could presumably open and close with the inertial period. We see strong cooling (loss of heat content) and mixing during the initial wind burst on October 27 which extends down to 200-m. Then the near-inertial motions from October 28 to November 1 possibly mixed warm water back up to $107-\mathrm{m}$ and $132-\mathrm{m}$ depths, but the heat content only rises slightly compared to the 
cooling event. At the $\mathrm{C} 3$ mooring we do not see the strong loss in heat content, yet see strong high frequency oscillations in the temperature records down to over 200-m during the time of strong near-inertial oscillations. The heat content at both sites does rise during October 29-31, a period of strong near-inertial oscillations, suggesting a flux of heat from below the lowest temperature measurement. The relative roles that the initial wind burst and subsequent near-inertial shears play in vertical mixing remains an open question and the subject of on-going work.

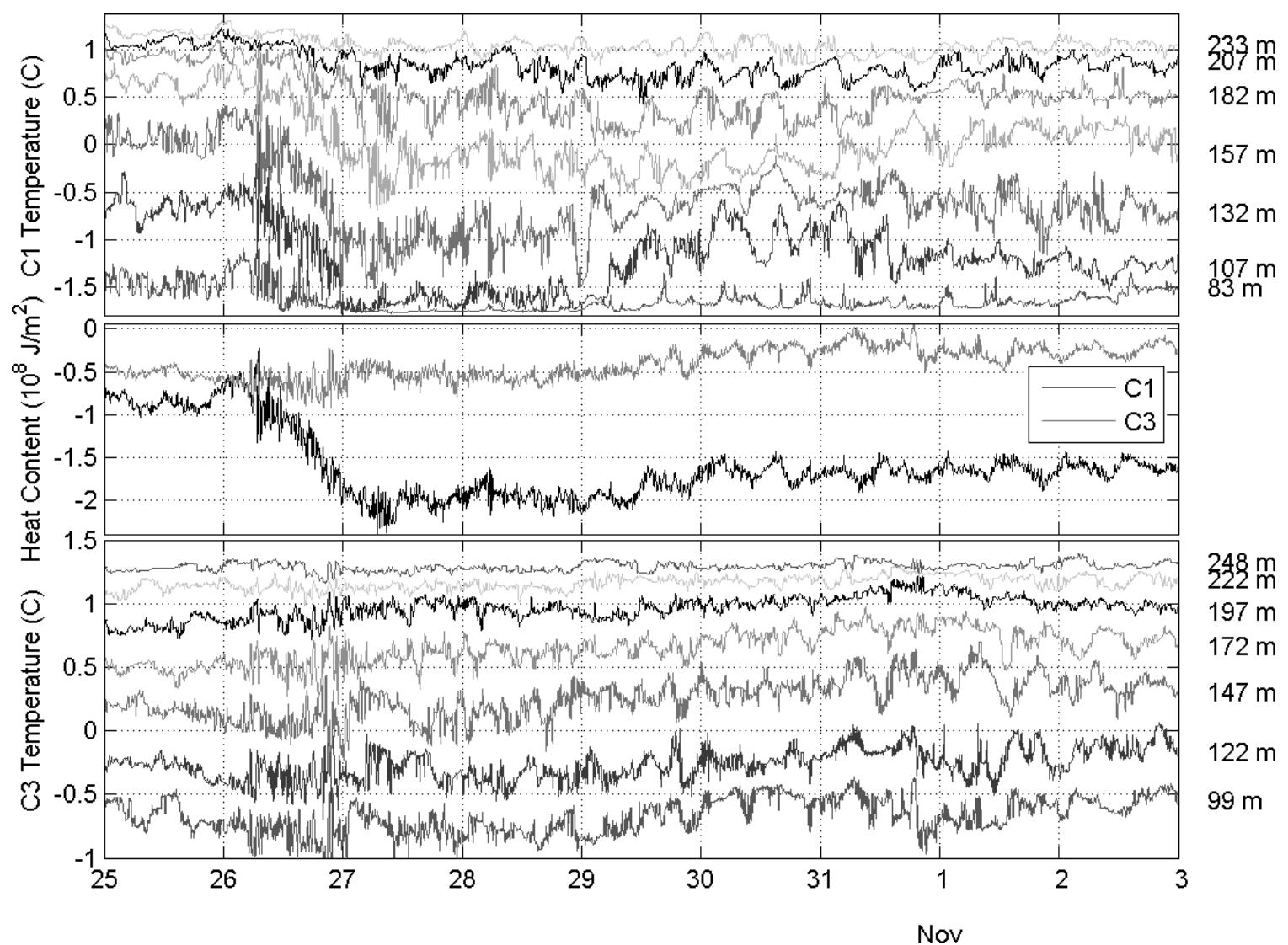

Figure 4.6.4 Time series of temperature at the (a) $\mathrm{C} 1$ and (c) $\mathrm{C} 3$ moorings before, during and after the wind burst and near-f oscillations in October, 2002 at various depths. The heat content (b) for C1 (black) and C3 (grey) is shown. The depth of each temperature record is labeled on the right. Note that (a)-(c) refer to top to bottom panels, respectively.

\subsection{Discussion and Conclusions}

We have presented two years of sea ice data which cover the winter ice seasons of 2001-2003 within Marguerite Bay and on the wAP shelf. The strong wind events in 
Marguerite Bay are primarily in a southwestward direction, and occurred more frequently in the first season.

In the first season, we found that the mid-shelf and Marguerite Bay sites are similar until mid-October, 2001, when the ice retreats from mid-shelf and thickens in the Bay. In the second season, the two sites within the Bay have similar and highly correlated ice concentrations and drafts. The primary difference between the two sites begins in mid-October, 2002, when the ice apparently broke up and left open water for a number of days at $\mathrm{C} 1$ but not $\mathrm{C} 3$. At this time, the ice draft dropped dramatically to $\sim 1 \mathrm{~m}$ at both sites, and the ice concentration also dropped somewhat from less than $70 \%$ to less than $40 \%$, but still remained above $60 \%$ for most of the remaining ice season. An interannual comparison at the $\mathrm{B} 2 / \mathrm{C} 3$ site shows that the onset of ice formation occurred about two months earlier in the second season. This is due to unseasonably cold air temperatures in May and June, 2002, the coldest on record since meteorological measurements were started in 1976 at Rothera Station in northern Marguerite Bay.

Our analysis suggests local formation of ice. The timing of the formation of at least $70 \%$ ice cover is correlated to the timing of $-9.2^{\circ} \mathrm{C}$ weather with a correlation coefficient of 0.81 over the 26 years of historical data available. Furthermore, the thick ice drafts suggest ridging and the importance of ice dynamics in the region.

A polynya on October 12, 2002 demonstrates how highly compacted ice in the Bay breaks apart, allowing easier advection and strong near-inertial responses to wind events. Both years show significant events happening in October involving a sudden noteworthy reduction in ice concentration and/or draft.

Ice speeds were typically around $10 \mathrm{~cm} / \mathrm{s}$, with the ice typically traveling about 3 $\mathrm{km}$ each day, with a time-mean net daily displacement of 200-500 $\mathrm{m}$. This indicates that there is considerable ice kinetic energy in all frequency bands from sub-daily to seasonal time scales. At B2/C3, the intermittent strong southwestward wind events act in conjunction with a slow but steady northward ocean current to keep ice from leaving the area for most of the second winter season when the winds were less energetic. At $\mathrm{C} 1$, however, the current is southward, and ice moves quickly through the area.

We calculate the subtidal momentum balance in the ice and find that the temporal acceleration term is essentially negligible, the Coriolis/tilt term is small, and the dominant 
balance is between the ocean stress, wind stress, and internal ice stresses. At the beginning and end of the ice season, when the ice concentration is slightly lower, the ocean stress becomes more important and the internal ice stresses less so. This has also been found to be true in both a numerical model of the Arctic Ocean (Steele et al, 1997) and observations made from ice buoys in the Weddell Sea (Uotila et al, 2000).

The experimental uncertainties in the measured variables (e.g., wind speed, ice thickness, ice and water velocity) used to compute the terms in the momentum balance are generally small, less than $1 \%$, indicating that the residual term contains little experimental error due to the measurements. As a result, uncertainty in the residual term is primarily sensitive to uncertainties in the parameterizations used to estimate the air-ice (air-ocean) stress and ice-ocean stress, which can be significantly larger than $1 \%$.

In order to investigate the sensitivity of the low-frequency momentum balance to the ice-ocean drag coefficient, we varied $\mathrm{C}_{\mathrm{d}}$ from 0.010 to 0.030 , a somewhat expanded range of measured values for rough first year ice (Shirasawa and Ingram, 1991) and contains $C_{d}=0.015$, the value used throughout this thesis. First, recall that the primary balance at all moorings is between the wind stress and the residual term, with a minor contribution from the ice-ocean drag at times. Therefore, if we let $\mathrm{C}_{\mathrm{d}}$ tend towards zero, the balance should tend towards wind stress and the internal ice stress, which is in fact the case with an unrealistically low $\mathrm{C}_{\mathrm{d}}$ of 0.005 .

The mean magnitude of the residual term only increases as $C_{d}$ increases. The increased ice-ocean stress is balanced not only by the wind stress, but also by the residual term. Upon inspection of the vectors at various times, this can be attributed to the fact that the ice-ocean stress does not purely oppose the wind stress, which would be the case in a motionless (or very slow moving) ocean beneath wind-forced ice. Furthermore, there is no value of $\mathrm{C}_{\mathrm{d}}$ that creates a balance between the wind and ocean stress and eliminates the residual term. The residual term not only balances the wind forcing, but also the ocean forcing. It should be noted that there is no physical reason to believe $\mathrm{C}_{\mathrm{d}}$ is even constant in time, since the ice could become rougher or smoother during the 8month ice season.

The calculated residual term is indeed sensitive to the chosen value of $\mathrm{C}_{\mathrm{d}}$, with the mean of the absolute value of the residual increasing significantly with a doubling of the 
drag coefficient. If one were to have any reason to believe that the ice-ocean drag were higher, then the balance would be a larger residual term balancing both the wind and the ice-ocean stresses. For these reasons, we conclude that while the stress parameterizations used here contribute some uncertainty in the momentum balance, the interpretation of the residual term as internal ice stress is robust.

We observed strong semi-diurnal oscillations in both the sea ice and upper ocean. Power density spectra and rotary spectra show that these are not tidal but near-inertial oscillations. An analysis of individual wind events elucidates the coupled ice-ocean response in this energetic band. A typical example at the end of October, 2002 shows a pulse of wind stress which spins up near-inertial oscillations in both the sea ice and upper ocean. These oscillations persist for 3 days, until an increase in internal ice stress forces northward motion in the ice. The cause of the strong internal ice stresses shows the importance of non-local processes, which are unknown in this case.

Future work will investigate the ocean mixing caused by these wind and nearinertial events. Specifically, how can these events move heat and nutrients up from deeper water? The periodic opening and closing of leads will cause ice production and thus convection. The stress at the ice-ocean interface creates turbulent kinetic energy which also acts to mix heat up from below. Finally, near-inertial shear at the base of the mixed layer could also cause vertical mixing and is now thought to be the primary source of small-scale mixing on the wAP shelf (Howard et al, 2004). 


\section{Acknowledgements}

The AWS stations and data acquisition and initial processing were provided by the Antarctic Meteorological Research Center at the University of Wisconsin, with the support and help of M. Lazzara. Thanks to the captain and crew of the RV L.M. Gould and RVIB N.B. Palmer, R. Limeburner and the WHOI Subsurface Mooring Operations Group led by S. Worrilow, and the Raytheon Polar Services support crew responsible for collecting the moored array and AWS data. Thanks to J. Tom Farrar for valuable comments on early drafts of the manuscript. This work was supported by the NSF Office of Polar Programs grant OPP 99-10092 and the WHOI Education Office.

\section{References:}

Arrigo, R. and van Dijken, G.L., 2003: Phytoplankton dynamics within 37 Antarctic coastal polynya systems. J. Geophys. Res., 108. No. C8, 3271-3289.

Beardsley, R., M. Caruso, and J. Hyatt, 2006: Marine surface conditions and atmospheric forcing over Marguerite Bay and adjacent shelf, western Antarctica Peninsula, 2001-2003. Deep-Sea Research, in prep.

Cavalieri, D., C. Parkinson, P. Gloerson, and H.J. Zwally. 1997, updated 2005. Sea ice concentrations from Nimbus-7 SMMR and DMSP SSM/I passive microwave data. Boulder, CO, USA: National Snow and Ice Data Center. Digital media.

Emery, W.J., and Thomson, R.E., 2001: Data Analysis Methods in Physical Oceanography. Elsevier Science, B.V., Amsterdam.

Fairall, C.W., Bradley, E.F., Hare, J.E., Grachev, A.A. and Edson, J.B., 2003: Bulk Parameterization of Air-Sea Fluxes: Updates and Verification for the COARE Algorithm. J. Climate, 16, 571-591.

Heil, P., I. Allison, and V. I. Lytle, 2001: Effect of high-frequency deformation on the sea-ice thickness. Scaling Laws in Ice Mechanics and Ice Dynamics, J. P. Dempsey and H. H. Shen, Eds., Kluwer Academic, 417-426.

Heil, P. and Hibler, W.D., 2002: Modeling the high-frequency component of Arctic sea ice drift and deformation. J. Phys. Oceanogr., 32, 3039-3057. 
Hibler, W.D., 1979: A Dynamic Thermodynamic Sea Ice Model. Journ. Phys. Oceanogr., 9, 815-846.

Howard, S., Hyatt, J. and Padman, L., 2004: Mixing in the pycnocline over the western Antarctic Peninsula shelf during Southern Ocean GLOBEC. Deep-Sea Research II, 51, 1965-1979.

Hyatt, J., Visbeck, M., Beardsley, R. and Owens, W.B., 2005: Measurements of sea ice properties using a moored upward-looking acoustic Doppler current profiler (ADCP). Deep-Sea Research II, this issue.

McPhee, M. G., 1978: A simulation of the inertial oscillation in drifting pack ice. Dyn. Atmos. Oceans, 2, 107-122.

Meredith, M.P., Renfrew, I.A., Clarke, A., King, J.C., and Brandon, M., 2004: Impact of the 1997/98 ENSO on upper ocean characteristics in Marguerite Bay, western Antarctic Peninsula. J. Geophys. Res., 109. 9013-9032.

Moffatt, C., Beardsley, R.C., Limeburner, R., Owens, B., Caruso, M., Hyatt, J., 2005: Southern Ocean GLOBEC Moored Array and Automated Weather Station Data Report. Woods Hole Oceanographic Technical Report WHOI-2005-07.

Pawlowicz, R., B. Beardsley, and S. Lentz, Classical Tidal Harmonic Analysis Including Error Estimates in MATLAB using T_TIDE, Computers and Geosciences, 2002.

Perovich, D.K., Elder, B.C., Claffey, K.J., Stammerjohn, S., Smith, R., Ackley, S.F., Krouse, H.R., and Gowa, A.J., 2004. Winter sea-ice properties in Marguerite Bay, Antarctica. Deep-Sea Research II, 51, 2023-2039.

Quetin, L.B., Ross, R.M., 1991. Behavioral and physiological characteristics of the Antarctic krill, Euphausia superba. American Zoologist 31, 49-63.

Quetin, L.B., Ross, R.M., Clarke, A., 1994. Krill energetics: Seasonal and environmental aspects of the physiology of Euphausia superba. In: El-Sayed, S.Z. (Ed.), Southern Ocean Ecology: The BIOMASS Perspective. Cambridge University Press, Cambridge, pp. 165-184.

Roed, L.P., and O'Brien, J.J., 1983. A Coupled Ice-Ocean Model of Upwelling in the Marginal Ice Zone. J. Geophys. Res., 88, 2863-2872 
Siegel, V., Loeb, V., 1995. Recruitment of Antarctic krill Euphausia superba and possible causes for its variability. Marine Ecology Progress Series 123, 45-56.

Shirasawa, K. and Ingram, R.G., 1991. Characteristics of the turbulent oceanic boundary layer under sea ice. Part 1: A review of the ice-ocean boundary layer. J. Mar. Sys. 2, pp. 153-160.

Stammerjohn, S. E., Drinkwater, M. R., Smith, R. C., and Liu, X., 2003. Iceatmosphere interactions during sea-ice advance and retreat in the western Antarctic Peninsula region. J. Geophys. Res., 108.

Steele, M., Zhang, J., Rothrock, D., and Stern, H., 1997: The force balance of sea ice in a numerical model of the Arctic Ocean. J. Geophys. Res., 102, 21,061-21,079.

Uotila, J., Vihma, T., and Launiainan, J., 2000: Response of the Weddell Sea pack ice to wind forcing. J. Geophys. Res., 105, 1,135-1,151. 


\section{Chapter 5}

\section{One-dimensional modeling of vertical mixing in a seasonally ice-covered, stratified, high-latitude coastal ocean}

\subsection{Introduction}

Air-sea heat flux can be one to two orders of magnitude larger over open water than over thick $(\sim 1 \mathrm{~m})$ sea ice. Therefore, the exchanges across small areas of open water or thin ice in the icepack (as little as 1\%) can dominate the overall air-sea heat flux budget. High frequency motions, such as near-inertial oscillations or tidal motions, can lead to differential ice motion. This can open and close leads on time scales shorter than the thermodynamic time scale to freeze them solidly enough to provide sufficient ice strength to inhibit relative ice motion. Consequently, the new ice formed in leads is crushed and deposited around floe edges. Inclusion of moderately high frequency (subdaily) deformation dynamics in the forcing of a thermodynamic ice model results in an increase in ice thickness of about $13 \%$ over a 5-month model simulation (Heil et al., 2001). Including an integrated momentum equation for the ice and upper ocean rather than the ice alone, or "inertial embedding" (McPhee, 1978), into the dynamics of the ice increased winter ice mass by about 20\% (Heil and Hibler, 2002). In addition to its role in augmenting ice formation, high frequency ice motion and lead formation will enhance oceanic mixing by near-inertial shear at the base of the mixed layer and convection during ice production and brine rejection.

As shown in Chapter 4, power density spectra of ice and ocean velocities at the Marguerite Bay moorings show peaks at the inertial frequency, with more energy in this

band in the ice than in the water. These energetic motions have rms amplitudes up to $\sim 30$ $\mathrm{cm} / \mathrm{s}$. Most of the periods of high kinetic energy at the inertial frequency occurred during 
periods of lower ice concentration (Figure 5.1.1), supporting the notion that a looser ice pack can sustain near-inertial oscillations. This motivates the investigation of oceanic near-inertial motions in the presence of sea ice.

(a)

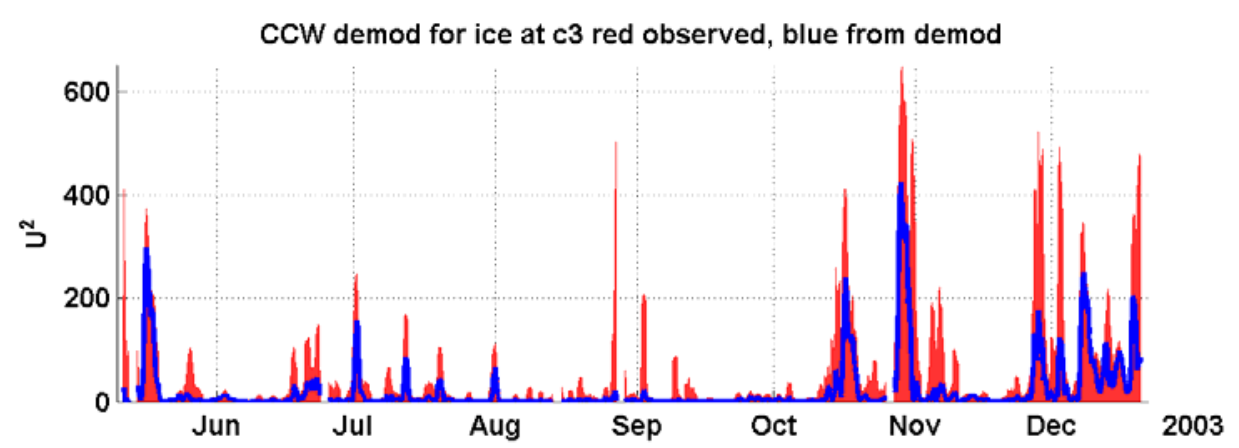

(b)

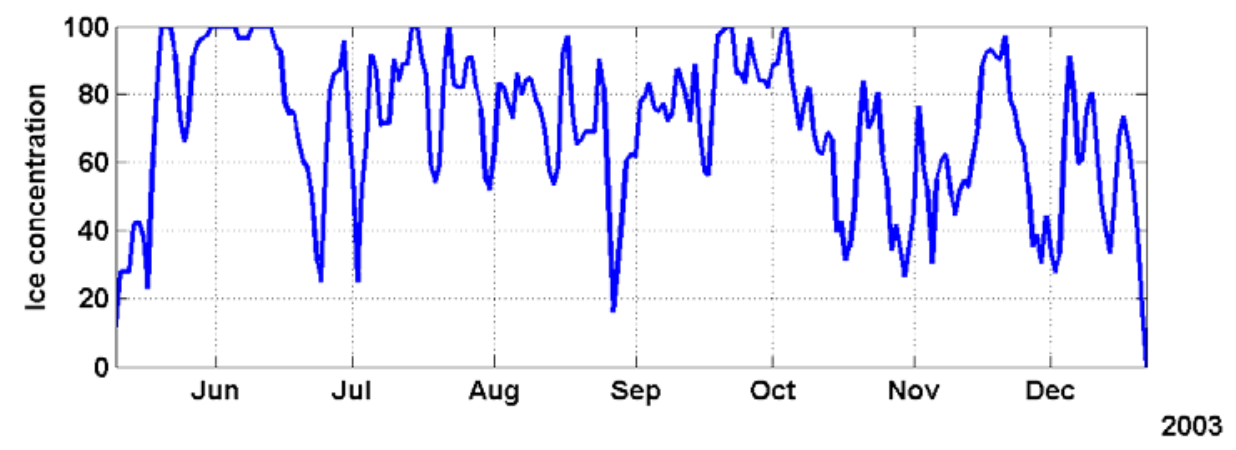

Figure 5.1.1 (a) Upper panel shows ice kinetic energy $\left(\mathrm{U}^{2}\right)$ observed (red) and that accounted for by near-inertial oscillations (blue) as calculated with a complex demodulation. The lower panel (b) shows observed ice concentrations at the $\mathrm{C} 3$ mooring. Similar results were found at the nearby $\mathrm{C} 1$ mooring site (not shown).

Deep-keeled icebergs precluded moored instrumentation in the upper $100 \mathrm{~m}$ of ocean in the SO GLOBEC field program. Therefore we are unable to observe important mixing processes with the moorings. For example, we cannot resolve the depth of the mixed layer. The long-wave radiative cooling has been shown to be an important term in the net air-sea heat flux (Beardsley, et al., 2006). The radiative heat fluxes were measured in-situ only with shipboard instruments, not on the Automatic Weather Stations, and there were no ships in this area during the spring break-up when strong icecovered near-inertial oscillations in both the sea ice and upper ocean were observed.

Furthermore, CTD casts and hull-mounted ADCPs provide important initial conditions 
for any mixing study. This prompts the use of an one-dimensional surface mixed layer model to study the relative importance of vertical mixing processes in an idealized seasonally ice-covered, stratified, high-latitude coastal ocean.

Here I examine two potentially important ocean mixing processes, namely shear associated with a wind event and subsequent near-inertial oscillations and convection due to brine rejection associated with freezing as leads open and close due to the near-inertial motions (Figure 3.1.1). Shear associated with near-inertial oscillations has been identified as a potentially important process, especially when compared with double diffusion (Howard et al., 2004).

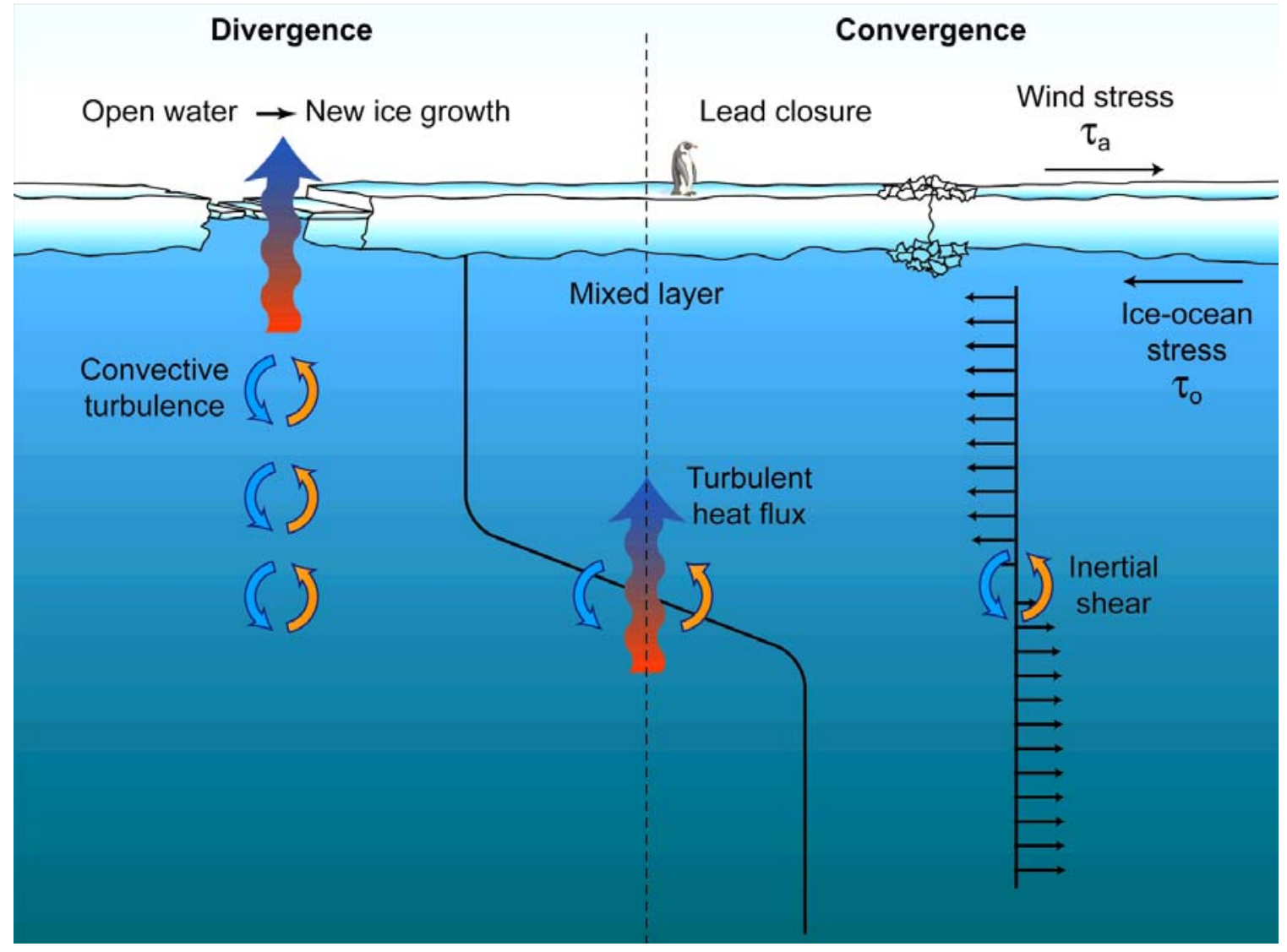

Figure 5.1.2 Schematic of mixing processes considered in the PWP model with ice.

It is important to examine these processes individually. Therefore the analysis begins with a base case with no ice and a wind event which generates inertial oscillations. Then the consequences of an ice cover are explored, as a function of both the thickness and roughness (drag coefficient) of the ice. The initial and surface boundary conditions are idealized based on the western Antarctic Peninsula (wAP) shelf environment. 
Subsequently, an air-sea heat flux modulated at the inertial frequency is included to simulate the phenomenon of leads opening and closing with divergent high frequency ice motion. The feedback associated with the upward flux of heat and ice production is discussed, as well as the slowing of the mixed layer due to entrainment of deeper motionless fluid. Additional effects of rotation of the wind stress vector and reflection of a barotropic wave from the coastal boundary are explored. Finally, the implications of the results on mixing in Marguerite Bay are discussed.

\subsection{The Model: PWP with ice.}

The mixing model employed is based on that of Price, Weller and Pinkel (1986) (PWP) with some modifications made as noted below.

\subsubsection{The basic PWP model}

The basic PWP vertical mixing model allows for mixing due to static instability (density inversions) and shear instability, and allows for free inertial oscillations. The basic horizontal momentum, salt and heat balance equations are as follows (with positive $z$ downward and downward surface wind stress, heat and salt fluxes positive into the ocean):

$$
\begin{gathered}
\frac{\partial \vec{u}}{\partial t}=-(f \times \vec{u})-\frac{1}{\rho_{o}} \frac{\partial \vec{\tau}}{\partial z} \\
\frac{\partial S}{\partial t}=-\frac{\partial Q_{S}}{\partial z} \\
\frac{\partial T}{\partial t}=-\left[\frac{1}{\rho_{o} c_{p}}\right] \frac{\partial Q_{H F}}{\partial z}
\end{gathered}
$$

with the following stability criteria:

$$
\begin{gathered}
\frac{\partial \rho}{\partial z} \geq 0 \\
R i_{b}=\frac{g \Delta \rho h}{\rho_{0}(\Delta \vec{u})^{2}} \geq 0.65
\end{gathered}
$$




$$
R i_{g}=\frac{g \partial \rho / \partial z}{\rho_{0}(\partial \vec{u} / \partial z)^{2}} \geq 0.25
$$

The model is initialized with specified temperature $(T)$, salinity $(S)$ and velocity $(\vec{u})$ profiles. Velocities rotate freely at the inertial frequency of $f$ (equation 5.1), which equals $2 \pi / 12.74 \mathrm{hrs}$ at $70^{\circ} \mathrm{S}$. Prescribed time series of surface fluxes of momentum $(\vec{\tau})$, heat $\left(Q_{T}\right)$ and salt $\left(Q_{S}\right)$ are applied as the surface flux boundary conditions for equations 5.1, 5.2 and 5.3.

At each time step, the model first applies the temperature and salinity surface boundary conditions (described in detail in section 5.2.3) in the top depth cell. Then the density profile is checked for static stability starting from the surface cell downward (Equation 5.4) and the water column is mixed, including momentum, until stability is met. This creates a homogenized surface layer, or slab, of depth $h$. Then the model applies the surface wind stress by adding the momentum to the "surface mixed layer", defined by a change in density, $\Delta \rho$, of $5 \times 10^{-4} \mathrm{~kg} / \mathrm{m}^{3}$ from the surface value. One consequence of this definition is that the "surface mixed layer" may contain some weak stratification and shear. The bulk Richardson number $R i_{b}$ stability criterion (equation $5.5)$ is then checked and cells are entrained into the slab layer until the profile is stable. The differences $\Delta \rho$ and $\Delta \vec{u}$ are taken between the slab layer and the level just beneath. This simulates entrainment into the mixed layer due to shear instability.

The first two criteria (equations 5.4 and 5.5) often produce a sharp jump in $\vec{u}$ and $\rho$ at the base of the slab layer. The final mixing criterion (equation 5.6) uses a gradient Richardson number $R i_{g}$ stability criterion to simulate mixing due to small-scale shear instability. A profile of $R i_{g}$ is made and any adjacent cells which do not meet the stability criterion have their temperature, salinity and momentum mixed together. Since this generally produces other cell pairs which do not meet the $R i_{g}$ stability criterion, the process iterates until the entire profile is stable. This process bears some resemblance to a diffusive mixing process in that it spatially smoothes the profile. The region between the base of the slab mixed layer and the depth to which the shear mixing penetrates is known as the transition layer (Schudlich and Price, 1992) (Figure 5.2.1). 


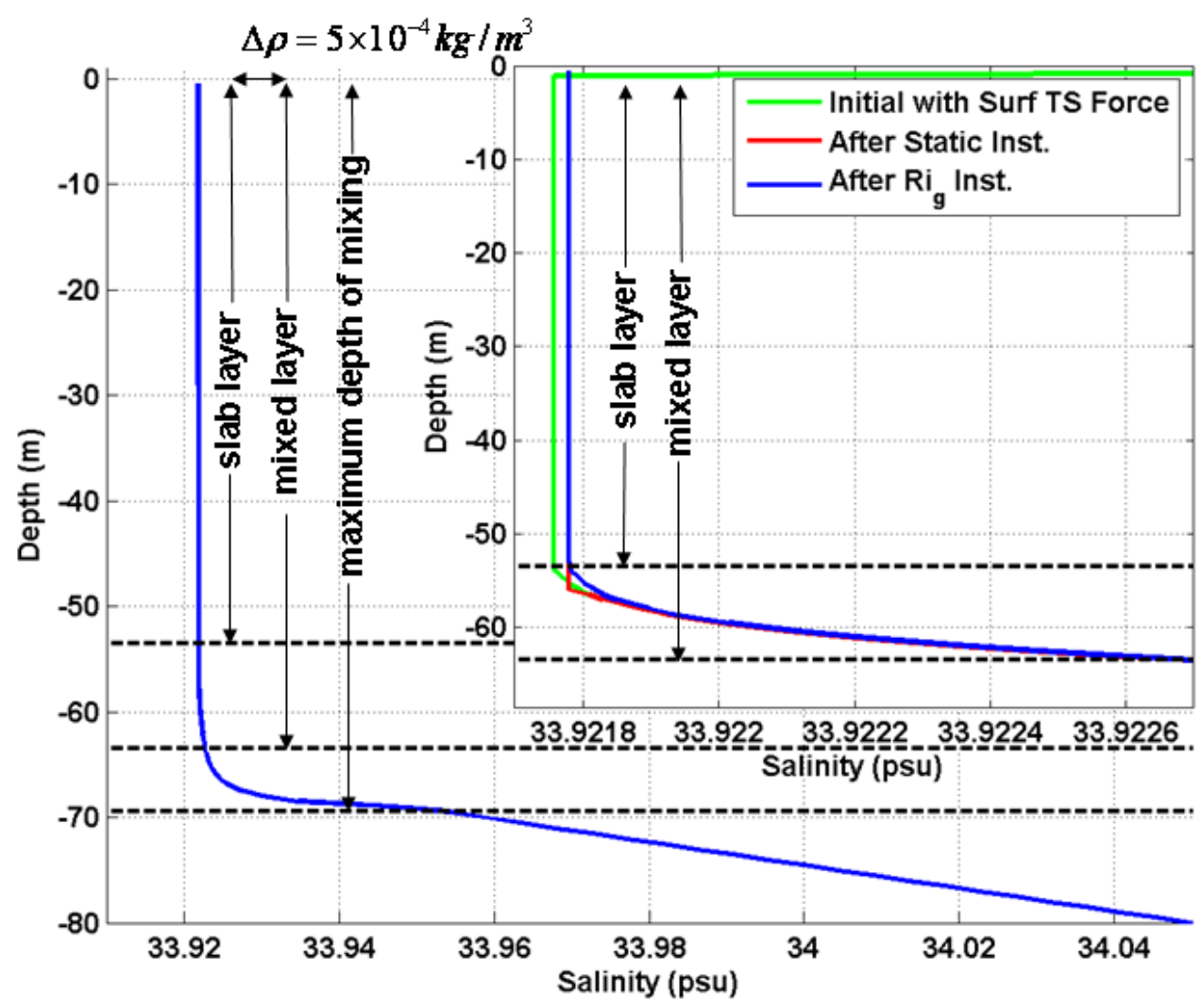

Figure 5.2.1 Illustration of the defined slab layer, model-defined mixed layer and depth of maximum mixing and (zoomed in inset) the sequence of the model's mixing scheme at $t=13 \mathrm{hrs}$. The model "mixed layer" contains a slab layer over a region of very weak ( $\Delta \rho$ of $5 \times 10^{-4} \mathrm{~kg} / \mathrm{m}^{3}$ ) stratification.

The inset shows salinity profiles at intermediate stages in the mixing scheme. The green line denotes the initial profile in the time step, with added brine in the surface cell. The red line indicates the profile after this added brine has been mixed down far enough to satisfy the static stability and $R i_{b}$ criterion (equations 5.4 and 5.5), producing a slab-like mixed layer with a sharp gradient at its base. The blue line shows the final salinity profile, after shear flow stability (equation 5.6) has been achieved by fluxing salt, heat and momentum upwards and smoothing the gradient. Note that the water column is salt stratified, with a weak destabilizing thermal gradient (not shown).

The density $\rho$ is calculated from the model temperature and salinity using the fully nonlinear equation of state (Fofonoff and Millard, 1983). There is a completely mixed layer resulting from criteria 5.4 and 5.5 which is treated as a slab layer with infinite vertical diffusivity and viscosity. After the gradient Richardson number criterion (equation 5.6) is applied, a final "surface mixed layer" is calculated for use in plotting the results. This final "surface mixed layer" is defined by a $\Delta \rho$ of $5 \times 10^{-4} \mathrm{~kg} / \mathrm{m}^{3}$ from the surface value, identical to the definition used for adding momentum from wind stress. This mixed layer is technically not a fully mixed slab layer, so the actual slab layer thickness is also shown in many figures. The choice of $\Delta \rho$ (within reasonable bounds) 
has a negligible effect on the modeled stratification and velocity. The simulations were run at high resolution, with a grid size, $\Delta z$, of $0.5 \mathrm{~m}$, a $\Delta t$ of $120 \mathrm{~s}$ and zero background vertical diffusivity for scalars and momentum.

Vertical fluxes of heat and salt are calculated after the simulation has been completed using equations 5.7 and 5.8, which integrate from the bottom of the domain up to the surface and are identical in form to equation 6.1 in PWP:

$$
\begin{gathered}
Q_{H F}(z)=\rho_{o} c_{p} \sum_{b o t}^{z} \frac{\Delta T}{\Delta t} \Delta z \\
Q_{S}(z)=\sum_{b o t}^{z} \frac{\Delta S}{\Delta t} \Delta z
\end{gathered}
$$

The water column in the Marguerite Bay region is salt stratified. Using the definitions in McDougall (1987), the change in density due to salt $\beta \Delta S$ is one order of magnitude larger than that due to temperature $\alpha \Delta T$, taking the differences in $S$ and $T$ between the top and bottom of the domain. Therefore, vertical fluxes of heat have a much smaller impact on the stratification than those of salt. This is discussed further in section 5.3.4.

\subsubsection{PWP with ice}

Simplified ice dynamics were added to the PWP model to investigate the role of ice in vertical mixing on a stratified continental shelf. Unlike standard PWP applications, the wind first acts on the ice, with the air-ice stress $\overrightarrow{\tau_{w}}$ calculated using the velocity difference between the two and, for simplicity, assuming neutral stability (Large and Pond, 1981). The ice motion is modeled as free drift and allows for inertial oscillations:

$$
\frac{\partial \overrightarrow{u_{i}}}{\partial t}=-\left(f \times \overrightarrow{u_{i}}\right)-\frac{1}{\rho_{i}} \frac{\partial\left(\overrightarrow{\tau_{w}}-\overrightarrow{\tau_{i o}}\right)}{\partial z}
$$

It is assumed that the ice covers a large enough percentage of the sea surface that the wind stress acts only on the ice. The ice-ocean stress $\overrightarrow{\tau_{i o}}$ is calculated using a quadratic drag law: 


$$
\overrightarrow{\tau_{i o}}=C_{d} \rho_{o}\left(\overrightarrow{u_{i}}-\overrightarrow{u_{o}}\right)\left|\overrightarrow{u_{i}}-\overrightarrow{u_{o}}\right|
$$

with $C_{d}=15 \times 10^{-3}$ (Shirasawa and Ingram, 1991) (unless otherwise noted), $\rho_{o}$ the density of seawater $\left(1024 \mathrm{~kg} / \mathrm{m}^{3}\right)$ and $\rho_{i}$ the density of sea ice $\left(920 \mathrm{~kg} / \mathrm{m}^{3}\right)$. The ice-ocean stress $\overrightarrow{\tau_{i o}}$ is used as the surface ocean boundary condition $\vec{\tau}$ in the PWP ocean model (equation 5.1).

The latent and sensible heat fluxes are calculated by applying bulk formula (Fairall et al., 1996) to the simulated sea surface temperature and salinity and a constant air temperature $\left(-20{ }^{\circ} \mathrm{C}\right)$ and relative humidity $(70 \%)$ based on observations in Marguerite Bay (Beardsley et al., 2006). After the wind event, a background wind of $5 \mathrm{~m} / \mathrm{s}$ is used in the bulk formula to calculate heat fluxes, based on the observed light and variable winds in Marguerite Bay, but is not used in the calculation of the surface stress to simplify interpretation of the model output. The radiative heat fluxes are assumed constant, with values based on shipboard measurements. The net radiative heat flux is set at $100 \mathrm{~W} / \mathrm{m}^{2}$ (loss), under the assumption that the shortwave heat flux is small during the period of time of interest, and the flux is primarily long-wave heat loss. Assuming no heat flux through the ice, the total heat flux is then scaled by the open water fraction $A$, the calculation of which is described in section 5.3.3.

The ice model does not contain dynamics such as ridging and breaking, a horizontally-two-dimensional problem impossible to include into the one-dimensional PWP model. The phenomenon of leads opening and closing due to convergence and divergence of the ice drift is incorporated by allowing the open water fraction $A$ to be time-dependent.

The simple thermodynamic ice model is achieved by creating ice when the ocean's surface temperature $T_{\text {surf }}$ drops below the freezing point of seawater $T_{f r z}$ at the surface salinity $S_{\text {surf }}$ in the simulation. The excess heat is removed by freezing and ice is created at a rate of $F_{i}$ at a salinity of $S_{i c e}$ which is set at 4 PSU (Perovich, 2004) (equation 5.11). The basic equations can be expressed as

$$
\rho_{i} L_{f} F_{i}=\rho_{o} c_{p} \frac{T_{f r z}-T_{\text {surf }}}{\Delta t} \Delta z
$$




$$
\frac{\Delta S}{\Delta t}=F_{i}\left(S_{\text {surf }}-S_{i c e}\right) / \Delta z
$$

with $c_{p}$ the specific heat of seawater $\left(4183.3 \mathrm{~J} / \mathrm{kg} /{ }^{\circ} \mathrm{C}\right)$ and $L_{f}$ is the latent heat of fusion of sea ice $\left(333 \mathrm{~kJ} / \mathrm{kg}\right.$, Wadhams, 2000)). $\quad F_{i}$ is then used to calculate the salt flux into the ocean at the surface (equation 5.12). This model ignores changes in ice temperature and the melting of ice and assumes that thin ice in the leads has no effect on the air-sea heat flux, which is reasonable since a maximum of $\sim 1 \mathrm{~cm}$ of ice is formed in the model during an inertial period. Note that more elaborate thermodynamic ice models exist (e.g. Maykut and Untersteiner, 1971), however we believe the simple ice production model used in this Chapter captures the essential feature of ice production on short time scales and subsequent brine rejection and that icemelt in these situations (especially the cold upper ocean) would be negligible (M. McPhee, pres. comm.).

The air-sea heat flux allows heat to vent out from the ocean. This venting is thought to be important as heat brought up from deeper waters by mixing, which would otherwise melt ice and form a thin fresh surface layer which would isolate the wind stress from the deeper waters (McPhee, pers. comm.), is instead released to the atmosphere. The crushing of newly formed thin ice in the leads is assumed to have no effect on the ice's momentum (equation 5.9).

The model is thought to be a spatial average over an area consisting of both open water and ice. Essentially, horizontal diffusivity over this area is thought to be infinite. No plume dynamics are included, but could be important. Plumes could potentially not mix completely as they carry denser water downwards and then overshoot the level predicted by the PWP model, causing further mixing. Furthermore, a spatial pattern of convecting plumes beneath leads could create a pattern of internal waves on the pycnocline, heaving upwards between leads and potentially causing feedbacks by melting ice (M. Levine, pers. comm.). This problem is inherently three-dimensional and beyond the scope of this study.

\subsubsection{Initial and Boundary Conditions}

All model runs were initialized with an idealized stratification which consisted of a uniform 65-m deep mixed layer overlying a linear stratification down to $100 \mathrm{~m}$ (Figure 
5.2.2a). The domain was limited to the upper $100 \mathrm{~m}$ because the maximum depth of mixing (defined as the deepest point which has been influenced by the mixing model) did not penetrate below that level in any of the simulations. The stratification was chosen to mimic a CTD cast taken on July 29,2001 in the region, at $66^{\circ} 15.27^{\prime} \mathrm{S}, 70^{\circ} 20.81^{\prime} \mathrm{W}$ (Figure 5.2.2b). This cast was chosen as it contains the essential features characterizing the western Antarctic Peninsula shelf regions, namely a deep ( $\sim 55 \mathrm{~m})$ mixed layer of cold $\left(-1.83{ }^{\circ} \mathrm{C}\right)$, fresh (33.91 PSU) Antarctic Surface Water overlaying a region of sharp stratification and a lower layer of Upper Circumpolar Deep Water. A linearized version of the stratification was used to simplify and clarify the interpretation of the model results and remove the small-scale vertical structure in the observed profile. It is noted that the details of the model results are sensitive to the initial temperature and salinity profiles, but the general conclusions regarding mixing are robust. The initial water and ice velocities are zero, unless otherwise noted. 
(a)

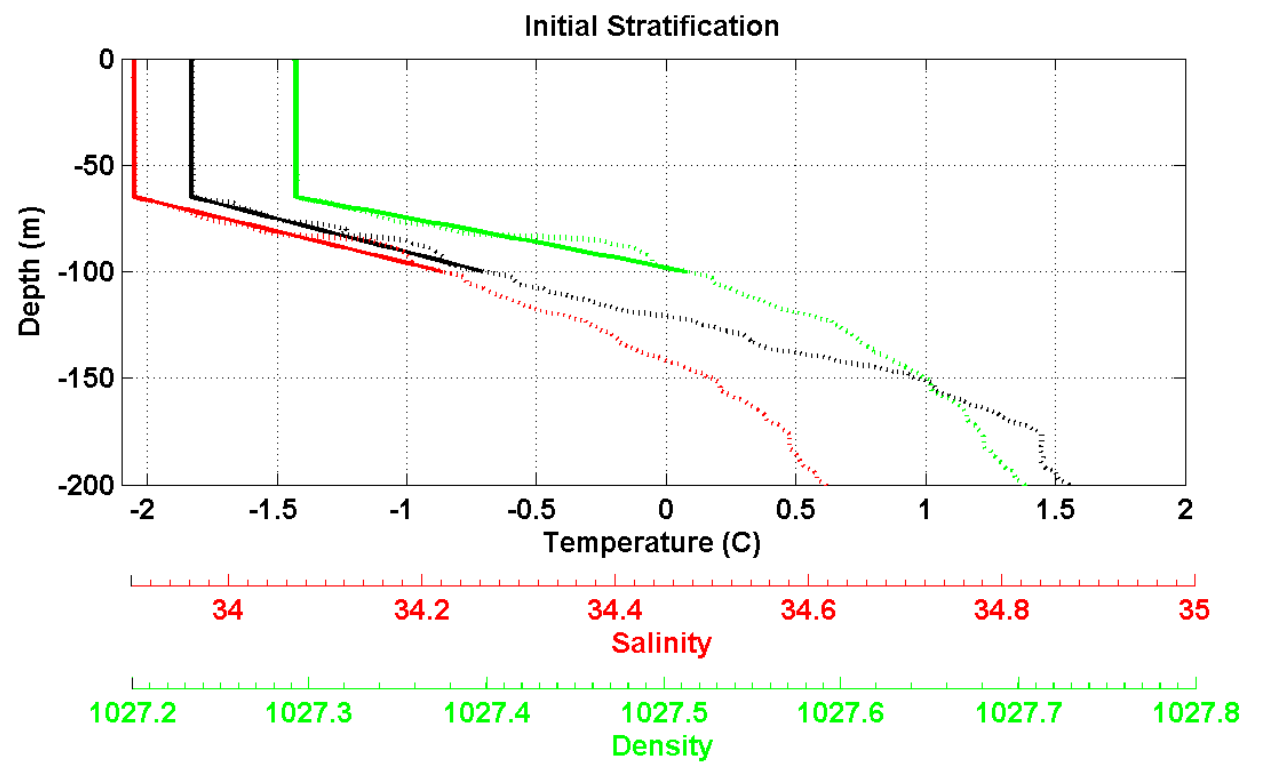

(b)

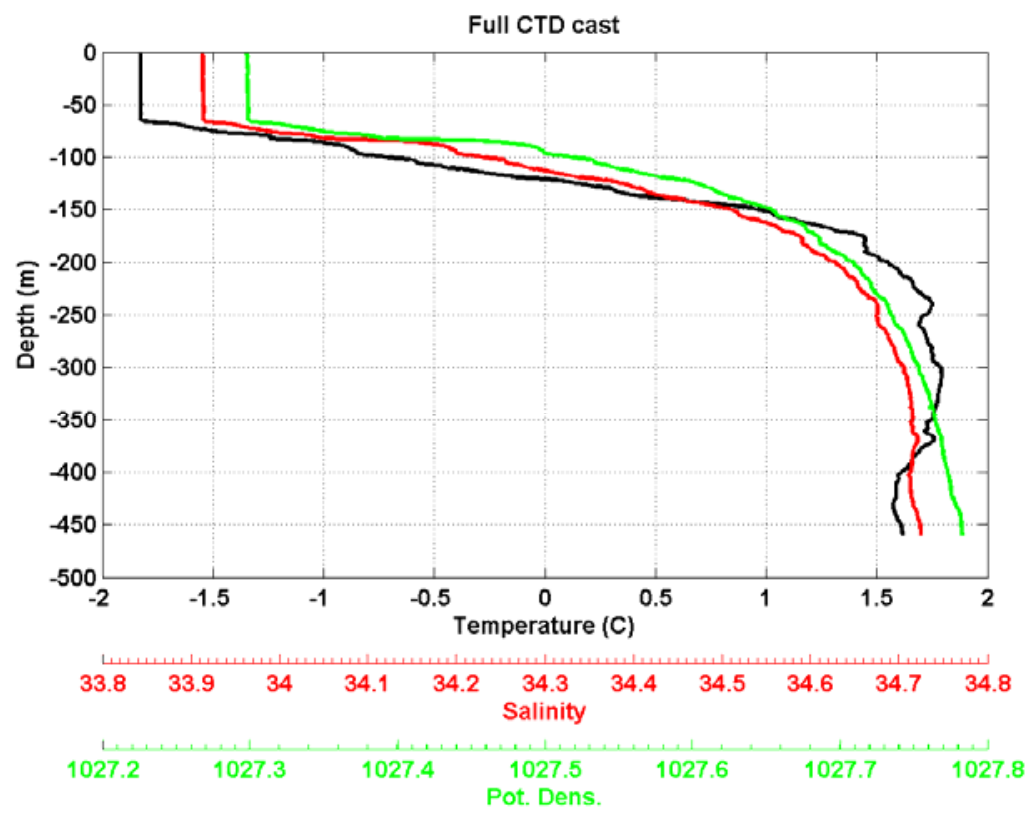

Figure 5.2.2 (a) Initial model temperature (solid black), salinity (solid red) and potential density (solid green) profiles used in the simulations overlaying the observed values (dotted lines). (b) The full CTD cast.

The model's surface wind was based on typical events observed on the wAP shelf (Beardsley et al., 2006): a unidirectional (eastward) wind event lasting 24 hrs with a Gaussian shape and a peak intensity varying between 5 and $25 \mathrm{~m} / \mathrm{s}$, depending on the 
simulation ( $15 \mathrm{~m} / \mathrm{s}$ in Figure 5.2.3). As noted earlier, the wind stress on the ice was calculated using the neutral quadratic drag formula of Large and Pond (1981). The iceocean stress was calculated using a quadratic drag law (equation 5.10) assuming rough first-year ice with the ice-ocean drag coefficient set at $15 \times 10^{-3}$ unless otherwise noted. Additional simulations were done with a rotating wind, as well as with non-zero air-sea heat fluxes.

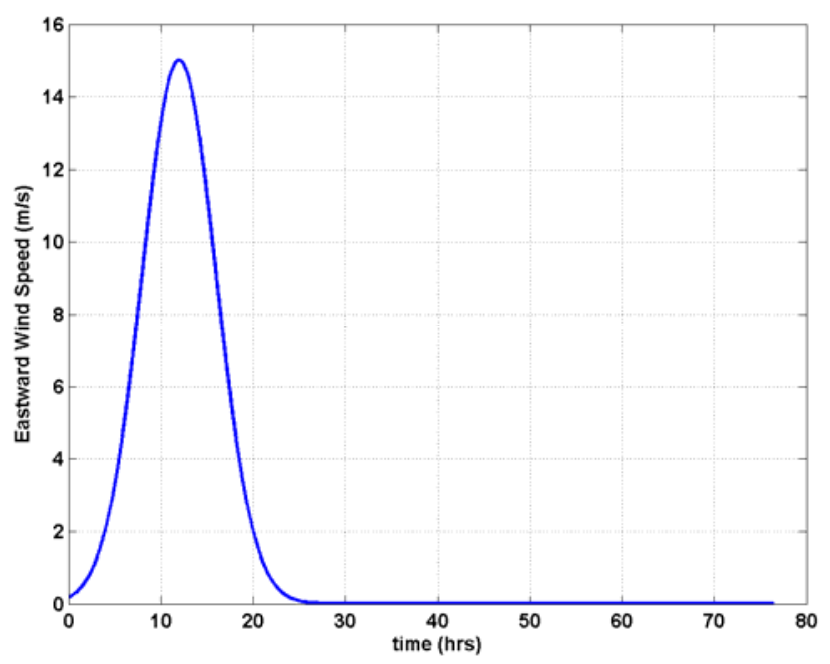

Figure 5.2.3 Wind forcing for idealized runs, with this example having a maximum wind of $15 \mathrm{~m} / \mathrm{s}$.

\subsection{Experiments}

\subsubsection{Ice versus no ice}

An initial set of experiments compared the ocean response to a wind event under ice-free conditions to those with total ice cover. Both surface heat and salt fluxes were set to zero and thus there was no static instability in the water column.

The initial wind event causes all of the observed mixing, with subsequent persistent inertial oscillations stable to shear instability. The presence of ice makes neither a large difference in the modeled response of temperature, salinity and velocity to the wind event (Figures 5.3.1, 5.3.2 and 5.3.3), nor has a great impact on the overall structure of the vertical heat and salt fluxes (Figures 5.3.4 and 5.3.5). While these results are for a wind event with a maximum velocity of $15 \mathrm{~m} / \mathrm{s}$ (Figure 5.2.3), ice had little impact on the model results for wind events ranging in strength between 5 and $25 \mathrm{~m} / \mathrm{s}$. 
(a)

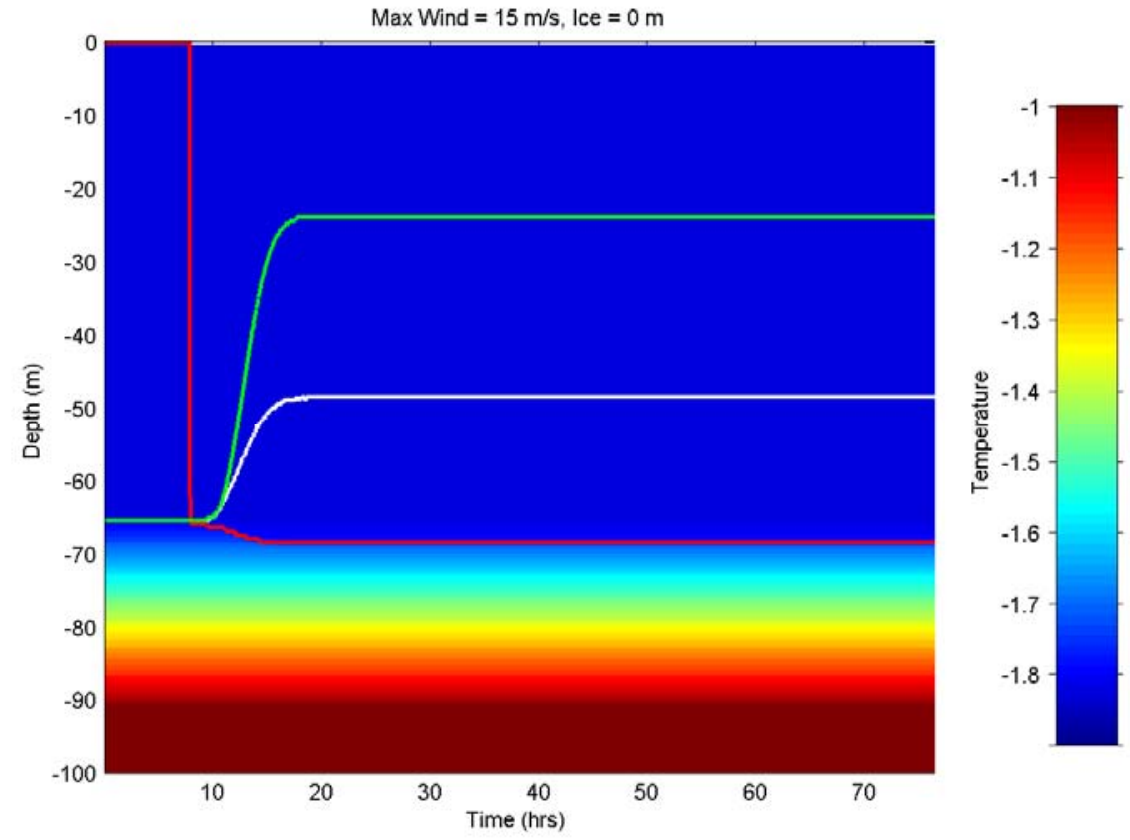

(b)

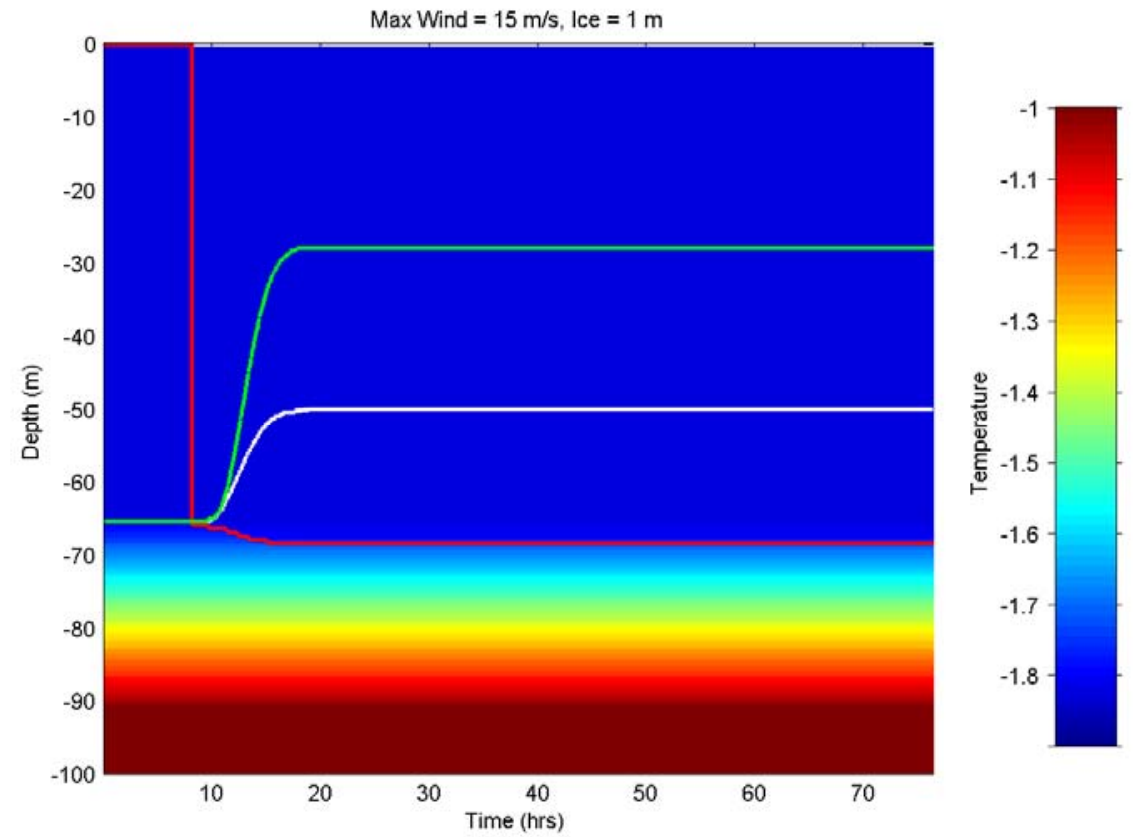

Figure 5.3.1 Depth-time contour plots of the temperature response to a wind event with a maximum speed of $15 \mathrm{~m} / \mathrm{s}$ and (a) no ice and (b) $1 \mathrm{~m}$ ice. White line denotes the model-defined mixed layer depth, the red line marks the maximum depth of mixing and the green line indicates the base of the slab layer. 
(a)

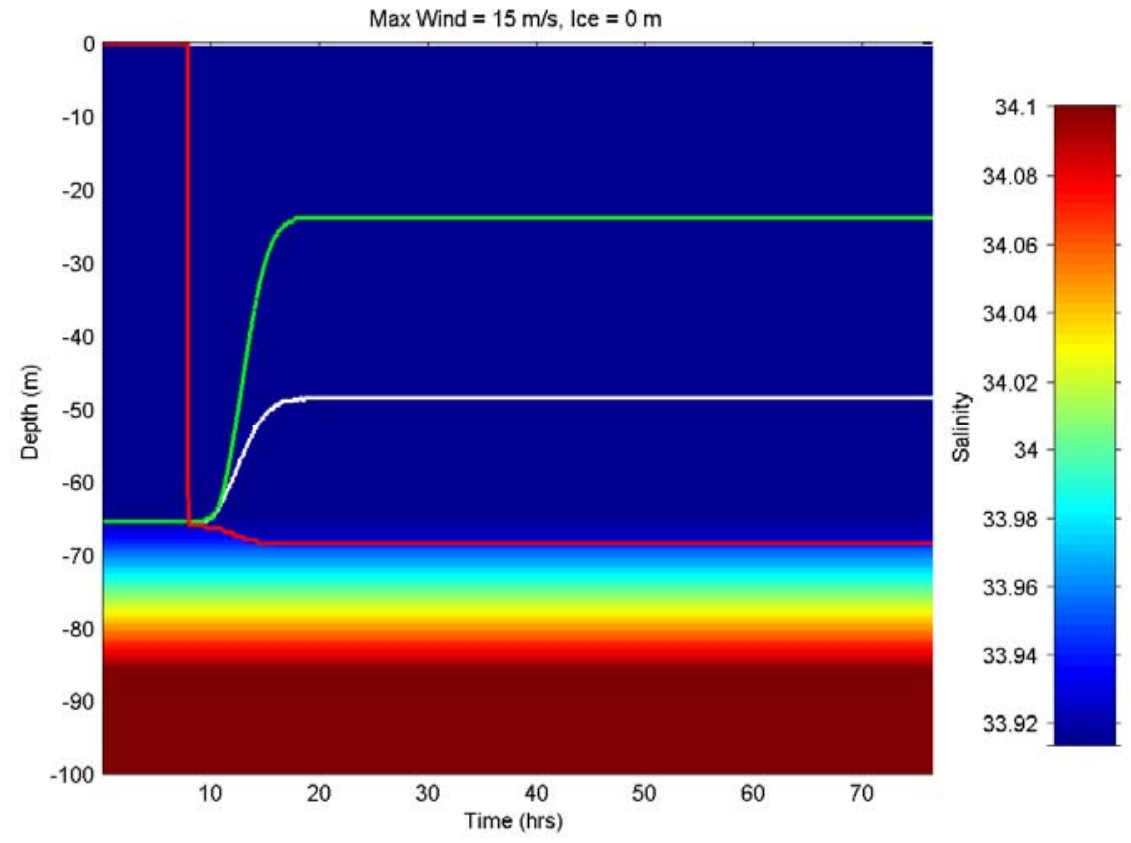

(b)

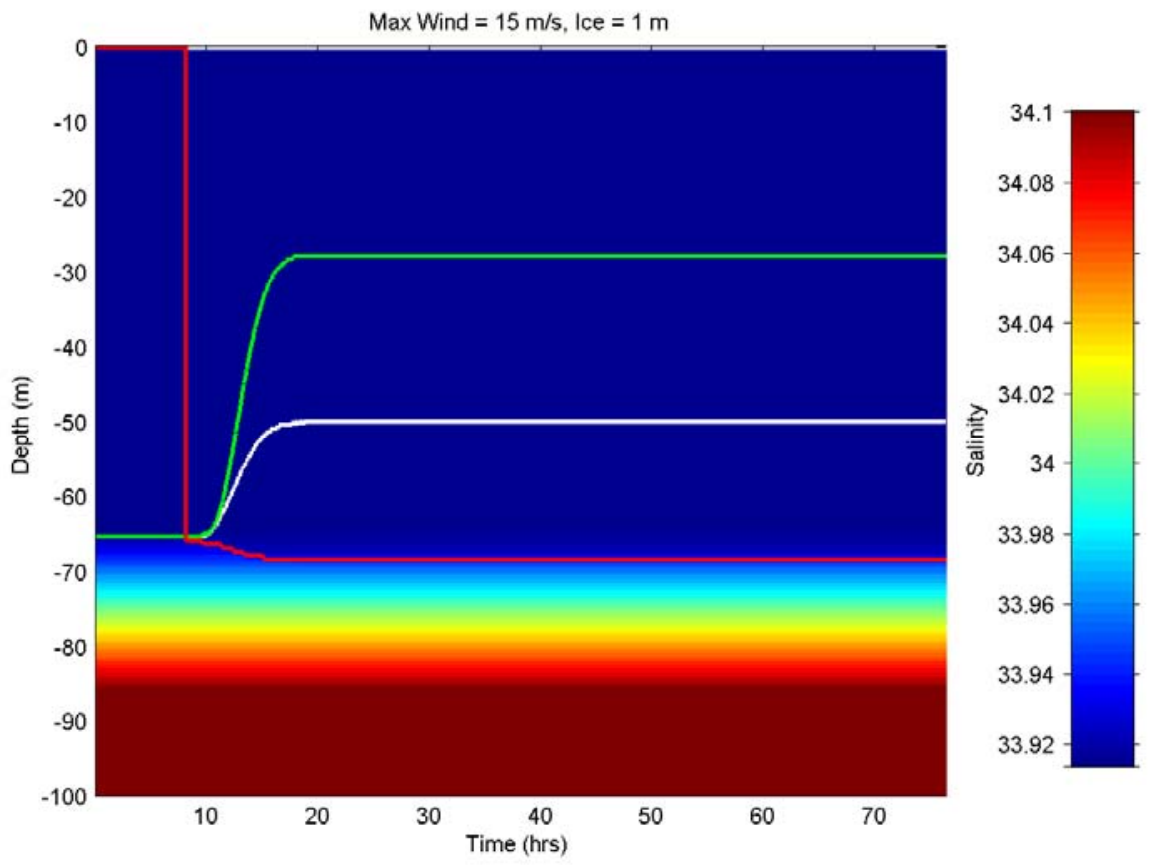

Figure 5.3.2 Depth-time contour plots of the salinity response to a wind event with a maximum speed of $15 \mathrm{~m} / \mathrm{s}$ and (a) no ice and (b) $1 \mathrm{~m}$ ice. White line denotes the model-defined mixed layer depth, the red line marks the maximum depth of mixing and the green line indicates the base of the slab layer. 
(a)
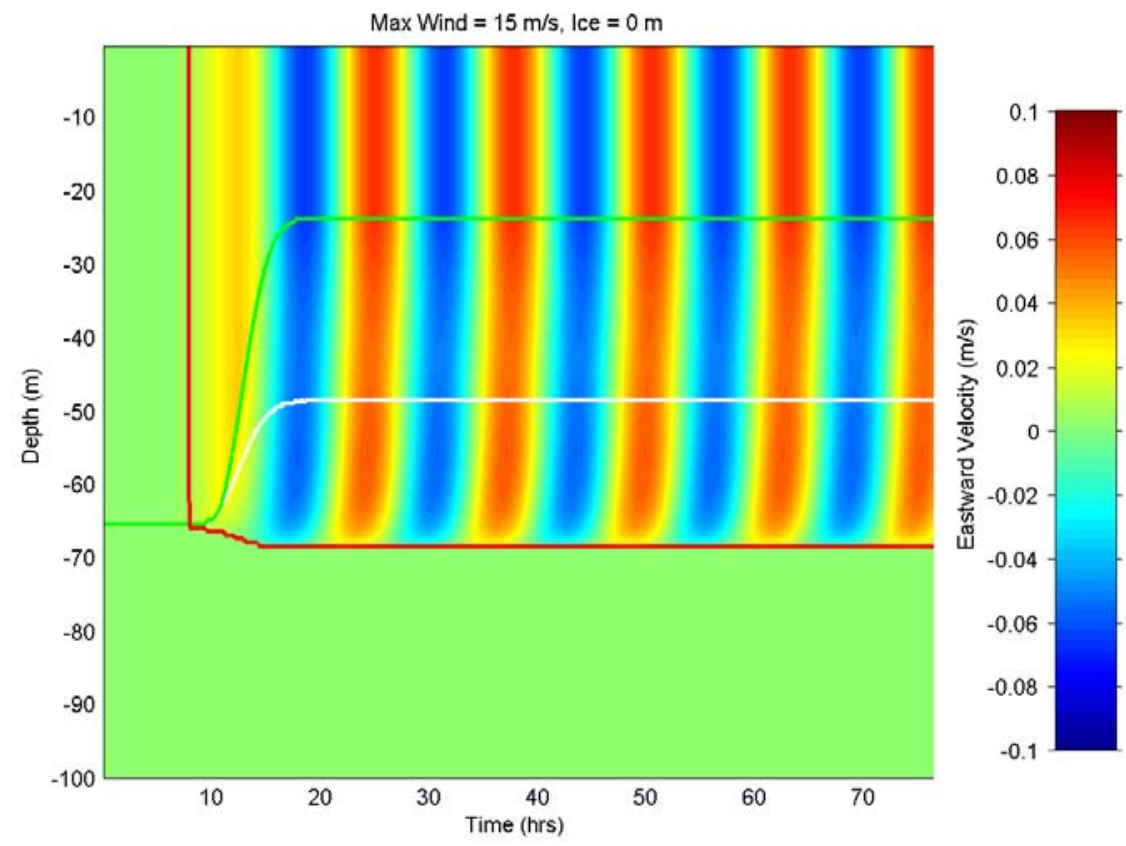

(b)
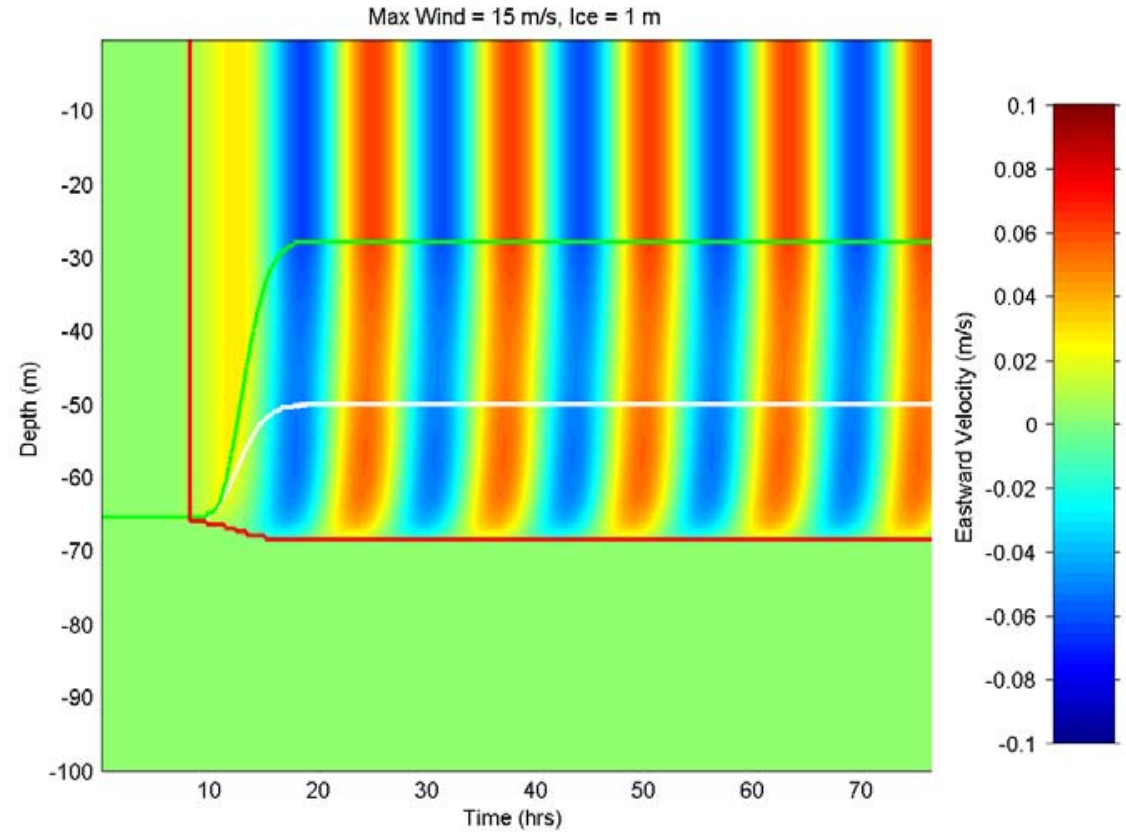

Figure 5.3.3 Depth-time contour plots of the velocity response to a wind event with a maximum speed of $15 \mathrm{~m} / \mathrm{s}$ and (a) no ice and (b) $1 \mathrm{~m}$ ice. White line denotes the model-defined mixed layer depth, the red line marks the maximum depth of mixing and the green line indicates the base of the slab layer. 
(a)

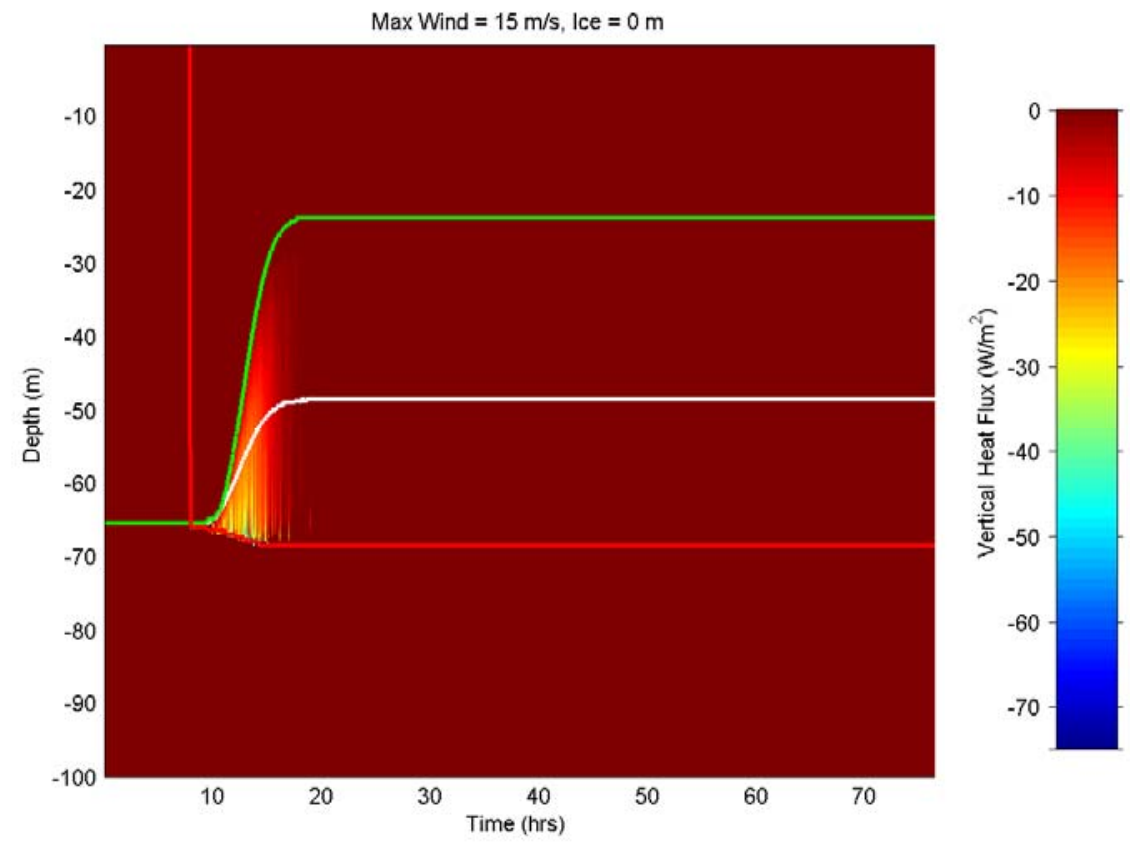

(b)

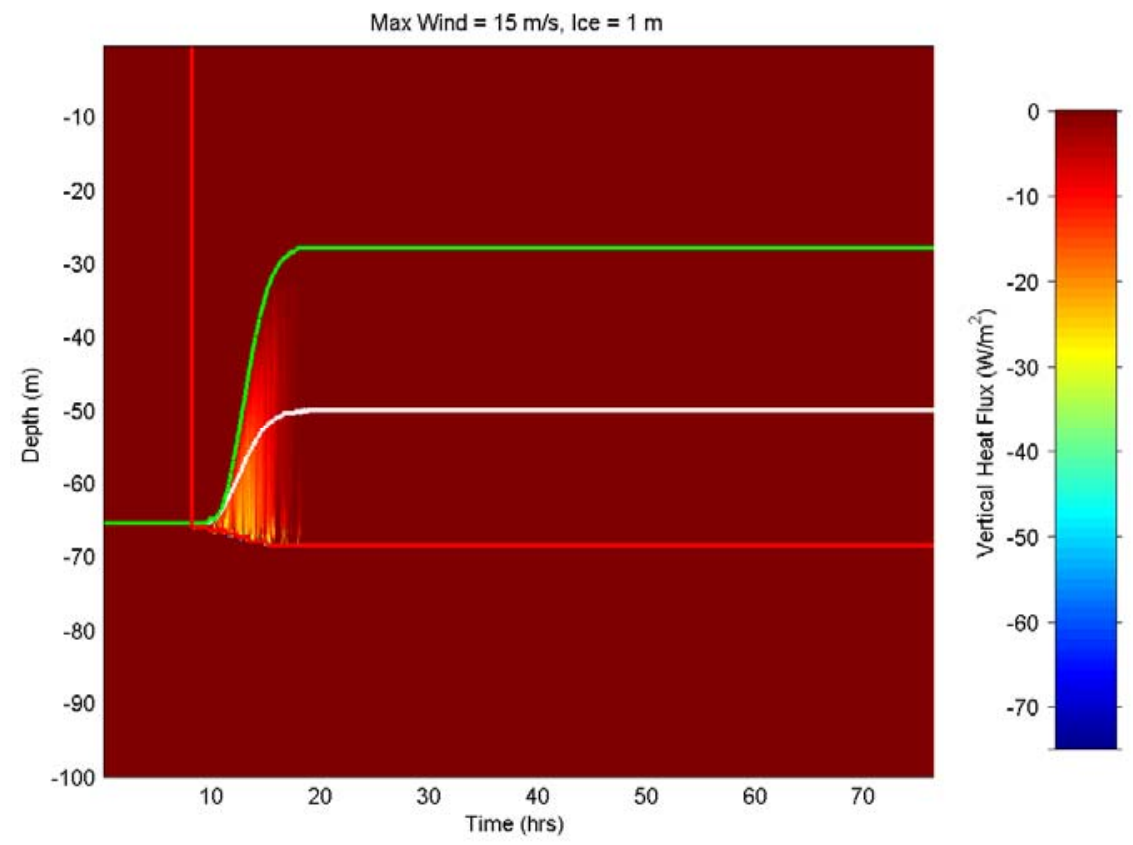

Figure 5.3.4 Depth-time contour plots of the vertical heat flux response to a wind event with a maximum speed of $15 \mathrm{~m} / \mathrm{s}$ and (a) no ice and (b) $1 \mathrm{~m}$ ice. White line denotes the model-defined mixed layer depth, the red line marks the maximum depth of mixing and the green line indicates the base of the slab layer. 
(a)

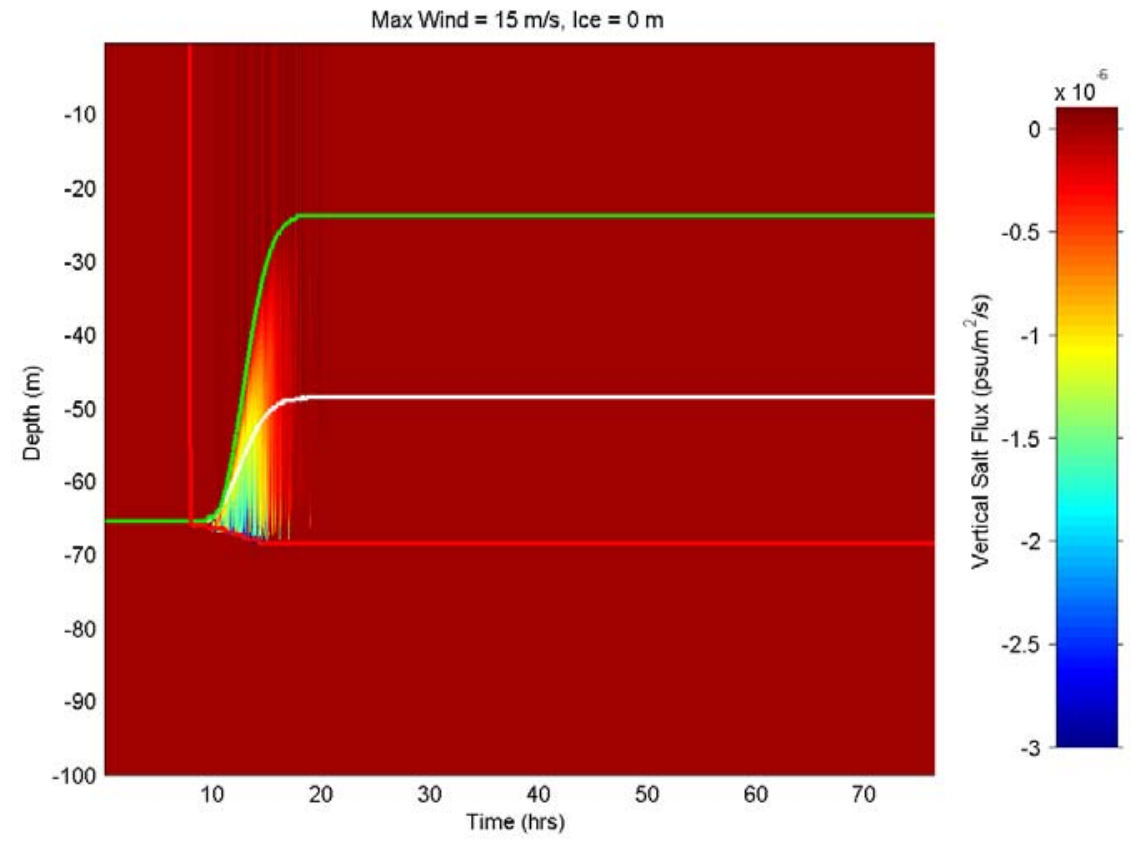

(b)

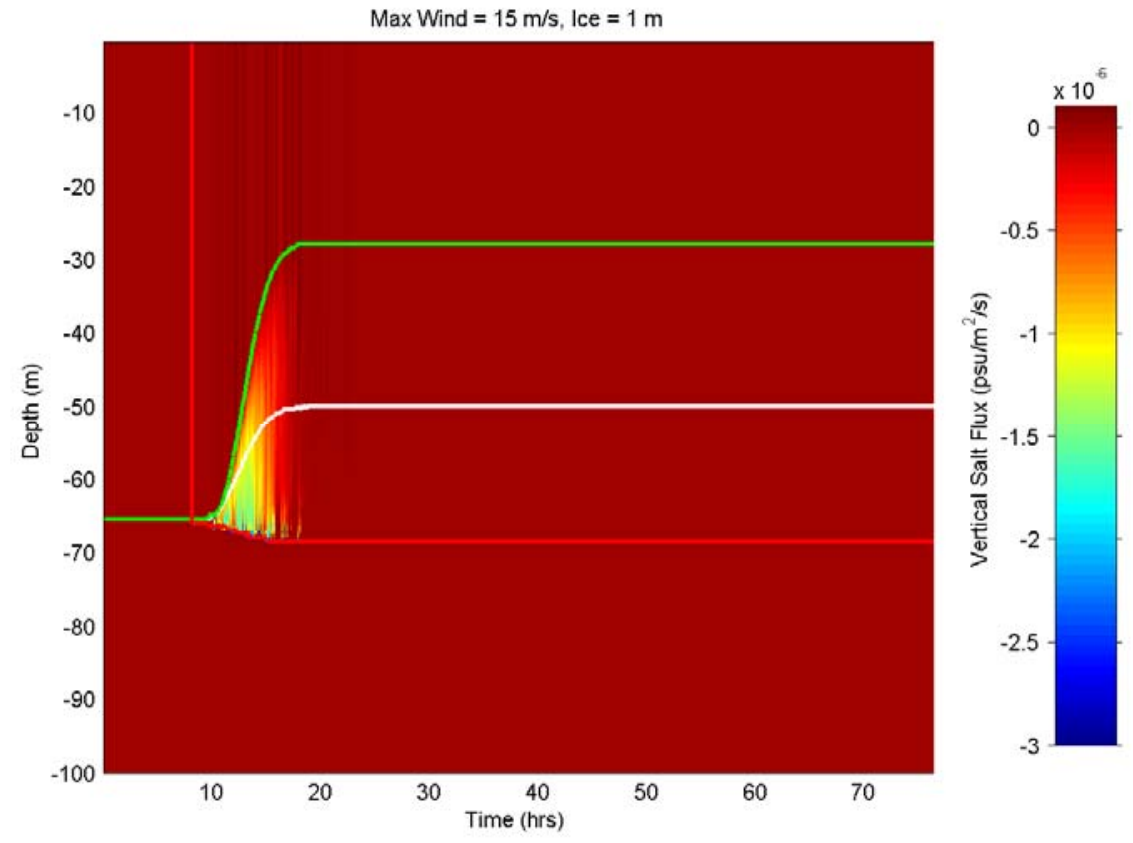

Figure 5.3.5 Depth-time contour plots of the vertical salt flux response to a wind event with a maximum speed of $15 \mathrm{~m} / \mathrm{s}$ and (a) no ice and (b) $1 \mathrm{~m}$ ice. White line denotes the model-defined mixed layer depth, the red line marks the maximum depth of mixing and the green line indicates the base of the slab layer. 
Varying the ice thickness between 0 and $2 \mathrm{~m}$ had little effect on neither the final stratification (Figures 5.3.6, 5.3.7 and 5.3.8) nor inertial oscillation speed (Figure 5.3.9) for a wind burst as shown in Figure 5.2.3. The small effect of ice thickness is due only to the added mass of ice, a relatively small effect when compared to the total mass of the ice/mixed layer system $(\sim 1.5 \%$ for $1 \mathrm{~m}$ ice $)$.

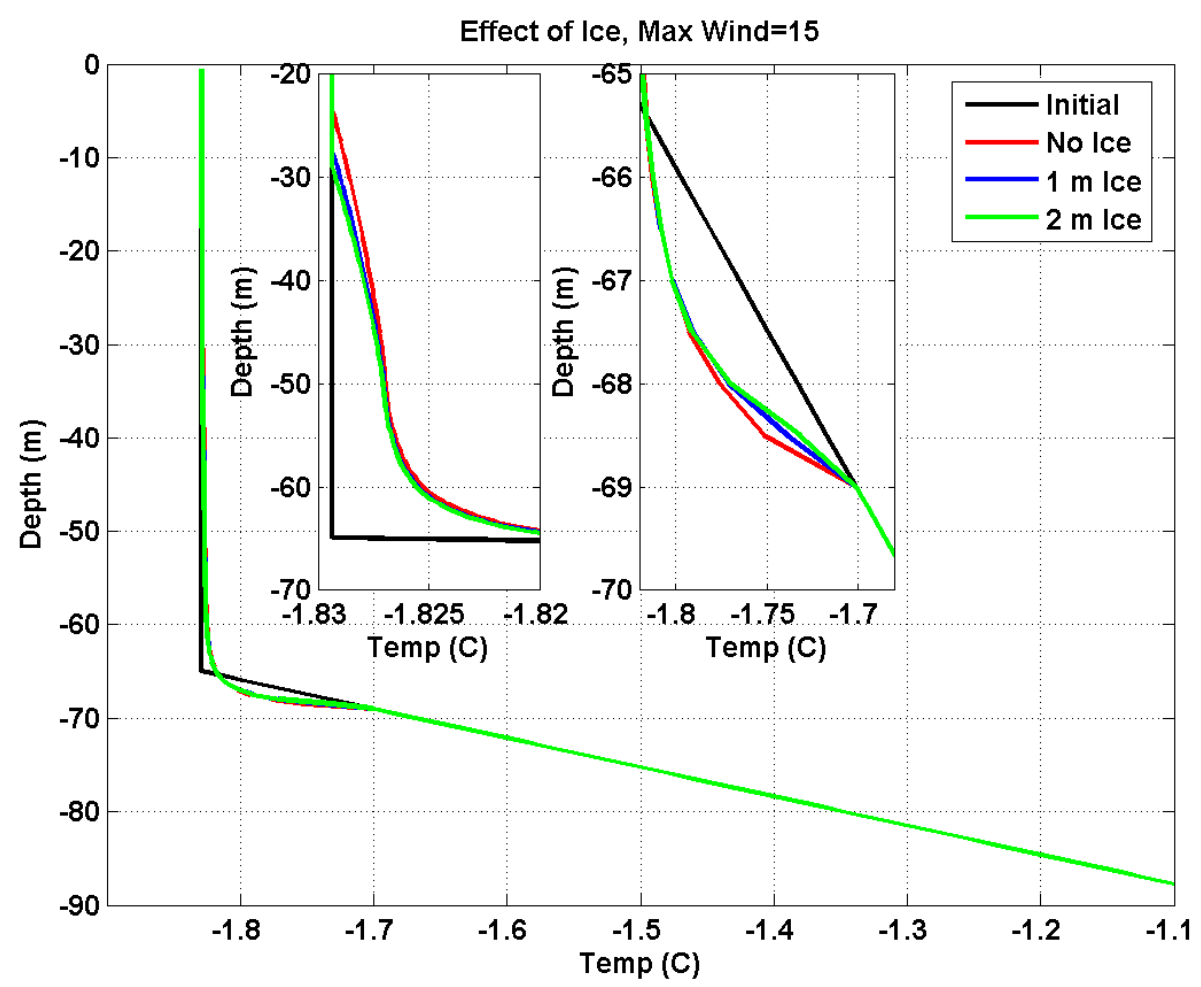

Figure 5.3.6 The effect of various ice thicknesses on the temperature profile. The insets are zoomed in on the change in the mixed layer depth (left) and maximum depth of mixing (right). 


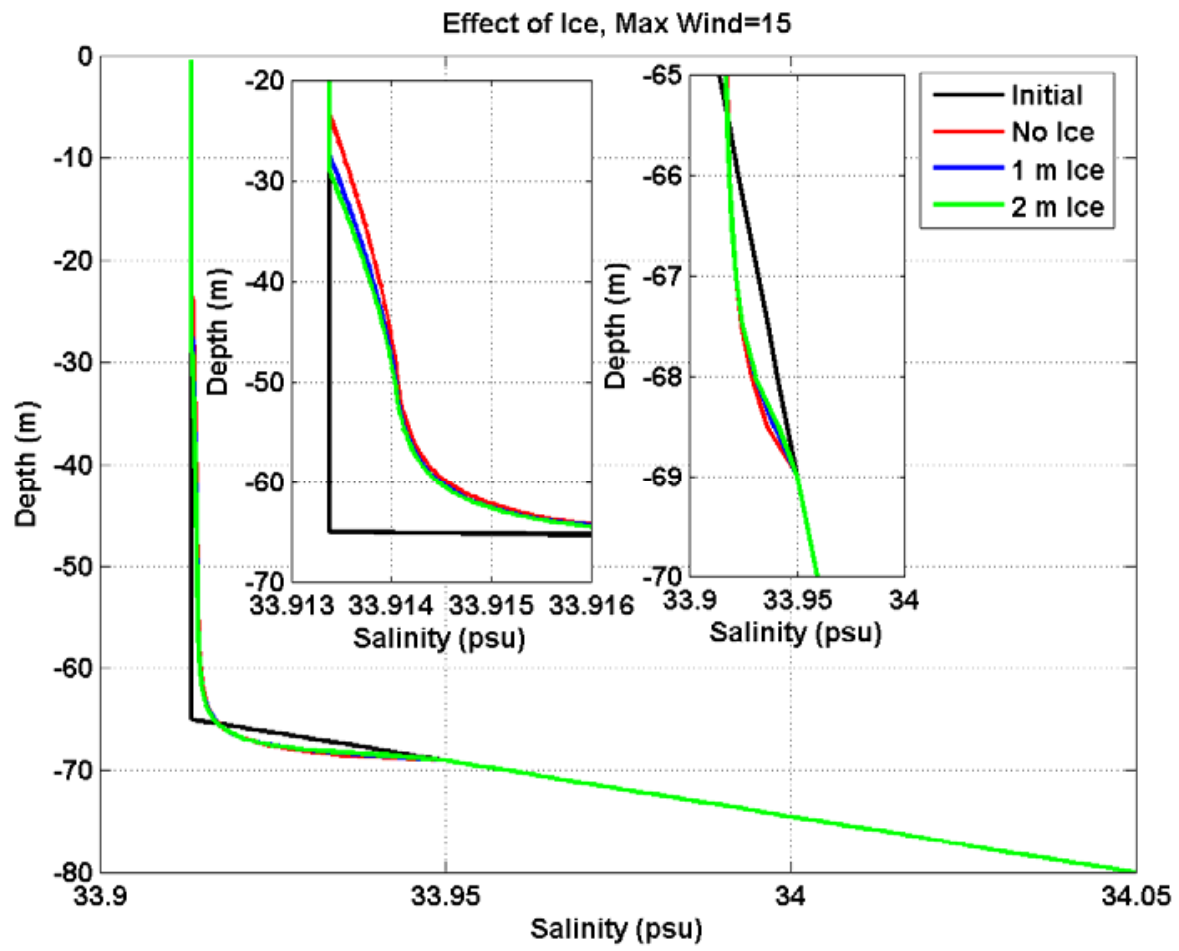

Figure 5.3.7 The effect of various ice thicknesses on the salinity profile. The insets are zoomed in on the change in the mixed layer depth (left) and maximum depth of mixing (right).

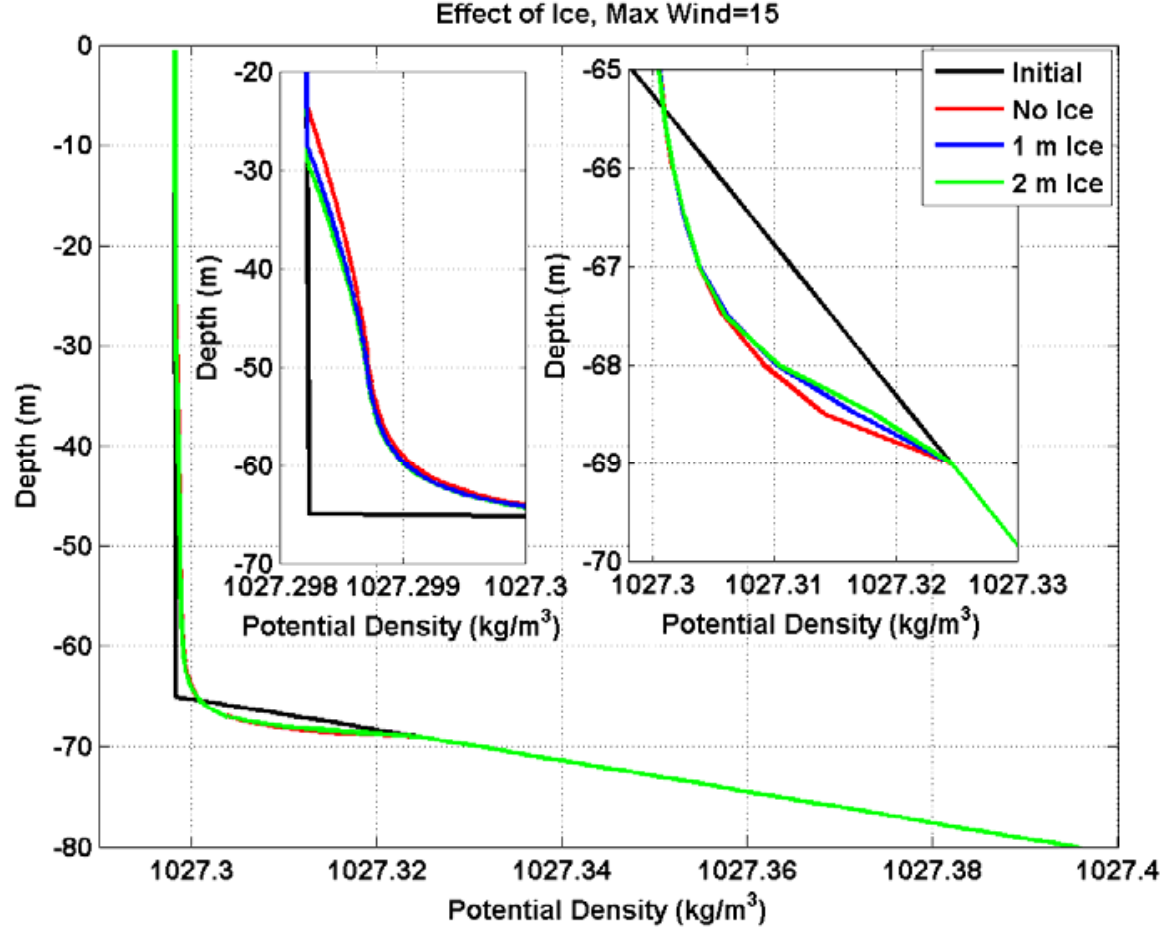

Figure 5.3.8 The effect of various ice thicknesses on the density profile. The insets are zoomed in on the change in the mixed layer depth (left) and maximum depth of mixing (right). 


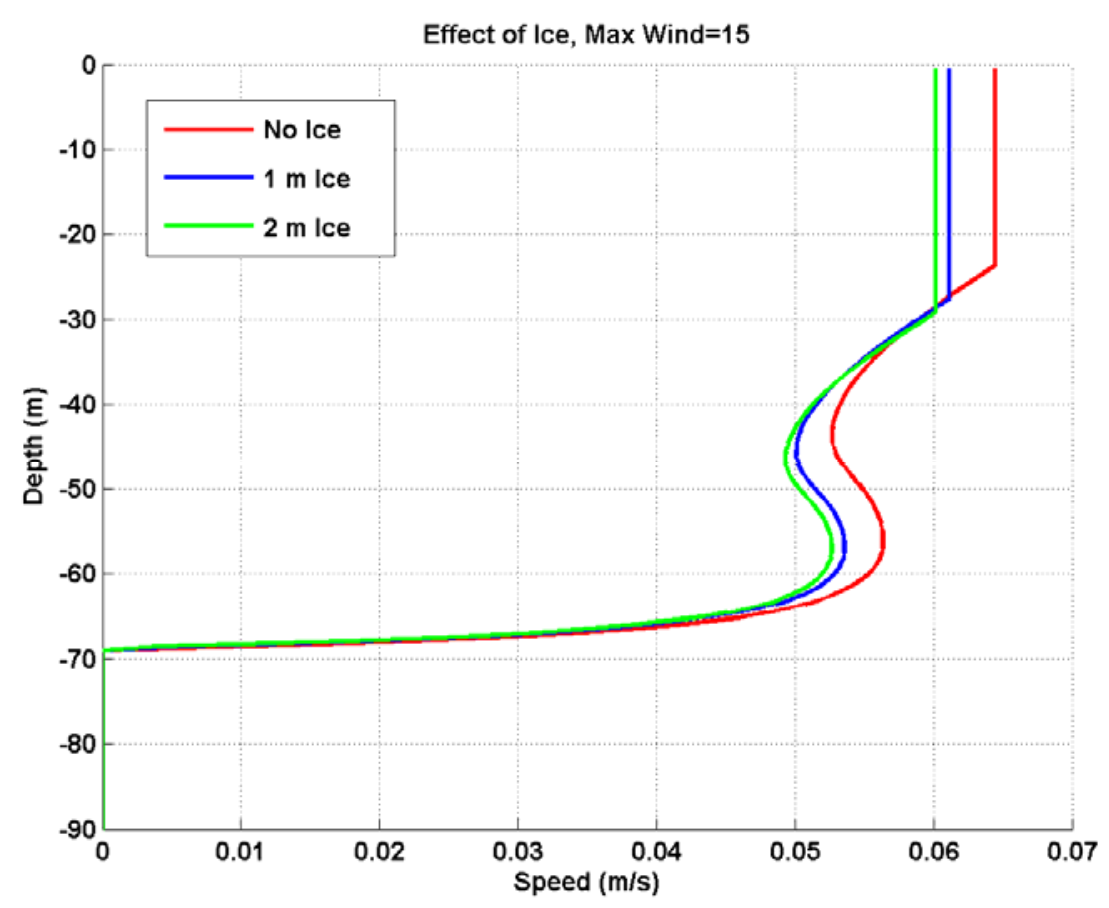

Figure 5.3.9 The effect of various ice thicknesses on the current speed profile.

The observation that the initial wind event causes all of the observed mixing is consistent with Plueddemann and Farrar (2006), who examined a variety of ice-free datasets and found that the majority of strong mixing events are very short, less than 1/10 of an inertial period, with the longest events being at most $1 / 2$ an inertial period.

\subsubsection{Sensitivity to the ice-ocean drag coefficient, $C_{d}$}

The next set of simulations explored the effect of varying the ice-ocean drag coefficient, $\mathrm{C}_{\mathrm{d}}$. To do this, $\mathrm{C}_{\mathrm{d}}$ was varied from 0.0001 to 0.030 , the range of values estimated through observational methods such as eddy correlation in a variety of regions in both the Northern and Southern Hemispheres (Shirasawa and Ingram, 1991). The large range in values reflects variations in the roughness of the bottom of the ice floes. The maximum wind speed was $15 \mathrm{~m} / \mathrm{s}$ and the ice thickness was $1 \mathrm{~m}$ for all runs in this section.

For the set of initial and boundary conditions tested here, changes in $\mathrm{C}_{\mathrm{d}}$ had little effect on the simulation for values greater than 0.001 . The ice velocity becomes sensitive to the choice of $C_{d}$ with values lower than 0.001 , even having a different final phase of 
the inertial oscillations compared with runs at higher values (Figure 5.3.10a). In particular, the distance covered by the ice during the initial wind burst is greatly increased for the very low values of $\mathrm{C}_{\mathrm{d}}$. One should note, however, that observationally based values of $\mathrm{C}_{\mathrm{d}}$ less than 0.001 have not been observed for first-year drifting ice (Shirisawa and Ingram, 1991) such as that found in Marguerite Bay, which is relatively rough (Perovich et al., 2004).

The response of the upper ocean mixed layer current to changes in the drag coefficient is small (Figure 5.3.10b), with all flows simulated with a $C_{d}>0.0005$ within $+/-3 \%$ of the open water value. This insensitivity is due to low values of the ice-ocean quadratic drag smoothing the ice-ocean stress in time, thus weakening the final magnitude of the inertial oscillations. More abrupt changes in surface stress lead to stronger inertial oscillations. Cases with low $\mathrm{C}_{\mathrm{d}}$ have lower ice-ocean stress and therefore allow higher ice velocities and lower ocean velocities. This creates a smoothing in time as the ocean takes longer to match velocity with the ice.

Changes in the ice-ocean drag coefficient act to distribute the momentum differently, but the total momentum of the system remains largely unchanged. Any small changes in the total momentum come from the dependence of the air-ice stress on the ice velocity, so when the ice moves faster (lower $C_{d}$ ) and the velocity difference between the ice and air is smaller, the total imparted momentum is decreased. 
(a)

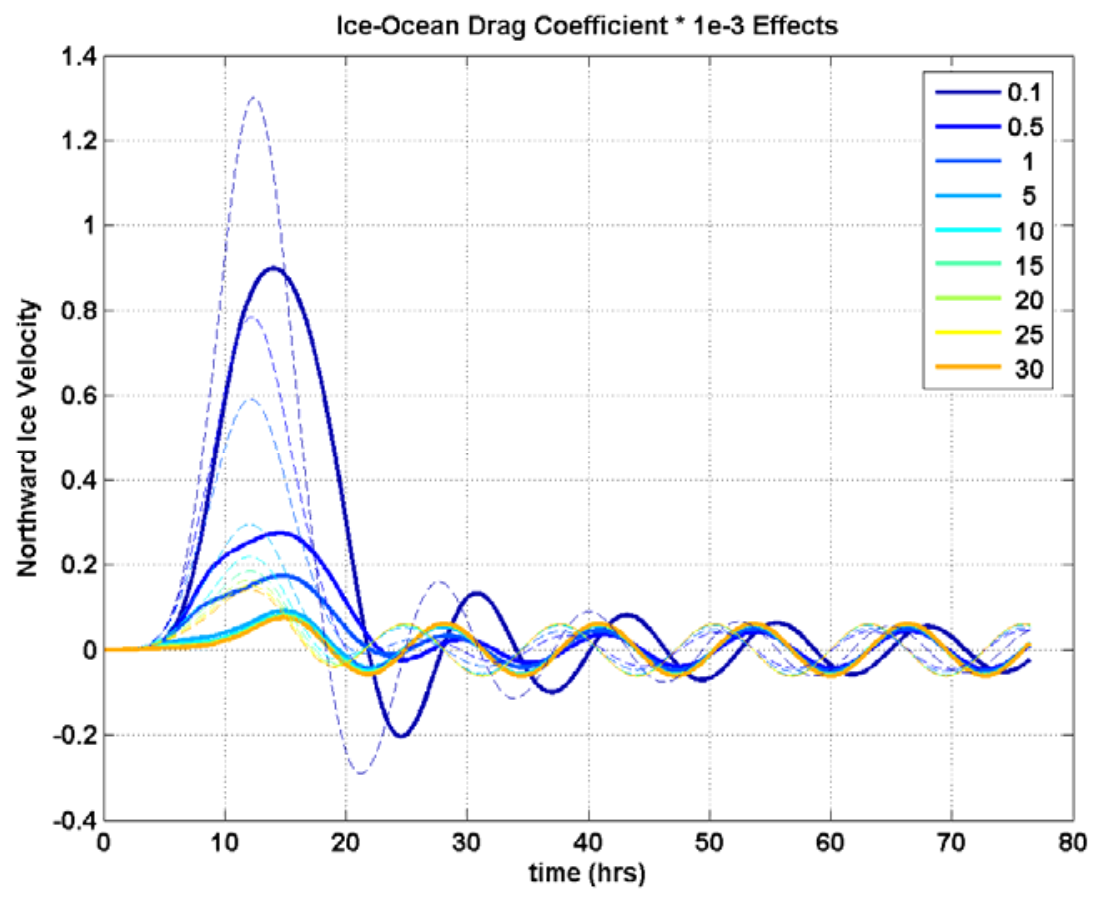

(b)

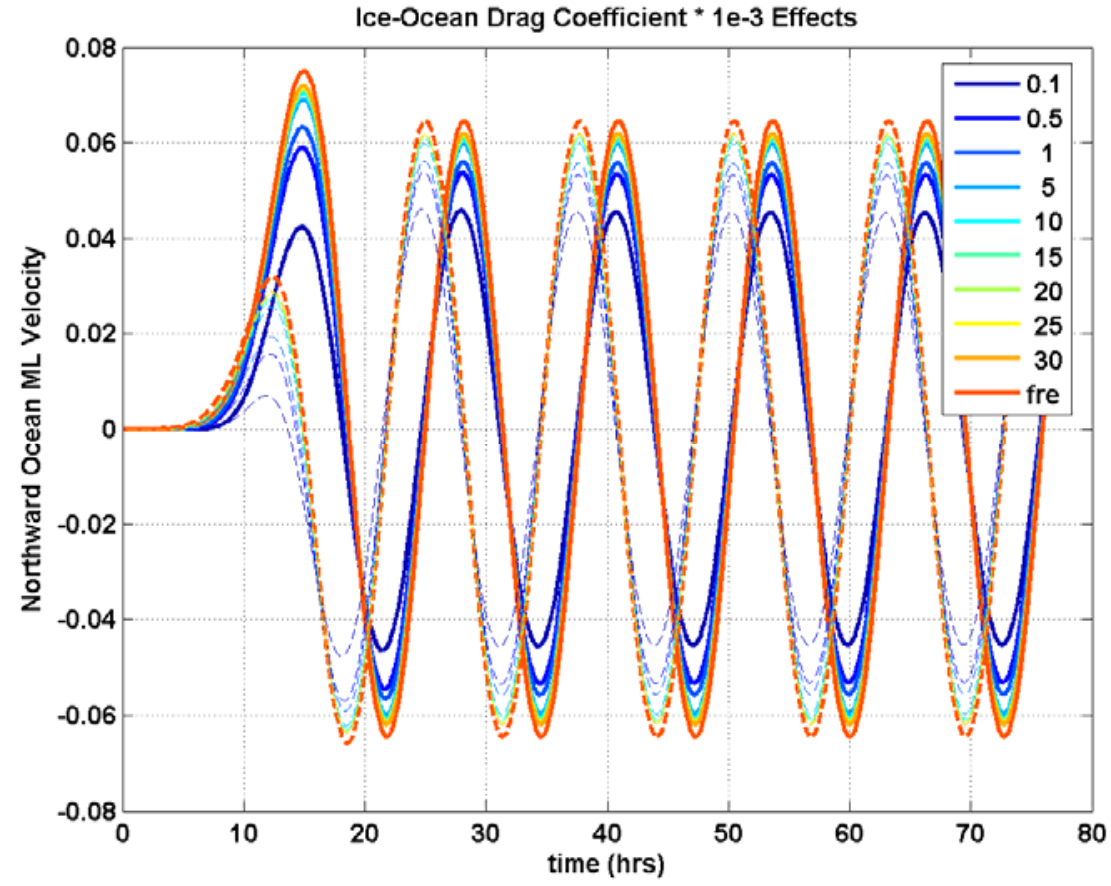

Figure 5.3.10 Northward (solid lines) and eastward (dashed lines) (a) ice velocity and (b) ocean mixed layer velocity $(\mathrm{m} / \mathrm{s})$ for runs with different ice-ocean drag coefficients. Values in the legend indicate the ice-ocean drag*10 ${ }^{3}$, with 'fre' in (b) referring to the open water case. 
Examination of the final temperature profile's response to changes in the drag coefficient reveals deeper maximum depth of mixing and shallower mixed layer as $C_{d}$ is increased (Figure 5.3.11). Again, for reasonable values of $C_{d}$ (greater than 0.001), the response does not vary greatly between runs.

One conclusion from these experiments is that as $C_{d}$ increases, the response in the model tends towards the open water case and maximum mixing for a given wind event. Furthermore, the modeled response of the upper ocean is not sensitive to the range of values reasonable for the rough deformed first-year ice found on the wAP shelf (Perovich et al., 2004), i.e. $C_{d}>0.001$ (Shirisawa and Ingram, 1991).

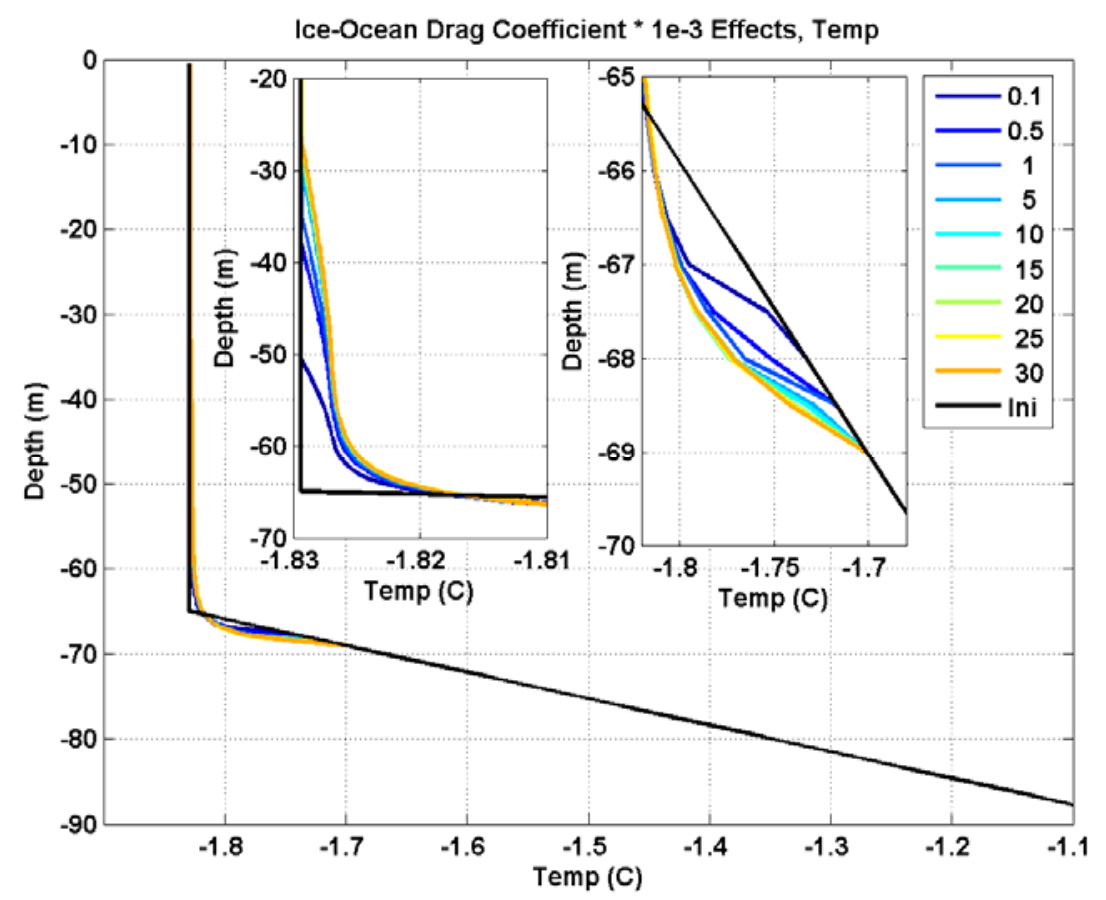

Figure 5.3.11 Final temperature profile of runs with different values of $C_{d}$. Values in the legend indicate the ice-ocean $\mathrm{drag}^{*}{ }^{*} 0^{3}$, with 'Ini' referring to the initial profile.

\subsubsection{Lead opening and closing and air-sea heat fluxes}

A second set of simulations was performed in which the effects of ice leads were examined. As presented earlier, this was accomplished by allowing a surface air-sea heat flux through leads that open and close due to inertial divergent motions in the ice pack. The hypothesis being tested is that periodic ice formation and subsequent brine rejection and static instability and mixing will influence the stratification and result in enhanced 
shear instability during and after the initial wind burst. All runs in this section had 1-m thick ice.

As described above, the surface heat flux is modulated by the open water fraction $A$, the fraction of the surface area that is ice-free over a spatial average. The open water fraction is set ad hoc proportional to the eastward ice motion $u_{i}(t)$,

$$
A=A_{\max } \frac{\left|u_{i, \max }-u_{i}(t)\right|}{2 u_{i, \max }} \text {, with } A_{\max } \text { depending on the individual simulation and } u_{i, \max }
$$

taken from the case with no lead opening and closing but the same wind forcing (Figure 5.3.12a). An alternative method for calculating $A$ could be to use $x_{i}(t)$ instead of $u_{i}(t)$. However, integrating $u_{i}(t)$ in time to get $x_{i}(t)$ simply changes the phase of the periodic signal by $\pi / 4$. Since these simulations are idealized such that the north-south and eastwest directions are interchangeable, the use of $u_{i}(t)$ or $x_{i}(t)$ in calculating $A$ does not change the results.

When the surface water is cooled below freezing, ice is formed and the equivalent amount of brine (equations 5.11 and 5.12) is injected into the top layer of the ocean model causing static instability and mixing. The simulated sea surface temperature and salinity and a constant air temperature $\left(-20^{\circ} \mathrm{C}\right)$ and relative humidity $(70 \%)$ are input into bulk formulae (Fairall et al., 1996) to calculate gross latent and sensible heat fluxes (Figure 5.3.12b blue and green lines) which are then scaled by the open water fraction $A$. In order to simulate the observed light and variable winds in Marguerite Bay (Beardsley et al, 2006), a background wind of $5 \mathrm{~m} / \mathrm{s}$ is used in the bulk formulae to calculate heat fluxes after the initial wind event but is not used in the calculation of the surface stress. This causes the non-zero sensible and latent fluxes after the initial 24 hours. The radiative heat fluxes are assumed constant at $100 \mathrm{~W} / \mathrm{m}^{2}$ (loss) (Figure 5.3.12b red line) before applying the open water fraction $A$. The total heat flux (sum of sensible, latent and radiative) is then scaled by the open water fraction $A$ to get the net heat flux applied in the model (Figure 5.3.12b black line). For example, with the maximum open water $A_{\max }$ set to 0.5 and a maximum wind of $15 \mathrm{~m} / \mathrm{s}$, the net surface cooling oscillates between 20 and $180 \mathrm{~W} / \mathrm{m}^{2}$. 


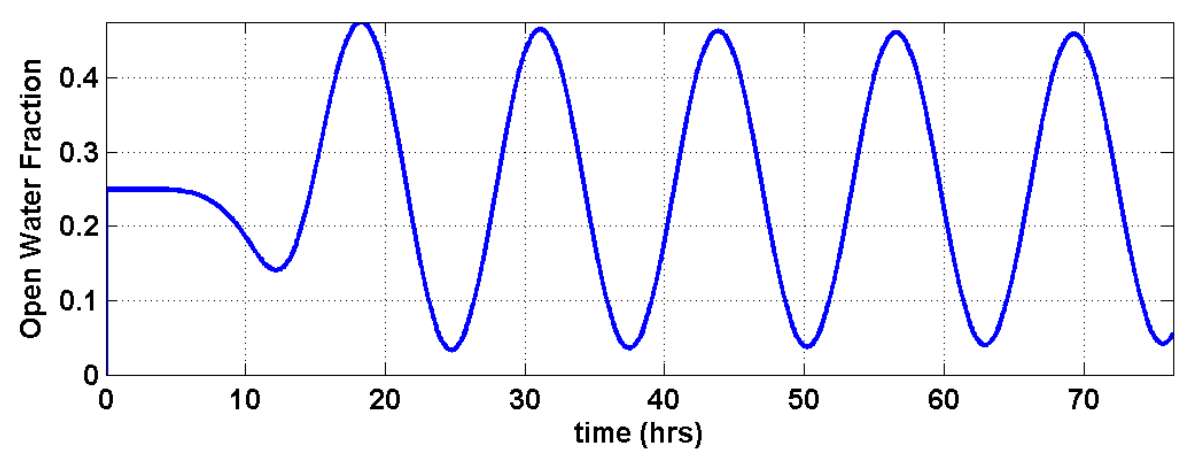

(b)

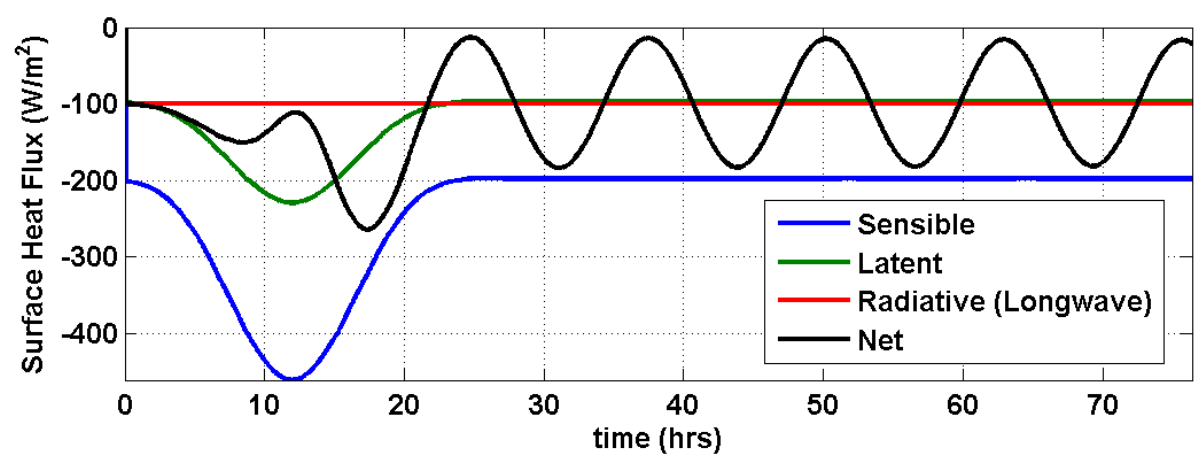

Figure 5.3.12 Time series of (a) applied open water fraction $A$ with a prescribed maximum $A_{\max }$ of 0.5 and (b) resulting air-sea heat fluxes consisting of sensible (blue), latent (green), net radiative (red) components. The net (black) heat flux is the sum of the sensible, latent and radiative fluxes multiplied by the open water fraction $A$.

The active air-sea heat flux not only allows for ice production and destabilizing brine rejection, the resulting vertical mixing vents stabilizing heat from deeper water to the mixed layer and ultimately the atmosphere. This eliminates the warming in the region from roughly 30- to 65-m depth seen in Figure 5.3.6 and acts to deepen the mixed layer.

Comparison of the evolution of the temperature profile with the forcing shown in Figure 5.3.12 (Figure 5.3.13) with the identical case without air-sea heat fluxes (Figure 5.3.1) shows both a deeper mixed layer $(71 \mathrm{~m}$ vs. $50 \mathrm{~m}$ ) and maximum depth of mixing (74 m vs. $69 \mathrm{~m})$. 


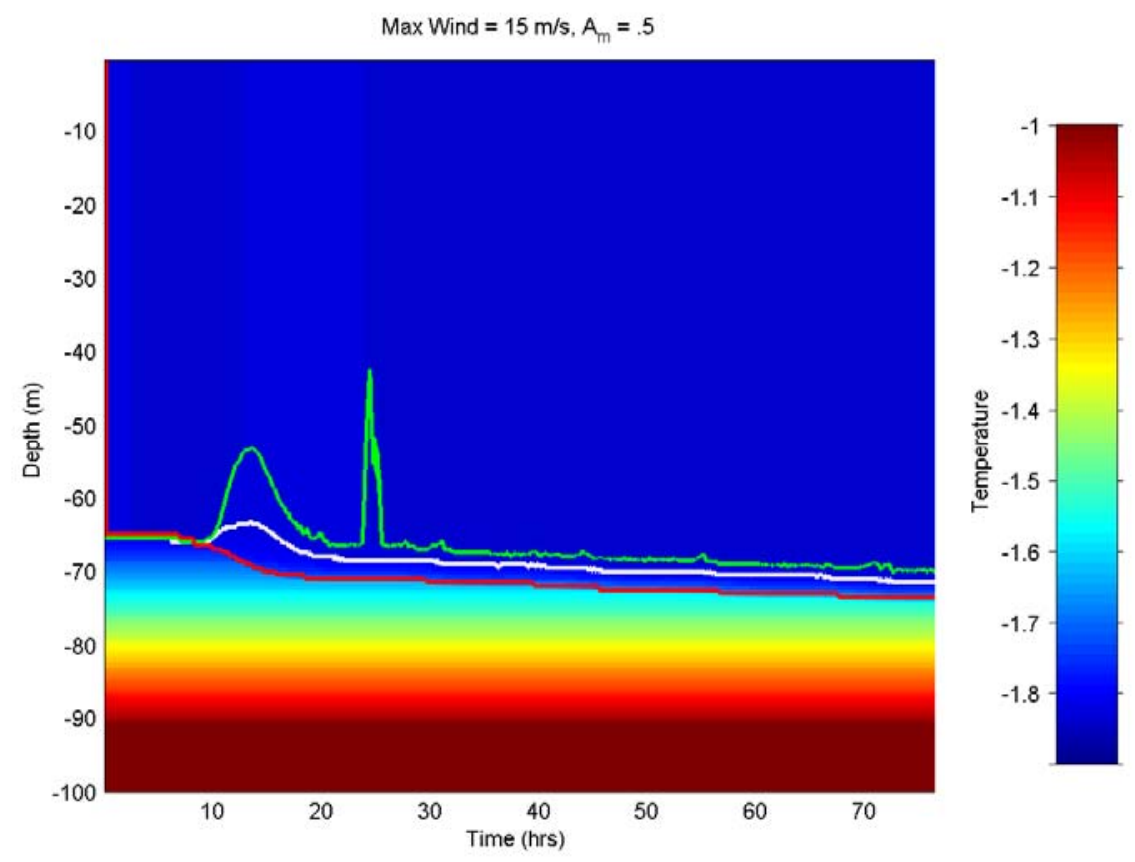

Figure 5.3.13 Depth-time contour plot of the temperature response to a wind event with a maximum speed of $15 \mathrm{~m} / \mathrm{s}$ and $50 \%$ maximum open water fraction. White line denotes the model-defined mixed layer depth, the red line marks the maximum depth of mixing and the green line indicates the base of the slab layer.

The combined effect of static and shear instability can be seen in the vertical heat flux (Figure 5.3.14a). The wind event causes the initial period of shear mixing as in the case with no leads (Figure 5.3.4), but it is combined with the initial surface cooling/brining (Figure 5.3.12) to flux more heat than wind alone. The pulsed brining causes static instability which changes the stratification. This new stratification is unstable with the existing background shear (equation 5.6) and mixes further. In the case without strong wind forcing and thus no strong inertial shear, the mixed layer depth is identical to the case with both wind and leads, but the transition layer has zero thickness (Figure 5.3.14b). 
(a)

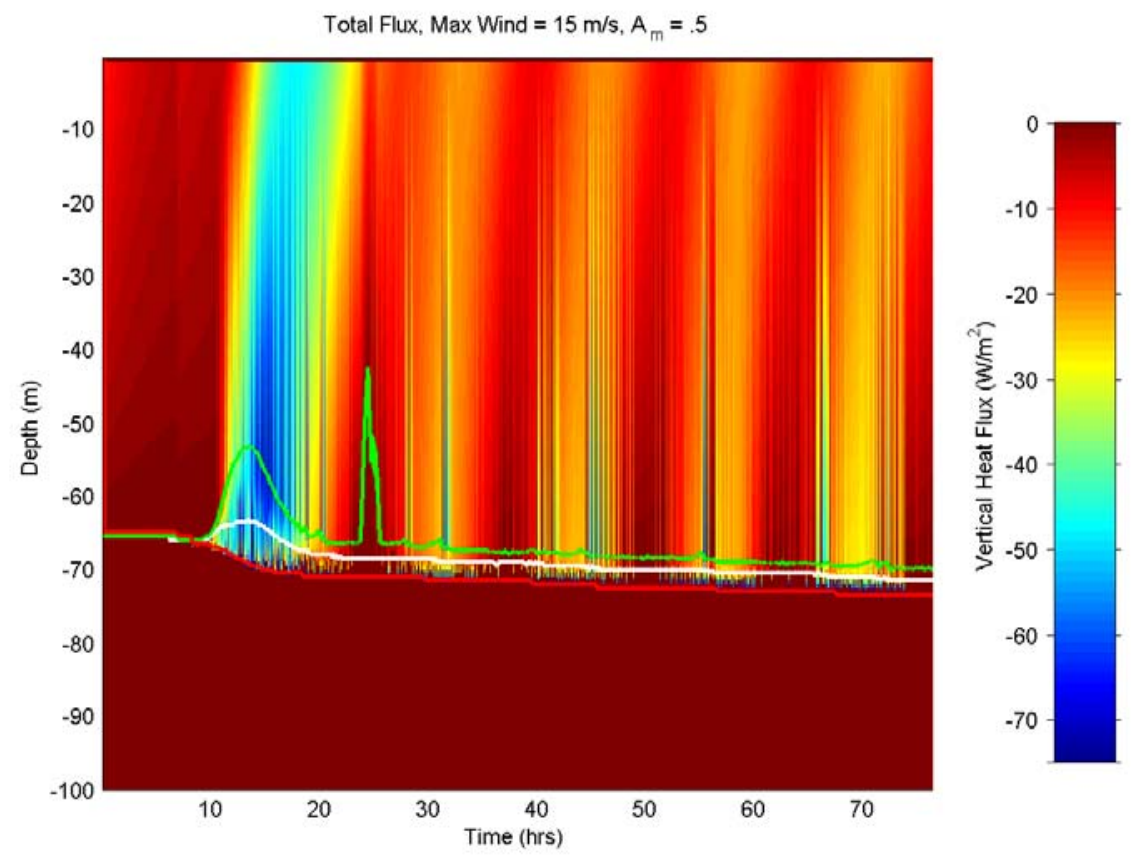

(b)

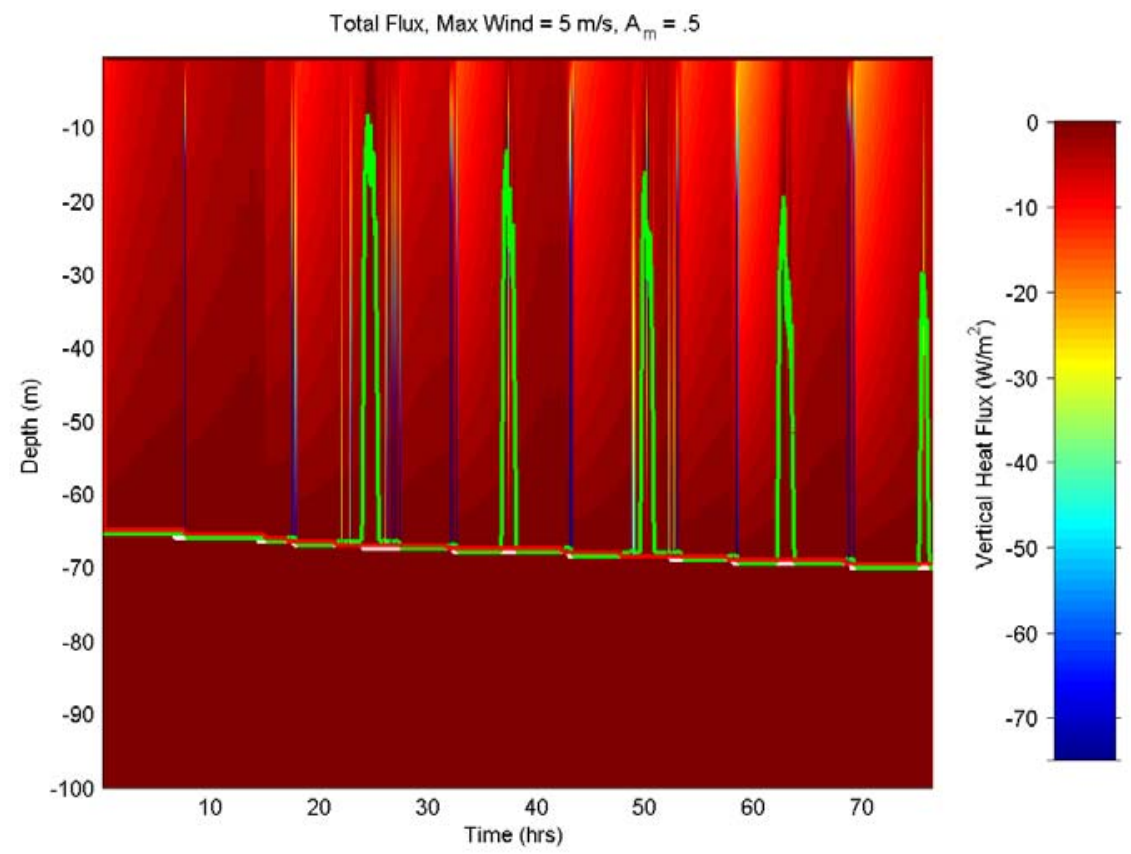

Figure 5.3.14 Depth-time contour plot of the vertical heat flux response to a wind event with a maximum speed of (a) $15 \mathrm{~m} / \mathrm{s}$ and (b) $5 \mathrm{~m} / \mathrm{s}$, both with $50 \%$ maximum open water fraction. White line denotes the model-defined mixed layer depth, the red line marks the maximum depth of mixing and the green line indicates the base of the slab layer. 
The relative roles of the mixing processes contained in the PWP model can be examined by saving the temperature and salinity profiles partway through each time step. First, output is saved after the static instability criterion has been met, then again after the bulk Richardson number criterion has been met, and then after the gradient Richardson number criterion has been satisfied. Fluxes can then be calculated for each process in the model, as shown in Figure 5.3.15 for a simulation with a $15 \mathrm{~m} / \mathrm{s}$ maximum wind and 50\% maximum open water fraction.

The PWP model first checks for static stability, starting at the surface, and entrains cells into the mixed layer until the profile is stable (Figure 5.3.15a). The addition of salt at the surface has caused the flux of heat and salt upwards into the mixed layer. The PWP model then checks the $\mathrm{Ri}_{\mathrm{b}}$ criterion, which was not exceeded for the simulation forced with a $15 \mathrm{~m} / \mathrm{s}$ maximum wind and $50 \%$ maximum open water fraction. Entrainment into the mixed layer due to shear ( $\mathrm{Ri}_{\mathrm{b}}$ criterion mixing) did occur in runs with stronger forcing, and played a significant role in the simulation in Section 5.4. Finally, the $\mathrm{Ri}_{\mathrm{g}}$ criterion is applied and the model iterates to make the flow in the transition layer stable (Figure 5.3.15b).

The region in the 'mixed layer' which shows $\mathrm{Ri}_{\mathrm{g}}$ fluxes, especially between hours 10 and 20, is the very weakly stratified part in the lower portion of the mixed layer which is not a true fully-mixed slab. The density difference between the base of the slab and the base of the mixed layer is of the order $10^{-5} \mathrm{~kg} / \mathrm{m}^{3}$. 
(a)

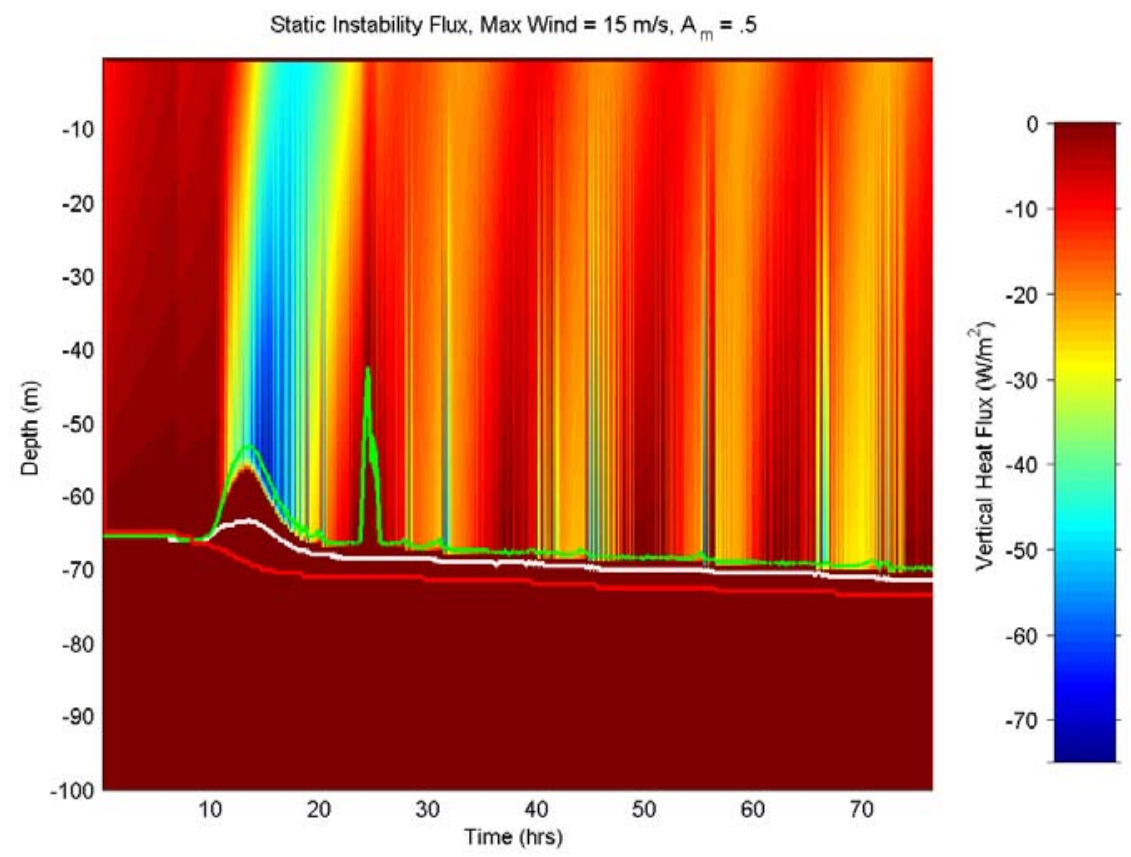

(b)

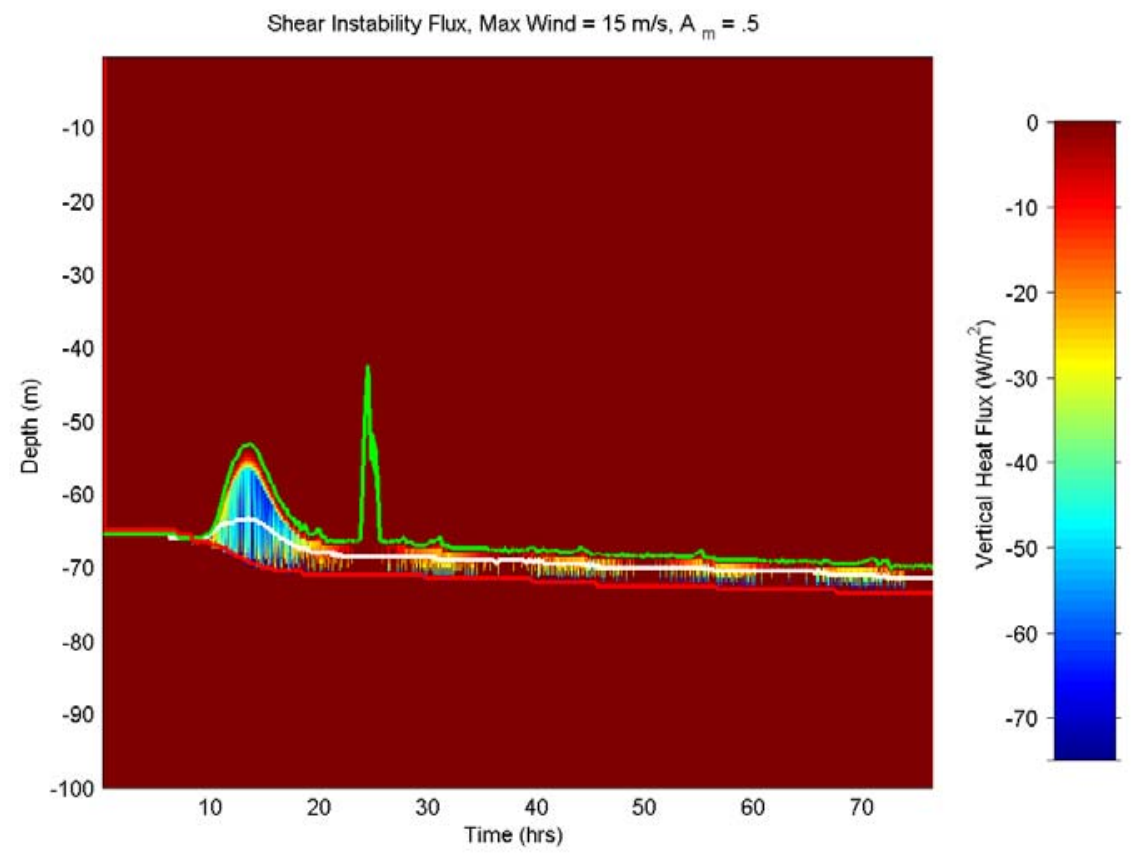

Figure 5.3.15 Depth-time contour plot of the (a) static instability and (b) shear instability vertical heat flux response to a wind event with a maximum speed of $15 \mathrm{~m} / \mathrm{s}$ and $50 \%$ maximum open water fraction. White line denotes the model-defined mixed layer depth, the red line marks the maximum depth of mixing and the green line indicates the base of the slab layer. 
The base ten logarithm of the inverse of $\mathrm{Ri}_{\mathrm{g}}$ is a convenient way of showing the potential for shear instability (Figure 5.3.16). The higher the value, the closer to instability, with the criterion for mixing $\log _{10}(1 / 0.25)=0.60$. The profile is rearranged until the criterion is met and no further, leaving $\mathrm{Ri}_{\mathrm{g}}$ nearly critical $(<1$, near the neutral value of 0.25 ) everywhere in the transition layer. Therefore, when the top of this region is changed due to some surface forcing, it becomes unstable and mixes with the layer below it. This nearly critical cell then becomes unstable and must mix even further down. This process continues down to the maximum depth of mixing where a previously undisturbed cell may need to be mixed upwards to satisfy the $\mathrm{Ri}_{\mathrm{g}}$ criterion.

The results were qualitatively the same for runs with different forcing. The wind burst causes shear instability combined with static instability from brine rejection. Then subsequent pulsed static instability deepens the mixed layer over time. The transition layer is nearly critical to shear instability, and undergoes frequent rearrangement to satisfy the stability criterion, particularly whenever another previously undisturbed model level is entrained.
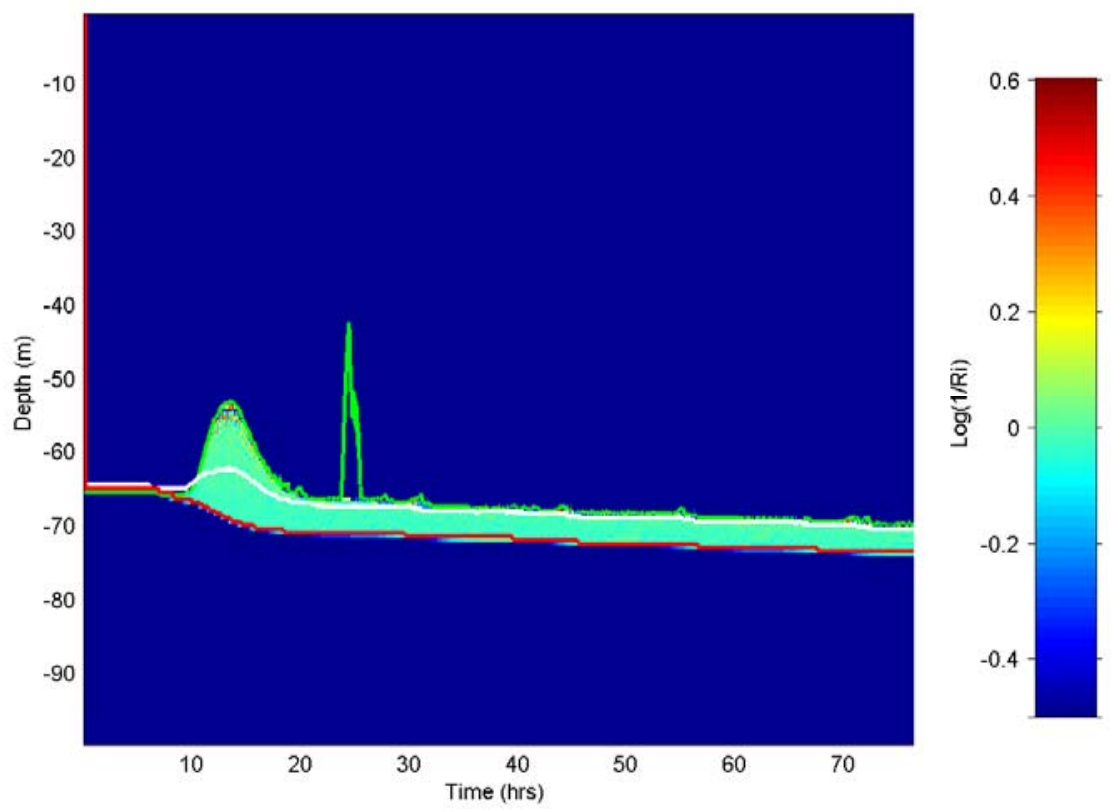

Figure 5.3.16 Depth-time contour plot of $\log _{10}$ of the inverse gradient Richardson number response to a wind event with a maximum speed of $15 \mathrm{~m} / \mathrm{s}$ and $50 \%$ maximum open water fraction. White line denotes the model-defined mixed layer depth, the red line marks the maximum depth of mixing and the green line indicates the base of the slab layer. 
The combination of shear and static instability also transports more passive tracer up to the mixed layer than either process by itself, as seen in the time series of concentration of a passive tracer in the model's surface mixed layer for runs with and without leads and wind (Figure 5.3.17). The initial tracer concentration profile (tracer $/ \mathrm{m}^{3}$ ) was prescribed as identical to the salinity profile minus the surface value, i.e. large concentrations below the halocline. This initial tracer profile simulates the salty and nutrient-rich UCDW underlying the nutrient-poor surface waters on the wAP shelf. There is no flux of tracer at the air-sea or ice-sea interface, which makes the final profile different from the salinity profile. The case without leads does not allow any tracer to the surface. The combination of wind and leads yields a concentration of passive tracer in the mixed layer which is more than double that caused by leads alone. These experiments demonstrate the critical role leads play in fluxing tracer to the underside of the ice.

The flux of tracer is relevant to biological processes which are limited by nutrient fluxes from deeper waters. It should be noted that those same processes which allow for greater upward tracer flux also allow heat to vent to the atmosphere, and thus keep the mixed layer at or near the freezing point.

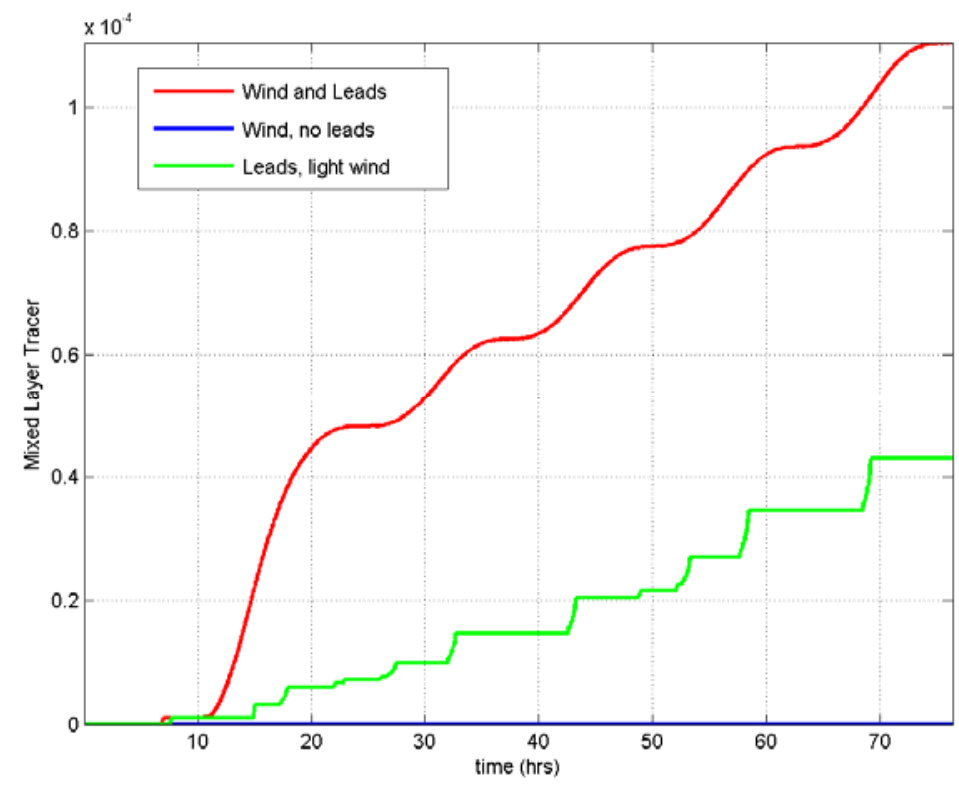

Figure 5.3.17 Time series of passive tracer concentration in the surface slab layer for runs with and without leads and wind. The "leads" and "no leads" cases have an $A_{\text {max }}$ of 0.5 and 0 , respectively. The "wind" cases have a maximum wind of $15 \mathrm{~m} / \mathrm{s}$ and the "light wind" case has a maximum wind of $5 \mathrm{~m} / \mathrm{s}$. 
Finally, simulations were repeated with the open water fraction constant at half the amplitude of the oscillating open water fraction of a comparable run (i.e. Figure 5.3.12a) to examine the effect of steady rather than pulsed brining. This results in a nearly identical final profile of temperature, salinity and velocity. In other words, the mixing averaged over the simulation period was the same. This indicates that the specific timing of the brining is not important. However, without the inertial oscillations and high frequency ice motion, there would be no mechanism to keep leads open to continue the strong heat fluxes and brine rejection.

\subsubsection{Feedbacks from vertical heat flux}

Taking the deltas as temporal changes in mixed layer properties during the simulations with leads opening and closing, $\beta \Delta S$ is three orders of magnitude larger than $\alpha \Delta T$. In other words, vertical fluxes of heat have negligible impact on the density of the mixed layer, and thus the overall stratification. This is due not only to the values of $\beta$ and $\alpha$ in this region of $T-S$ space, but also because the mixed layer temperature remains at the freezing point as excess heat is vented out through open leads and ice is formed once the temperature reaches the freezing point, producing a very small $\Delta T$ in the mixed layer during the simulation.

However, the vertical heat flux does impact the formation of ice and hence the amount of brine rejected which has a large impact on the final stratification. This can be seen by taking the total heat flux specified at the surface (Figure 5.3.12b, black line) and calculating the amount of ice it produces (taking into account depression of the freezing point by the added brine) and comparing with the full model. The $15 \mathrm{~m} / \mathrm{s}$ maximum wind, $50 \% A_{\max }$ case without mixing produces $18 \%$ more ice. This difference is due to the fact that in the full model, the surface heat flux must first cool the mixed layer to the freezing point before creating brine. The excess heat in the mixed layer has been fluxed up from deeper waters.

The vertical flux of heat has little direct effect on the stratification. However, it does have a large effect on ice and brine production, which plays a large role in the stratification, especially in the presence of shear. This suppression of ice and brine 
formation causes less mixing, which in turn causes less vertical heat flux, or a negative feedback. The actual change in ice production will depend on the initial profiles of temperature and salinity, but is noted as significant when compared with the modeled $20 \%$ increase in ice production associated with high frequency ice motion (Heil and Hibler, 2002).

\subsubsection{Slowing of mixed layer due to entrainment}

The high frequency differential ice motion associated with the mixing processes outlined above is reported to be responsible for a $20 \%$ increase in ice volume in a simulation of the Arctic (Heil and Hibler, 2002). However, Heil and Hibler (2002) did not take into account any oceanic mixing and subsequent effects on the velocity of the mixed layer/ice system. A change in mixed layer velocity due to entrainment could have an effect on a large-scale ice model, which uses the velocity of the mixed layer/ice system (and its spatial gradients) in the calculation of ice dynamics such as ridging and breaking. Here I compare the final mixed layer inertial current amplitude for the case with no leads with the case with leads. The decrease in final mixed layer inertial current amplitude is due to entrainment of deeper fluid which is at rest.

Figure 5.3.18 shows that the mixed layer slows by up to $10 \%$ compared to the case with no open water. Furthermore, one can see that the combined effect of shear and static instability causes the largest relative slowing of the mixed layer. 


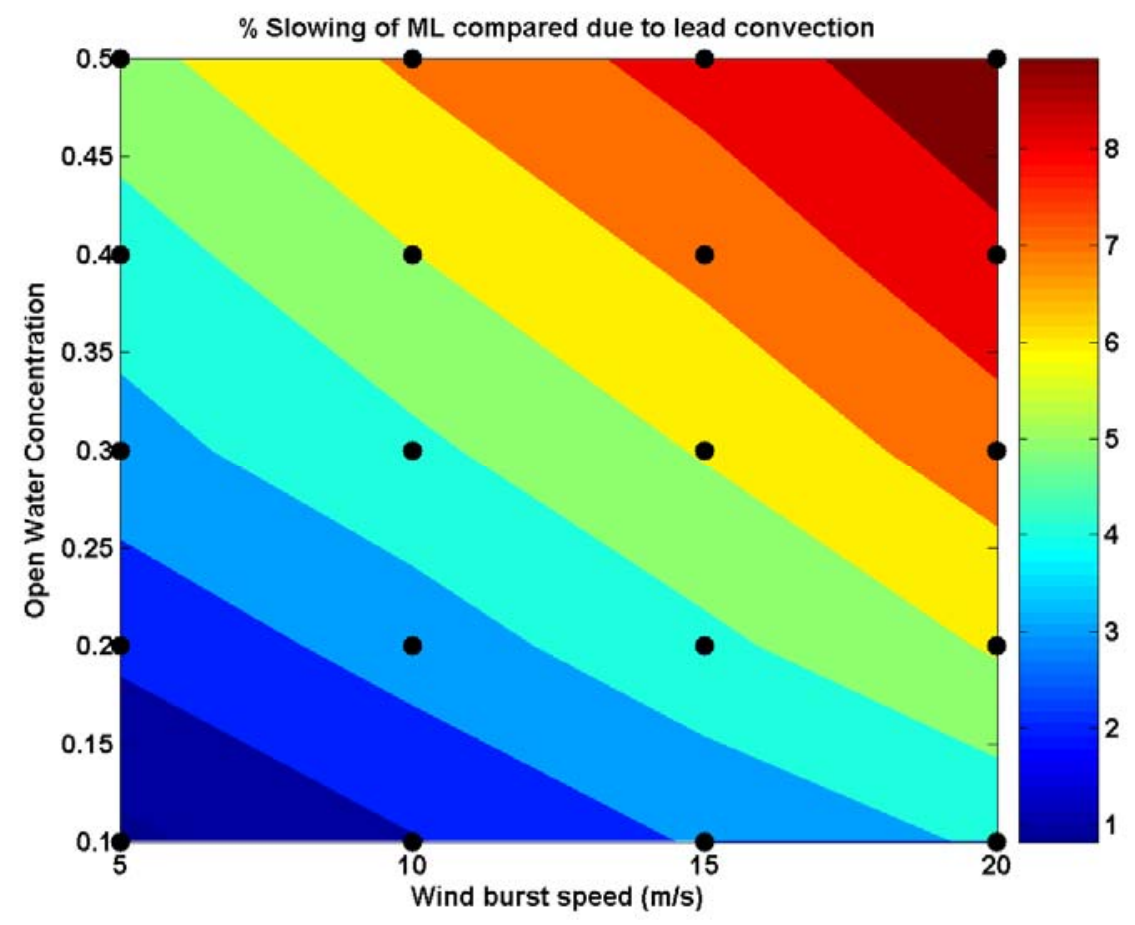

Figure 5.3.18 Slowing of mixed layer due to lead convection and shear processes. The slowing is shown as a percentage decrease compared to the case of no leads for each wind speed.

The specific results shown in Figure 5.3.18 are sensitive to the initial and boundary conditions. The main point is to show that if one chooses to include the mechanism of high-frequency ice motion in creating a significant ice volume, one must also consider entrainment which slows the mixed layer, and hence the ice.

\subsubsection{Effects of a Rotating Wind}

The oceanic mixed layer currents respond primarily to the component of wind stress rotating at the inertial frequency (counterclockwise in the Southern Hemisphere) (e.g. D’Asaro, 1985; Pollard and Millard, 1970). All simulations presented thus far have been for a purely eastward wind event. In this section the effects of a rotating wind in the presence of ice are examined.

In Figure 5.3.19 the red dots show the rotation versus wind stress recorded at the Dismal Island Automatic Weather Station during 2001 and 2002. The blue dots indicate October, November and December, 2002, the period with lower observed ice concentration and more inertial energy. The strong winds (greater than $0.2 \mathrm{~N} / \mathrm{m}^{2}$ ) were observed to rotate very little, mostly between plus and minus $10 \mathrm{deg} / \mathrm{hr}$, far from the 
inertial frequency ( $28 \mathrm{deg} / \mathrm{hr})$. The black dotted line in Figure 5.3.19 shows the winds for October 26, 2002, the strong forcing event which produced the observed near-inertial oscillations described in the previous chapter. For reference, the wind stress from a 10 $\mathrm{m} / \mathrm{s}$ wind is $0.14 \mathrm{~N} / \mathrm{m}^{2}$ and a $20 \mathrm{~m} / \mathrm{s}$ wind yields a stress of $0.87 \mathrm{~N} / \mathrm{m}^{2}$, assuming neutral stability (Large and Pond, 1981).

Despite the fact that strong winds were not observed to have strong rotation in the wAP region, the basic PWP with ice model was run with a rotating wind event at different frequencies. A wind burst of $10 \mathrm{~m} / \mathrm{s}$ and no rotation generates small inertial motions of $3 \mathrm{~cm} / \mathrm{s}$ (cyan curve in Figure 5.3.19). A wind of $10 \mathrm{~m} / \mathrm{s}$ rotating at the inertial frequency does not generate inertial oscillations as strong as a non-rotating wind of 20 $\mathrm{m} / \mathrm{s}$. A $20 \mathrm{~m} / \mathrm{s}$ wind rotating at the inertial frequency drives just over double the inertial currents as the non-rotating case. Conversely, a wind rotating at the inertial frequency in the opposite sense to $f$ generates virtually no inertial current. Note that true resonance (and unrealistically high mixed layer velocities) at $f$ can only occur in an undamped slab model. Any model with damping, in this case in the form of vertical mixing of momentum, has a restriction on mixed layer velocity. 


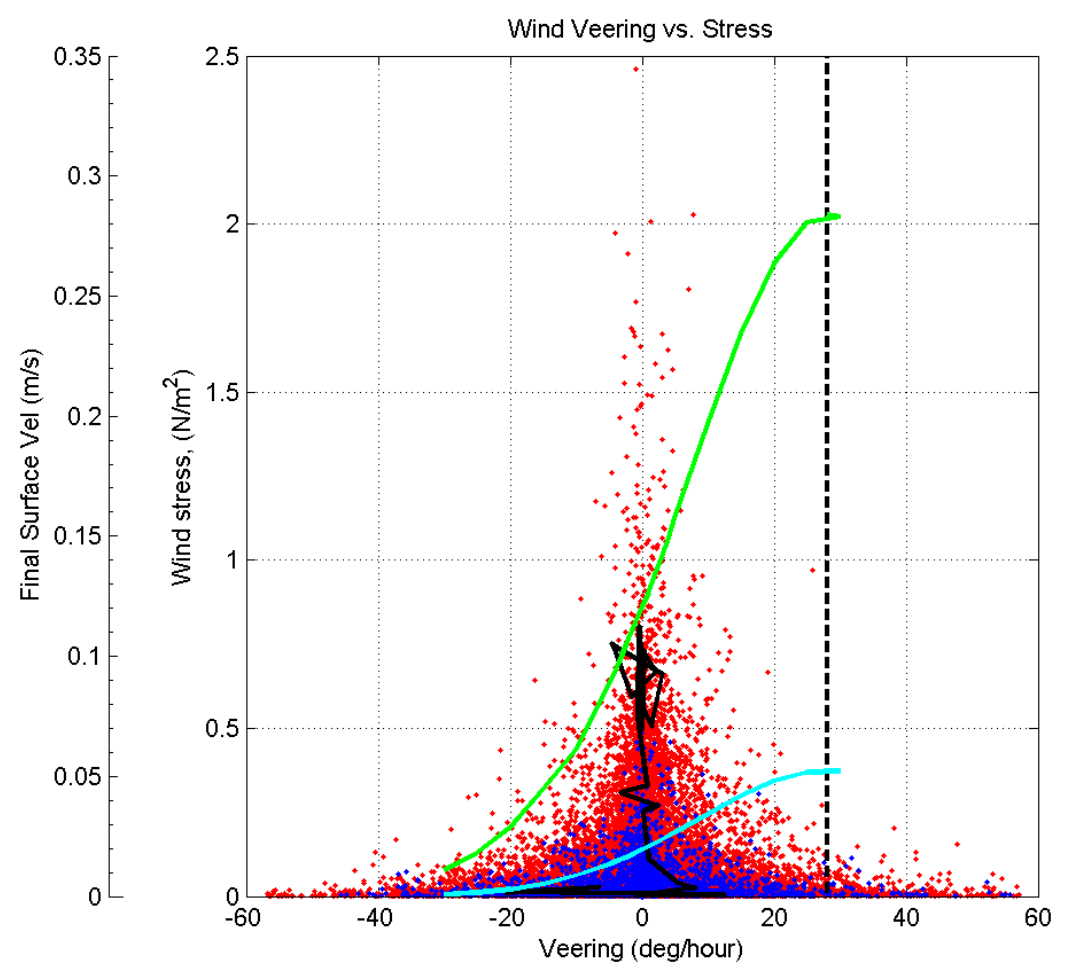

Figure 5.3.19 Observed rotation versus wind stress (red dots), with blue denotes denoting the period of lower ice concentration in October through December, 2002. The black dotted line shows October 26, 2002. The vertical dashed black line shows the inertial frequency. The green curve shows the modeled final ocean mixed layer surface velocity (leftmost y-axis) when forced by a $20 \mathrm{~m} / \mathrm{s}$ wind rotating at the frequency denoted on the $x$-axis. The cyan curve shows the results for a rotating 10 $\mathbf{m} / \mathbf{s}$ wind.

When the observed wind stress vector in the wAP region was strong enough to generate notable near-inertial motions, it did not rotate enough to make a great difference to the overall conclusions in this study. The inertial period is shorter than the timescale for rotation of strong winds in this region. This, however, is not always the case at lower latitudes with longer inertial periods or other high-latitude regions with faster rotating winds.

\subsection{Application of idealized study to WAP region}

Assessing the role of near-inertial oscillations/high frequency ice motion and production in mixing the waters of the wAP region presents significant challenges. First, the air-sea heat fluxes are not well constrained, given that the net radiative flux plays a significant role (Beardsley et al., 2006) and was only measured by shipboard instrumentation. Ships were not present in the region for much of the study period, in 
particular October through December when high near-inertial activity was observed. Therefore, the surface boundary condition is not well known. Second, the lack of initial conditions from CTD casts, not only to initialize the computations, but also to compare with the results, further precludes any detailed simulations. Furthermore, the mixed layer depth is unknown for most of the year since there were no temperature or salinity measurements above $104 \mathrm{~m}$. Finally, the wind stress has a significant portion of its energy put into the internal ice stress term during the strong wind event as described in Chapter 4, the modeling of which is beyond the scope of this study.

Despite these obstacles, in this section I make a rough estimate of the potential mixing caused by shear and static instabilities. The results of the idealized experiments reveal several key features which allow for simplification of the modeling. First, while static and shear instabilities together create more mixing than either alone, the timing of the buoyancy and wind stress forcing is not critical at higher (inertial) frequencies. Therefore one can apply a heat flux on the daily-averaged open water fraction and make the assumption that high frequency motions are keeping the leads open. Next, in order to work around the complicated and often strong observed internal ice stresses, I apply the observed ice motion as the surface boundary condition and calculate the ice-ocean stress directly from that (observed winds are not used). I linearly interpolate the available moored temperature and salinity measurements, and assume an initial mixed layer of 65 $\mathrm{m}$ with the same temperature and salinity properties of the CTD cast shown in Figure 5.2.2. Again, the net radiative air-sea heat flux is assumed to be a constant $100 \mathrm{~W} / \mathrm{m}^{2}$ loss.

I concentrate on the inertial event described in Chapter 4 at the $\mathrm{C} 3$ site, October 25 through October 31, 2002. The end of the run is chosen just before the "non-local" forcing due to divergence of internal ice stresses occurs. This October 26 storm is a strong event, with slightly weaker but noteworthy inertial current events occurring roughly on the order of once a month (Figure 5.1.1a). Figure 5.4.1 shows the boundary conditions used to force the There is a large net heat flux during the wind event followed by a period of relatively warm air (but still at or below the sea surface temperature) and heat flux comprised primarily of the specified $100 \mathrm{~W} / \mathrm{m}^{2}$ radiative loss. Warm air is typically associated with the strong "föhn" winds in Marguerite Bay 
(Beardsley et al., 2006). There is an initial southward velocity in the ice, followed by near-inertial oscillations. The time step in this simulation is 15 minutes. The simulation start time is October 25, 2002:

(a)

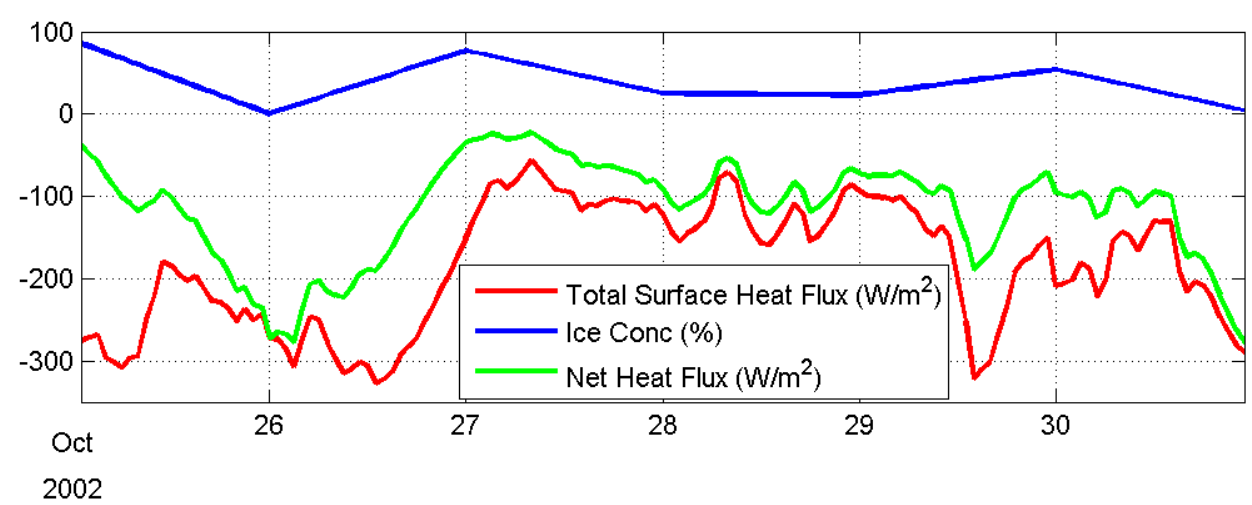

(b)

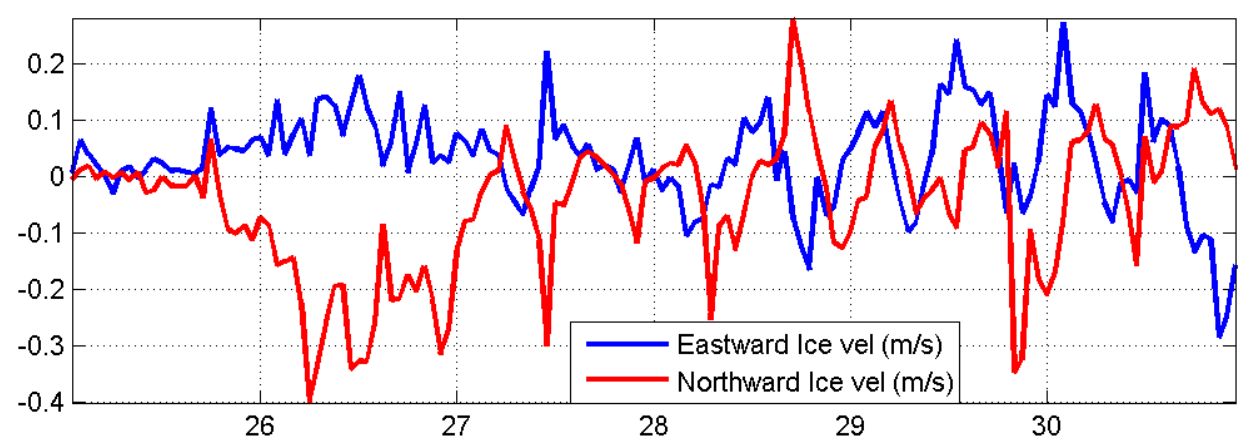

Figure 5.4.1 Time series of (a) total surface heat flux before multiplying by the open water fraction, ice concentration (1-A), and the resulting net heat flux. (b) Ice velocity.

The simulation is not meant to reproduce the observations, but rather to give some insight into a plausible mixing scenario in Marguerite Bay. The modeled temperature, salinity and velocity fields are qualitatively similar to those for the idealized experiments, with the initial wind event causing large changes, with smaller changes during the inertial oscillations (Figure 5.4.2). The initial wind event causes current velocities of about 12 $\mathrm{cm} / \mathrm{s}$, with the subsequent oscillations of 6 to $8 \mathrm{~cm} / \mathrm{s}$, similar to what was observed.

About $4.5 \mathrm{~cm}$ of ice was formed in the model during the first one and a half days, with no subsequent ice formation and brine rejection. 
(a)
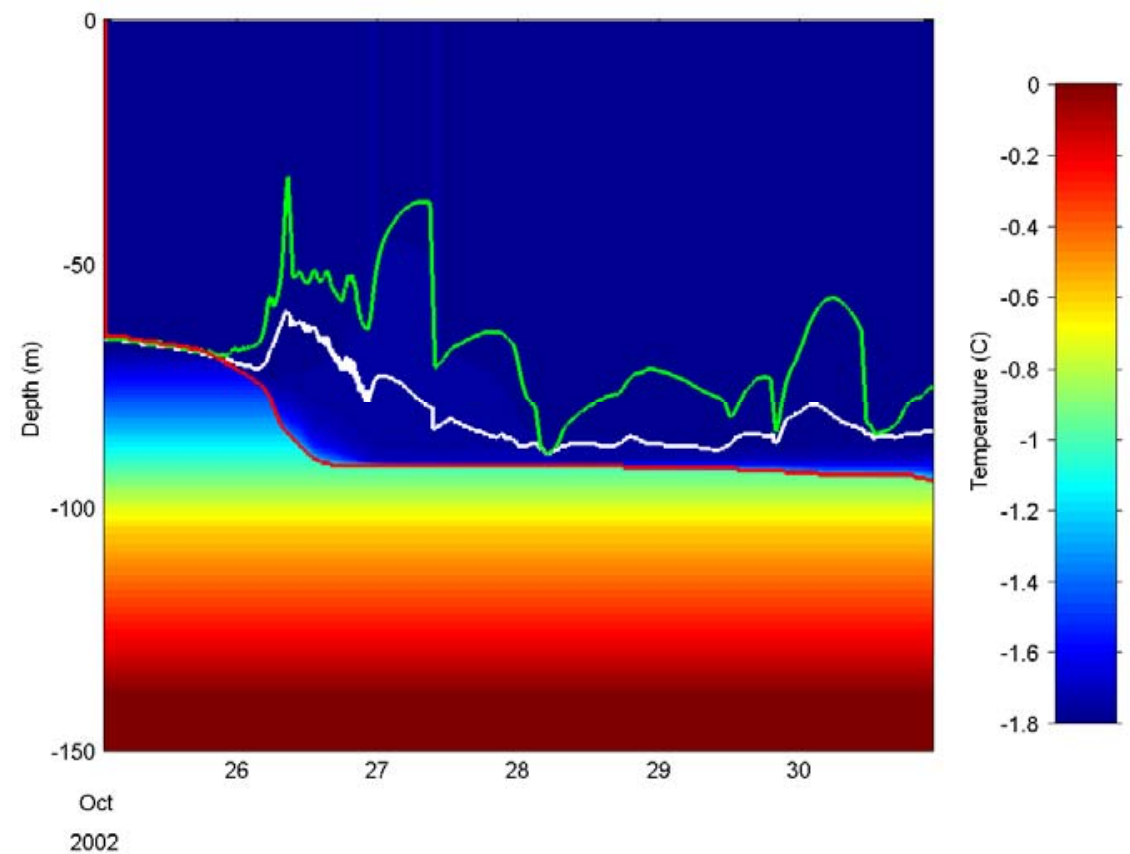

(b)

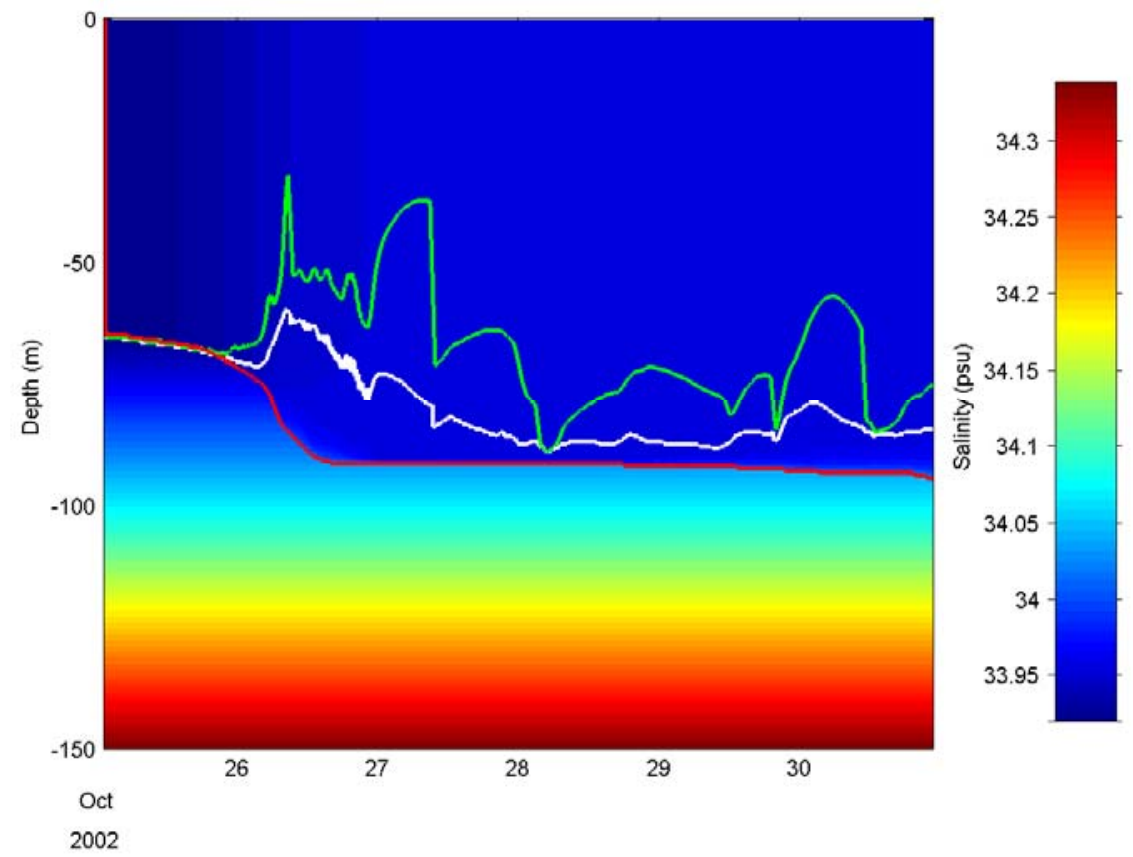


(c)

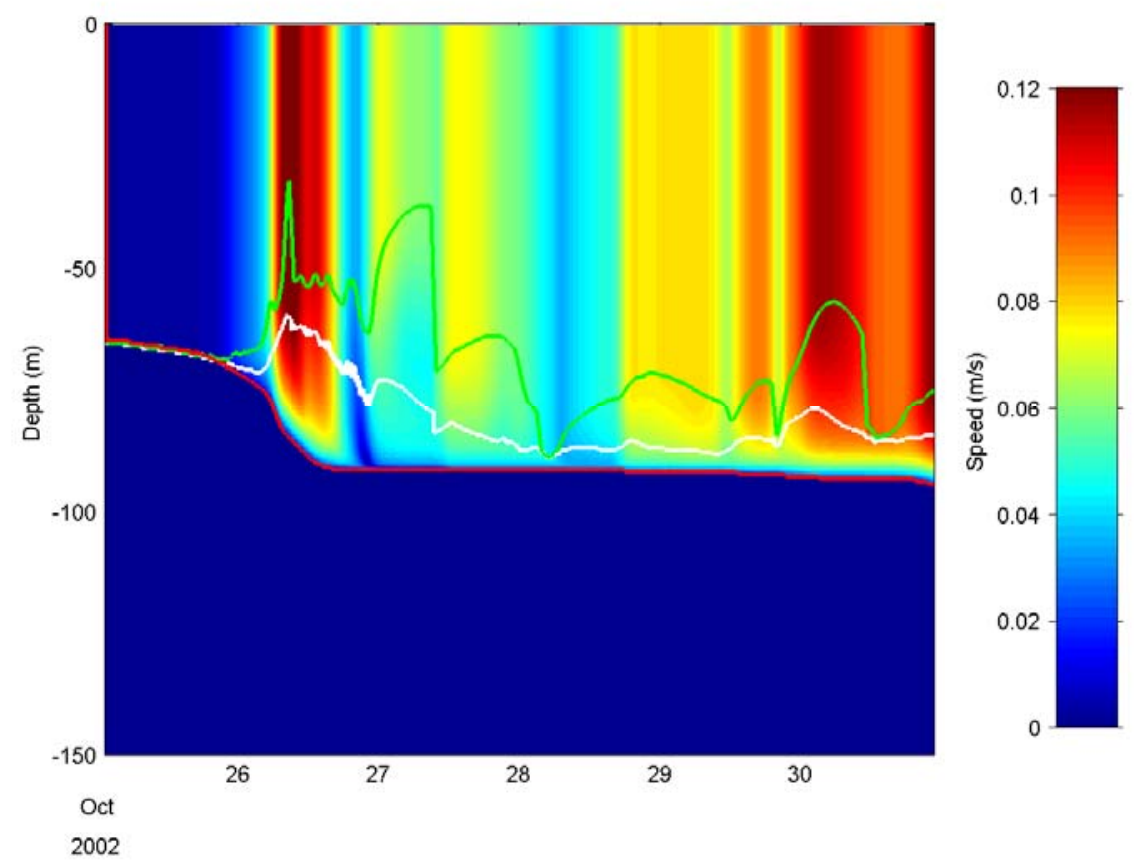

Figure 5.4.2 Depth-time contour plot of the (a) temperature, (b) salinity and (c) speed response to a simulation based on an observed event in October, 2002. White line denotes the model-defined mixed layer depth, the red line marks the maximum depth of mixing and the green line indicates the base of the slab layer.

The model vertical heat flux is shown in Figure 5.4.3. The maximum depth of mixing descends quickly during the large surface forcing (both stress and density), then remains somewhat steady, consistent with the findings earlier in this chapter. After the initial wind event, the mixed layer depth moves up and down, with the main pycnocline remaining at the maximum depth of mixing. The movement of the mixed layer depth is due to a weak stratification in conjunction with weak shear smoothing the gradient. 


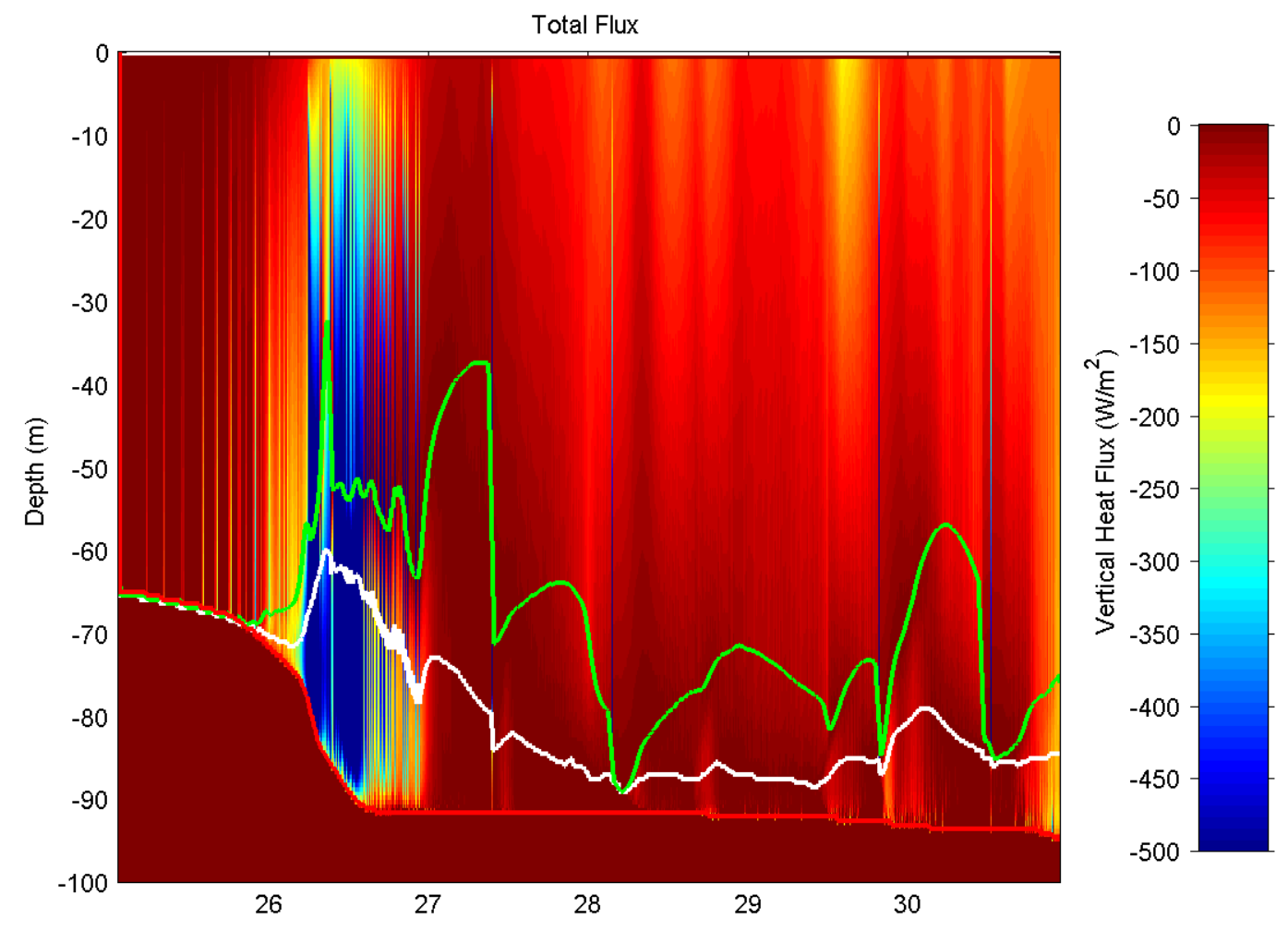

Figure 5.4.3 Depth-time contour plot of the vertical heat flux response to a simulation based on an observed event in October, 2002. White line denotes the model-defined mixed layer depth, the red line marks the maximum depth of mixing and the green line indicates the base of the slab layer. 
(a)

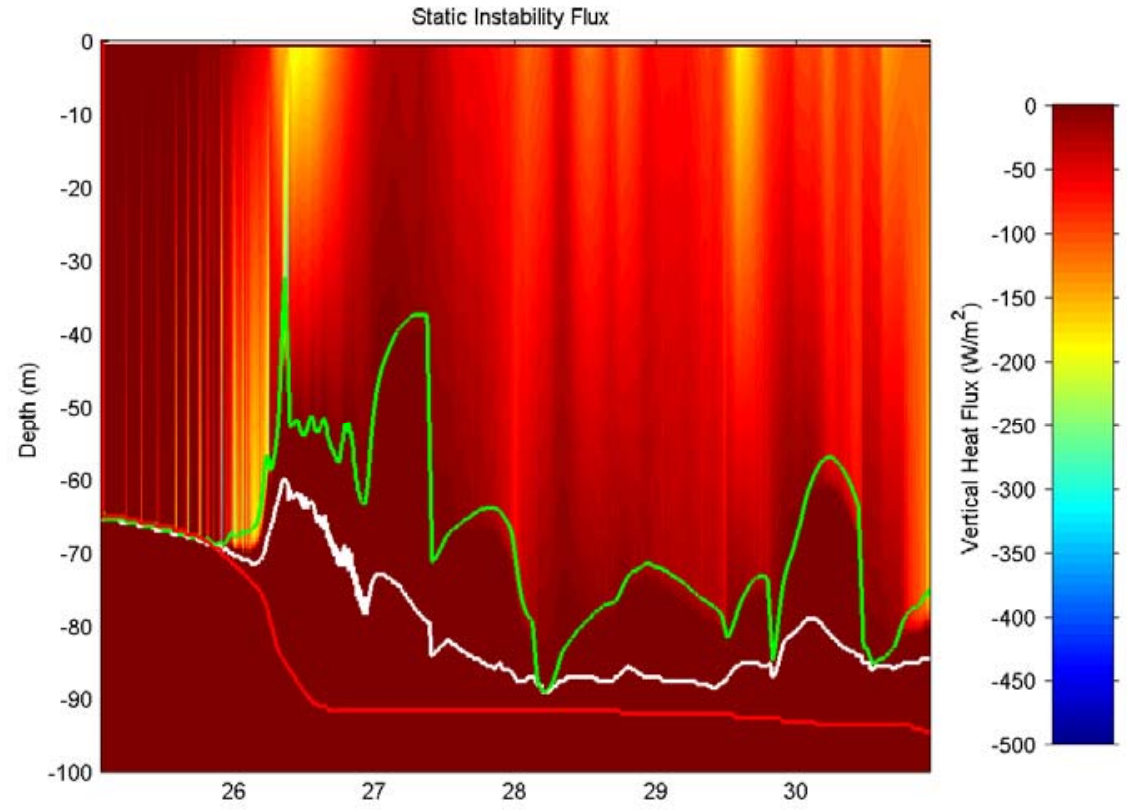

(b)

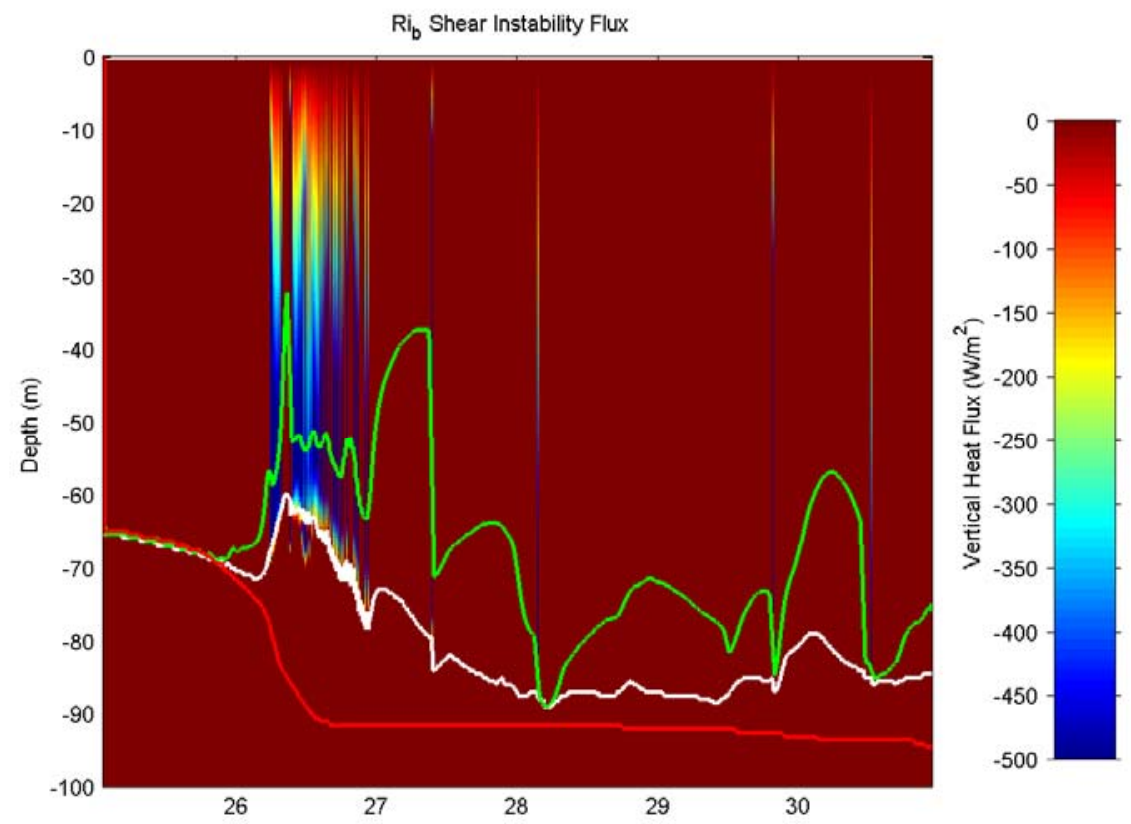


(c)

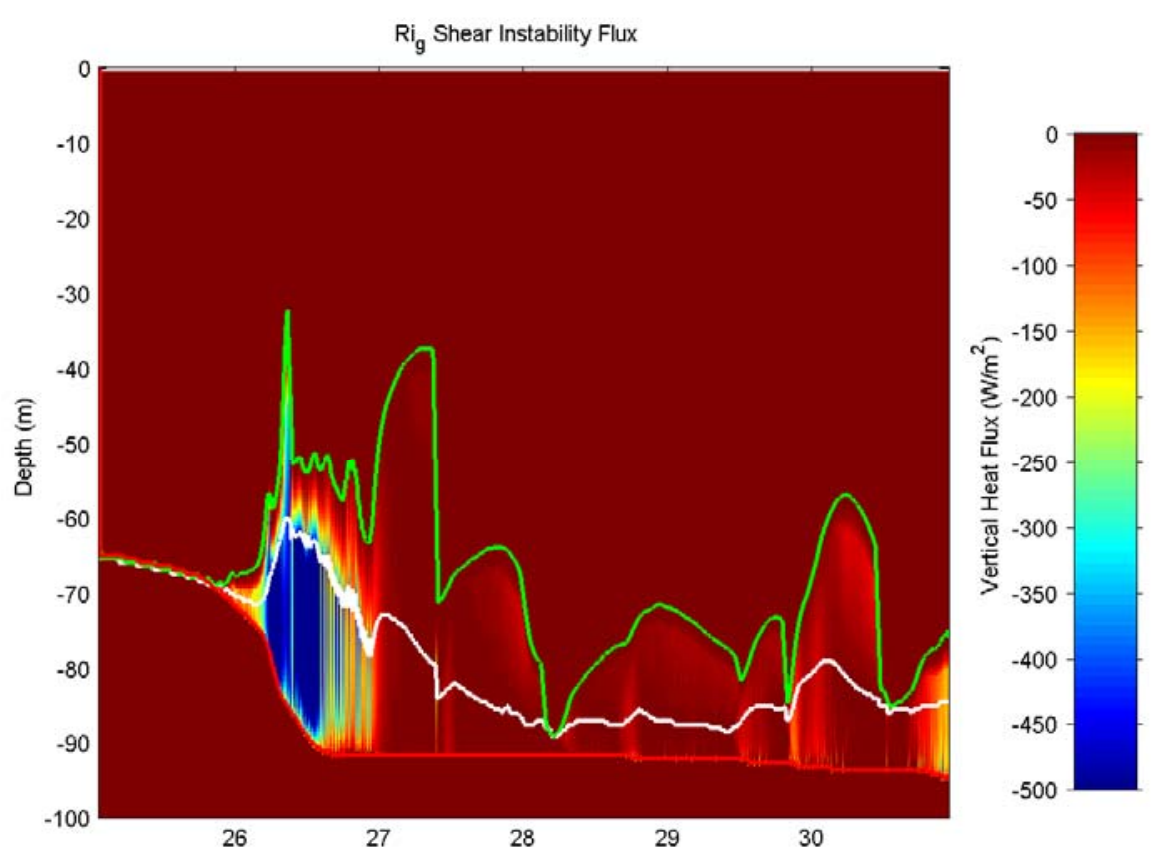

Figure 5.4.4 Depth-time contour plots of the contributions to the vertical heat flux response from (a) static (b) bulk Richardson number and (c) gradient Richardson number instability in a simulation based on an observed event in October, 2002. White line denotes the model-defined mixed layer depth, the red line marks the maximum depth of mixing and the green line indicates the base of the slab layer.

The flux resulting from the individual mixing mechanisms can be separated for analysis (Figure 5.4.4). Before the wind burst on October 26, there is no shear mixing, and static instability due to brine rejection causes a deepening of the mixed layer from 65 $\mathrm{m}$ to $70 \mathrm{~m}$. Then the ice formation and brine rejection continue for an additional half day (first half of October 26), the first half of the initial wind burst and sea ice movement. During this $\sim 1 / 2$ day period of strong forcing, the addition of salt and momentum cause entrainment into the mixed layer by bulk Richardson number mixing. The associated changes in the profiles of density and velocity at the top of the transition layer triggers gradient Richardson number mixing, which deepens the maximum depth of mixing to 90 m. The heat fluxed upward from the deeper waters is released to the atmosphere until midday October 26, when the surface heat flux is reduced (Figure 5.4.1) due to higher air temperature and humidity, yet the strong surface stress continues for another half day. This results in a warming of the surface layer to about $\sim 0.1^{\circ} \mathrm{C}$ above the freezing point. 
After the strong forcing event,there is both weak surface cooling and weak shear. The vertical bands of flux are due to the surface being relatively warm after the strong wind event and then subsequent weak surface cooling adding enough density without ice formation to convect partway down before the upward flux of salt stabilizes the density profile. The static instability does not penetrate into the deep reservoir of heat, while the weak shear creates some mixing to smooth the gradients. There is little change in the temperature and salinity profiles after the strong forcing (Figure 5.4.2a,b).

Overall, the simulation reflects the salient features shown in the idealized experiments. The initial wind burst performs the majority of the mixing with subsequent oscillations stable to shear instability. The surface heat flux and brining keeps the surface mixed layer cold and changes the stratification, which causes further shear instability. However, the strong surface stress persists longer than the cooling, causing warming of the surface waters above freezing. Thus, the duration of the strong surface heat flux and stress are important. After the strong event, mixing (deepening maximum depth of mixing) does not penetrate significantly into the deep reservoir of heat and salt. Therefore it is the initial wind event which is of greatest interest to studies of mixing in Marguerite Bay, especially since the wind events tend to be followed by relatively warm $\left(-5\right.$ to $\left.0{ }^{\circ} \mathrm{C}\right)$ air (Beardsley et al., 2006).

The upward heat flux evaluated at the base of the mixed layer is quite large for a short period, with a peak value of $\sim 900 \mathrm{~W} / \mathrm{m}^{2}$ and an average of $385 \mathrm{~W} / \mathrm{m}^{2}$ for October 26. The average heat loss for October $27-30$ is $17 \mathrm{~W} / \mathrm{m}^{2}$, which can be compared to the $1-2 \mathrm{~W} / \mathrm{m}^{2}$ estimated from an analysis of observed near-inertial oscillations on the wAP shelf in Chapter 2. Furthermore, low values of heat flux $\left(0-5 \mathrm{~W} / \mathrm{m}^{2}\right)$ have been found with a CTD-mounted microstructure measurements, but these data are still being processed and analyzed so it is not clear if they were taken during strong atmospheric forcing events (L. Padman, pers. comm.).

The time-averaged vertical heat flux for the entire 6-day simulation is $79 \mathrm{~W} / \mathrm{m}^{2}$. Making the rough assumption of one large event every month during the ice season, (or equivalently one day of $385 \mathrm{~W} / \mathrm{m}^{2}$ and 29 days of $17 \mathrm{~W} / \mathrm{m}^{2}$ ) gives an average flux of $\sim 29$ $\mathrm{W} / \mathrm{m}^{2}$ across the base of the mixed layer. This can be compared with estimates of an average vertical heat flux across the pycnocline based on wAP hydrography of between 5 
and $10 \mathrm{~W} / \mathrm{m}^{2}$ (Klinck, 1998; Smith et al., 1999). Note that while an annual average is calculated, the conditions under which the 6-day simulation was made do not occur throughout the year. Ice covers the wAP shelf about seven months a year (Chapter 4), and through half of that interval strong observed near-inertial motions are not observed (Figure 5.1.1). Overall, this work supports the idea of a weak average vertical heat flux across the pycnocline in Marguerite Bay made up of episodic strong events which may be difficult to capture observationally. In this rough calculation, nearly half of the total flux across the base of the pycnocline during a month occurs during a one-day event.

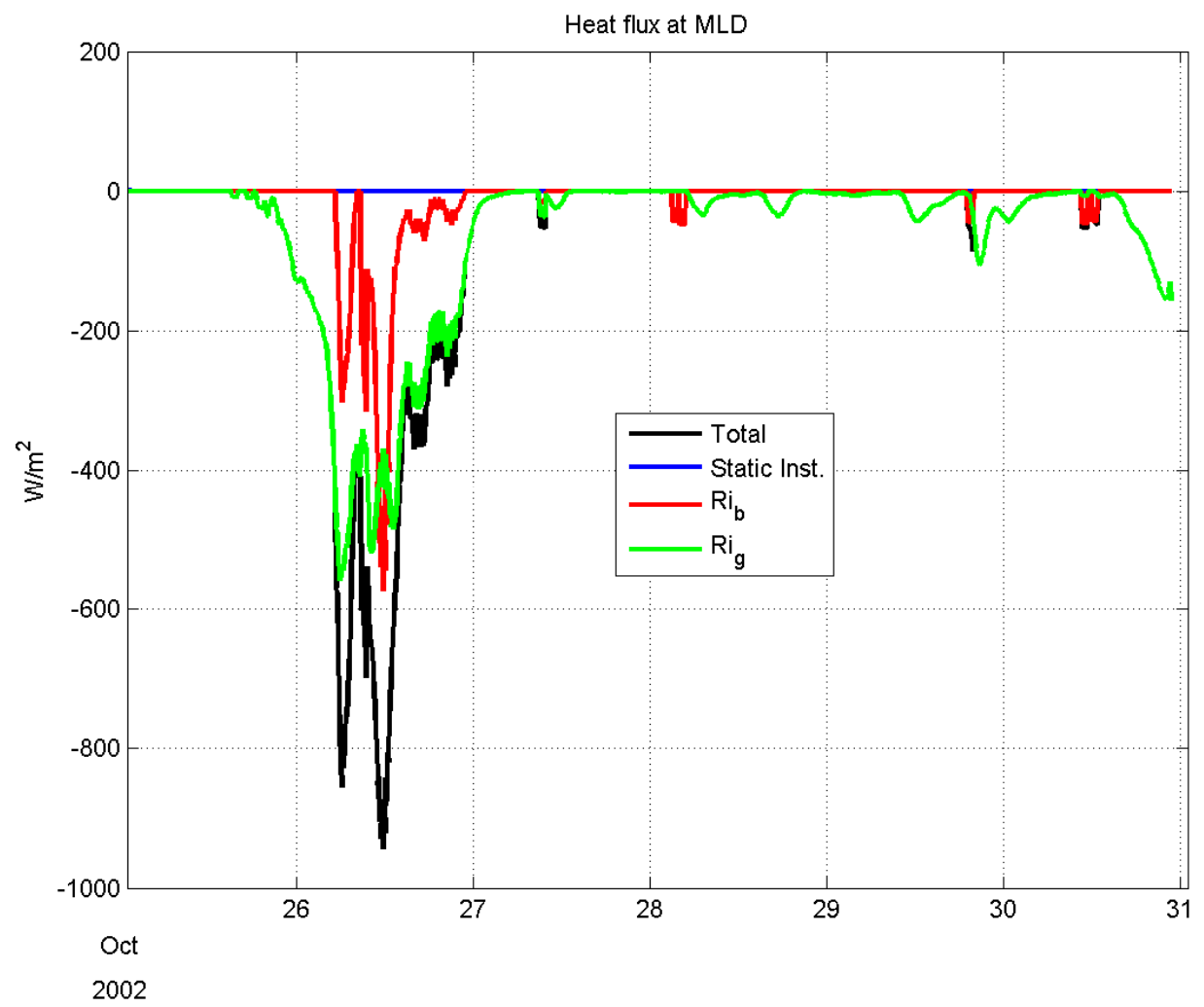

Figure 5.4.5 Time series of downward vertical heat flux at the model mixed layer depth (black line) and the individual contributions from static (blue), bulk Richardson number (red) and gradient Richardson number (green) instability in a simulation based on an observed event in October, 2002.

\subsection{Summary and Discussion}

In this chapter I have used the PWP one-dimensional upper ocean model to examine vertical mixing beneath sea ice, with an emphasis on inertial oscillations and high frequency ice motion. In the parameter space tested, nearly all mixing occurs within the first inertial period, consistent with Plueddemann and Farrar (2006). The presence of 
ice acts to smooth the surface stress on the ocean in time, but does not reduce mixing for reasonable values of the ice-ocean drag coefficient (0.015). The response of the model begins to diverge from the open water case with drag coefficients less than 0.001 . Overall the presence of ice has little effect on the flows and mixing.

The model results revealed an interesting synergy between wind and buoyancy forcing in ocean mixing beneath ice in inertial events. High frequency ice motion, particularly leads opening and closing, had a great effect. The active surface heat flux allows for heat loss and subsequent ice formation. The resulting brine rejection leads to periodic changes in the stratification, causing subsequent shear instability and more mixing than that caused by air-sea heat flux alone. The leads also allow atmospheric venting of heat mixed up from the deeper water.

The oscillatory opening and closing of leads introduces an average open water fraction that allows for heat loss to the atmosphere. It is not the details of the oscillations, but the open water they create, which has a great effect. Furthermore, entrainment of slower fluid into the mixed layer decreases the mixed layer speed by up to $10 \%$. This could affect ice models such as those employed in Heil and Hibler (2002).

Based on a simplified simulation of an observed event, the modeled vertical heat flux across the base of the mixed layer during a strong forcing event is quite large, $\sim 385$ $\mathrm{W} / \mathrm{m}^{2}$ averaged over one day. The remainder of the simulation was characterized by weak fluxes, with the 6-day average value over the entire simulation coming to $79 \mathrm{~W} / \mathrm{m}^{2}$. This translates into an estimated overall average heat flux of $29 \mathrm{~W} / \mathrm{m}^{2}$, assuming roughly one strong event per month with the remainder of the month having weak fluxes. The heat gained by the mixed layer from the UCDW was completely fluxed to the atmosphere by the end of the 6-day simulation (see Appendix 5A.2)

A deep flow $180^{\circ}$ out of phase with the mixed layer flow was observed in the shipboard ADCP data (Chapter 2), but not simulated in the one-dimensional PWP model. This deep flow is probably due to a barotropic wave reflecting from the coastal boundary. This deep flow does not appear to have a great effect on mixing (see Appendix 5A.1).

The structure in the moored time series temperature data (last Figure from Chapter 4) suggest something more is happening in Marguerite Bay. One possibility is dense brine plumes penetrating the pycnocline and generating internal waves. This could 
potentially be investigated in a three dimensional high resolution simulation, but is beyond the scope of this study. Another possibility is that large wind events set deepkeeled icebergs in motion that drives mixing and radiate internal waves.

It should be noted that the divergent high frequency ice motion can occur in the absence of a coast. Other causes for such divergent motions could be a horizontally inhomogeneous wind forcing field or a horizontally inhomogeneous ice strength field (Heil and Hibler, 2002). In fact, Heil and Hibler (2002) found that even with a temporally-smoothed wind forcing field, inertial oscillations in the ice occurred due to the nonlinearity of the sea ice model. The ice model can produce abrupt ice motions when strength thresholds are exceeded, and thus creating temporally abrupt and spatially inhomogeneous ice-ocean stresses.

\section{APPENDIX 5.A.1 Coastal Boundary Effects}

The modeled response of an ice-covered ocean thus far has not included the flow observed in the lower layer which is $180^{\circ}$ out of phase with the upper layer flow (Chapter 2). This lower layer flow is most likely the result of a barotropic wave reflecting off of the coastal boundary (Pettigrew, 1981; Kundu et al., 1983). This lower flow is predicted to begin at time $t=x / \sqrt{g H}$, where $\mathrm{x}$ is the distance to the coast, $\mathrm{H}$ is the total water depth, and $t=0$ is the initiation of the surface wind forcing. This is about 18 minutes for the mooring sites in Marguerite Bay, and therefore may be considered instantaneous. Furthermore, the observation that the inertial band ice velocities are greater than the water velocities (Chapter 4), may also be due to these coastal boundary effects. Since this flow is part of a fundamentally three-dimensional process, the one-dimensional PWP model can reproduce neither the lower layer flow nor the inertial band velocities which are stronger in ice than the water.

Despite this obstacle, an effort was made to investigate the potential role of the opposite phased lower layer flow by using an $a d$ hoc approach of simulating oscillations after the wind event has occurred. This was accomplished by taking the mixed layer velocity resulting from a certain strength wind event in a run with no leads $\left(A_{\max }=0\right)$, then using the resulting surface current speed to scale the mode 1 structure of the 
stratification profile. The modal structure was made using the full observed stratification (not the idealized linear profile) shown in Figure 5.2.2b. This scaled mode 1 velocity profile was then used as the initial condition in a run with no wind stress forcing, and a specified varying open water fraction as described earlier. The mode 1 velocity profile was chosen because it resembles the observed velocity profile presented in Chapter 2, Figure 4.

The resulting heat flux is nearly identical to a simulation with leads and no wind forcing at all (Figure 5.3.14). The modal velocity structure does not provide enough shear to alter the mixing when compared with a simulation which begins at rest. This result is robust for a range of velocities and open water fractions.

The modal structure has a gradient Richardson number profile which is finite throughout the water column below the mixed layer (where $\mathrm{Ri}_{\mathrm{g}}$ is undefined), i.e. where there is non-zero shear and stratification (blue line in Figure 5.5A.1). The model runs which begin at rest spin up inertial oscillations which have a $\mathrm{Ri}_{\mathrm{g}}$ which is undefined in both the mixed layer and infinite below the maximum depth of mixing, where there is no shear (red line in Figure 5.5A.1). However, in the transition layer, $\mathrm{Ri}_{\mathrm{g}}$ is critical, so any destabilizing change to the profile results in mixing.

The barely stable profiles of temperature, salinity and velocity which result from the initial wind event are vital to proper simulation of response to subsequent forcing. Therefore, the coastal boundary effects must be simulated, including the actual wind event, with a true higher-dimensional model to investigate the details of vertical mixing beneath high frequency sea ice motion. 


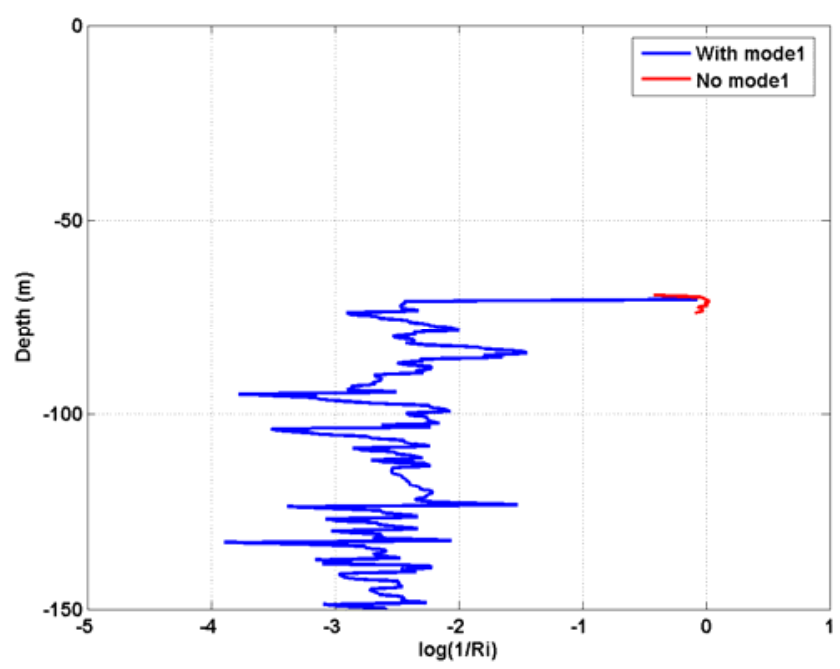

Figure 5.5A.1 Profile of $\log _{10}\left(1 / \mathrm{Ri}_{\mathrm{g}}\right)$ at the end of two simulations, the red having no initial modal velocity structure, the blue with an initial velocity structure.

\section{APPENDIX 5.A.2 Mixed Layer Heat Balance}

In order to investigate the fate of heat fluxed from the UCDW into the AASW in the simulation described in section 5.4, one can also calculate a depth-integrated heat balance for the mixed layer (e.g. McPhaden, 1982), ignoring lateral effects:

$$
h \rho c_{p} \frac{\partial \bar{T}}{\partial t}+\rho c_{p}(\bar{T}-T(-h)) \frac{d h}{d t}=-\left(Q_{H F}(0)+Q_{H F}(-h)\right)
$$

where $Q_{H F}(0)$ and $Q_{H F}(-h)$ are positive upwards and $\bar{T}$ is the average temperature in the mixed layer of thickness $h . Q_{H F}(0)$ represents only the heat flux at the surface after any latent heat of fusion in ice production has been removed. On the second day, when the surface stress is strongest, upward heat flux through the base of the mixed layer is primarily balanced by a warming, with some loss of heat to the atmosphere (Figure 5.5A.2). For the remainder of the simulation, the balance is maintained by a reduction in mixed layer temperature as heat is lost to the atmosphere. 


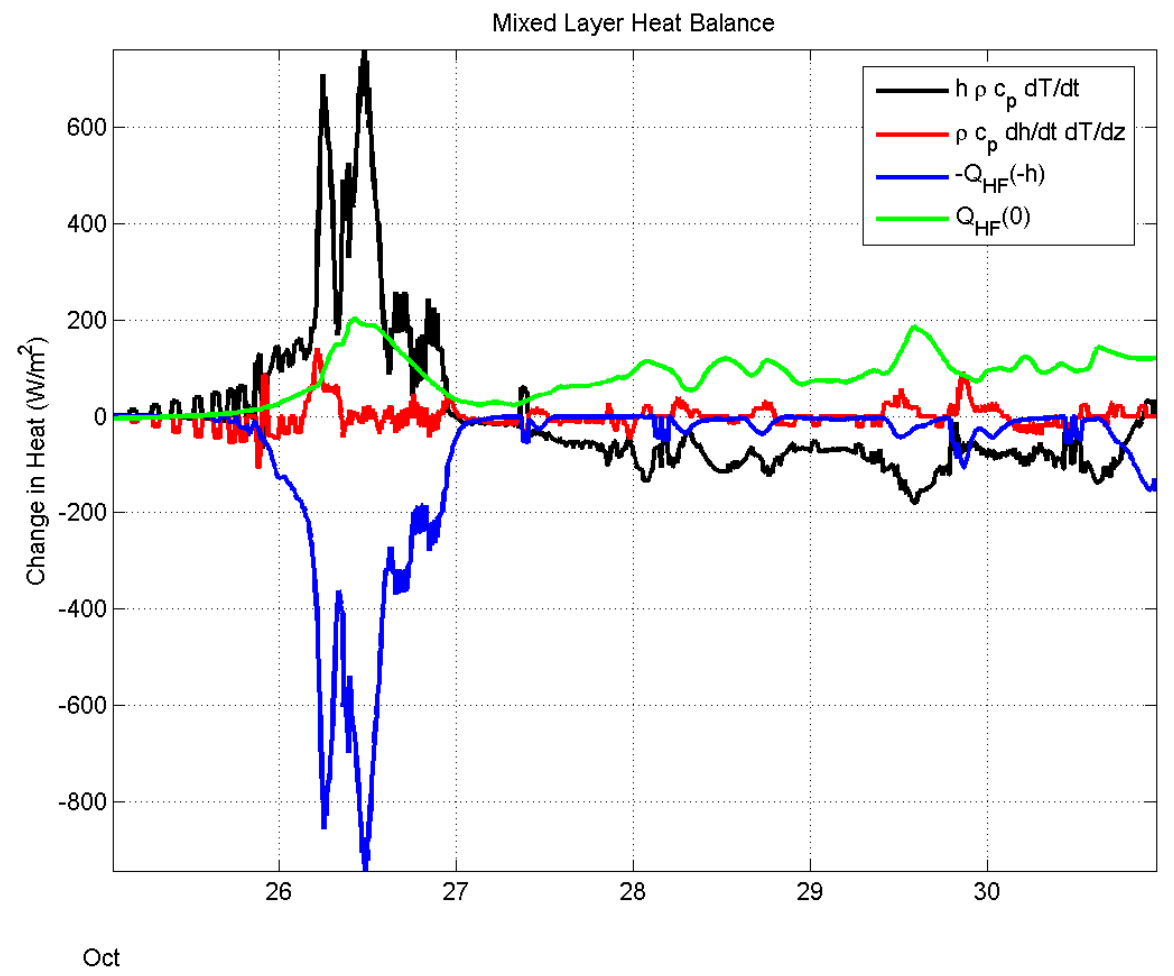

Figure 5.5A.2 Terms in the mixed layer heat balance in a simulation based on an observed event in October, 2002. The sign convention has the terms sum to zero for clarity.

Integrating these terms in time (Figure 5.5A.3) shows that the heat content in the mixed layer returns to its original value at the end of the 6-day simulation. The heat gained by the mixed layer from the deeper waters during the wind event is gradually lost to the atmosphere during the following four days of cooling. This suggests the importance of the cooling between strong events to maintain the wintertime temperature profile. Heat from the UCDW effectively moves through the mixed layer to the atmosphere. The heat lost from the UCDW must be replenished through some process not included in the PWP model, such as lateral advection of UCDW from offshore onto the shelf. 


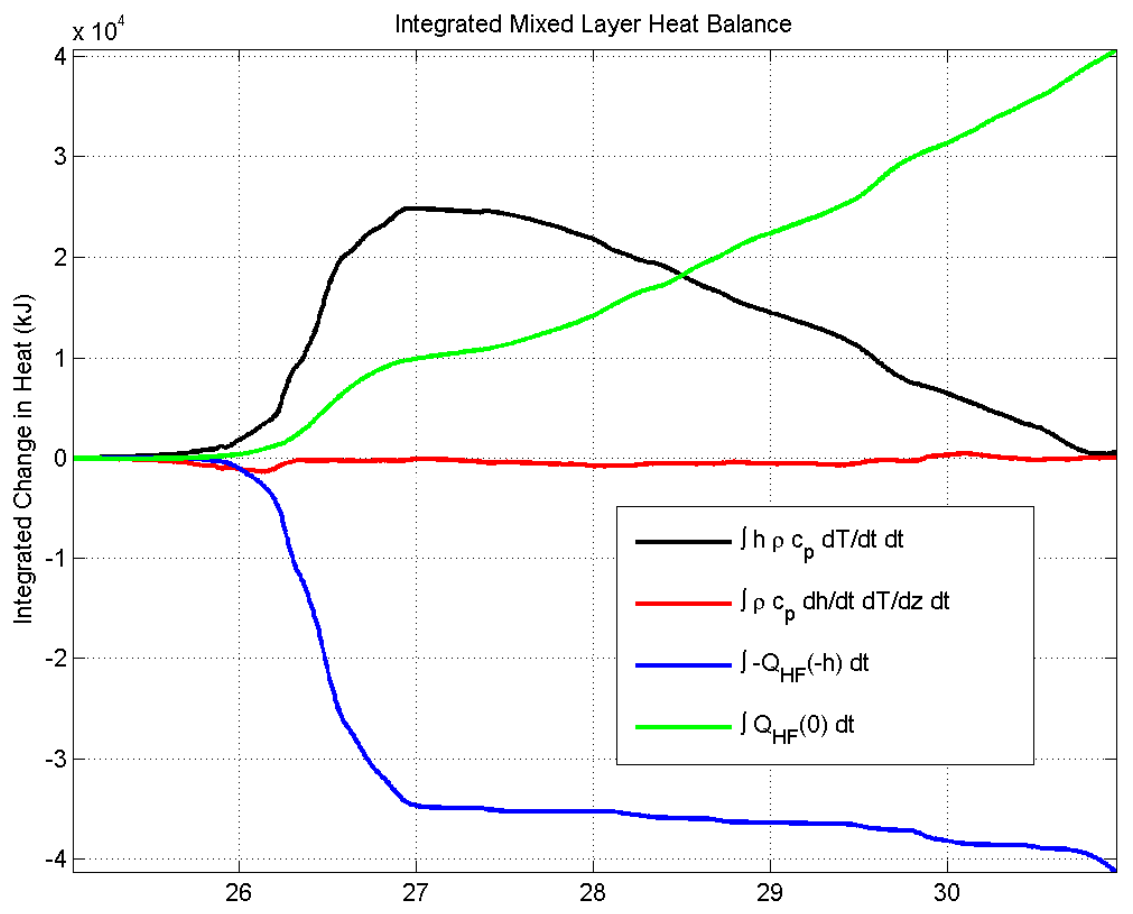

Figure 5.5A.3 Time-integrated terms in the mixed layer heat balance in a simulation based on an observed event in October, 2002. The sign convention has the terms sum to zero for clarity.

\section{References:}

Beardsley, R., M. Caruso, and J. Hyatt, 2005: Marine surface conditions and atmospheric forcing over Marguerite Bay and adjacent shelf, western Antarctica Peninsula, 2001-2003. Deep-Sea Research, in prep.

D'Asaro, E.A. (1985), The energy flux from the wind to near-inertial motions in the surface mixed layer. J. Phys. Oceanogr., 15, 1043-1059.

Fairall, C. W., E. F. Bradley, D. P. Rogers, J. B. Edson, G. S. Young, 1996: Bulk parameterization of air-sea fluxes for Tropical Ocean-Global Atmosphere CoupledOcean Atmosphere Response Experiment. J. Geophys. Res., 101, 3747-3764. Large and Pond (1981), J. Phys. Oceanogr.., 11, 324-336.

Fofonoff, P. and Millard, R.C. Jr, 1983: Algorithms for computation of fundamental properties of seawater. Unesco Tech. Pap. in Mar. Sci., No. 44, 53 pp. 
Heil, P. and Hibler, W.D., 2002: Modeling the high-frequency component of Arctic sea ice drift and deformation. J. Phys. Oceanogr., 32, 3039-3057.

Heil, P., I. Allison, and V. I. Lytle, 2001: Effect of high-frequency deformation on the sea-ice thickness. Scaling Laws in Ice Mechanics and Ice Dynamics, J. P. Dempsey and H. H. Shen, Eds., Kluwer Academic, 417-426.

Howard, S., Hyatt, J. and Padman, L., 2004: Mixing in the pycnocline over the western Antarctic Peninsula shelf during Southern Ocean GLOBEC. Deep-Sea Research II, 51, 1965-1979.

Kundu, P.K., S.-Y. Chao, and J.P. McCreary, 1983: Coastal currents and inertio-gravity waves. Deep-Sea Res., 30, 1059-1082.

Maykut, G.A. and N. Untersteiner, 1971: Some results from a time-dependent thermodynamic model of sea ice. J. Geophys. Res., 76, 1550-1575.

McDougall, T.J. 1987. Neutral Surfaces. J. Phys. Oceanogr.. 17 ,1950-1964.

McPhee, M. G., 1978: A simulation of the inertial oscillation in drifting pack ice. Dyn. Atmos. Oceans, 2, 107-122.

Meredith, M.P., Renfrew, I.A., Clarke, A., King, J.C., and Brandon, M., 2004: Impact of the 1997/98 ENSO on upper ocean characteristics in Marguerite Bay, western Antarctic Peninsula. J. Geophys. Res., 109.

Perovich, D.K., Elder , B.C., Claffey, K.J., Stammerjohn, S., Smith, R., Ackley, S.F., Krousee, H.R., and Gowa, A.J., 2004. Winter sea-ice properties in Marguerite Bay, Antarctica. Deep-Sea Research II, 51, 2023-2039.

Pettigrew, N. R., 1980. The dynamics and kinematics of the coastal boundary layer off Long Island. Ph.D. Thesis, MIT/WHOI Joint Program in Oceanography, Woods Hole, MA, $262 \mathrm{pp}$.

Plueddemann A.J. and Farrar J.T., 2006: Observations and models of the energy flux from the wind to mixed-layer inertial currents. Deep-Sea Research II, 53, 5-30.

Pollard, R. T., and R. C. Millard Jr., 1970: Comparison between observed and simulated wind-generated inertial oscillations, Deep Sea Res., 17, 813-821.

Price, J. F., R. A. Weller, R. and R. Pinkel, 1986: Diurnal cycling: Observations and models of the upper ocean response to diurnal heating, cooling, and wind mixing. $J$. Geophys. Res., 91, 8411-8427. 
Schudlich, R. R., and J. F. Price, 1992: Diurnal cycles of current, temperature, and turbulent dissipation in a model of the equatorial upper ocean. J. Geophys. Res., 97, 5409-5422.

Shirasawa, K. and Ingram, R.G., 1991. Characteristics of the turbulent oceanic boundary layer under sea ice. Part 1: A review of the ice-ocean boundary layer. J. Mar. Sys. 2, pp. 153-160.

Wadhams, Ice in the Ocean., 2000. Gordon and Breach Publishers. 


\section{Chapter 6}

\section{Summary and Discussion}

\subsection{Summary}

Subsurface intrusions of Upper Circumpolar Deep Water (UCDW) onto the western Antarctic Peninsula (wAP) shelf are believed to provide much of the heat, salt and nutrient flux into the region (Smith et al, 1999). In order to investigate the possible mechanisms responsible for this flux, moored oceanographic and automatic weather station data were collected within Marguerite Bay on the shelf as part of the Southern Ocean Global Ocean Ecosystems Dynamics (SO GLOBEC) program. The subsurface moorings were deployed in the ice-free austral summer and observed the onset, draft and motion of sea ice during the winter ice seasons of 2001-2003, in addition to oceanic temperature, salinity, pressure and velocity at various depths. In this thesis I develop a novel method for observing sea ice with an upward-looking acoustic Doppler current profiler (ADCP) and use it to characterize the sea ice within Marguerite Bay on the wAP shelf; then I investigate the possible processes responsible for vertical fluxes of heat, salt and nutrients in an ice-covered ocean.

In Chapter 2, initial estimates were made of upward diapycnal fluxes of heat, salt and nutrients from the UCDW to the surface mixed layer due to two small-scale processes, double diffusive convection (DDC) and shear instability. The estimates were based on data from conductivity-temperature-depth (CTD) and vessel-mounted ADCP data collected during three research cruises between April and September 2001. Nearinertial motions generated by wind stress provided most of the shear across the sharp pycnocline at the base of the mixed layer. The mean vertical diffusivity associated with shear instability was estimated at $\leq 1 \times 10^{-5} \mathrm{~m}^{2} \mathrm{~s}^{-1}$, corresponding to a heat flux into the base of the mixed layer of $\leq 2 \mathrm{~W} \mathrm{~m}^{-2}$. While prior work suggests that DDC could provide 
upward heat fluxes of order $10 \mathrm{~W} \mathrm{~m}^{-2}$ on the wAP shelf (Marguerite Bay north to the tip of the Antarctic Peninsula) (Smith and Klinck, 2002), the analyses in Chapter 2 indicate almost no contribution to diapycnal fluxes from DDC $\left(\leq 0.2-0.4 \mathrm{~W} \mathrm{~m}^{-2}\right)$. A cursory analysis of one observed wind event prompted the suggestion that mixing on the wAP shelf could be dominated by episodic events not captured in the hydrographic survey data.

In Chapter 3, a methodology was presented for determining ice coverage, draft and velocity from data from a moored upward-looking ADCP. The technique was successfully applied to data collected on the wAP shelf during SO GLOBEC. Ice detection was accomplished using windowed variances of ADCP vertical velocity and error velocity, with the daily-average ice concentration estimated as the percentage of time ice in which was detected during a given day. The ADCP-derived ice concentration compared well with a satellite-derived estimate (Cavalieri et al., 1997). Furthermore, the ADCP-derived ice concentration data improved on observation of ice concentrations on small spatial scales, observing a localized polynya over the $\mathrm{C} 1$ mooring site which appeared as a broad area of low ice concentration in the satellite-derived ice concentration data (Chapter 4). Acoustic signal correlation and backscatter intensity were found to be poor indicators of the presence of ice at this site. Ice draft was estimated using a combination of ADCP backscatter, atmospheric and oceanic pressure data, and information about the stratification. This estimate required corrections to the ADCP-derived range for instrument tilt and sound speed profile. Uncertainties of \pm 0.20 $\mathrm{m}$ during midwinter and $\pm 0.40 \mathrm{~m}$ when the base of the mixed layer was above the ADCP for ice draft were estimated based on (a) a Monte Carlo simulation, (b) uncertainty in the sound speed correction and (c) performance of the zero-draft estimate during times of known open water. Ice velocity was taken as the ADCP-measured horizontal velocity in the depth bin specified by the range estimate. This method is currently in use by other researchers in both the Arctic (F. Straneo, C. Lee) and Antarctic (M. Meredith).

Presented in Chapter 4 are time series, spanning the winter ice seasons of 20012003, of sea ice concentration, thickness and motion within Marguerite Bay that were estimated using the methodology described in Chapter 3. Both years have roughly seven months of nearly complete ice cover, but the onset of ice formation was about two 
months earlier in 2002-2003 than in the prior year due to one of the coldest May/June periods on record since 1976. Satellite data show that the onset of ice at the mouth of Marguerite Bay correlates well with the first instance of $-9.2^{\circ} \mathrm{C}$ air temperatures during the period of 1978-2002. Sizeable ice draft of $3 \mathrm{~m}$ or more lasted for weeks during both observed winters, with an annual mean sub-inertial ice velocity of $\sim 10 \mathrm{~cm} \mathrm{~s}^{-1}$ during the ice-covered period. A linear momentum balance shows the importance of internal ice stresses that are necessary to explain the observed motion of the ice pack. These internal ice stresses are consistent with the observed high concentrations and deep drafts of the ice and the semi-enclosed nature of Marguerite Bay. Tidal motions are weak, and most of the kinetic energy in the ice and upper ocean is in the near-inertial band.

In Chapter 5 the PWP (Price et al, 1986) one-dimensional vertical mixed layer model was adapted for investigation of mixing beneath an ice-covered ocean. Simulations using an idealized storm forcing of a stratification representative of winter on the wAP shelf revealed the relative roles of wind mixing and convection due to brine rejection in vertical mixing. When reasonable ice-ocean drag coefficients were used $(0.015)$, the presence of ice did not greatly change the modeled response of the water column when compared with the open water case. Shear mixing driven by the initial wind event, not the subsequent shear associated with inertial oscillations, caused the mixing and subsequent deepening of the mixed layer.

The model results indicate that the combined effects of shear and static instability can be significant over short time scales. The model forced by observed atmospheric and ice conditions on the wAP shelf produces large vertical fluxes for short periods, a $\sim 385$ $\mathrm{W} / \mathrm{m}^{2}$ one-day averaged heat flux across the base of the mixed layer during a storm event. However, when averaged over the entire 6-day simulation, the flux reduces to a more modest $79 \mathrm{~W} / \mathrm{m}^{2}$ across the base of the mixed layer. Making the rough assumption of one storm event per month with the remainder of the month having a weak flux (17 $\mathrm{W} / \mathrm{m}^{2}$ ) one estimates a monthly average flux of $29 \mathrm{~W} / \mathrm{m}^{2}$ across the base of the mixed layer.

The small $\left(17 \mathrm{~W} / \mathrm{m}^{2}\right)$ fluxes estimated during the period of inertial oscillations following the storm event are consistent with the estimate made in Chapter 2 of $\sim 5 \mathrm{~W} \mathrm{~m}^{-2}$ over the sharp pycnocline during a 4-day period of inertial oscillations in August, 2001. 
Furthermore, the results in Chapter 5 support the notion proposed in Chapter 2 that intermittent but relatively energetic events may be the dominant contributors to mean turbulent diapycnal fluxes.

\subsection{Discussion}

Prior to the SO GLOBEC observational program the average upward heat flux through the pycnocline was thought to be about $10 \mathrm{~W} \mathrm{~m}^{-2}$ (Klinck, 1998; Smith et al., 1999), with a significant contribution from DDC based on the need for different diffusivities of heat and salt to close the annual budgets (Smith and Klinck, 2002). These initial studies calculated a net heat loss from the upper ocean based on budgets in a onedimensional model and observed hydrography. These estimates rely on the net differences of large air-sea heat fluxes over the annual cycle, themselves containing nontrivial uncertainty. In Chapter 2, an analysis of observations made in the first year of SO GLOBEC could not find evidence of notable DDC fluxes $\left(\leq 0.2-0.4 \mathrm{~W} \mathrm{~m}^{-2}\right)$ and very weak shear mixing $\left(\sim 1 \mathrm{~W} \mathrm{~m}^{-2}\right)$. However, nutrient data collected subsequently as part of the SO GLOBEC program reinforced the idea that there must be some upward material transport from the UCDW to the Antarctic Surface Water (AASW) (Y. Serebrennikova, pers. comm.).

The analysis in Chapter 5 suggests that the vertical mixing during times of ice coverage in Marguerite Bay is driven by episodic wind events. Thus, the shipboard observations used in the analysis in Chapter 2 may have missed significant mixing events. In fact, the simulations in Chapter 5 showed weak fluxes associated with nearinertial oscillations after the wind event, consistent with Chapter 2.

Despite the fact that their five-year PWP simulation did not reproduce the observed stratification, Meredith et al. (2004) found ice production to be the main control on upper ocean stratification. That work, which focuses on interannual variability in the northern arm of Marguerite Bay, may have missed key one-dimensional vertical processes, but instead attributed the model-data discrepancy to lateral processes. The Rothera Time Series program measured stratification approximately weekly, but did not make velocity measurements, vital to any estimate of shear mixing. However, careful inspection of the stratification before and after strong wind events during times of lower 
ice concentrations (more freely drifting ice) could potentially give further insight into the vertical mixing mechanisms at work in the region.

This thesis suggests that the important factors to consider in vertical mixing beneath sea ice are not only the frequency and magnitude of strong wind events, but the ice conditions at the time of the events. In particular, mixing should occur under ice conditions favorable for the transfer of momentum from the atmosphere through the ice to the upper ocean, i.e. less of the wind stress balanced by internal ice stresses. Lower ice concentrations $(<\sim 80 \%)$ (Chapter 5) and larger distances from coastal boundaries ( 400 km) (Thorndike and Colony, 1982) are generally conditions which favor a sea ice momentum balance closer to the free drift solution (i.e., $\nabla \cdot \vec{\sigma}=0$, see Chapter 4 ). In fact, the first set of simulations in Chapter 5 showed that the air-sea momentum flux through free drift sea ice is nearly identical to that of an ice-free ocean (not yet taking into account the importance of sea ice effects on air-sea heat flux). Higher ice concentrations and associated internal ice stresses not only insulated the wAP shelf upper ocean from air-sea heat flux, but also from momentum flux, which was shown in Chapter 5 to be the primary factor in mixing.

\subsection{Implications and Future Work}

Vertical fluxes of momentum, heat and salt beneath an ice-covered ocean remains an open topic in physical oceanography. Researchers now recognize that in order to understand and simulate sea ice, the surface ocean must be taken into account (e.g. Heil and Hibler, 2002). Furthermore, observations continue to highlight the dominant role of internal ice stresses in balancing the wind stress (e.g. Chapter 4; Uotila et al, 2000). Ice dynamics is fundamentally a spatially two-dimensional problem, and therefore very difficult to measure.

Exciting research is currently underway to observe the mixing processes discussed in Chapter 5. A field program known as ICORTAS (Ice Covered Ocean Response to Atmospheric Systems) is being organized serve and quantify mixing associated with high-frequency ice motion and formation in the Laptev Sea in the Arctic Ocean by deploying an array of moorings similar to those used in the SO GLOBEC field 
program (H. Simmons, pers. comm.). This program has initial plans to use the methods described in Chapter 3.

Moored observations of temperature and salinity in the upper ocean beneath sea ice (including those made in SO GLOBEC) often encounter problems with drifting deepkeeled icebergs (i.e. keel depths $>\sim 50 \mathrm{~m}$ ). There have been significant technological advances to address this, such as transmitting upper ocean temperature and salinity data to a deeper logger via an acoustic modem. The upper instrumentation is attached to the deeper portion of the mooring via breakable links, so if an iceberg moved across the mooring site, the instruments may be lost, but the data and the rest of the mooring may still be recovered (C. Lee, pers. comm.). There have also been advances in winched systems which profile when no iceberg is detected, but remain deep when an iceberg is drifting through the mooring site (F. Straneo, pers. comm.). Measurements of the upper ocean stratification will not only provide the measured sound speed profile useful for the methodology described in Chapter 3, but will provide a basis for comparison with simulations such as those in Chapter 5. In particular, the observed response of the upper ocean to a storm event and any subsequent high-frequency ice motion and brine production. A favorable model-data comparison (or lack thereof) could point towards the importance of physics not included in the model, such as lateral advection.

Finally, a full three-dimensional model of sea ice and the upper layers of the ocean in an idealized marginal sea with idealized forcing could possibly illuminate some of the important processes in mixing beneath sea ice. In particular, the divergence and convergence of high-frequency ice motion would provide a more realistic time series of the spatially inhomogeneous open water fraction, rather than the idealized open water fraction used in Chapter 5. Modern sea ice models, such as that of Zhang and Hibler (1997) are capable of reproducing realistic lead structures (J. Zhang, pers. comm.). Run at high enough spatial resolution, the model could simulate buoyancy flux at distinct points on the surface, rather than an average flux distributed over an area containing leads and ice as envisioned in Chapter 5. This could potentially produce convective plumes and give insight into any important effects on the three-dimensional structure of the stratification and mixing. The results from Chapter 5 provide an excellent starting point for a full three-dimensional modeling study. 


\section{References:}

Cavalieri, D., C. Parkinson, P. Gloerson, and H.J. Zwally. 1997, updated 2005. Sea ice concentrations from Nimbus-7 SMMR and DMSP SSM/I passive microwave data. Boulder, CO, USA: National Snow and Ice Data Center. Digital media.

Price, J., Weller, R., Pinkel, R., 1986.Diurnal Cycling: Observations and Models of the Upper Ocean Response to Diurnal Heating, Cooling, and Wind Mixing. $J$. Geophys. Res., 91, 8411-8472.

Smith, D.A., Hofmann E.E., Klinck, J.M., Lascara C.M., 1999: Hydrography and circulation of the West Antarctic Peninsula Continental Shelf. Deep-Sea Research I (46) 925-949.

Thorndike, A. S., and R. Colony, 1982: Sea ice motion in response to geostrophic wind. J. Geophys. Res., 87, 5845-5852.

Uotila, J., Vihma, T., and Launiainan, J., 2000: Response of the Weddell Sea pack ice to wind forcing. J. Geophys. Res., 105, 1,135-1,151.

Zhang, J., and W. D. Hibler III, On an efficient numerical method for modeling sea ice dynamics, J. Geophys. Res., 102, 8691-8702, 1997. 